\title{
BEING (Becoming Empowered in Nursing Growth): Training guide for nursing students on sexuality and gender
}

Maryann Washington

Follow this and additional works at: https://knowledgecommons.popcouncil.org/departments_sbsr-rh

Part of the Demography, Population, and Ecology Commons, Family, Life Course, and Society Commons, International Public Health Commons, Maternal and Child Health Commons, and the Public Health Education and Promotion Commons How does access to this work benefit you? Let us know!

\section{Recommended Citation}

Washington, Maryann. 2009. "BEING (Becoming Empowered in Nursing Growth): Training guide for nursing students on sexuality and gender," Health and Population Innovation Fellowship Programme training guide. New Delhi: Population Council. 

The module entitled "BEING: Becoming Empowered In Nursing Growth" was undertaken as part of the Health and Population Innovation Fellowship (HPIF) awarded to the author in 2006.

The HPIF programme is administered by the Population Council, New Delhi and is a continuation of the MacArthur Foundation's Fund for Leadership Development (FLD) fellowship programme that continued over the period 1995 to 2004. The Council is grateful to the MacArthur Foundation for its support to this programme.

The HPIF programme aims to support mid-career individuals who have innovative ideas, leadership potential, and the capacity to help shape policy and public debate in the field of population, reproductive health and rights in general, with a focus on two priority themes - maternal mortality and morbidity, and the sexual and reproductive health and rights of young people. Since the transfer of the programme to the Population Council through 2006, a total of 17 individuals have been supported under the HPIF programme.

\section{For additional copies of this report, please contact:}

Maryann Washington

355 Wheeler Road

St. Thomas Town PO

Bangalore - 560084

Email: maryannvc@gmail.com
Population Council

Zone 5A, Ground Floor

India Habitat Centre, Lodi Road, New Delhi 110003

Phone: 011-24642901/02

email: info-india@popcouncil.org

Web site: http://www.popcouncil.org/asia/india.html

The Population Council is an international, non-profit, non-governmental organisation that seeks to improve the well-being and reproductive health of current and future generations around the world and to help achieve a humane, equitable and sustainable balance between people and resources. The Council conducts biomedical, social science and public health research, and helps build research capacities in developing countries.

\section{Copyright $@ 2009$ Maryann Washington}

About the author: Maryann Washington holds a Master's degree in Child Health Nursing and an M.Phil in Hospital and Health Systems. She has been working with nursing colleges as well as civil society organisations for a number of years. Presently she consults with International Training and Education Center on Health (I-TECH), Seattle, USA for development of curriculum for the India Nurse Practitioner on HIV/AIDS and ART (INSHAA).

Suggested citation: M. Washington. 2009. BEING (Becoming Empowered In Nursing Growth): Training Guide for Nursing Students On Sexuality and Gender. Health and Population Innovation Fellowship Programme. New Delhi: Population Council.

\section{A Population Council}




\section{BEING}

\section{(Becoming}

Empowered In

Nursing Growth)

\section{TRAINING GUIDE FOR \\ NURSING STUDENTS ON \\ SEXUALITY AND GENDER}

\section{Maryann Washington}

Fellow

Health and Population Innovation Fellowship Programme 


\section{Contents}

Acknowledgements __ii

Preface — iv

Introduction: How to Use the training guide ___ 1

Glossary of Terms __ 14

Module 1: Talking about Ourselves_Exploring Concepts of Sexuality __ 31

- Facilitators Guide _— 33

- Worksheets _ 49

- Handouts 256

Module 2: Discovering Who I am-Basic Concepts of Gender $\quad 75$

- Facilitators Guide

- Worksheets — 94

- Handouts

Module 3: Knowing my Rights—Sexual and Reproductive Health and Rights

- Facilitators Guide __ 111

- Worksheets 131

- Handouts _ 143

Module 4: I am Able! Life Skills_My Armour ___ 165

- Facilitators Guide _— 167

- Worksheets — 190

- Handouts

References

Annexures —_. 234 


\section{Acknowledgements}

Several people provided valuable assistance during the course of developing this training module.

I would like to thank all the experts who helped in validating this Training Module-Edwina Pereira, Programme Director-Training, International Services Association (INSA-India); Prasiddha Rama Rao, Coordinator for Nursing Initiative and M\&E, International Training and Education Centre (ITECH-India office), Chennai; Srinath Maddur, Senior Training Manager, Karnataka Health Promotion Trust (KHPT), Bangalore; Jennifer Tavares, External Lecturer, St. John's College of Nursing, St. John's National Academy of Health Sciences, Bangalore; Reynold Washington, Director STI and Surveillance, KHPT, Bangalore; Florence David, Programme Director, Administration, INSA; and M Prakasamma, Director, Academy of Nursing Studies (ANS), Hyderabad.

I am grateful to the Director of Medical Education, Karnataka; Medical Superintendent, Victoria Hospital; Principals of St. Martha's College of Nursing, Government College of Nursing, Kempegowda Institute of Nursing Sciences and Victoria Hospital, School of Nursing for granting permission and supporting the project throughout the pilot phase. The students and faculty of participating nursing institutions provided inputs and feedback on the content and conduct of the training programme; their valuable suggestions and recommendations, incorporated in the guide, are gratefully acknowledged. I would also like to thank Prathiba, Theresa and Shiji Mathew for secretarial assistance in putting together the different parts of the training guide.

I have borrowed methodologies and resources for use in this guide from several organisations-INSA-India, Bangalore; ANS, Hyderabad; TARSHI, Delhi and CREA, Delhi-and I would like to acknowledge the influence that these have had on the development of this guide. I would also like to express my gratitude to the Sexuality and Rights Institute, which helped me conceptualise the training package.

I would like to thank Shireen Jejeebhoy, K.G. Santhya, Shveta Kalyanwala and Komal Saxena at the Population Council for their guidance throughout the Fellowship period and on previous versions of this guide. I am grateful to Vinita Nathani and Manju Chhugani, M Prakasamma, Radha Ramansree, Jyothi, G Francis Raj, Vishnu Priya, Akshana and A.M. Raja Reddy for reviewing the modules and to Gila Pereira and Veronica George for editing the modules.

Most importantly, I would like to thank my mentor-Prof. H. Lalitha at St John's College of Nursing; and my husband, children, mother and members of my extended family, whose encouragement helped me persevere and complete this project. 


\section{Preface}

Sexuality is part of human life. All human beings are sexual and have developed their sexuality from a variety of influences, including social, cultural, biological, economic and educational factors. Sexuality shapes people's identity and relationships and is linked with gender power relations, health, economics, livelihoods and social development.

In India, sexuality has become a growing area of focus in the fields of gender and development, HIV/AIDS, human rights, reproductive health, education, violence prevention, legal issues, women's rights and the media. Within all these areas, the understanding of sexuality varies and has been approached from different perspectives.

Sexuality is an essential and integral part of all stages of human life. It is a topic that is still taboo in almost every country. Sexuality has been largely ignored in the discourse of human development and when considered, with several limitations. For example, public health has focused on those aspects of sexuality that are linked with heterosexual reproduction, without any consideration of the wide patterns that exist in our country. Similarly, with the HIV pandemic, sexuality has been looked through the prism of safe and unsafe sex.

Nurses are considered as essential players in the health scenario of any country. Their rigorous training of three to four years, which incorporates both practical experiences in the hospital, school or community setting and exposure to theoretical concepts are intended to equip them to meet the challenges of the changing health care scenario. The core of nursing is caring for the total health and well-being of a person. If holistic care is sought to be delivered, nurses need to be prepared to meet the modern day challenges they are likely to face in the continuum of wellness and illness.

Nurses must therefore be prepared to provide information, counselling and treatment to their clientele. These may well include addressing the sexual concerns of their clientele. Educational programs are needed to help nurses develop the confidence and skills required to provide sexuality-related awareness, counselling, services or referrals to their clients.

In order to be prepared to address such concerns, nurses need to address their own sexual identity and overall sexual adjustment; have up-to-date technical awareness about these issues; and display an ability to speak openly, honestly as well as confidently about any aspect of human sexuality with any client, be it individuals or communities. This training guide is aimed to help faculty of nursing students to deliver comprehensive sexuality education effectively and efficiently, that would help trainee nurses see the whole picture of sexuality in its matrix of safety, pleasure, reproduction, illness and health. The package is called 'BEING' (acronym for Becoming Empowered in Nursing Growth) as it is assumed that, if delivered well, it could empower nurses' growth to address these issues. 


\section{Introduction: How to Use the Training Guide}

This training guide is designed to be easy to use. It is adapted from various sources and does not in any way reflect the personal views and perceptions of the author. The intention of the training guide is to provide a guide to help the faculty at nursing teaching institutions explain sexuality and gender issues to nursing students. References and additional readings are appended. Some key points to remember when using this training guide are:

1. Remember the philosophy on which this training guide is based (Box 1).

\section{Box 1: Philosophy of the training guide}

What I hear, I forget

What I hear and see, I remember a little

What I hear, see and ask questions about or discuss with someone else, I begin to understand

What I hear, see, discuss and do, I acquire knowledge and skill.

What I teach another I master

From Mel Silberman (1998), Active Training (2nd Edition)

San Francisco: Jossey-Bass/Pfeiffer,

The training guide seeks to facilitate 'active learning' among participants. Active learning occurs when participants are involved through various participatory instructional activities or teaching methods, and thus think about what they are doing. The purpose of using various instructional methods is to increase participants' enthusiasm, build their confidence, and help them take ownership for their own learning.

2. Be familiar with the Table of Contents and with all the topics that will be covered.

3. Understand the intricacies and linkages between the four modules of the training guide. The training guide has been organised, based on feedback from participants in the pilot phase, and experts who reviewed the initial module. Please feel free to add, delete or modify any part of the module to suit the needs of the participants, keeping in mind their cultural background and levels of awareness. The information provided in this training guide would have to be updated from time to time. The four modules of the training guide include:

\subsection{Module 1: 'Talking about Ourselves'-Exploring the Concepts of Sexuality}

The module covers topics such as the meaning of sexuality, components of sexuality; one's perception of one's body; one's perception of sexuality and sex; mapping the human body; the meaning of the word 'sex'; and exploring different terminologies on sexuality and sex.

\subsection{Module 2: 'Discovering who I am'-Basic Concepts of Gender}

The module covers the characteristics of males and females; the difference between the concepts of sex and gender; gender roles and expectations; the impact of gender on life goals, sexuality, and health; and the concept of gender equity in health.

\subsection{Module 3: 'Knowing my Rights'-Exploring Sexual and Reproductive Health Rights}

This module includes a review of human rights; sexual health and rights, such as sexual relationships and sexual violence; and reproductive health issues including contraception, safe pregnancy, abortion and STIs and HIV.

\subsection{Module 4: 'I am Able'-Life Skills, My Armour}

The module highlights the need for life skills; and provides an overview of various life skills such as, managing stress, time, emotions, becoming aware of oneself, decision making, empathy, problem solving, interpersonal relationships and communicating assertively. 
4. Read the training guide thoroughly, to be able to find what you need from each module. PowerPoint presentations (PPTs) are included for each of the modules. Some are hyperlinked to a video or trigger tape. However, if you do not have access to an LCD, you could make and use your own OHP slides. If you do not have access to a video or DVD player during the training, you could discuss the idea with the participants and ask them to enact it through role plays. Each module is organised under the following headings:

4.1 Content considerations highlight the main points that will have to be considered in the module.

4.2 Aim is the overall purpose of the module.

4.3 Objectives are what the participants will be able to do and what they are expected to gain at the end of the module.

4.4 Time or duration gives you the minimum time you would require to cover the content of the module.

4.5 Key messages are the main points in the module.

4.6 Time line break up provides, at a glance, an outline of the number of activities that will be covered, the materials to be used and the time required for each activity.

4.7 Content is broken down into 'activities' based on the content to be covered. Before each activity or group of activities, there are notes for the facilitator. Although the content is broken into different activities, remember to let one activity flow into another; avoid using each activity as an independent activity. Each activity has the same format:

- Purpose: Describes why this activity is needed.

- Materials: Includes worksheets, handouts, PPTs, paper, pen, charts, flip charts/black/white board, LCD/OHP, Video/DVD player. The purpose of the presentations is to help the flow of the content and reduce the time spent on writing key points on the board/OHP transparency. The introduction and the modules each have a separate set of PPTs that are numbered sequentially based on the module. Each PPT is designed with just the content matter, or in addition to the content and will also indicate the activity to be undertaken, the worksheet and handout to be used. You may notice that some slides are animated, and this is indicated in the process of the activity.

If you do not have a DVD reader in the computer, you would require a DVD player to play the videos. Hence it is important that you check the materials you would require before starting an activity.

- Process: Describes each activity in points, e.g. the use of a particular PPT slide would be indicated by a particular point in the activity.

4.8 Worksheets are either for individual self-reflection, or for group activities. If the worksheet is to be used for a group activity, make one copy for each group. You must know in advance what topics will be covered on a particular day and be prepared with the required copies. In case the participants are not able to understand terms given in the worksheet, explain these terms to them.

4.9 Handouts contain information relevant to the topics in the module which can also help to explain the various concepts and facts clearly to participants. It is absolutely necessary that you are thorough with the content in the handouts. You could read up additional sources to enhance your understanding of the topics before you take the session. Since handouts are a permanent record of the information already discussed, it is important that you share them with participants so that they can all have access to the same information and can refer to them whenever needed.

\section{Participants}

It is preferable that you use all the four modules as one comprehensive unit for the first year undergraduate nursing students. The training guide has been organised such that each module is linked with the previous module, and the information is reinforced and built upon. It is assumed that if first year undergraduate nursing students are trained on these aspects, just after the completion of their Preliminary Training Session (PTS) period, it could help them address sexual and reproductive health concerns of their clientele or handle the various challenges they are likely to face more effectively when they are exposed to the clinical area for longer hours. The courses in which it could be integrated include Basic Concepts of Nursing, Psychology, or Introduction to Community Health. 
The same content could be covered for both the diploma and degree nursing students. However, as mentioned earlier, depending on the level of understanding of the participants you could pace the content accordingly. Keep the following points in mind when you use the training guide:

5.1 The size of the class: If the group is large (such as 50 or more participants) ensure that in activities where indicated, participants are divided into smaller groups. This could facilitate better interaction and understanding amongst participants. Each module has been designed in such a way that you can use it with a group of participants as large as 100 or as small as 40 . Please avoid using lecture as the 'easy way out' to handle a large group.

5.2 The demographic characteristics of the participants: This could vary depending on participants. The age of participants at the entry level could vary from 17-35 years with a mix of both males and females. The ratio of males to females also varies between and within institutions. Most often, the number of males will be less than the number of females. Therefore group activities need to be managed such that different needs of participants are addressed while overall group cohesiveness is fostered.

\section{How to start using the training guide}

6.1 Once you have decided when you will start the modules for the participants, use the introductory PPT slides. You will need to secure the support of other faculty members so that when you start the modules you are able to cover at least 4 hours/week. This would enable you to complete all four modules in a continuous block. Or you could choose to implement the training guide as a workshop (minimum 5 days).

6.2 Introduce yourself and tell participants what your role will be (See Point 7); conduct an ice breaker activity (See Annexure A); and then do a pre-evaluation (See Annexure B for a sample).

6.3 Inform participants of the philosophy of the training guide. Project slide 2 (animated) and do Activity 1 (Box 2) of the introduction.

\section{Box 2: Process of Activity 1}

- $\quad$ Ask the participants to write number nine in Roman script (IX) in their note books.

- Once they have done so, ask them to convert this to number six with just a single stroke of a pen within 5 minutes. Wait till someone comes up with the answer (SIX).

- Debrief the participants about the activity. In this activity, they may have made several attempts to convert the 'IX' to 'SIX', and that it could have appeared difficult. However, the activity itself is easy, if they could change their way of thinking, by being open and avoid being fixated on a particular point.

\section{Learning from Activity 1:}

o Just like in this activity, it is necessary during the training that participants are reminded to be open to differences and to think differently. This may be difficult initially, but once they accept the principles of respect, autonomy and justice it will be easier.

- Inform participants that the training will use different methods of teaching to facilitate sharing of ideas, self examination and introspection that enable active learning.

o Just like in this small activity, if we learn to see things and issues from a different perspective, then we would be able to reach out to many more people and not just to the clientele that are accessed through the hospital.

6.4 Brainstorm: Why do you think we need gender and sexuality sensitisation for nursing students? Then give them the reasons for such training by projecting slide 3 (Box 3). 


\section{Box 3: Purpose for the training guide}

- The Nursing Training Curriculum currently being used has certain gaps. Life Skills are taught mostly as a subject matter. The focus needs to be contextual and practice oriented.

- Participants' capacities need to be built to address sexual and reproductive health concerns of clientele in a positive and productive way.

- HIV/STI is a gender and sexuality issue.

- $\quad$ Building capacity to manage possible exposure to sexual harassment in the work setting.

6.5 Enable the participants to develop ground rules and choose Group Coordinators (Activity 2-Box 4). Remember that some of the content and methods that are recommended in the training guide could be sensitive. Moreover, participants are likely to have differences in opinions, values and feelings about the various issues covered. It is essential that they draw out for themselves certain guidelines/norms/particular behaviours that they could all expect of each other and of the facilitator/s during the training - these are called Ground Rules.

\section{Box 4: Process for Activity 2}

- Divide the participants into groups of 6-8 members. Ask each group to have someone volunteer as the Group Coordinator. The role of the Group Coordinator would be to assist in organising the sessions and in leading the group. Since the whole course takes approximately 30-40 hours, make sure that all participants take turns to be a Group Co-ordinator.

- Ask each group to come out with at least 3 guidelines/norms or behaviours. Ask each Group Coordinator to present the ground rules from her/his group.

- Get one of the Group Coordinators for the day to write the agreed upon ground rules on the chart provided. Paste this in the class where it is visible to all.

- If certain ground rules do not figure in the list provided by the participants, it will be good as a facilitator to remind them of the ground rules given in Box 5 (slide 4). However, if these ground rules have already been listed by the participants reinforce the meaning of these terms so that all share the same understanding of the rules.

\section{Box 5: Three main ground rules to be followed during the training}

Respect: To maintain the dignity of each person. This could be by maintaining confidentiality (to keep any information that was expressed as confidential by any participant as secret i.e. only within the class room. This will not be discussed outside the classroom). Reinforce that respect will need to be given despite differences of opinions, values or perceptions.

Autonomy: To maintain the individual's freedom to make decisions, have own values, beliefs, opinions and perceptions with regards to any issues. This comes with responsibility for one's action and maintaining the rights of others as well as self. It would also mean granting permission to allow everyone to express their views or to ask questions even if it may seem silly to another.

Justice: To maintain and preserve the rights of every individual. This could refer to the participant's right to a set of attitudes, values or choice of responses to various activities or to the clientele's sexual and reproductive health rights.

4 Introduction: How to Use the Training Guide 
6.6 Explain the overall purpose of the training; the behavioural and personal outcomes of such training, as well as, the long term clientele outcomes anticipated from the training (slide 5-8).

6.7 Initiate Activity 3 (slide 9-animated) which is a game. The purpose of the activity (Box 6) is to help participants become aware of the need to be open to variations that may exist in their attitudes, values, perceptions and behaviours.

6.8 Conclude by telling participants that the four modules will be used sequentially.

\section{Box 6: Process for Activity 3}

- Project slide 9. If the LCD is not available then draw the nine dots on white/black board.

- Once the participants see the nine dots, ask them to join all the dots with a single stoke of the pen within 5 minutes. Caution them that they cannot overwrite on any given line. Wait for the participants to complete the task.

- After one participant or a few have completed the task, ask one of them to volunteer to demonstrate to others how this can be done. Then ask participants what they learnt from the activity. Show them how they were able to join all the dots by looking beyond the boundary of the dots.

\section{Learning from Activity 3:}

- Inform participants that just like in this game, it is important to think, act and value beyond one's own box of feelings, perceptions and values.

- This can be achieved by showing respect; being open beyond the boundaries that they have drawn for themselves; and being able to keep in confidence any information that has been shared during the sessions.

- Reinforce that like in the activity they were not allowed to overwrite any given line, it is important that they are not dogmatic about any value or attitudes they may have but are open to the variations that are likely to exist in the group.

\section{Points you need to keep in mind when using the training guide}

\section{Be a facilitator, not a teacher}

This training guide emphasises the use of participatory methods. It is recommended that before you attempt using the training guide you are trained in the use of participatory techniques. It is also important that you give up the traditional role of a teacher and instead take on the role of a facilitator. Remember there is only reference to the 'participant' in the training guide and never to a 'student' so that you think beyond the traditional faculty-student relationship.

A facilitator is a role model, therefore it is important that as a facilitator you participate on an equal basis with the participants. Do not hesitate to share your own experiences as this may foster a culture for sharing among the participants. However exercise caution in sharing your own values. Instead encourage participants to review and confirm their own values and attitudes. 


\section{Box 7: Remember the Facilitator's Role-What it is and is not}

\begin{tabular}{|l|l|l|l|}
\hline \multicolumn{2}{c|}{ Facilitator is } & \multicolumn{2}{c|}{ Facilitator is/does not } \\
\hline Positive & Inspiring & Negative & On an ego trip \\
\hline Firm & Purposeful & Timid & Gives magical answers \\
\hline In control & Confident & Bossy & Lecture \\
\hline Open & Clear & Solve problems & Rigid \\
\hline Motivating & Organiser & Sarcastic & Boring \\
\hline Supporting & Approachable & Superior & One who knows it all \\
\hline & Trusted & Perfectionist & \\
\hline
\end{tabular}

Remember to be ENTHUSIASTIC-ENERGETIC-ENCOURAGING

The following are some non-verbal and verbal facilitation skills to make your sessions lively and interesting:

\subsubsection{Non-verbal facilitation skills}

- Make eye to eye contact with everyone in the group. Focus your attention on all the participants-do not favour some over others.

- Move around the room as you speak in a slow and calm way.

- Show participants that you are listening to what they say by nodding, smiling and even responding to them.

\subsubsection{Verbal facilitation skills}

- When preparing to take sessions, formulate your questions to encourage the right kind of responses and to facilitate open discussions. All modules have sufficient questions that could be asked to participants. You could make your own set of questions based on the participants needs.

- Use open-ended questions such as, 'What do you think about...?' 'Why...?' 'How...?'

- Use snowball techniques to enrich information that is provided to the participants. After one of the participants makes a statement, ask other participants for their opinions.

- Encourage participants to talk. The best and ideal situation is when they are able to talk more than you.

- Know how to answer their questions (Annexure C). Some suggestions are given in the annexure for handling questions.

- Encourage the participants to answer each other's questions, e.g. if a participant asks you a question 'what do you think about...?' refer the question to others in the room and ask them for their opinion. In that way everyone can learn to listen and to show respect for each other.

- You could also frequently paraphrase important points made by the participants to reinforce them.

- Encourage participants to share personal experiences to articulate their views or opinions. Reinforce the ground rules 'respect, autonomy and justice'.

- You may find that participants may want to share personal issues with you. Remember, if you are not able to address such issues, ensure that help is provided to any participant who may require it.

7.2 Other points that you should keep in mind while implementing the four modules are:

\subsubsection{Have respect}

Facilitators need to model respectful behaviour. It is critical to take seriously and be sensitive to participant's individual differences and perspectives, as well as any discomfort participants may experience discussing an emotional and personal topic. Use the acronym 'RESPECT' as given below in Box 8 to demonstrate respect for your participants. 


\section{Box 8: RESPECT-What it means}

R: Have responsibility for what you say without blaming others

E: Use empathetic listening

S: Be sensitive to differences in communication styles

P: Ponder on what you hear and feel

E: Always examine your own assumptions

C: Maintain confidentiality

T: Learn to trust ambiguity, because we are here not to debate who or what is right or wrong

Source: (http://www.ladiocese.org/ki/trainers.htp)

\subsubsection{Avoid being judgmental}

Do not reinforce stereotypes - for example, that 'boys will be boys' or that 'girls are powerless victims'. Keep the focus on the facts. Even when participants ask questions that you think reflects their biases or misconceptions, be neutral and answer the questions in an unbiased or neutral manner (Please refer to Annexure C-How to answer questions). Sometimes participants may disagree with what you or the other group members say. If the discussion becomes heated, remind participants that there are ways to disagree respectfully_without resorting to name calling or insults. You could also ask participants to put their thoughts in writing.

\subsubsection{Ensure safety and be mindful about disclosure issues}

Sometimes during the course of the training some participants may ask to meet you individually to share their personal experiences, which they may not like to share with the rest of the participants. Respect them for wanting to share their experiences. It is important that you make plans for ways of dealing with such situations. This could be by providing assistance yourself or if permitted by the participant, referring them further for professional help.

When you talk about sensitive issues like sexual harassment, you could ask the participants what they expect from you and from their peers in order to feel safe. For example, do they require confidentiality, and if so remember to review the ground rules before you begin such an activity.

A way to create a safe space for particularly sensitive topics is to set up a 'Question Box'. Participants can put questions that might be difficult to ask in front of other participants in the box. You can then read aloud and answer the question/s without disclosing names.

Make sure that questions once answered are recorded in the computer if required and slips are destroyed so that no one can find out who wrote and asked a particular question.

\subsubsection{Respect diversity}

While dividing participants for small group activities, aim to create different groups every-day, ensuring that participants get an opportunity to work with a new mix of colleagues during the training. However, for some activities related to sensitive issues, allow participants to make their own groups to facilitate easier discussion.

\subsubsection{Listen actively}

Listen to and respect each person's point of view before responding. It is important not only to understand what a person is trying to say, but also to allow her/him an opportunity to express herself/himself. Recognise that there are many views on any topic. No one view or opinion is correct. The whole purpose of discussion is to share ideas/information and thus, enhance learning from each other.

\subsubsection{Ask open-ended questions}

A good way to start and continue a discussion is to use open ended questions. Open-ended questions start with: how, why and what. ('How do you think this affect us?' 'Why do you think this is it an issue?' 'What do you think you can do to change this situation?'). 


\subsubsection{Acknowledge different opinions}

When a participant introduces a controversial point, try to separate facts from opinions. Should a disagreement occur, encourage participants to challenge the ideas, not the participants. Reinforce that discussions could encourage learning. Avoid arguments. Participants may some-times tend to have strong convictions and discussions can become heated when talking about sensitive and emotional issues, like sexual violence and relationships. You might want to consider and discuss why this is happening.

\subsubsection{Stay focussed}

When the discussion seems to get off track, try to reintroduce the original issue being addressed (example 'Rena, I think you have a point there, but can we get back to talking about...').

\subsubsection{Do not feel you have to be an expert on an issue}

If you do not know something, admit it. If a participant raises a difficult question, ask if anyone knows the answer, or if the question is important, state, 'my understanding is that..., but I will have to look into it further'. Or 'that is an excellent question - to be frank I do not have the answer but I will find it for you'. Remember, you can make this an opportunity to learn more on these issues from the internet, attending workshops or seminars on these topics or watching films on these issues.

\subsubsection{State that abusive behaviour is not acceptable}

In the spirit of respecting differences, abusive or insulting behaviour is not acceptable. Language that poisons the environment-words and ideas that are biased against particular groups of people (based on their age, cultural background, behaviour, religion or physical abilities etc) should be challenged. Remember that 'discussion is great; hurtful words are not'. It is also important that you are mindful of your own behaviour towards the participants. This is more important when the views, values and perceptions of the participants differ from yours.

\subsubsection{Energise using games/exercises}

Provide for some physical exercise to re-energise the group. The training guide has some exercises and games incorporated within some activities. Keep a set of several easy exercises ready that could be done in the classroom to be used when participants seem tired or distracted (See Annexure A). Ask participants to volunteer to lead these exercise breaks.

\section{Training Methods}

This training guide uses different methods to facilitate the experiential learning cycle of hearing, seeing, doing, sharing, discussing and teaching others. Using multiple methods will help facilitate meeting the variety of needs of the participants and could stimulate interest in them. Some of the methods may take more time when used, but they do have their advantages. Box 9 lists some of the common methods that are used and some key highlights to be kept in mind when using the methods.

\section{Box 9: Teaching methods used in the training guide}

\begin{tabular}{l|l|l|l|} 
Method & What is it & When to use & Comments \\
\hline Case scenario & $\begin{array}{l}\text { Participants study } \\
\text { a situation that } \\
\text { briefly describes a } \\
\text { problem and then } \\
\text { develop possible } \\
\text { steps to solve the } \\
\text { problem or discuss } \\
\text { related issues that } \\
\text { arise from the case } \\
\text { scenario }\end{array}$ & $\begin{array}{l}\text { To encourage } \\
\text { their knowledge } \\
\text { and skills to similar } \\
\text { problems/situations they } \\
\text { may encounter on the }\end{array}$ & $\begin{array}{l}\text { The situations presented in the case scenarios } \\
\text { are comparable to one experienced by } \\
\text { participants. Details in the case scenario } \\
\text { should be just enough to enable participants to } \\
\text { recommend solutions/discuss related issues. }\end{array}$ \\
& $\begin{array}{l}\text { Generally case scenarios are more extensive } \\
\text { than hypothetical situations (see below) and } \\
\text { raise more issues. Spend enough time so as to } \\
\text { facilitate as much discussion as possible within } \\
\text { the predetermined objectives }\end{array}$
\end{tabular}


Cont'd...

\begin{tabular}{|c|c|c|c|}
\hline Method & What is it & When to use & Comments \\
\hline $\begin{array}{l}\text { Critical } \\
\text { incident }\end{array}$ & $\begin{array}{l}\text { Participants analyse } \\
\text { their own or other } \\
\text { experiences at an } \\
\text { important point of } \\
\text { decision }\end{array}$ & $\begin{array}{l}\text { To focus on key issues } \\
\text { and concerns }\end{array}$ & $\begin{array}{l}\text { Critical incidents are often told from the first } \\
\text { person perspective. It can include feelings } \\
\text { about the experience as well as the events that } \\
\text { influenced decision making. The incident can } \\
\text { come from the participants themselves. } \\
\text { It needs to be focused on the predetermined } \\
\text { objectives of the activity }\end{array}$ \\
\hline Discussion & $\begin{array}{l}\text { Facilitators } \\
\text { exchange ideas } \\
\text { for the purpose of } \\
\text { reaching specified } \\
\text { objectives }\end{array}$ & $\begin{array}{l}\text { To increase knowledge } \\
\text { To improve } \\
\text { communication skills } \\
\text { To test progress toward } \\
\text { learning objectives }\end{array}$ & $\begin{array}{l}\text { This method could be the most successful } \\
\text { if predefined objectives are made. It could } \\
\text { allow the participants to openly express their } \\
\text { opinions on a subject as well as listen to the } \\
\text { opinions of others thus facilitating learning } \\
\text { through interchange of ideas. This method } \\
\text { is one of the commonest methods used in } \\
\text { this training guide. You could ensure that all } \\
\text { participants take part in the discussion by } \\
\text { dividing them in smaller groups }\end{array}$ \\
\hline Games & $\begin{array}{l}\text { Participants } \\
\text { learn through } \\
\text { participating in a } \\
\text { game or activity } \\
\text { that they are asked } \\
\text { to reflect up on } \\
\text { later }\end{array}$ & $\begin{array}{l}\text { To help participants } \\
\text { apply their knowledge } \\
\text { to various situations, } \\
\text { to develop skills } \\
\text { in teamwork, to be } \\
\text { actively involved in the } \\
\text { training }\end{array}$ & $\begin{array}{l}\text { Games are effective in breaking the ice, in } \\
\text { charting pace or reaching the predetermined } \\
\text { objectives. It is important that the attention } \\
\text { of the participants is drawn to the learning } \\
\text { expected to take place after the game or } \\
\text { activity }\end{array}$ \\
\hline $\begin{array}{l}\text { Hypothetical } \\
\text { situation }\end{array}$ & $\begin{array}{l}\text { Participants study a } \\
\text { situation that briefly } \\
\text { describes a problem/ } \\
\text { situation that } \\
\text { they are likely to } \\
\text { encounter and then } \\
\text { develop solutions/ } \\
\text { suggestions on how } \\
\text { to tackle the given } \\
\text { situation }\end{array}$ & $\begin{array}{l}\text { To help participants to } \\
\text { apply their knowledge, } \\
\text { thoughts or perceptions } \\
\text { and skills to problems/ } \\
\text { situations even before } \\
\text { they face it in reality }\end{array}$ & $\begin{array}{l}\text { Hypothetical situations are like case scenarios, } \\
\text { but are shorter and simpler. They foster } \\
\text { introspection and an awareness of one's } \\
\text { thoughts and perceptions with regards to a } \\
\text { particular issue. It could help participants } \\
\text { to learn from each other as they share their } \\
\text { thoughts and discussions with each other }\end{array}$ \\
\hline $\begin{array}{l}\text { Mini Lecture/ } \\
\text { Presentation }\end{array}$ & $\begin{array}{l}\text { Facilitator speaks } \\
\text { to a group from } \\
\text { prepared notes }\end{array}$ & $\begin{array}{l}\text { To increase knowledge } \\
\text { i.e. to convey } \\
\text { information and } \\
\text { concepts }\end{array}$ & $\begin{array}{l}\text { Mini Lectures are an efficient way to deliver } \\
\text { information. These are rarely used as a } \\
\text { method in teaching the various concepts in } \\
\text { this training guide as the communication is } \\
\text { usually one way-flowing from the facilitator } \\
\text { to the participants. The participation of the } \\
\text { participants is limited and thus learning could } \\
\text { be limited. It is used when a new concept is } \\
\text { introduced to the participants }\end{array}$ \\
\hline
\end{tabular}

Cont'd on next page... 
Cont'd...

\begin{tabular}{|c|c|c|c|}
\hline Method & What is it & When to use & Comments \\
\hline $\begin{array}{l}\text { Question } \\
\text { answer } \\
\text { session/ } \\
\text { Brainstorming }\end{array}$ & $\begin{array}{l}\text { Facilitator prepares } \\
\text { questions pertaining } \\
\text { to a topic; then asks } \\
\text { questions in a series } \\
\text { to the participants } \\
\text { in order to reach } \\
\text { the predefined } \\
\text { objectives }\end{array}$ & $\begin{array}{l}\text { To increase participants, } \\
\text { introspection and } \\
\text { internal inquiry } \\
\text { To increase participants' } \\
\text { ability to collect } \\
\text { information through } \\
\text { research and analysis }\end{array}$ & $\begin{array}{l}\text { This is an efficient way to encourage self } \\
\text { learning and participation. It helps to generate } \\
\text { ideas quickly and fluidly while permitting } \\
\text { freedom to express any idea or thought. It } \\
\text { could have a snowball effect as one person's } \\
\text { thought may facilitate another person's } \\
\text { thought process and thus increase learning } \\
\text { from each other. It could also be a lot of } \\
\text { fun. It is important that attention is paid to } \\
\text { every response or a good enough sample of } \\
\text { responses of participants, to encourage their } \\
\text { participation }\end{array}$ \\
\hline $\begin{array}{l}\text { Readings/ } \\
\text { Handouts }\end{array}$ & $\begin{array}{l}\text { Participant receives } \\
\text { information from } \\
\text { the facilitator during } \\
\text { or after a particular } \\
\text { session }\end{array}$ & $\begin{array}{l}\text { To increase participants, } \\
\text { knowledge about } \\
\text { different concepts }\end{array}$ & $\begin{array}{l}\text { This is an efficient way to deliver large } \\
\text { amounts of information to participants. } \\
\text { It provides permanent record of what the } \\
\text { facilitator wanted to convey and thus becomes } \\
\text { a reference. The method is most efficient when } \\
\text { it includes immediate application to problems } \\
\text { and projects, discussion and testing. } \\
\text { It is important that you follow up such reading } \\
\text { material with questions on the topic so that } \\
\text { you are sure that participants are aware of all } \\
\text { the concepts and are clear about the same. An } \\
\text { efficient follow up method could be to conduct } \\
\text { a quiz on selected reading material }\end{array}$ \\
\hline Role plays & $\begin{array}{l}\text { This is a simulation } \\
\text { technique and } \\
\text { involves participants } \\
\text { imitating or acting } \\
\text { out a situation }\end{array}$ & $\begin{array}{l}\text { To increase one's own } \\
\text { awareness of one's } \\
\text { thought processes } \\
\text { To encourage } \\
\text { participants to apply } \\
\text { their knowledge and } \\
\text { skills to problems } \\
\text { like those they may } \\
\text { encounter on the job or } \\
\text { in real life } \\
\text { To sensitise participants } \\
\text { to issues that they may } \\
\text { be uncomfortable to } \\
\text { address }\end{array}$ & $\begin{array}{l}\text { It allows participants to practice and thus think } \\
\text { about situations even before they encounter } \\
\text { such situations in real life. It could be } \\
\text { interesting to participants. It may take time. } \\
\text { It is thus essential that clear guidelines are } \\
\text { given to participants with regards to what is } \\
\text { expected of them and how much time would } \\
\text { be allotted for the role play. If permissible, } \\
\text { take feedback from the participants who } \\
\text { enacted the role play and the participants who } \\
\text { viewed it about what worked well and what } \\
\text { did not work well. A good way to be mindful } \\
\text { of time is to give participants role-play } \\
\text { guidelines the day before the session, so that } \\
\text { they could come prepared for the session }\end{array}$ \\
\hline
\end{tabular}

Cont'd on next page... 
Cont'd...

\begin{tabular}{|c|c|c|c|}
\hline Method & What is it & When to use & Comments \\
\hline Self reflection & $\begin{array}{l}\text { Participants learn } \\
\text { to introspect on } \\
\text { their own values, } \\
\text { perceptions and } \\
\text { possible ways they } \\
\text { would act in a } \\
\text { particular situation }\end{array}$ & $\begin{array}{l}\text { To help participants } \\
\text { reflect on and examine } \\
\text { their own values, } \\
\text { perceptions and } \\
\text { possible ways to act in } \\
\text { a particular situation } \\
\text { To facilitate in learning } \\
\text { through interchange } \\
\text { of thoughts, ideas and } \\
\text { discussions amongst } \\
\text { and within groups of } \\
\text { participants } \\
\text { To facilitate in } \\
\text { sensitising participants } \\
\text { to differences in } \\
\text { opinions, values and } \\
\text { attitudes within and } \\
\text { amongst participants }\end{array}$ & $\begin{array}{l}\text { The participants are usually given worksheets } \\
\text { with statements or situations that reflect a } \\
\text { particular issue. They will be asked to read } \\
\text { the statements and then to respond to the } \\
\text { statements based on how they would feel, } \\
\text { value or act in the particular situation. There } \\
\text { is bound to be differences of opinions and } \\
\text { values amongst and within participants. Help } \\
\text { participants remember the Ground Rules. } \\
\text { You could also reaffirm to participants } \\
\text { that despite the differences of opinion it is } \\
\text { important to respect each other. It is necessary } \\
\text { that you explain to participants that by } \\
\text { examining their own values, attitudes and the } \\
\text { ways they would possibly act in a particular } \\
\text { situation, it would help them prepare for such } \\
\text { situations in real life. You could tell them the } \\
\text { story of 'The blind men and the elephant'. } \\
\text { (See Annexure E) }\end{array}$ \\
\hline $\begin{array}{l}\text { Video/Trigger } \\
\text { tapes }\end{array}$ & $\begin{array}{l}\text { Facilitator uses } \\
\text { videos to help } \\
\text { participants } \\
\text { comprehend a } \\
\text { concept better }\end{array}$ & $\begin{array}{l}\text { To sensitise participants } \\
\text { on issues that are best } \\
\text { learnt by seeing and } \\
\text { hearing }\end{array}$ & $\begin{array}{l}\text { It is an efficient way to get participants to } \\
\text { reflect on concepts that seem abstract or } \\
\text { difficult to comprehend. You would need to } \\
\text { check for the sound and the need of other } \\
\text { equipments such as DVD player, speakers, etc } \\
\text { for it to be effective. You would have to be } \\
\text { familiar with the video clipping itself to know } \\
\text { how to use it efficiently }\end{array}$ \\
\hline
\end{tabular}


$\# 1.1$

\section{Introduction}

\section{Training Guide on Sexuality and Gender for Nursing Students 'BEING'}

\#1.3

\section{Need for Gender and Sexuality Sensitization}

- Why do you think we need gender and sexuality sensitization in nursing curricula?

Need

- Curricula has gaps

- Focus needs to be contextual and practice oriented

- Life skills taught but as subject matter not contextual

- Sexual harassment in the health care setting and early exposure of nursing students to the health care setting

- HIV/ STI is a gender and sexuality issue

- Nursing students' capacity needs to be built to address sexual and reproductive health concerns of clientele
\#1.2

\section{Philosophy of the training}

- What I hear, I forget

- What I hear and see, I remember a little

- What I hear, see and ask questions about or discuss with someone else, I begin to understand

- What I hear, see, discuss and do, I acquire knowledge and skill.

- What I teach another I master

- From Mel Silberman, Active Training (2nd Edition) San Francisco: Jossey—Bass/Pfeiffer, 1998

Activity 1
\#1.5

\section{Purposes of this Training Guide}

- Participants will be able to

- Understand and cope with their own sexual and reproductive health concerns

- Understand the client's sexual and reproductive health concerns
\#1.4

\section{Ground Rules}

- Respect:

- Maintaining the person's dignity

- Maintaining confidentiality

- Autonomy

- Freedom to make choices

- Freedom to have and express one's own values and attitudes

- Justice

- Maintain and preserve the rights of every person

- Avoid violating the rights of another

Activity 2
\#1.6

\section{Behavioural Outcomes}

Participant Student Nurses will

- Take an active part to identify needs of self and clientele

- Update self on sexual and reproductive health issues

- Educate clientele on these issues

- Seek counseling if relevant on sexual and reproductive health concerns

- Participate actively in care of clientele with sexual and reproductive health concerns

- Refer clientele for appropriate services, if needed 


\section{Personal Outcomes}

Participant Student Nurses will

- Demonstrate openness towards sexuality and its variations

- $\quad$ Take measures to reduce stigma towards sexual minorities and clientele with sexual health concerns

- Demonstrate skills in forming healthy relationships

\section{Long term Clientele Outcomes}

Clientele will

- Seek relevant counselling services

- Be aware of sexual and reproductive health and rights

- Report any relevant sexual and or reproductive health issues

- Seek appropriate sexual and reproductive health services

\#1.9

\section{Important to Remember During Training}

Lessons learnt

- Look beyond the box

- Be open to differences

- Thus be accepting of clientele with sexual and reproductive health concerns

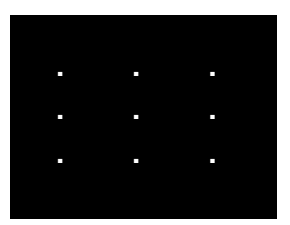

Activity 3:Join these dots with a single stroke of your pen 


\section{Glossary of Terms}

A

Abortion is the termination of a pregnancy by any means before the foetus is sufficiently developed to survive outside the uterus. An abortion can happen spontaneously (miscarriage) or it can be provoked by a deliberate intervention (induced abortion). The term abortion is normally used in connection with the latter. The stage and legality of the process vary according to local legislations and recommendations.

Abstinence is the voluntary decision to avoid sexual relations of any kind. Different people have different definitions of sexual abstinence. For some, it may mean the decision to avoid only penetrative sex, for others it may mean only engaging in outer course. Reasons for abstinence could include contraception or pregnancy prevention, disease and abstinence for religious reasons.

Abuse refers to any form of violence towards a person. There are at least five types of abuse: physical, psychological, social (referring to negative social attitude and practices), economic and sexual mistreatment. Usually the abuser is in a position of power.

Adultery is any extramarital sexual activity.

After play is the affectionate, sensual, and erotic interaction between partners. It follows sexual intercourse and/or orgasm.

AIDS (Acquired Immuno-Deficiency Syndrome) is the late stage of the chronic disease caused by the infection with Human Immunodeficiency Virus (HIV), in which the immune system is weakened and unable to fight opportunistic infections.

Anal sex is the sexual activity characterised by anal stimulation or penetration with various devices including finger, penis, lips, mouth, tongue or objects.

Analingus is the oral stimulation of the anal area.

Anti-retroviral therapy (ART) is the course of drugs or medications taken by a patient to fight HIV.

Arranged marriage refers to the marital contract or union between a male and female negotiated by the parents or by family elders.

Artificial insemination is the process of depositing semen, fresh or frozen, into the vaginal canal or uterine cavity by any other means other than sexual intercourse. Intrauterine insemination is one type of artificial insemination that places the sperm inside the uterus after the sperm has been treated to obtain the best quality fraction.

Asexual is a person who has no evident sex or sexual organs. In common language could be referred to a person who is not sexually active, or not sexually attracted to other people.

Autoeroticism relates to the sexual and erotic activities directed toward oneself and engaged in without a partner.

$14 \mid$ Glossary of Terms 
Bacterial Sexually Transmitted Infections (STIs) refers to those sexually transmitted infections that are caused by bacteria which include, amongst others, Syphilis, Gonorrhoea and Chlamydia. These infections respond effectively to correct antibiotic treatment.

Barrier method is a method of contraception that uses a physical or chemical barrier, thus preventing the sperm to travel up into the uterus (womb). It includes condoms, caps, spermicides, sponges and diaphragms. Condoms are one of the most effective methods that protect against pregnancy and STIs, including HIV infection.

Bias is an inclination toward or against someone or something, a prejudice or impartial treatment. The term is often used in reference to attitudes and actions in favor of or against a particular person or group of persons, such as women or homosexuals.

Bigendered refers to those who feel they have both a male and female side to their personalities. Some "bigendered" people for example cross-dress, others may eventually have a sex-change operation, and others may do neither.

Beijing Conference or Fourth World Conference on Women, held in 1995, closely followed the deliberations of the 1994 International Conference on Population and Development (ICPD) where the advancement and empowerment of women, and women's rights to control their fertility had already been negotiated. In many ways the Beijing Conference furthered the progress made at the ICPD and emphasised the importance of women to have control over and to decide freely about their sexuality, including sexual and reproductive health.

Birth Control is the term initially used as synonym of family planning. Although often the two terms are used interchangeably, birth control refers to all methods of preventing births including abstinence and abortion.

Bisexual is a person who is sexually attracted to both women and men.

Body image refers to an individual's personal and subjective self-image or mental picture of the body, one's sexual attractiveness and competence.

Body rubbing (dry humping) means rubbing bodies together, especially sexual organs, sometimes leading to orgasm.

C

Casual sex refers to sexual encounters between people who barely know each other where pleasure is generated by excitement and novelty, or between people who have sexual encounters but have no intention to develop the relationship into a long-term commitment.

Call boy or girl are male or female sex workers who work by telephone appointment or by word-or-mouth references only, catering to more affluent clients, unlike sex workers who work the streets and bars.

Celibacy is the abstinence from all sexual activities and sexual relations, especially for religious reasons.

Cervix is the lower part of the uterus that protrudes into the vaginal canal and allows passage of menstrual flow from the uterus and passage of sperm into the uterus.

Circumcision is the act of cutting off the prepuce or foreskin of males or the external structures and/or clitoris of females. 
Clitoris is the erectile, hooded organ at the upper joining of the labia that contains a high concentration of nerve endings and is very sensitive to stimulation.

Climacteric or male climacteric, male menopause or andropause are synonyms. Men experience a different type of 'menopause' or life change. It usually occurs between the ages of 45 and 60 years. Unlike women, men can continue to father children, but the production of the male sex hormone (testosterone) diminishes gradually after age 40. Male menopause, is a distinct physiological phenomenon that is in many ways akin to, yet in some ways quite different from the female menopause. Testosterone is the hormone that stimulates sexual development in the male infant, bone and muscle growth in adult males, and is responsible for sexual drive. It has been found that even in healthy men, by the age of 55, the amount of testosterone secreted into the bloodstream is significantly lower than it is just ten years earlier. In fact, by age 80 , most male hormone levels decrease to pre-puberty levels.

Condom is a flexible sheath (usually made of thin latex or polyurethane) designed to cover the penis (male condom) or vagina (female condom) during sexual intercourse for contraceptive purposes or as a means of preventing STIs. Both the male and female condoms if used consistently and correctly are $95 \%$ effective in preventing pregnancies as well as the spread of STIs including HIV.

Contraceptive is a chemical agent and/or physical device for the prevention of fertility. Contraceptives prevent conception resulting from sexual intercourse.

Closeted refers to someone who keeps his or her sexual orientation secret from friends, relatives, co-workers, or the public.

Cross living means living full-time in the preferred gender image, opposite to one's assigned sex at birth, generally in preparation for a sex change operation.

Coitus is the insertion of the penis into the vagina, followed by rhythmic movement often leading to orgasm. It is also referred to as copulation, or vaginal intercourse.

Coming out is the phrase for recognising one's sexual orientation, and being open about it, with oneself or to others.

Convention on the Elimination of All Forms of Discrimination against Women (CEDAW), adopted in 1979 by the UN General Assembly is a Human Rights treaty that lays down governmental obligations corresponding to individual rights and freedoms. It is described as an International Bill of Rights for Women. The Convention defines discrimination against women as "...any distinction, exclusion or restriction made on the basis of sex which has the effect or purpose of impairing or nullifying the recognition, enjoyment or exercise by women, irrespective of their marital status, on a basis of equality of men and women, of human rights and fundamental freedoms in the political, economic, social, cultural, civil or any other field." The Convention assures the possibility of achieving equality between men and women through equal access to and equal opportunities in public life, education, health and employment. It is the first human rights treaty that affirms the reproductive rights of women and targets cultural and traditional practices that shapes gender roles. Countries that have ratified the convention are legally bound to implement the provisions laid out in the document at national level.

Cross dresser refers to individuals with a desire to wear the clothing of the other sex but not to change their sex. Most cross dressers view themselves as heterosexual men who like to wear women's clothing in private or in public and may even occasionally fantasise about becoming a woman. Once referred to as a transvestite, cross dresser has become the term of choice.

Cybersex refers to all sex-related products, services, and activities exchanged through the use of Internet. It includes any sexual fantasy between individuals or groups through games, chat rooms, bulletin boards, instant messaging services, and other sources.

$16 \mid$ Glossary of Terms 
Desire is the first stage of the sexual response cycle, characterised by a strong wanting for sexual intimacy or satisfaction. It is also called libido.

Domestic partner is the person who lives with their beloved and/or is at least emotionally and financially connected in a supportive manner with another. It is another word for spouse, lover, significant other, etc.

Domestic violence usually refers to men inflicting violence on their wives or children but there has also been growing concern over violence inflicted on men and within gay and lesbian relationships. Domestic violence may be physical, emotional (such as constant humiliation) or economic (such as withholding of financial support).

Dowry is a gift of money, jewellery, clothing or household items to a daughter when she gets married. The bride brings the dowry with her to the groom's household. Originally, the dowry was meant as a type of insurance she could use in case she was mistreated or if the marriage failed. Today, it has become a burden in societies where it is still required, particularly in India, where wives have been mistreated or even killed because they brought in too little dowry.

Discrimination is the act of showing partiality, to make a difference in the treatment of a person on a basis other than individual merit. Action based on prejudice against age, physical abilities, class, ethnicity, sex, race, colour or religion would be considered discrimination.

Drag is the act of dressing in gendered clothing as part of a performance. Drag kings dress in exaggerated male costumes; Drag Queens perform in highly feminine attire. Drag may be performed as a political comment on gender, as parody, or simply as entertainment. Drag performance does not necessarily indicate sexuality, gender identity or sex identity.

Dry sex is the use of herbs, cloth, or other materials to dry out the vagina and increase friction during penile-vaginal intercourse. Dry sex increases a woman's chances of experiencing tears, scrapes, or other damage to the vagina and may increase a woman's risk of contracting HIV or other sexually transmitted infections. It also refers to sexual activities that do not involve the exchange of any bodily fluids.

Dual protection is the protection against both pregnancy and sexually transmitted infections including HIV. For sexually active people, the condom is the only method that is effective by itself for dual protection. To provide extra protection condom can be used in combination with other contraceptive methods.

Dysfunction is the persistent or recurrent inability to react emotionally or physically to sexual stimulation in a way expected of the average healthy person or according to one's own standards of acceptable sexual response.

Dyspareunia is a condition occurring in women characterised by recurrent genital pain during sexual activity. It usually occurs with penetration but can occur also during non-penetrative genital stimulation.

$\mathbf{E}$

Emergency Contraception (ECP) is a contraceptive method used after unprotected intercourse. The ECP should be used as soon as possible or within 72 hours after the unprotected sexual intercourse. ECP prevents ovulation, fertilisation and/or implantation of the egg. However once the process of implantation has begun, it will not cause an abortion. Other names that are used for ECP in India include 'morning after pill', 'unwanted 72', 'i-pill' etc.

Embryo is an animal or a plant in the early stages of development. In humans an embryo is the fertilised egg up until eight weeks, afterwards it is called foetus. 
Empowerment of women is the social, economic, political and legal enablement of women to act by strengthening rights, abilities, and access to facilities, resources, and equal participation previously denied or restricted. Differential access to power and resources by men and women is a key characteristic underpinning gender-based division of labour.

Ejaculation is the moment when rhythmic contractions of the ejaculatory ducts and prostate cause semen to be discharged from the penis.

Engorged means congested with blood.

Erectile dysfunction (ED) is the persistent or recurrent inability to achieve or maintain a penile erection. It is also called impotence.

Erection is the firm and enlarged condition of a body organ (e.g., penis, clitoris, nipples) when the erectile tissue becomes filled with blood or due to muscular contraction.

Erogenous zones are highly innervated areas of the body that are especially sensitive and responsive to sexual stimulation, thus causing sexual arousal and sexual pleasure. Common areas identified as erogenous zones include neck, earlobes, mouth, lips, nipples, genitalia, buttocks, inner thighs, anus, back of knees, fingers, and toes.

Erotic refers to something or someone tending to arouse sexual desire.

Erotic fantasy means reading, watching, imagining, telling, or acting out erotic fantasies with or without a partner.

Erotic massage is the sensual and sexually arousing body massage, which sometimes includes stimulation of the sexual organs with hands, body, or mouth.

Excitement (arousal) is the second stage of the sexual response cycle which is characterised by increased heart rate and blood pressure, body muscle tension, sexual flush, and erection of the nipples in both sexes. In women, vaginal lubrication and swelling of the vulva also occur. In men, there is scrotal thickening and movement of the testes closer to the body.

Exhibitionism is the sexual arousal achieved by undressing, performing sex acts, or masturbating in front of others; or by exposing one's genitalia to strangers as a means of obtaining sexual arousal.

$\mathbf{F}$

Fellatio is the stimulation of the penis using the lips, mouth, or tongue. This practice may or may not be continued to orgasm, and the partner may or may not swallow the ejaculate.

Family planning refers to the conscious effort of couples or individuals to plan their family and be able to conceive the desired number of children they want. Family planning is achieved through the availability of family planning services where contraceptive methods are available for all.

Female genital mutilation (FGM) or female circumcision is the traditional and cultural practice which involves partial or total cutting or injury of the female genital organs. It is usually performed by traditional practitioners in unhygienic conditions making intercourse and childbirth painful and potentially dangerous. The World Health Organisation (WHO) has grouped the FGM into the following types: type I or clitoridectomy, which involves the cutting of the prepuce sometimes together with part of all of the clitoris; type II involves the cutting of the clitoris with the partial or total removal of the labia minora; type III or infibulation involves the cutting of the clitoris, labia minora and part or total removal of external labia which are then stitched together to narrow the vaginal opening; type IV refers to any practice involving pricking, piercing or incision either of the clitoris or of the labia, or the introduction of substances into the vagina to cause bleeding or with the purpose of narrowing or tightening it. 
Female sexual arousal disorder (FSAD) is the persistent and recurrent inability to achieve or maintain an adequate lubrication-swelling response until completion of the sexual activity.

Fertility is the extent to which an individual, group or society has reproduced.

Foetus is the fertilised egg in the uterus which has survived beyond eight weeks.

Fetishism refers to the sexual arousal occurring in response to any nonsexual object or practice or to a non genital body part. Fetishes vary widely and might include items of clothing (such as shoes, boots, or undergarments), materials (such as leather, rubber, or silk), or body parts (such as hair, feet, or legs).

Fisting is the insertion of a hand into the rectum or vagina of a sexual partner, forming a fist during or after insertion.

Foreplay is the physical and sexual stimulation (such as kissing, touching, stroking, and massaging) usually preceding sexual intercourse. Sometimes, it is also referred to as outer course when this stimulation is engaged without intercourse.

Frottage is the sexual arousal achieved by rubbing against another person, particularly by rubbing against a stranger in a public place.

FTM stands for female to male transsexual. An individual whose birth sex was female but whose gender identity is male.

G

Gay is a term currently used to describe a man who is sexually attracted to other men. Colloquially used as an umbrella term to include all lesbian, gay, bisexual, transgender and queer people.

Gender is a concept that refers to the differences between males and females that are socially constructed, changeable over time, and that have wide variations within and between cultures. As opposed to biologically determined characteristics, gender refers to learned behaviour and expectations to fulfill one's image of masculinity and femininity. It is used as a socio-economic and political variable with which to analyse roles, responsibilities, constraints and opportunities of people; it considers both males and females.

Gender biases are prejudiced actions or thoughts based on gender-based perceptions that women are not equal to men.

Gender conformity means that gender identity and the sex of the person match or fit with the "prescribed" social norms.

Gender identity refers to an individual's self-awareness or fundamental sense of himself or herself as being masculine or feminine or of the third sex, and male or female or of the third sex.

Gender roles are roles expected to be played by men or women based on social expectations.

Gender stereotyping is the term used when gender roles are based on biological differences than on social expectations. Gender stereotyping is said to occur when there is no consideration for the individual's skills, talents and capabilities.

Genetics refers to the chromosomal heritage of each individual with emphasis on the sex chromosomes which are $\mathrm{XX}$ in women and $\mathrm{XY}$ in men. 
Glans penis (glans) is the head of the penis. The glans is the most highly innervated part of the penis and is covered by the foreskin in men who are not circumcised.

G-spot (Grafenberg spot) is a small area (about 1-2 cm) on the front wall of the vagina that is especially sensitive to stimulation in some women and may be the source of a small amount of fluid ejaculated at orgasm.

Heterosexual is an individual who is sexually attracted to people of a gender other than their own and/or identifies as being heterosexual.

Heterosexism is the assumption that every person should be heterosexual thus marginalising others who do not identify themselves as heterosexual. It also implies that heterosexuality is superior to homosexuality and all other sexual orientations and identities.

Heterosexuality is the sexual, emotional and/or romantic attraction to a sex other than your own. It is commonly thought of as "attraction to the opposite sex", but since there are not only two sexes (see intersex and transsexual) this definition is inaccurate.

Heterosexuality privilege is the benefit derived automatically by being (or being perceived as) heterosexual that are denied to homosexuals, bisexuals, and queers.

Hijra is a term used in the Indian subcontinent that includes those who aspire to and/or undergo castration, as well, as those who are intersexed. Although some Hijra's refer to themselves as feminine, others say they belong to a third gender and are neither men nor women.

Homophobia is the irrational fear and intolerance of people who are homosexuals or of homosexual feelings within one's self. This assumes that heterosexuality is superior and it is usually expressed by discriminatory attitudes towards homosexuals, or even the use of outright violence against homosexuals. It is often associated with religious prejudices, which view homosexuality as sinful.

Hormonal contraceptives are the contraceptive methods based on either progesterone combined with an oestrogen hormone or progesterone alone. The hormones could be in pill form (oral contraceptives), injectables or implants. These methods are all short term, reversible methods.

Hymen is a fold of thin, fleshy tissue that stretches across part of the opening of the vagina in some women.

Hysterectomy is the medical removal of the uterus. Total hysterectomy includes the removal of the ovaries (oopherectomy) and fallopian tubes (salpingectomy) at the time of removing the uterus and cervix. Supracervical (subtotal) hysterectomy involves removal of the uterus while preserving the upper vagina and cervix.

Human Immunodeficiency Virus (HIV) is the virus that causes AIDS. The virus is transmitted through unprotected sexual contact, through blood, sharing of needles, accidental exposure in the health care setting (example through a needle stick injury) and from mother to child either during pregnancy, child birth or breast feeding. HIV infection is said to occur when a person is exposed to HIV. It is diagnosed with antigen or antibody tests. Commonly, the antibody test is performed to diagnose HIV infection. People who have HIV infection may be appear healthy, will be able to do most of their daily activities and could continue to work. As HIV damages the immune system of the person some opportunistic infections such as chronic diarrhoea, unexplained prolonged fever, Tuberculosis, Pneumonia etc begin to develop becoming progressively severe. It is then that a person is considered to be progressing towards AIDS. 
Incest is the sexual contact between closely related individuals that violates socio-cultural or religious norms or laws. The types of kinship within which sex is forbidden vary widely between cultures and countries. Even in India variations exist between cultures.

Infertility is the inability to have children. This term is used when a couple has been trying to become pregnant conceive for at least 12 months without success.

International Conference on Population and Development (ICPD) Since 1974, every ten years, the United Nations has held a series of conferences to discuss the issues related to population and development. In 1984 the conference concentrated on the demographic targets placing great emphasis on population control. In 1994 the ICPD conference, considered a landmark conference, placed greater emphasis on the linkages between population, education, health, environment and poverty. The ICPD introduced a new concept of reproductive health focusing on the rights of individuals and couples to decide the number, timing and spacing of their children. The new focus called for the integration of sexual and reproductive health services and for better quality of services for all, including adolescents. It also emphasised the importance of inclusion of women's interests as components of development.

Intercourse is the insertion of the erect penis into the vagina or anus. It may also be used to describe other forms of sexual activity, such as interfemoral (moving the penis between the thighs) intercourse, oral intercourse, or mammary (between the breasts) intercourse.

Intersex people are born with "sex chromosomes", external genitalia, or reproductive systems that are not considered "standard" for either male or female. The individual is born with physical characteristics of both males and females. These individuals may or may not identify as men or women.

Intersexuality refers to a set of medical conditions that feature congenital anomaly of the reproductive and sexual system. The existence of intersexuals shows that there are not just two sexes. This word replaces 'hermaphrodite which is generally considered impolite and/or derogatory.

Intrauterine device (IUD) is a small flexible contraceptive device which is inserted into the womb (uterus) to prevent pregnancy. This method is effective for at least four years.

Inhibited sexual desire (ISD) refers to the persistent or recurrent inability to achieve or maintain an adequate lubrication/swelling response until completion of sexual activity.

Impotence is the inability to achieve erection. It could be due to a physiological or psychological problem and would need investigations to identify the cause.

$\mathbf{K}$

Kothi is a feminised male identity, which is adopted by some people in India and is marked by gender nonconformity. A Kothi, though biologically male, adopts feminine modes of dressing, speech and behaviour and looks for a male partner who has a masculine mode of behaviour, speech and dress. Some believe that this not an identity but a behaviour.

$\mathbf{L}$

Labia majora are the two spongy folds of skin (one on either side of the vaginal opening) that cover and protect the genital structures.

Labia minora are the two erectile folds of skin between the labia majora that extend from the clitoris on each side of the urethral and vaginal openings, covering the vestibule. 
Lactational Amenorrhoea Method (LAM) refers to the process of exclusive breast-feeding for six months after birth which produces a very high degree of natural protection against pregnancies. The body of a breastfeeding woman produces a hormone called prolactin, which suppresses ovulation and menstruation thus preventing pregnancy. Lactational amenorrhoea is therefore considered a method of contraception.

Lesbian is a female who is sexually attracted to other women.

Libido is the drive or energy associated with sexual desire.

\section{M}

Male circumcision refers to the surgical removal of the retractable skin (foreskin) covering the glans penis.

Male involvement according to the ICPD, focuses on men and women's joint responsibilities, so that they become equal partners in public and private life and on the involvement of men to take responsibility for their sexual and reproductive behaviour. However programmes that involve men in reproductive health have used many definitions and names to describe the shift towards a more active role of men, including men's participation, men's responsibility, male motivation, male involvement, men as partners and men and reproductive health. There is no consensus about which term best describes the new shift and attention on men, or how men can best be involved in reproductive health activities without being a hindrance to women's health. The main purpose is to describe a complex process of social and behavioural change that is needed for men to protect their own reproductive and sexual health and to play more responsible roles in reproductive health. The goal is to achieve the best attainable reproductive health for everybody through the active and positive support and involvement of both women and men.

Masochism refers to the sexual arousal or orgasm dependent on receiving punishment, discipline, humiliation, or servitude.

Mastectomy is the surgical removal of the nipple, areola and breast tissue, usually related to cancer. Radical mastectomy involves the removal of the chest muscles, lymph nodes under the arm and additional fat and tissue.

Masturbation refers to the manual stimulation of oneself or of a partner for sexual pleasure.

Menarche is the first occurrence of menstruation.

Menstruation is the cyclic flow of blood, fluid, and tissue out of the uterus and through the vagina approximately every 28 days (usually lasting $3-5$ days).

Menopause is the time in a women's life when the natural cessation of her menstruation occurs.

Men who have sex with men (MSM) refer to men who engage in same-sex behaviour, but who may not necessarily self-identify as gay. In many cultures, men have sex with other men but do not think of themselves as homosexual. The category "men who have sex with men" is presently used as a neutral term.

Mons pubis is a pad of fatty tissue over the pubic bone that protects the internal sexual and reproductive organs of women.

MTF stands for male to female transsexual or transvestite. An individual whose birth sex was male but whose gender identity is female.

Multiple orgasms refers to the act of passing immediately from the orgasm stage of the sexual response cycle to the plateau stage and back to the orgasm stage without passing through the resolution stage.

Mutual masturbation is the sexual activity in which partners stimulate each other's genitals with hands or sex toys. Sometimes used to refer to a couple watching each other masturbate. 
Nymphomania is the term used to refer to a very sexually active woman, implying excessive or uncontrollable desire. This term is often pejorative and reflects gender biases which dictate that women should be sexually naive and without active desire.

Nocturnal emissions are the normal discharges of semen through the penis occurring during the night as a result of erotic dreams. They are also referred to as wet dreams. They are a natural phenomena that bring no physical or mental harm. Wet dreams are common also amongst girls. Erotic dreams as a result of sexual desire may lead to orgasm during sleep.

Non-op refers to transsexuals who seek sex reassignment through hormones and who cross-live, but stop just short of surgery. Some have concerns about major surgery, which is not always successful, others are unable to pay for the expensive procedures, and still others feel that they are complete without the surgery.

$\mathbf{O}$

Orgasm is the fourth stage of the sexual response cycle, characterised by the peak of sexual tension, resulting in release of tension through muscular contractions of the uterus, vagina anus and pelvic floor in women, and contractions of the urethra, anus and pelvic floor in men. In men, orgasm can trigger contractions of the ejaculatory duct and prostate gland, causing semen to be ejected from the body through the penis.

Orgasmic platform is the congestion of blood vessels and tissue in the outer third of the vagina during sexual arousal; simultaneous contractions of the pubo-coccygeous muscles, anal sphincter, rectum and perineum to form the orgasmic reflex.

Outer course refers to any form of sexual pleasure or stimulation between partners that does not include insertion of the penis into the vagina, anus, or mouth. Activities may include masturbation, erotic massage, rubbing together of body parts, erotic fantasy etc.

Ovaries are the organs located at the end of each fallopian tube that produce the ova (eggs) released during the menstrual cycle. The ovaries produce sex hormones responsible for the development of secondary female sex characteristics, sexual function and genital tract integrity.

Ovulation is the periodic release of an ovum from the ovary during the middle of the menstrual cycle. In humans, the few days near ovulation constitute the fertile phase. The average time of ovulation is the fourteenth day of an average length (twenty-eight day) menstrual cycle. It is normal for the day of ovulation to vary from the average, with ovulation anywhere between the tenth and nineteenth day being common. Women near ovulation can experience changes in the cervix, in mucus produced by the cervix and in their basal body temperature. Some women also experience secondary fertility signs and heightened sense of smell. Many women experience heightened sexual desire in the several days immediately before ovulation.

$\mathbf{P}$

Pansexual is a person who has fluid sexual orientation and/or gender or sex identity.

Penis is the male organ with the capacity to be flaccid or erect, used for both passage of urine and sexual intercourse.

Paedophilia is the sexual arousal of an adult obtained by sexual contact with or through fantasies about children.

Perimenopausal refers to the years leading up to menopause. This term is interchangeable with the term climacteric. 
Perineum is a network of muscles located between and surrounding the vagina and anus in women, and the penis and anus in men.

Periodic abstinence is a traditional method of contraception which is based on the avoidance of sexual intercourse during the women's fertile period. This method requires the ability to determine the fertile phase or fertility awareness. There are several techniques used to identify the fertile period: the basal body temperature (BBT) based on the increased body temperature that happens shortly after ovulation; the cervical mucus or ovulation method or Billings method, based on the changes in a women's mucus during the pre and post ovulatory phases of her period; and the calendar method or rhythm method based on previous menstrual cycles to predict the fertile day. The use of multiple techniques is more accurate for determining the fertile period. These methods can be used by couples who want to avoid pregnancy but also by those who are trying to increase their chances to conceive.

Penile deformity is a deformity of the penis that may be severe enough to make penetration during sexual activity difficult or impossible.

Plateau is the third stage of the sexual response cycle; this is the highest moment of sexual excitement before orgasm. This stage may be lost and regained several times without the occurrence of orgasm.

Pornography refers to the erotic imagery including films, books, photographs, that depict explicit sexual interaction, intended to create sexual arousal in the consumer.

Post-op refers to a transsexual who has had their sex change operation and now has the physical anatomy which mimics that of the sex they have transitioned to.

Postmenopausal is the one-to two-year period after menopause.

Premature ejaculation (PE) is a condition in men characterised by persistent or recurrent ejaculation with minimal sexual stimulation before, on, or shortly after penetration and before the person wishes it.

Prenatal sex selection is the abortion preformed because the sex of the foetus is judged to be undesirable to one or both parents. This usually happens in societies where there is a strong son preference and usually refers to the abortion of female foetuses. It has been banned in India with the Prenatal Diagnostic Techniques Act of 1994.

Primary HIV infection is the flu-like illness that occurs soon after infection with HIV or within 2-4 weeks of being exposed to HIV.

Progesterone is a sex hormone produced in the ovaries (corpus luteum) that has a role in menstruation, pregnancy, and contraception.

Prostitute refers to women or men who engage in sex acts or sexual intercourse for money or goods. The term prostitute is now less used as it is considered derogatory. Instead the term 'sex worker' is used.

Prostatectomy is the removal of the prostate and some of the tissue around the gland.

Prostate disease refers to a number of conditions of the prostate, including benign prostatic hyperplasia (BPH), prostatitis, and prostate cancer.

Prostate gland is a walnut-sized glandular structure that secretes approximately $30 \%$ of the fluid that makes up semen.

Prostatitis is an acute, chronic, or noninfectious inflammation of the prostate often caused by bacteria. Symptoms include pain in the testicles, or rectal area and may sometimes include problems with ejaculation, urination, or defecation. 
Pubescent means having reached puberty.

Puberty is the age at which the sex organs become active and external genitals mature to adult form.

\section{Q}

Queer is a term used to refer to all lesbians, gay, bisexual, transgender, intersex and queer people. It is also used as a label to explain a complex set of sexual behaviours and desires. For example, a person who is attracted to multiple genders may identify as queer. Originally the term was a synonym for "odd". The word 'queer' became derogatory expression for gays in the last century. Even though many people still use 'queer' as an anti-gay epithet, a movement emerged in the 1980s that calls itself 'queer'. In this context, queer means sexually dissident. Many gays, transsexuals, bisexuals and even heterosexuals whose sexuality doesn't fit into the cultural standard of monogamous heterosexual marriage have adopted the 'queer' label.

$\mathbf{R}$

Rape is any form of non consensual sexual intercourse (vaginal, anal, and oral) or other sexual contacts forced by a person or persons upon another using physical force, threat or coercion. Although this term is included in a list of sexual practices, rape should be considered a form of violence rather than as a form of sex.

Rape fantasy refers to the sexual arousal reached by fantasising about being raped, being forced to engage in sexual activity, or forcing a person to engage in sexual activity. Having rape fantasies or consensually acting out rape fantasies does not imply an actual desire to be raped or to rape.

Refractory period is the time immediately following orgasm during which a man cannot achieve an erection.

Reproductive health as defined in the Platform of Action of the ICPD is a state of complete physical, mental and social well-being and not merely the absence of disease or infirmity in matters relating to the reproductive system and its functions and processes. The ability to enjoy sexual relations without fear of infection, to avoid unwanted pregnancy or coercion, to regulate fertility without risk, to go safely through pregnancy and childbirth, and to bear and raise healthy children.

According to the ICPD, reproductive health care, in the context of primary health care should, amongst others, include: family-planning counselling, information, education, communication and services; education and services for prenatal care, safe delivery, and post-natal care, especially breast-feeding, infant and women's health care; prevention and appropriate treatment of infertility; prevention of abortion and the management of the consequences of abortion; treatment of reproductive tract infections; sexually transmitted diseases and other reproductive health conditions; and information, education and counselling, as appropriate, on human sexuality, reproductive health and responsible parenthood. Within reproductive health services, referral for family-planning services and further diagnosis and treatment for complications of pregnancy, delivery and abortion, infertility, reproductive tract. infections, breast cancer and cancers of the reproductive system, sexually transmitted diseases and HIV/AIDS should always be available, as needed. Harmful practices such as female genital mutilation should be discouraged.

Reproductive system is formed by the organs involved in reproduction.

Reproductive rights are the basic rights of all couples and individuals to decide freely and responsibly on the number, spacing and timing of their children, to have access to the information and means to do so, to be able to attain the highest standards of reproductive health and to make decisions concerning reproduction free of discrimination, coercion, or violence.

Reproductive tract infection (RTIs) refers to any infectious diseases of the genitourinary tract that include sexually transmitted infections, other common infections of the genital tract (e.g., Candidiasis), and infections associated with clinical procedures, such as IUD insertion. 
Reproductive years are the period of life when men and women are fertile.

Retrograde ejaculation refers to an ejaculation in which semen is expelled back into the bladder rather than out through the penis.

Resolution is the last stage of the sexual response cycle, this is the period following orgasm, during which body muscles relax and the body begins to return to its pre excitement state.

Risk factor is a factor that increases the chance of developing a disease.

\section{$\mathbf{S}$}

Sadism refers to the sexual arousal or orgasm dependent on giving punishment, disciplining or humiliating a partner, or requiring servitude.

Sadomasochism is the consensual use of domination or pain for sexual arousal and stimulation; fantasising or playing out dominant and submissive roles. The "sadist" is the partner who dominates or inflicts pain, and the "masochist" is the partner who is dominated or receives pain.

Safe sex (often "safer sex") is a term used to refer to sexual behaviours that do not pose risks for the transmission of sexually transmitted diseases and infections, including HIV/AIDS. However, some argue that with the exception of abstinence and solo masturbation there are no sexual behaviours that are totally safe and therefore, the term safer sex is more appropriate. In this context safer sex refers to sexual behaviours that reduce or do not pose any risks of STI transmissions. The consistent and correct use of condoms during sexual activity or non penetrative sexual activities is an example of safer sex techniques. Other definitions of safe sex might include relations that lower the risk of disease transmission and unintended pregnancy, violence, coercion, or abuse of power. In this case, safer sex also includes protected sex which is any sexual behaviour that provides protection either from unwanted pregnancies or from sexually transmitted diseases.

Safe motherhood means ensuring that women receive the appropriate care to be safe and healthy throughout pregnancy and childbirth with low risk of death or ill health. In order to ensure this several programmatic priorities should be implemented at country level including the empowerment of women to ensure choices, delay marriage and first birth, ensure good quality skilled delivery, and improve access to reproductive health services and prevention of unwanted pregnancies. Safe motherhood is a Millennium Development Goal and is depicted using a white ribbon presently.

Salpingectomy is the surgical removal of one or both of the fallopian tubes.

Scrotum is a pouch of skin hanging directly under the penis that contains the testes. Its functions are to protect the testes and to maintain the temperature necessary for the production of sperm by the testes.

Satyriasis is the desire by a man to have sex frequently with different partners, implying excessive or uncontrollable desire. As with nymphomania, this term is often pejorative.

Semen is the fluid which is expelled during ejaculation, which normally contains sperm and seminal fluid.

Seminal vesicles are the pair of glandular sacs that secrete approximately $60 \%$ of the fluid that makes up semen in which sperm are transported.

Sex is the biological difference including genetic, anatomical, and biochemical differences that define humans at birth as males or females.

Sexual anatomy is the structure and organs that make up the genital tract of women and men. 
Sexual behaviours are any actions such as touching, kissing and other stimulation of the body, related to the expression of one's sexuality.

Sexual fantasy refers to any sexually pleasing mental images unrestrained by the realities of the external world.

Sexual flush is the reddening of the skin during sexual activity.

Sexual harassment is the use of status and/or power to coerce or attempt to coerce a person into engaging in having any kind of sexual contact. It refers to any unwanted practice, comments and attitudes that have sexual implications directed by individuals in a power position towards subordinates especially in occupational, educational, therapeutic, or research settings.

Sexual health refers to the women's and men's ability to enjoy and express their sexuality free from the risk of sexually transmitted diseases, unwanted pregnancy, coercion, violence and discrimination. It means being able to have an informed, enjoyable and safe sex life, based on a positive approach to sexual expression and mutual respect in sexual relations. It is positively enriching, includes pleasure and enhances self-determination, communication and relationships.

Sexual identity is the identification of how a person thinks of oneself in terms of attraction to the same sex or members of the other sex based on one's own experiences, thoughts and reactions, rather than on the gender or sex of the sexual partner(s). This can include refusing to label oneself with a sexual identification.

Sexual intercourse is the sexual activity that involves vaginal, anal, or oral penetration.

Sexual orientation and sexual preference are two terms that are used interchangeably, to refer to whom someone is sexually attracted to. In western psychology and psychiatry, the standard division is 'heterosexual' for someone who is mainly attracted to someone of the "opposite" sex while a 'homosexual' is someone attracted to someone of the same sex. A bisexual, on the other hand, is someone attracted to both sexes. We have used quotation marks around the terms 'opposite' and 'same' because increasingly, there has been a questioning of these concepts that are dichotomous, based only on two biological sexes of male and female. Cross-cultural research suggests that different societies will have different definitions of 'sexes' and 'attraction' which may not fit the western categories. For example, in Thailand, Indonesia and the Philippines there are 'third sex' or transgender categories of men who are sometimes called 'homosexual' but who will claim they are not attracted to other homosexuals. Instead, they are attracted to 'real men'. 'Real men', on the other hand, will have sex with these 'third sex' categories but will say they are not homosexual. The term 'sexual orientation' has connotations that a person's choice of sexual partners is biologically determined, i.e., that one is born already 'oriented' toward a particular sex. The term 'sexual preference' suggests the choices are more flexible.

Sexual practices are activities related to sexual expression that are performed habitually or repeatedly.

Sexual reassignment is a complex range of procedures that a person undergoes to transform from one sex to another. This includes hormonal therapy, hair transplants or removal, speech therapy and surgeries to change one's sexual and sometimes reproductive organs.

Sexual responses are psychological and physical reaction patterns to sexual stimulation.

Sexual rights are a person's right to have control and decide freely and responsibly in matters related to her or his sexuality, free of coercion, in the preservation of their physical, mental and moral integrity. Sexual rights include, amongst others, the right to happiness, dreams and fantasies; the right to explore one's sexuality free from fear, shame, guilt and false beliefs; the right to live one's sexuality free from violence, discrimination and coercion; the right to sexual health, which requires access to the full range of sexuality and sexual health information, education and confidential services and the right to choose to be sexually active or not. 
Sexual scripts are those behaviours considered appropriate by members of a culture for sexual interactions. For example, during courtship there may be 'rules' on what can or can't be said and done, or what body parts can be touched.

Sexually Transmitted Infections (STIs) are the infections usually passed from person to person by sexual contact, although some can be passed on by other means (e.g. through blood or needle-stick injury).

Sexuality is a central aspect of being human throughout life and encompasses sex, gender identities and roles, sexual orientation, eroticism, pleasure, intimacy and reproduction. Sexuality is experienced and expressed in thoughts, fantasies, desires, beliefs, attitudes, values, behaviours, practices, roles and relationships. While sexuality can include all of these dimensions, not all of them are always experienced or expressed. Sexuality is influenced by the interaction of biological, psychological, social, economic, political, cultural, ethical, legal, historical and religious and spiritual factors.

Sixty-nine refers to the mutual and/or simultaneous oral sex between two people.

Skene's glands are two small glands near the urethral opening in women.

Smear (Papanicolaou smear) is a test of the cells collected from the cervix to look for changes of the cells which relate to cancer or other anomalous changes. Sexually active women are recommended to have regular Pap smear test every two years.

Sodomy is any sexual act that is not penile-vaginal penetration. Usually refers to oral or anal intercourse, but various legal definitions may include other activities.

Spermicides are chemical contraceptives that neutralize or kill sperm and form, to a certain extent a barrier in the cervix. They are more effective when used in combination with other methods such as condoms or diaphragms.

Striptease is the eroticised, gradual undressing performed by a man or a woman.

Syphilis is a sexually transmitted infection caused by a micro-organism called spirochete. The spirochete enters the body through invisible breaks in the skin or mucous membranes of the mouth, rectum or genital tract. After three weeks sores containing large number of spirochetes develop at the entry site. The sores will heal but the spirochetes will spread throughout the body. Syphilis is curable with treatment but if left untreated may progress to systemic infection and may cause general paralysis.

$\mathbf{T}$

Testes are the paired, oval-shaped organs located in the scrotum that produce sperm and male sex hormones.

Testosterone is a sex hormone responsible for the development of male secondary sex characteristics and for the sex drive (libido) in men and in women.

Total Fertility Rate (TFR) is the average number of children that would be born alive to a woman during her lifetime if the age-specific fertility rates of a given year applied throughout her childbearing years.

Trafficking is the recruitment, transportation, purchase, sale, transfer, harbouring or receipt of persons by threat or use of violence, abduction, fraud, deception or coercion (including the abuse of authority) or debt bondage for the purpose of placing or holding such a person, whether for pay or not, in forced labour or slavery-like practices in a community other than the one in which such person lived at the time of the original act (Special Rapporteur on Violence Against Women to the UN Commission on Human Rights 2000). 
Transgender is a term used in recent years to refer to "third sex" categories found in many societies, examples being the kathoey in Thailand, the bakla in the Philippines and the waria in Indonesia. They are usually men who will behave like women, in the clothes they wear, body gestures, etc., but who also remain distinct as a "third sex" category. Western terms such as "gay" and "homosexual" are often applied to transgender but may not be accurate since there is more than sexual orientation involved here. Transgender have an entirely distinct lifestyle, neither male nor female, which has been accepted, to some extent, by society.

Transgenderist is a person who lives either full time, or most of the time, in a gender role different than the role associated with their biological or chromosomal sex. They could be men who dress, act or behave like women or women who dress act and behave like men. They do not however identify as homosexual.

Transvestite is a man who enjoys wearing women's clothing for pleasure, or for sexual, emotional or sexual gratification.

Transvestism (cross-dressing) refers to the ritual of dressing in clothes traditionally used by members of the opposite sex. In some people, cross-dressing may be a compulsion, or sexual arousal may be dependent upon cross-dressing. Many transvestites are heterosexual men whose behaviour pattern does not lead to transsexualism (living and passing socially as a member of the opposite gender). Other transvestites are homosexual men ("drag queens"), who often develop elaborate feminine personas.

Transsexual refers to a person who experiences a mismatch of the biological sex they were born as and the biological sex they identify as. A transsexual sometimes undergoes medical treatment to change his/her physical sex to match his/her sex identity through hormone treatments and/or surgical procedures.

\section{$\mathbf{U}$}

Unsafe abortions are procedures for terminating an unwanted pregnancy performed either by persons lacking the necessary skills or in an environment lacking the basic medical and sanitary standard conditions or both. A quarter of women worldwide live in countries where there is no access to legal abortions and they may not be able to obtain the necessary bureaucratic permissions. In these circumstances women frequently resort to unsafe abortions which expose them to an increased risk of mortality or morbidity.

Uterus is a hollow, thick-walled, pear-shaped, muscular organ located between the bladder and rectum. It is the site for the implantation of the fertilised ovum (egg), the location where the foetus develops during pregnancy, and the structure that sheds its lining monthly during menstruation.

\section{V}

Vagina is the muscular, highly expandable cavity leading from the external genital opening to the uterus. The vagina serves as a passage for discharge of menses, for reception of the penis during sexual intercourse and for delivery of the foetus during childbirth.

Vas deferens (pl. vasa deferentia) in men is one of the paired tubes that carry the mature sperm from the epididymis to the urethra.

Vestibule is the area of the external female genitalia that includes the vaginal and urethral opening and the opening of the Bartholin's and Skene's glands.

Violence against women as defined by the United Nations Declaration on the Elimination of Violence Against Women is "Any act of gender-based violence that results in, or is likely to result in, physical, sexual or mental harm or suffering to women, including threats of such acts, coercion or arbitrary deprivation of liberty, whether occurring in public or in private life." The Declaration goes on to say that violence against women encompasses, amongst others, "physical, sexual and psychological violence occurring in the family and in the general community including 
battering, sexual abuse of female children, dowry-related violence, marital rape, female genital mutilation and other traditional practices harmful to women, non-spousal violence and violence related to exploitation, sexual harassment, and intimidation at work, in educational institutions and elsewhere, trafficking in women, forced prostitution, and violence perpetrated or condoned by the state".

Viral load refers to the number of viral particles (usually HIV) in a sample of blood plasma. HIV viral load is used to monitor HIV infection.

Voluntary surgical contraception refers to the long term contraceptive method called also sterilisation or tubectomy, tubal ligation or tubal occlusion in women and vasectomy in men. This method is one of the most effective methods for men and women who desire not to have any more children. Vasectomy blocks the sperm ducts so the sperm cannot enter the ejaculate, whilst female sterilisation blocks the fallopian tubes to prevent the ovum from reaching the uterus.

Vulva is the external genital organ of the female, including the labia majora, labia minora, clitoris, and vestibule of the vagina.

\section{W}

Withdrawal is one of the oldest methods of contraception which entails the withdrawal of the penis from the vagina before ejaculation. It is also known as coitus interruptus.

Womb is the uterus.

\section{Adapted from source:}

- $\quad$ South East Asian Consortium on Gender, Sexuality and Health. 2005. Glossary of Terms on Gender and Sexuality. Thailand. <www.seaconsortium.org>.

- TARSHI. 2006. Basics and Beyond. New Delhi: TARSHI. 


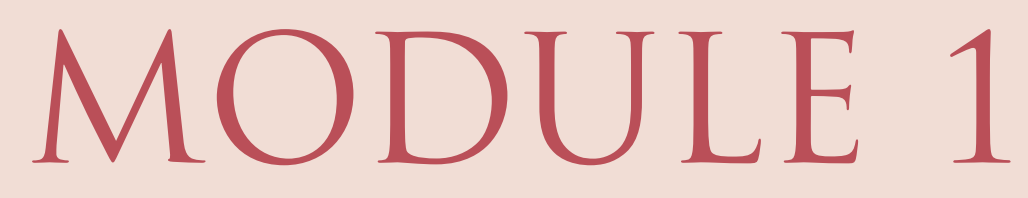

\author{
TALKING ABOUT OURSELVES- \\ EXPLORING CONCEPTS OF SEXUALITY
}




\section{Facilitators Guide}

\section{Content Considerations}

1. Emphasise that sexuality encompasses a broad range of human experience. It includes human development, emotions and relationships, sexual health, sexual behaviour and sexual violence.

2. Compare the terms "sexuality" and "sex," as they are often confused.

3. Talk about the continuum of sexuality throughout life, the range of events that may occur and the many different expressions of sexuality.

4. Discuss the differences and similarities in how people experience their sexuality.

5. Discuss and agree on the terms all participants will use in the course.

\section{Aim}

Participants have a broader understanding of human sexuality, appreciate the variations in expressions of one's sexuality and apply this knowledge when dealing with their clientele.

\section{Objectives}

By the end of this module participants will:

1. Realize the need for training on sexuality and gender.

2. Comprehend the meaning of human sexuality.

3. Examine and review own ideas and perceptions of body parts; different sexual behaviours and sexual orientations/ identities.

4. Explore own attitudes to various sexual behaviours and expressions.

\section{Duration: 4 hours}

\section{Key Messages}

1. There are many different ways to define the term 'sexuality'.

2. Sexuality is an integral part of being human. It is socially constructed and determined and is expressed differently based on several factors.

3. To simplify the term 'human sexuality', it can be split into the following five components all of which are interrelated:

- Human development

- Relationships and emotions

- Sexual behaviour

- Sexual health

- Sexual violence

4. Sexuality is essential to the continued existence of humanity. But it is not just about the process of reproduction. Sexual behaviour is only one part of sexuality.

5. Awareness and examination of one's own perceptions of sexual orientation, body parts and sexual behaviours could help one be more open to existing variations. 
Module 1: Topic, time, activity/method and resources needed

\begin{tabular}{|c|c|c|c|}
\hline Topic & Time & Activity/Method & Resources Needed \\
\hline Introduction & 5 minutes & & $\begin{array}{l}\text { - Black/white board, flip chart, OHP/LCD Projector } \\
\text { - Chalk/marker pens/OHP transparencies } \\
\text { - Duster } \\
\text { - Slide } 1.1-1.4\end{array}$ \\
\hline \multirow[t]{2}{*}{$\begin{array}{l}\text { Meaning of } \\
\text { human sexuality }\end{array}$} & 20 minutes & $\begin{array}{l}\text { Activity 1.1: } \\
\text { Group discussion } \\
\text { on meaning of } \\
\text { human sexuality }\end{array}$ & $\begin{array}{l}\text { - Black/white board or flip chart or OHP/LCD Projector } \\
\text { - Chalk/marker pens/OHP transparencies } \\
\text { - Duster } \\
\text { - White paper and chart paper } \\
\text { - Slide } 1.5-1.6\end{array}$ \\
\hline & 30 minutes & $\begin{array}{l}\text { Activity } 1.2 \text { : } \\
\text { Components of } \\
\text { human sexuality }\end{array}$ & $\begin{array}{l}\text { - Black/white board or flip chart or OHP/LCD Projector } \\
\text { - Chalk/marker pens/OHP transparencies } \\
\text { - Duster } \\
\text { - Worksheet } 1.1-1.2 \text {, Handout } 1.1-1.2 \\
\text { - Slide } 1.7\end{array}$ \\
\hline \multirow[t]{6}{*}{$\begin{array}{l}\text { Exploring the } \\
\text { concepts of sex } \\
\text { and sexuality }\end{array}$} & 40 minutes & $\begin{array}{l}\text { Activity } 1.3 \text { : } \\
\text { What do I } \\
\text { perceive about } \\
\text { my body? }\end{array}$ & $\begin{array}{l}\text { - Black/white board or flip chart or OHP/LCD Projector } \\
\text { - Chalk/marker pens/OHP transparencies } \\
\text { - Duster } \\
\text { - Chart papers } \\
\text { - Stamp ink } \\
\text { - Sticky tape or clips } \\
\text { - Worksheet } 1.3 \text { (only for Facilitator) } \\
\text { - Slide } 1.8-1.9\end{array}$ \\
\hline & 10 minutes & $\begin{array}{l}\text { Activity } 1.4 \text { : } \\
\text { My view on } \\
\text { sexuality and sex }\end{array}$ & $\begin{array}{l}\text { - Black/white board or flip chart or OHP/LCD Projector } \\
\text { - Chalk/marker pens/OHP transparencies } \\
\text { - Duster } \\
\text { - Worksheet } 1.4 \text { (only for facilitator) } \\
\text { - Handout } 1.3 \text { (only for facilitator) }\end{array}$ \\
\hline & 40 minutes & $\begin{array}{l}\text { Activity } 1.5 \text { : } \\
\text { Mapping the } \\
\text { body }\end{array}$ & $\begin{array}{l}\text { - Black/white board or flip chart or OHP/LCD Projector } \\
\text { - Chalk/marker pens/OHP transparencies } \\
\text { - Duster } \\
\text { - Chart paper } \\
\text { - Colour pens } \\
\text { - Sticky tape/pins or clips }\end{array}$ \\
\hline & 30 minutes & $\begin{array}{l}\text { Activity 1.6: } \\
\text { What is sex? }\end{array}$ & $\begin{array}{l}\text { - Black/white board or flip chart or OHP/LCD Projector } \\
\text { - Chalk/marker pens/OHP transparencies } \\
\text { - Duster } \\
\text { - Handout } 1.4 \\
\text { - Slide } 1.10-1.13\end{array}$ \\
\hline & 30 minutes & $\begin{array}{l}\text { Activity } 1.7 \text { : } \\
\text { What is my view } \\
\text { of sex? }\end{array}$ & $\begin{array}{l}\text { - Black/white board or flip chart or OHP/LCD Projector } \\
\text { - Chalk/marker pens/OHP transparencies } \\
\text { - Duster } \\
\text { - Worksheet } 1.5 \\
\text { - Handout } 1.5-1.6 \\
\text { - Slide } 1.14\end{array}$ \\
\hline & 30 minutes & $\begin{array}{l}\text { Activity } 1.8 \text { : } \\
\text { Exploring my } \\
\text { vocabulary on } \\
\text { sex and sexuality }\end{array}$ & $\begin{array}{l}\text { - Black/white board or flip chart or OHP/LCD Projector } \\
\text { - Chalk/marker pens/OHP transparencies } \\
\text { - Duster } \\
\text { - Worksheet } 1.6 \\
\text { - Slide } 1.15\end{array}$ \\
\hline Conclusion & 10 minutes & Summary & $\begin{array}{l}\text { - Slide } 1.16-1.18 \\
\text { - Worksheet } 1.7\end{array}$ \\
\hline
\end{tabular}




\section{Introduction}

\section{Slides: 1.1-1.4}

Introduce the topic. Tell participants that before learning about sexuality, one will need to truly understand what 'sexuality' means. Hence the next couple of hours will be spent talking about and exploring what sexuality is and how it is a part of every human life. Explain the objectives of the module (slide 1.2). Then review with the participants the definition of 'health' and 'sexual health' as given by the World Health Organisation (WHO) (slide 1.3-1.4). Reinforce to participants that sexual health encompasses all that is defined in 'health' in addition to the 'emotional' well being of a person.

Although the module is divided into Activities, when you take the module, let each activity flow into each other. For example once Activity 1.1 is over, say "Let's look into the Components of Sexuality". You could use the title of the Activity to introduce each concept successively.

\section{A. MEANING OF HUMAN SEXUALITY}

\section{Note for Facilitators: Activity 1.1-1.2}

Activity 1.1 and 1.2 would help in introducing the concepts of human sexuality to the participants. Participants may sometimes be embarrassed to talk about these concepts in the beginning. Make all attempts to ensure that the environment is safe (see Box 1.1), and supportive. It is necessary that you demonstrate a spirit of being neutral in your views about the topic.

\section{Box 1.1: How do you create a safe environment?}

- Introduce yourself along with participants

- Have icebreakers

- Make small groups when discussing sensitive issues.

- Work with participants to develop ground rules that will guide behaviour through the training

- Draw from the participants' own experiences

- Set up the room to be as friendly/informal as possible

- $\quad$ Ensure confidentiality

In Activity 1.2, participants sometimes will expect you to give your opinion about some of the concepts or words. Examine these concepts in your mind before you take the module and know what you feel about them. It would be preferable for you to be open to the fact that the views of the participants may be different. Hence it is important for you to avoid giving your opinions about the various concepts. Instead remember to be open with facts of the various concepts. For example, participants are likely to ask you what you think about men who have sex with men (MSM) or about a particular sexual behaviour. Give them the basic facts, avoid personal opinions and reinforce that they are entitled to form their own opinions about these issues. Reinforce the basic principles that will be followed throughout the training: respect, autonomy and confidentiality.

Be mindful that you can say as much and more with your nonverbal actions. Be sensitive to the nonverbal cues of the participants too. In fact, emphasise that it is okay for each one to have different views and that it would be good to agree that they are likely to disagree on certain aspects.

Avoid going into too much of detail with each of the components of human sexuality as described in Handout 1.1. It is important that you clarify any misconceptions and terms that are not understood. A good way to ensure security amongst participants to discuss the concepts described under the components of human sexuality would be to conduct a quiz. 


\section{Activity 1.1: Discussion on meaning of human sexuality}

Purpose: The participants will

- $\quad$ Explore own perceptions with regards to sexuality.

- Be sensitised that sexuality is a broad concept.

\section{Materials:}

- Black/white board or flip chart or OHP/LCD projector

- Chalk/marker pens/OHP transparencies

- Duster

- $\quad$ Slides $1.5-1.6$

- White paper and chart paper

\section{Process:}

1. Tell participants that you will now be exploring the concept of sexuality. Divide the participants into groups of 5-6 members each.

2. To begin, ask each participant to take 2 minutes and write their own meaning of the word 'human sexuality' and also any word or term that comes to mind when they hear the word 'sexuality'.

3. This is followed by a 5 minute discussion in the small group about what each person has written.

4. Get a participant from each group to volunteer to be a reporter. The responsibilities of this person would be:

- To write down the points of discussion on a paper

- When asked, to come forward and present their group's discussion points.

5. Write down the responses of each group for all to see on a board/flipchart/overhead transparency.

6. If the participants are hesitant about coming forward to present their points of discussion, ask them to write their points of discussion on a piece of paper, and pass it on to you. You could then write the points on the board/flip chart/OHP transparency randomly so that no one knows whose points are written. However as much as is possible encourage them to express themselves verbally.

7. Point out that each group may have different opinions. For example, some of them may think sexuality is a broad concept, while others may think that it just refers to sexual intercourse or sexual behaviours.

8. Project slides 1.5-1.6. Using the participants' opinions, bring out the idea that sexuality is a broad concept. Discuss the points given below:

- Sexuality includes: attitudes, values, emotions, desires and behaviours

- It has biological aspects (all aspects referring to the human body, how well the body is functioning, health status etc.); psychological aspects (feelings towards sexuality and sexual expressions, values one has, past experiences that are both positive or negative etc.); and social aspects (all aspects concerning how sexuality is expressed that is controlled by societal norms, laws, religious expectations etc.)

- Components include: human development, relationships and emotions, sexual behaviour, sexual health and sexual violence.

9. Conclude that human sexuality is more than sexual acts or reproduction. It is not 'good' or 'bad', or 'right' or 'wrong' but a part of being which deserves understanding and attention. Ask the participants to come out with a common definition for sexuality. Get one of the Group Coordinators to write this on a chart/OHP transparency. You may have to keep reminding the participants about this definition during other sessions or when taking the other modules.

\section{Adapted from source:}

- World Health Organization. 2000. Information Series on School Health Doc 9. Skills For Health-Skills Based Health Education Including Life Skills: An Important Component of a Child Friendly Health Promoting School. Geneva: WHO. 


\section{Activity 1.2: Components of human sexuality}

Purpose: The participants will

- List the various components of human sexuality.

- Identify what terms/concepts come under each component.

- Give a simple meaning for all terms in Handout 1.1.

\section{Materials:}

- Black/white board or flip chart or OHP/LCD projector

- Chalk/marker pens/OHP transparencies

- Duster

- $\quad$ Slide 1.7

- Worksheet 1.1-1.2, Handout 1.1-1.2

\section{Process:}

1. Tell participants that you are now going to explore the concept of 'sexuality' in more depth. Tell them one way of discussing sexuality is by dividing it into components/parts. Remember sexuality has been described in several ways, and this way of describing human sexuality has been chosen in this training guide, for its comprehensiveness. Project slide 1.7 or write on the board the main components of human sexuality:

- Human Development

- Relationships and Emotions

- Sexual Behaviours

- Sexual Health

- Sexual Violence

2. Let participants remain in the same groups they were in for Activity 1.1. Distribute Worksheet 1.1. Divide the list of words equally amongst the groups. Tell the participants that they have 10 minutes to discuss and decide the assignation of the words given to them under the five components. Words that they do not understand can be checked/marked. They can clarify these doubts by either asking aloud or writing a question and putting it in the question box.

3. Once they have completed Worksheet 1.1, ask them to remain in their groups, as you go through each word on the list. Take a word on the list and ask a participant from the respective group to share under which component they have listed it and generate a short discussion. For each word:

- Ask the participants as a whole: 'Do you think this word belongs under this component?'

- If there is any disagreement, ask the group of participants that placed it there: 'Why did you decide to put this word in this category?'

- Ask others what they think. If they don't agree, ask: 'Why not? Where do you think it belongs?'

- Ask questions and use the participants' comments and ideas to guide them to the correct placement.

4. Treat each word the same way regardless of whether it is correctly or incorrectly placed to generate discussion. Use information in the Handout 1.1 'An explanation of the components of sexuality' to supplement the discussion and clarify points.

5. However, do not get into a long discussion about any of the words at this point. If necessary, tell participants that you will look more closely at these components later in the course.

- If there is a lot of disagreement, you can note that many of the topics overlap and people may have different ideas about where they go, but you are trying to find the place where it fits best.

- Explain any terms/words that the participants did not understand.

6. Distribute Handout 1.1 and 1.2. Handout 1.1 gives the meaning of human sexuality and its various components. Handout 1.2 gives facts about girls and boys. While participants are likely to find information provided in Handout 1.2 familiar, remind them that they might learn new information. Tell participants to read both Handouts and come to the next class with questions and doubts. 
7. Conclude by giving each group Worksheet 1.2 to complete. Once completed, collect Worksheet 1.2 from each group, quickly go through the last part and check for questions written by the participants. Be sure to answer any questions before you proceed with the next activity or tell participants that you will do so in the next class. A more creative way could be to conduct a quiz on the terms before you move to the next session.

\section{Adapted from source:}

- Irvin, A. 2004. Positively Informed-Lesson Plans And Guidance For Sexuality Educators And Advocates. New York: International Women's Health Coalition (IWHC).

\section{B. EXPLORING CONCEPTS OF SEXUALITY}

\section{Note for Facilitators: Activity 1.3-1.5}

Activity 1.3 is assumed to be the foundation of the whole training. The training guide is based on the philosophy that through one's experiences, one can learn to affirm one's own uniqueness and strengths. This session is about participants understanding and affirming the human body. Remember that you will be referring to this activity through all the other modules. Sometimes this activity may evoke emotions connected to early childhood experiences or lead to comparisons with an ideal self as portrayed by media or society. Remind participants of the learning from Activity 3 (Joining the Dots) that was done in the Introduction - to think outside the box.

Activity 1.4 will help the participants to recognise their own perceptions to sexuality through the life span. Participants are likely to come with different views with regards to sexuality through the life span. You may notice that views of participants are very strong sometimes in favour of or against a statement. It is essential that you encourage participants as far as possible to avoid the option 'don't know.' Remember to reaffirm the facts. Do not hesitate while still being neutral in your facilitation to ask groups that have moved to different corners of the room to express their views or to debate their points.

Activity 1.5 could be an energiser as well as a good learning experience. Participants will take time for this activity. Sometimes if there is enough time, you may find some of the groups expressing a lot of creativity. As they do this activity, move around the class to each group and ask questions that lead them to reflect on why they have marked a particular part of the body to be a source of pleasure while another part a source of pain. It is important to remember that when you do this activity you should keep participant groups as homogenous as possible, for example same gender/culture/language/age group etc.

\section{Activity 1.3: What do I perceive about my body?}

Purpose: The participants will

- Be able to examine their perceptions of their own bodies.

- Recognise the need for valuing one's own body as great/wonderful/lovable.

\section{Materials:}

- Black/white board or flip chart or OHP/LCD projector

- Chalk/marker pens/OHP transparencies

- Duster

- Chart papers

- $\quad$ Stamp ink

- Sticking tape/clips to hang the charts in the class room

- $\quad$ Slides-1.8-1.9

- Worksheet 1.3 (only for facilitator) 


\section{Process:}

1. Tell participants that you will now be helping them to examine their perceptions about their body. Ask participants to make three columns in their note books and name them as follows: the left column 'Great-Love it', the middle column 'Okay-Don't mind it' and the right column 'Really bad-Hate it'. Tell them that this is an exercise that could help them to see how they feel about their bodies. Encourage them to evaluate their bodies truthfully without discussing with others or looking at what their friends have marked. Assure them that what they write will remain private.

2. Then call out in a neutral tone, the parts of the body as given in Worksheet 1.3. Ask participants to mark off in one of the columns the way they perceive that part of the body. Remind them that they should respect each others privacy as they do this exercise.

3. Once all the body parts have been called out, ask the participants to total the number of tick marks in each column.

4. Then ask participants to raise their hands if they had marked themselves 25 out of 25 in the 'Great! Love it' column. Allow for the silence that may prevail. Then ask for a show of hands of how many have got 24 out of 25 , and continue $23,22 \ldots 15 \ldots 10 \ldots 5 \ldots 3 \ldots 1 \ldots 0$ out of 25 in the 'Great-Love it' column.

5. Begin a debate on what 'Great!' means to them. Is it the commercial connotation of 'beautiful/handsome'? Would it be good if all looked alike? Ask the participants, 'What went through your mind when you were evaluating a part of the body?' Probe further 'Were you making comparisons? Were you evaluating the part based on what media projected as great! beautiful! handsome! or just wonderful!?'.

6. Review with participants how each part of the body is wonderful/great with examples giving facts about the anatomy and physiology of the respective part. For example how coordination of the fingers occurs to perform a function such as writing; how coordination of all the parts could result in a wonderful dance etc. Reinforce how each one is unique (Discuss why they thought a part of their body was not 'great'. How did positive or negative reinforcement affect the way they thought of themselves).

7. Project Slide 1.8 or draw a complete circle to highlight a person who feels every part of his/her body is 'great'. Explain using the different stages in life - infancy, adolescence, adulthood — to highlight how perceptions towards one's own body changes depending on positive or negative experiences.

8. If time permits you could divide the participants into five groups. Make chits of paper with each of the stages and the events depicted in Box 1.2. Distribute one chit to each group. Give participants 5 minutes to prepare for a 3 minute role play of the events stated in their chit. They could add on any other positive or negative event/s relevant for the particular stage in life, based on their own knowledge or past experience. When each group comes forward to enact the role play, with each example that is negative, rub parts of the circle on the board to show how the full circle is broken or repair the full circle when there is a positive statement or event depicted in the role play. Slide 1.8 is animated so you could use it as you go through each stage. Remind participants to maintain the three most important ground rules: respect, autonomy, and justice; especially since some participants may share personal details of their own life. 


\section{Box 1.2: Examples of positive and negative experiences during each stage of life}

\begin{tabular}{|c|c|}
\hline Stages of Life & Examples of Positive and Negative Experiences \\
\hline Infancy & $\begin{array}{l}\text { Positive experiences: For example, at birth the love a baby may feel when it is wanted } \\
\text { through the cuddling, the touch, the warmth from the care givers. } \\
\text { Negative experiences: For example, the feelings of rejection a baby may feel/experience } \\
\text { when its basic needs are not met, it is neglected etc. }\end{array}$ \\
\hline Toddler period & $\begin{array}{l}\text { Positive experiences: For example, encouragement from parents/care givers when the } \\
\text { child takes his/her first step; says the first word; attempts a new task; expresses his/her } \\
\text { desires, etc. } \\
\text { Negative experiences: For example, the experience of getting spanked or shouted at by } \\
\text { elders, when the child touches his/her genitals in the process of discovering the body. } \\
\text { How the genitals are covered or people would say 'Shame'! This small child slowly } \\
\text { perceives that this part of his/her body is not great! }\end{array}$ \\
\hline Preschool period & $\begin{array}{l}\text { Positive experiences: For example, at } 3-5 \text { years, the experience of being praised for } \\
\text { singing a rhyme, telling the colours correctly, being able to feed self to some extent, } \\
\text { how well they are growing etc. } \\
\text { Negative experiences: For example, when the child is criticised for not doing some } \\
\text { tasks-e.g. not writing neatly on the line or filling colour outside the lines; forgetting a } \\
\text { poem and so on. }\end{array}$ \\
\hline School age & $\begin{array}{l}\text { Positive experiences: For example, such as being commended for doing well in studies } \\
\text { or painting or games or of changes occurring in the body. } \\
\text { Negative experiences: For example, getting comments from others about not being good } \\
\text { in sports, studies or about changes in the body etc. }\end{array}$ \\
\hline Adolescent stage & $\begin{array}{l}\text { Positive experiences: For example, being given responsibility for one self, being } \\
\text { commended when one tries a new outfit or some make up, doing well in studies, } \\
\text { handling relationships well etc. } \\
\text { Negative experiences: For example, being told to either act like a child or like an adult } \\
\text { or when they get negative comments about body type and looks. }\end{array}$ \\
\hline
\end{tabular}

9. Provide participants with chart paper and ask one or two of the Group Coordinators to be responsible for getting each participant's finger print and signature on the chart. Ask participants then to observe the uniqueness of each finger print.

10. You could provide participants with some helpful tips as given below to rediscover the wonder of the human body:

- Write 'I am wonderful' and stick it somewhere that you can see every day to remind yourself that you are great/unique!

- For the next week make an attempt to compliment your close friend about at least 'one wonderful' thing that you see in her/his body and suggest that he/she reciprocate.

Conclude with slide 1.9. Reinforce that sexuality includes a broad concept as given in the slide. How one perceives one's body could have implications on how one expresses the self, relate to others and could thus also influence expression of sexuality.

\section{Adapted from source:}

- $\quad$ INSA India. 2003. Experiencing Options. Bangalore: Books for Change. 


\section{Activity 1.4: My views on sexuality and sex}

Purpose: The participants will

- Explore their views on sexuality through the life span.

- Respect the differences in perceptions of their peers.

\section{Materials:}

- Black/white board or flip chart or OHP/LCD projector

- Chalk/marker pens/OHP transparencies

- Duster

- Worksheet 1.4 (only for facilitator)

- Handout 1.3 (only for facilitator)

\section{Process:}

1. Tell participants that you will now help them examine their views on sexuality through life. Divide the room into three areas and assign one area as 'agree', another area as 'unsure' and the third area as 'disagree'.

2. Explain to participants that you will be projecting/calling out statements one by one (Box 1.3/Worksheet 1.4: My views on sexuality through life). They will have to listen to each statement and then decide their response-agree/ are unsure or disagree. Responses should be independent of their friends' opinions. Based on their response they must move to the respective area of the room.

3. Discuss each statement with the group by asking participants from each area to give reasons for their choice. Clarify any misconceptions. You could use Handout 1.3 for your reference to explain certain statements. This handout gives basic information about sexuality through life, emphasizing the relationship of physiological changes occurring in the body with age and its impact on sexual expression.

\section{Box 1.3: Statements to be used in Activity 1.4}

- Young people have the right to sexuality education.

- It is normal for people over 50 years to be sexually active.

- Older men who fantasise about young women are abnormal.

- Women who are menopausal must be advised not to have sex.

- It is normal for older women to fantasise about young men.

- My community would support my mother if she talks to children about sexuality.

- As people get older they do not need information about sexuality.

- Girls who have attained menarche must be at home since it is dangerous to be outside.

- $\quad$ Talking about sexuality could lead to experimentation.

- Encouraging the use of condoms could increase multi partner sex behaviour.

- Some cultures allow their children to explore their sexuality openly when they are young. They let them walk around naked, ask questions, etc. This is inappropriate.

- $\quad$ Teaching about sexuality is a good way to prevent HIV and other STIs.

- Young people have the right to sexuality education.

- Teaching about sexuality is a good way to prevent HIV and other STIs.

- $\quad$ Nurses need to address patients' sexual issues. 
4. Conclude by saying that sexuality can be expressed throughout the life span. This is dependent on one's perceptions of sexuality and its various components; past experiences; social expectations; one's own set of personal values; emotional make up; the ability to overcome challenges positively; one's perception towards one's own body and one's health status.

\section{Adapted from source:}

- $\quad$ TARSHI. 2006. Basics And Beyond. New Delhi: TARSHI.

\section{Activity 1.5: Mapping the body}

Purpose: The participants will

- Be sensitized to their perceptions of the human body.

- Become aware of the differences in perceptions of the human body and the factors that may affect these perceptions.

\section{Materials:}

- Black/white board or flip chart or OHP/LCD projector

- Chalk/marker pens/OHP transparencies

- Duster

- Chart paper

- Colour pens

- $\quad$ Sticky tape/pins or clips

\section{Process:}

1. Tell participants that you will now be helping them examine their perceptions of what the human body could feel. Divide participants into smaller groups of 6-8 persons. Participants can form their own groups.

2. Distribute charts and colour pens to each group.

3. Ask each group to draw the body on the chart or on the floor and then to mark those parts of the body that they feel are sources of:

- $\quad$ Pleasure/Pain

- $\quad$ Power

- Public/Private

- Honour/Shame

If there is some disagreement amongst group members, tell them they can mark those parts over which they had a difference of opinion.

4. Once they finish drawing and marking the parts of the body as specified above, ask each group to come forward and show their charts to all the other participants. A group representative will report what they have drawn. If any group has decided to draw the body on the floor, then allow all participants to see the drawing when it is the respective group's turn to report.

5. Share your observations of how the participants went about doing the activity:

- There may be some groups who would actually make a person lie down and draw the outline of the person.

- Some may draw only a male or a female body, while some may draw both male and female bodies combined in one figure.

- Still others may draw a male and female body, on separate chart papers. 
- If all the groups have drawn only the front (anterior) of the body and either none or few have drawn the back (posterior) of the body, point that out.

- Ask some groups who may have had a participant lie down and draw the outline of the body to share their feelings when this was done.

Ask participants what they learnt from this experience. Help them to explore both positive and negative feelings of the body they may have experienced in the past. Remind them of Activity 1.3: My perceptions of my body, and how the positive experiences could help in reinforcing the wonder of the body.

6. Conclude by telling participants that

- Parts of the body experiencing pleasure or pain, honour or shame are interchangeable. Some parts of the body are expected to be a source of pain during sexual relationships. For example, in certain cultures 'female genital mutilation' is practiced so that the woman will experience pain during sexual encounters.

- Just as all parts of the body can feel pain, so also all parts of the body can feel pleasure. However there are some erogenous zones in the body that are highly sensitive and responsive to sexual stimulation. These include neck, earlobes, mouth, lips, nipples, genitalia, buttocks, inner thighs, anus, back of knees, fingers, and toes.

- The whole body could be a source of honour for people or a source of shame. Talk about the general perception of genitals or breasts as a source of shame, and yet it is these organs that form and nourish the body in its early stages.

- Explore with them how some cultures dress differently, exposing all of their body, with no feelings of embarrassment, or shame while in some other societies people are expected to cover all of their bodies.

\section{EXPLORING CONCEPTS OF SEX AND SEXUALITY}

\section{Note for Facilitators: Activity 1.6-1.8}

Activity 1.6-1.8 will help in discussing sexual expressions in the context of larger picture of sexuality. It is important that you refer back to the learnings of previous activities of Module 1 (Activity 1.3: My perceptions of the body and Activity 1.5: Mapping the body parts). Reinforce to participants that all bodies are beautifully and wonderfully made, and that it is important to recognise that the way a person perceives his or her body is dependent on several factors such as culture, past experiences, health status, economic status, emotional status etc. As a first part of your preparation for Activity 1.6-1.8, ask yourself the following questions

- How comfortable am I with these issues and the content?

- How comfortable am I with my own sexual orientation?

- What are the politics of this issue in my own institution?

- Do I have the support of my colleagues? My supervisor? Of the administration?

- How will I react if a participant 'comes out' (reveals his/her sexual identity)?

Remember, when you ask participants to give the meaning of the word 'sex' in Activity 1.6, often participants may give a narrow view of the word 'sex' based on their previous conditioning or experiences. Remind them that when the word 'sex' is used in this activity it refers to all behaviours shared between two or more persons. Be neutral in your views and be sure to work on your own perceptions before you present the facts.

Activity 1.7 will help participants examine their own perceptions of sexual expression shared between people. Be neutral and present facts. Be aware of your own nonverbal communication when you discuss any of the statements given in Worksheet 1.5. Be sure to encourage participants to avoid selecting the 'unsure' column as much as possible. In this activity you will also be discussing about sexual orientation. Given the intensity of feelings and general perception about sexual orientation, this could prove to be very challenging. It is important that you are up to date with knowledge about same gender relationships; are aware of your own sexual orientation; are comfortable to talk about the topic; and have an accepting attitude regarding other sexual orientations (hetero-/homo-/bisexual). 
Activity 1.8 will help to clarify as well as examine one's view with regards to various sexual behaviours. Again you will find this activity sometimes demands that you too express your own views on certain behaviours. However refocus the attention of the participants by asking them:

- What is the purpose of sex?

- What are the ways in which sex can occur?

- What is the context in which sexual behaviours occur?

Help participants identify the grey line of good and bad sex on the basis of the principles of 'respect for human dignity', 'autonomy' and 'justice'. Reinforce that although 'autonomy' is recognised as one of the principles this is tagged with 'responsibility for one's behaviour'. Help participants to recognise that it is the context in which sexual behaviours occur that is important in deciding whether it is a case of sexual violence.

While reviewing the concept 'sexual identities', be aware that participants may express strong views with regards to sexual minorities. Reaffirm to participants that all these sexual groups/identities do exist in our country and it is important that even while one may be uncomfortable about the identity, if they come across such a person in their workplace or personal lives, to keep in mind the principles of 'RAJ' 'respect, autonomy and justice' and the rights of the individual.

\section{Activity 1.6: What is sex?}

Purpose: The participants will

- Explore their own definition/meaning of the word 'sex'.

- List the purpose of 'sex'.

- Recognise that they learn when openly discussing with others about the word 'sex'.

- Become aware of various expressions in sexual relationships.

\section{Materials:}

- Black/white board or flip chart or OHP/LCD projector

- Chalk/marker pens/OHP transparencies

- Duster

- $\quad$ Slide-1.10-1.13

- $\quad$ Handout 1.4

\section{Process:}

1. Tell participants that they will explore the concept 'Sex'. Depending on the number of participants you could choose any one of these methods:

- Ask each participant to choose a friend from the group that they are most familiar with and then to share with each other when they first heard the word 'sex', what they felt when they first heard the word and what comes to mind when they hear the word 'sex'.

\section{Or}

- Distribute small chits of paper and ask each participant to write out what they heard and felt about the word 'sex' and what terms come to mind when they hear the word 'sex'. Read out some of the chits randomly.

\section{Or}

- Brainstorm with participants 'What comes to mind when you hear the word sex?' 
2. Write their response on the board/OHP transparency and project for all to see. Then project the slide 1.10 and give participants the reasons for talking about sex.

- Humans are sexual beings

- It constitutes a personal right of the individual

- It has an important impact on life and health

- There is a definite link between sex and HIV

- People face discrimination based on sexual behaviours or identities

3. Discuss the barriers we face in talking about sex openly as given in slide 1.11. Explain to participants that just like parents and elders make efforts to help a child walk, talk, solve problems etc, it is essential to make efforts to teach a person about sexuality.

4. Project slides 1.12-1.13 on the meaning of sex and the reasons for sex. This will help in reinforcing information that they have learnt through all the previous activities. Explain that a sexual relationship works when both individuals in the relationship consider the other's needs and rights. This means that with every choice and action, comes responsibility for the decision or action.

5. Give participants Handout 1.4. Tell them it provides information on sexual relationships. It also gives information on 'age of consent' for sexual relationships that has been prescribed by law in India and in other countries. Ask them to read it before the next session.

6. Conclude by asking for questions and clarifying any doubts. Use the box available for collecting questions. An alternative way to get participants to ask questions is to distribute chits of paper at specific periods, ask participants to write any question on it and then to collect it or place it in the box.

\section{Activity 1.7: What is my view of sex?}

Purpose: The participants will

- $\quad$ Explore individual views about sex.

- Clarify their doubts about different sexual expressions.

- Become aware of the range of sexual orientations.

\section{Materials:}

- Black/white board or flip chart or OHP/LCD projector

- Chalk/marker pens/OHP transparencies

- Duster

- $\quad$ Slide-1.14

- Worksheet 1.5

- Handout 1.5-1.6

\section{Process:}

1. Tell participants that they will now examine their personal views about sex. Distribute Worksheet 1.5 to all the participants. Allow them to continue to remain in the groups of their own choice. Ask each of them to respond to each statement in Worksheet 1.5: from strongly agree to strongly disagree. They should avoid selecting 'unsure' as much as possible. Give them a few minutes to complete the worksheet individually. Tell them to discuss their views with their group members and to remember the ground rules as they complete the discussion.

2. Then call out statements randomly and ask the participants to volunteer their responses.

3. Distribute Handout 1.5 to participants. Ask them to read it and return with any questions on it for the next class. 
4. Project slide 1.14 and explain about sexual orientations. Tell participants that sexual orientation refers to the sexual gender(s) to which a person is attracted. It forms the focus of a person's erotic desires, fantasies, and spontaneous feelings. In other words the gender(s) toward which one is primarily 'oriented'. The alternative terms are sexual preference, sexual inclination (preferably not used as it may have a negative or a derogatory meaning) or sexual identities all of which have similar meanings. Also explain the points given below:

- Typically a person may be identified as primarily heterosexual (the person is attracted to person of the opposite sex), homosexual (people of the same sex are attracted to each other), bisexual (a person who feels physical attraction to both or either sexes), or asexual (a person who has no sexual attraction for either sex).

- The term sexual orientation may also refer to the "identity" of a person, either by choice or as an expression of an inner attribute.

- These classifications are also used to describe sexual behaviour, which may depart from an individual's chosen identity or spontaneous desires.

- Classification of individuals into these groups is controversial, and different observers may prefer orientation, behaviour, or self-identification as the sorting criterion, and make different judgments as to degree.

5. Give participants Handout 1.6. Ask them to read each of the sexual orientations and respond to the last column 'How would you feel when dealing with a person who expresses the following orientations?' Reinforce to participants that their responses will be private and that they need not discuss their responses with others. However remind them it is important to respect the differences in one's feelings to the different sexual orientations that are likely to exist within the class. Sexual orientation is not dependent on how a person was brought up in childhood or whether the parents were of a particular sexual orientation; and today it is not considered a sexual disorder. It is also important to remember that all of these orientations exist in all societies.

6. To help participants explore their perceptions towards various sexual orientations tell participants that you will be calling out various statements as given below. They should be able to identify whether these are 'myths' or 'facts'. Participants can be asked to remain seated if they think the statement is a 'myth' and to stand if they think the statement is a 'fact'. Rationale for the response of each statement is given in Handout 1.6. You could recommend participants to read it later. Refer to Box 1.4 for the statements. The correct response is given in parenthesis.

\section{Box 1.4: Statements with correct responses to be used in Activity 1.7}

- Homosexual behaviour is unnatural-(myth)

- Gay and lesbian people can be identified by the way they look and act-(myth)

- People choose their sexual orientation-(myth)

- Parents are the major influence on whether their child is homosexual or heterosexual or bisexual-(myth)

- There is no such thing as a true bisexual. Bisexuals are generally confused about their sexuality or they are exploring-(myth)

- The majority of people in the world with HIV infection and AIDS are heterosexual-(fact)

- In a lesbian or gay relationship, one partner plays the male (butch) role and other the female (femme) role-(myth)

- Gay people can't have children-(myth)

7. Conclude by highlighting the following:

- Sex could be for any one, at any particular age irrespective of their physical structure but it could be constrained by law to a group above a certain age (Review Handout 1.4: Age of Consent) and is based on the principles of respect, autonomy and justice coined with responsibility.

- By respecting individuals freedom of choice, they could be non judgmental towards people with different sexual orientations, despite their own levels of comfort or discomfort. 
- People with different sexual orientations or with questions on these issues would be more open to speak about their concerns to a person who is open to the issue than who is fixed in their view points.

\section{Adapted from source:}

- $\quad$ Ahmed, A. and S. Menon. 2006. Rights and Desire-A Facilitator's Manual to Healthy Sexuality. New Delhi: Breakthrough.

- Irvin, A. 2004. Positively Informed-Lesson Plans and Guidance for Sexuality Educators and Advocates. New York: International Women's Health Coalition(IWHC).

- $\quad$ TARSHI. 2006. Basics and Beyond. New Delhi: TARSHI.

- World Health Organization. 2000. Information Series on School Health Doc 9. Skills For Health- Skills Based Health Education Including Life Skills: An Important Component of a Child Friendly Health Promoting School. Geneva: WHO.

\section{Activity 1.8: Exploring one's vocabulary on sex and sexuality}

Purpose: The participants will

- Become comfortable with discussing common sexual behaviours.

- Become aware of common terms used for these behaviours.

- Comprehend these behaviours in the context of sexual identities, pleasure, pregnancy and infections.

\section{Materials:}

- Black/white board or flip chart or OHP/LCD projector

- Chalk/marker pens/OHP transparencies

- Duster

- $\quad$ Slide-1.15

- Worksheet 1.6

\section{Process:}

1. Tell participants that they will now be exploring various sexual behaviours in the context of all that has been discussed so far on sexuality. Ask participants to remain in the same groups and to name some sexual behaviours/ activities. After 5 minutes ask each Group Coordinator to report what they discussed in their respective groups. If they do not come forward with responses, ask them to write the behaviours on slips of paper. Collect the slips and write the behaviours/activities on one half of the board/flip chart/OHP transparency.

2. Brainstorm with participants 'Which behaviours could be practiced by people with different sexual orientations?' Project slide 1.16. Explain that all behaviours could be practiced by each of the different sexual orientations with the exception of vaginal intercourse (only between male and female) and anal intercourse (not between lesbians).

3. Distribute Worksheet 1.6 to all participants

- Tell participants to put a tick mark based on their response for every behaviour listed in the first column 'I am comfortable-yes/no' and in the second column, respond to "How do you feel about the behaviour?". This exercise is private and participants need not discuss what they have marked with the others unless they want to.

- Then divide the board into two halves. Write 'good sex' on one half and 'bad sex' on the other half.

- Brainstorm with the participants whether they would consider each of the sexual behaviours listed in the worksheet as 'good sex' or 'bad sex'. Call out a behaviour and ask participants if they have responded as 'good sex' for the particular behaviour. Mark the number of participants who have responded as 'good sex' or 'bad sex' on the board/flip chart or OHP transparency for all to see. 
- Depending on their responses, reinforce the fact that 'good sex' and 'bad sex' is usually not determined based on a particular behaviour but on the context within which the behaviour occurred. Give them the example of a woman who is raped. Would they consider it as 'good or bad sex'. Wait for their responses. Then point out to what their responses were for peno-vaginal sex. Another example-if two people of the same sex or of different sex who are committed to each other, respect each other and by choice have made a decision to share a sexual behaviour (e.g. anal sex) would they consider it as 'good or bad sex'. Wait for their responses and point out if any difference exists in the numbers that were written on the board/flip chart.

- Ask them to fill in the last part of the Worksheet, in the privacy of their own rooms. This could help them recognise those factors that influenced their comfort levels with regard to a particular behaviour.

4. Distribute the Glossary of Terms to the participants. Tell them that you will be conducting a quiz on the terms, before starting the next module. Ask participants whether they have any questions.

5. Conclude by debriefing: 'What did you learn from this exercise?'

\section{CONCLUSION}

- Conclude the module by reviewing all the content with the key messages given in slide 1.16-1.17.

- Distribute Worksheet 1.7 to each of the participants and ask them to complete it. This will help you to know how the module has helped the participants and for you to make appropriate changes in the next classes.

- If participants had any questions, ask them to write them in the last part of the Worksheet 1.7 and to hand over the same to you. Ensure confidentiality, by instructing them not to write their names on the sheet.

\section{Adapted from source:}

- Ahmed, A. and S. Menon. 2006. Rights and Desire-A Facilitator's Manual to Healthy Sexuality. New Delhi: Breakthrough.

- TARSHI. 2006. Basics and Beyond. New Delhi: TARSHI. 


\section{Worksheets}

\section{Worksheet 1.1: Components of human sexuality (Group)}

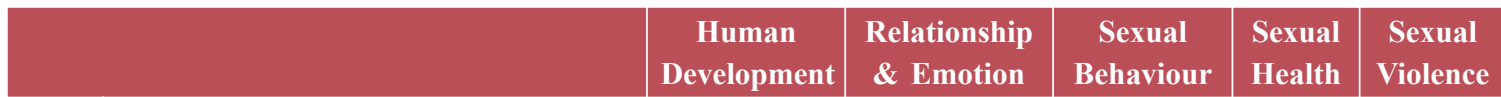

1. Abortion

2. Attraction and Desire

3. Abstinence

4. Body Image

5. Breast Self-Exam

6. Courtship/Engagement

7. Climacteric and Menopause

8. Contraception

9. Domestic Violence

10. Dating

11. Families

12. Fantasy

13. Flirting

14. Friendships

15. Gender Discrimination

16. Gender Identity and Roles

17. Genital Care and Hygiene

18. Harmful Practices

19. Incest

20. Infertility

21. Intimacy

22. Kissing

23. Loving, Liking and Caring

24. Manipulation through Sex

25. Marriage and Lifetime Commitments

26. Masturbation

27. Menarche and Menstruation

28. Prenatal Care

29. Prevention of STIs/HIV

30. Prevention of Unwanted Pregnancy

31. Puberty

32. Raising Children

33. Rape

34. Reproduction

35. Reproductive Physiology and Anatomy

36. Reproductive Tract Infections, STIs and HIV/AIDS 
Cont'd...

\begin{tabular}{|c|c|c|c|c|c|c|}
\hline & & $\begin{array}{c}\text { Human } \\
\text { Development }\end{array}$ & $\begin{array}{l}\text { Relationship } \\
\text { \& Emotion }\end{array}$ & $\begin{array}{c}\text { Sexual } \\
\text { Behaviour }\end{array}$ & $\begin{array}{l}\text { Sexual } \\
\text { Health }\end{array}$ & $\begin{array}{c}\text { Sexual } \\
\text { Violence }\end{array}$ \\
\hline 37. & Sexual Abuse & & & & & \\
\hline 38. & Sexual Dysfunction & & & & & \\
\hline 39. & Sexual Harassment & & & & & \\
\hline 40. & Sexual Intercourse & & & & & \\
\hline 41. & Sexual Orientation/identities & & & & & \\
\hline 42. & Testicular Self-Exam & & & & & \\
\hline 43. & Touching and Caressing & & & & & \\
\hline 44. & Wet dreams & & & & & \\
\hline
\end{tabular}

\section{Adapted from source:}

- Irvin A. 2004. Positively Informed-Lesson Plans And Guidance For Sexuality Educators And Advocates. New York: International Women's Health Coalition (IWHC).

\section{Worksheet 1.2: Reflection on Activity-Components of human sexuality (Group)}

1. Did anything surprise you about this activity?

2. What thoughts and feelings did you have while doing this activity?

3. Looking at these components, what part does sexual intercourse play in sexuality?

4. What do you notice about sexuality?

5. Which component do you already know the most about? 
6. Under which one of these components that you have most questions/doubts for you?

7. Write down at least 5 questions that you have on this topic

\section{Adapted from source:}

- Irvin A. 2004. Positively Informed-Lesson Plans And Guidance For Sexuality Educators And Advocates. New York: International Women's Health Coalition (IWHC).

\section{Worksheet 1.3: What do I perceive about my body? (Only for Facilitator)}

\begin{tabular}{|c|c|c|c|c|}
\hline & Part of the body & Great—Love it & $\mathbf{O K}$ & Really bad-Hate it \\
\hline 1. & Head & & & \\
\hline 2. & Hair & & & \\
\hline 3. & Forehead & & & \\
\hline 4. & Eyes & & & \\
\hline 5. & Ears & & & \\
\hline 6. & Cheeks & & & \\
\hline 7. & Nose & & & \\
\hline 8. & Lips and mouth & & & \\
\hline 9. & Teeth & & & \\
\hline 10. & Neck & & & \\
\hline 11. & Shoulders & & & \\
\hline 12. & Arms & & & \\
\hline 13. & Hands & & & \\
\hline 14. & Fingers & & & \\
\hline 15. & Nails & & & \\
\hline 16. & Chest (men)/breast (women) & & & \\
\hline 17. & Stomach/waist line & & & \\
\hline 18. & Penis for men/vulva for women & & & \\
\hline 19. & Thighs & & & \\
\hline 20. & Buttocks & & & \\
\hline 21. & Height & & & \\
\hline 22. & Legs & & & \\
\hline 23. & Feet & & & \\
\hline 24. & Toes & & & \\
\hline 25. & Complexion & & & \\
\hline
\end{tabular}

\section{Adapted from source:}

- $\quad$ INSA India. 2003. Experiencing Options. Bangalore: Books for Change. 


\section{Worksheet 1.4: My views on sexuality through life (For Facilitator)}

Divide the room into 3 sections: one for 'Agree'; second for 'Disagree'; and third for 'Do Not Know'. Tell participants that you will be reading out a statement. They must decide whether they agree or disagree with the statement and move to the appropriate section in the room accordingly. Discourage participants from choosing the option 'Do Not Know'.

\section{Statements}

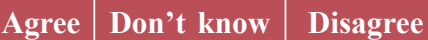

1. Young people have the right to sexuality education.

2. It is normal for any-one over 50 years of age to be sexually active.

3. It is normal for older men to fantasise about young women.

4. Women who are menopausal must be advised not to have sex.

5. It is normal for older women to fantasise about young men.

6. My community would support my mother if she talks to children about sexuality.

7. It is not necessary to talk about sexuality with most people as they get older.

8. Girls who have attained menarche must remain in the home since they have a risk of pregnancy.

9. Talking about sexuality could lead to experimentation.

10. Teaching about sexuality is a good way to prevent HIV and other STIs.

11. Encouraging the use of condom could increase multi sex partner behaviour.

12. Some cultures allow their children to explore their sexuality openly when they are young. They let them walk around naked, ask questions etc. This is inappropriate.

13. Nurses need to address sexual issues of patients.

14. Sexual need is not a reality during illness.

15. People with disability can be allowed to express their sexuality.

\section{Adapted from source:}

- TARSHI. 2006. Basics and Beyond. New Delhi: TARSHI. 


\section{Worksheet 1.5: What is my view of sex?}

Below is a list of statements. Please read each statement and then mark a tick in the column that best describes what you feel about the statement. As far as possible, avoid choosing the response 'unsure'.

\begin{tabular}{|c|c|c|c|c|c|c|}
\hline & I feel that & $\begin{array}{l}\text { Strongly } \\
\text { agree }\end{array}$ & Agree & Unsure & Disagree & $\begin{array}{l}\text { Strongly } \\
\text { disagree }\end{array}$ \\
\hline 1. & $\begin{array}{l}\text { It is my right to experience sexual } \\
\text { pleasure. }\end{array}$ & & & & & \\
\hline 2. & $\begin{array}{l}\text { Sex is only for people who are physically } \\
\text { and mentally healthy. }\end{array}$ & & & & & \\
\hline 3. & $\begin{array}{l}\text { The aim of sex is just to have pleasure. } \\
\text { Too much of it could lead to multi-partner } \\
\text { sexual relationships. }\end{array}$ & & & & & \\
\hline 4. & $\begin{array}{l}\text { Same sex partners can experience pleasure } \\
\text { as much as heterosexual partners. }\end{array}$ & & & & & \\
\hline 5. & $\begin{array}{l}\text { Sexual intercourse is really the best way } \\
\text { to express your love for someone. }\end{array}$ & & & & & \\
\hline 6. & Men get aroused by the idea of sex. & & & & & \\
\hline 7. & $\begin{array}{l}\text { Women do not have orgasms. So when the } \\
\text { partner reaches orgasm, sex is finished. }\end{array}$ & & & & & \\
\hline 8. & $\begin{array}{l}\text { Women can experience an orgasm only } \\
\text { through penetrative sex. }\end{array}$ & & & & & \\
\hline 9. & $\begin{array}{l}\text { A marriage can be sustained only with } \\
\text { experience of sexual pleasure. }\end{array}$ & & & & & \\
\hline 10. & $\begin{array}{l}\text { Sexual relationships must occur only with } \\
\text { one life partner. }\end{array}$ & & & & & \\
\hline 11. & $\begin{array}{l}\text { One cannot have sex during pregnancy or } \\
\text { menstruation. }\end{array}$ & & & & & \\
\hline 12. & $\begin{array}{l}\text { Alcohol and other addictive drugs make it } \\
\text { easier to get sexually aroused. }\end{array}$ & & & & & \\
\hline
\end{tabular}

\section{Adapted from source:}

- $\quad$ Ahmed, A. and S. Menon. 2006. Rights and Desire-A Facilitator's Manual to Healthy Sexuality. New Delhi: Breakthrough.

- $\quad$ TARSHI. 2006. Basics and Beyond. New Delhi: TARSHI. 


\section{Worksheet 1.6: Sexual behaviours-Self reflections}

Please look through the list of diverse sexual behaviours below. Of these behaviours, please tick those with which you feel personally comfortable and those with which you are uncomfortable. List the factors that influence your attitudes and level of comfort with the various kinds of behaviour. You could go through the Glossary of Terms to be clear about the meaning for each of these behaviours.

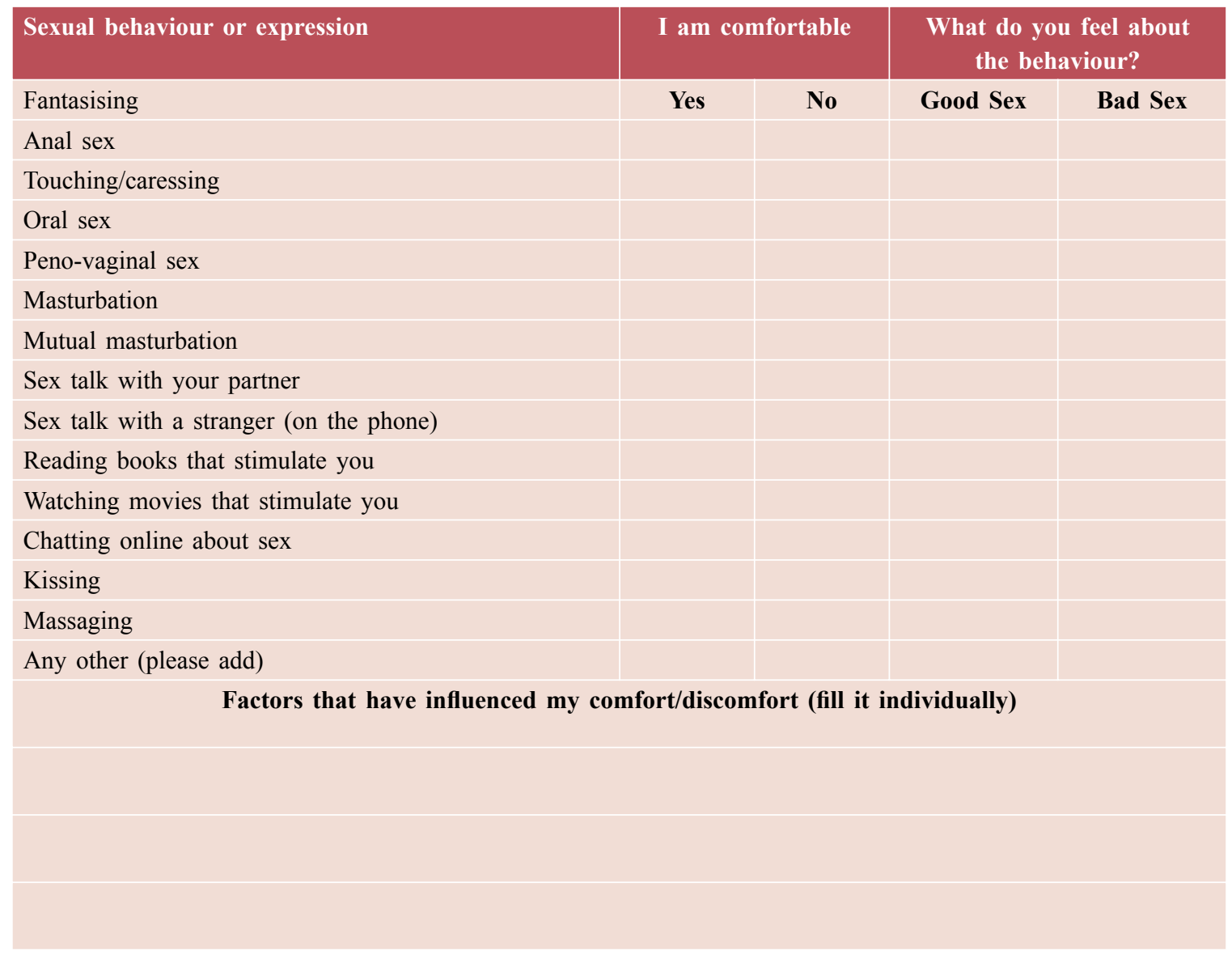

\section{Adapted from source:}

- $\quad$ Ahmed, A. and S. Menon. 2006. Rights and Desire-A Facilitator's Manual to Healthy Sexuality. New Delhi: Breakthrough.

- $\quad$ TARSHI. 2006. Basics and Beyond. New Delhi: TARSHI. 


\section{Worksheet 1.7: Review of the Module}

Kindly take 5 minutes to complete the following and hand the paper over to me. You need not write your name anywhere but it is important that you give your responses, to help assess if this session was useful or not. You have the freedom to write your own thoughts in the space that is provided.

1. What are the new terms that you learnt from this session? And give the brief meaning of the term.

2. Write at least three things you learnt from the session:

3. Write down at least one thing you never thought of in relation to sexuality:

4. Write down any questions you may have in relation to this module: 


\section{Handout}

\section{Handout 1.1: An explanation of the components of sexuality}

\section{Sexuality}

- Is an important aspect of human life and encompasses sex, gender identities and roles, sexual orientation, eroticism, pleasure, intimacy and reproduction.

- Is experienced and expressed in thoughts, fantasies, desires, beliefs, attitudes, values, behaviours, practices, roles and relationships. While sexuality can include all of these dimensions, not all of them are always experienced or expressed. Sexuality is influenced by the interaction of biological, psychological, social, economic, political, cultural, ethical, legal, historical and religious and spiritual factors.

\section{Sexuality includes:}

- Our awareness and feelings about our own body and other people's bodies.

- Our understanding of what it means to be female or male or the third sex (gender identity).

- Our ability and need to be emotionally close to someone else.

- Our feelings of sexual attraction to other people.

- $\quad$ Our physical capacity to reproduce.

Sexuality is

- Complex

- Much more than simply our sexual feelings

- Much more than having sexual intercourse

- An important part of being a person

\section{The components of sexuality include:}

\section{A. Human Development}

Human development involves the interrelationship between physical, emotional, social and intellectual growth. This component (you could refer to Handout 1.2-1.3 for more details on this component) includes:

1. Reproductive physiology and anatomy: The parts of the body that form the reproductive and sexual systems and their functions. Although the whole body is involved in human sexuality, these systems are central to sexuality and to understanding puberty, menstruation, erections, wet dreams, reproduction and sexual pleasure.

2. Growth and development: Includes the following key processes related to sexuality:

- Puberty: The period when the physical and emotional changes occur, the body matures, including the development of secondary sex characteristics (such as broad hips and facial hair) and the maturing of the reproductive system. Puberty results in the ability to reproduce.

- Menarche and menstruation: The onset of menstruation, as early as 9 and as late as 15 years. During menstruation the lining of the uterine wall is shed through the vagina, because the uterine lining is not required for fertilisation.

- Reproduction: The process of conception, pregnancy and birth - the beginning of human development. 


\section{Physical development during puberty-milestones}

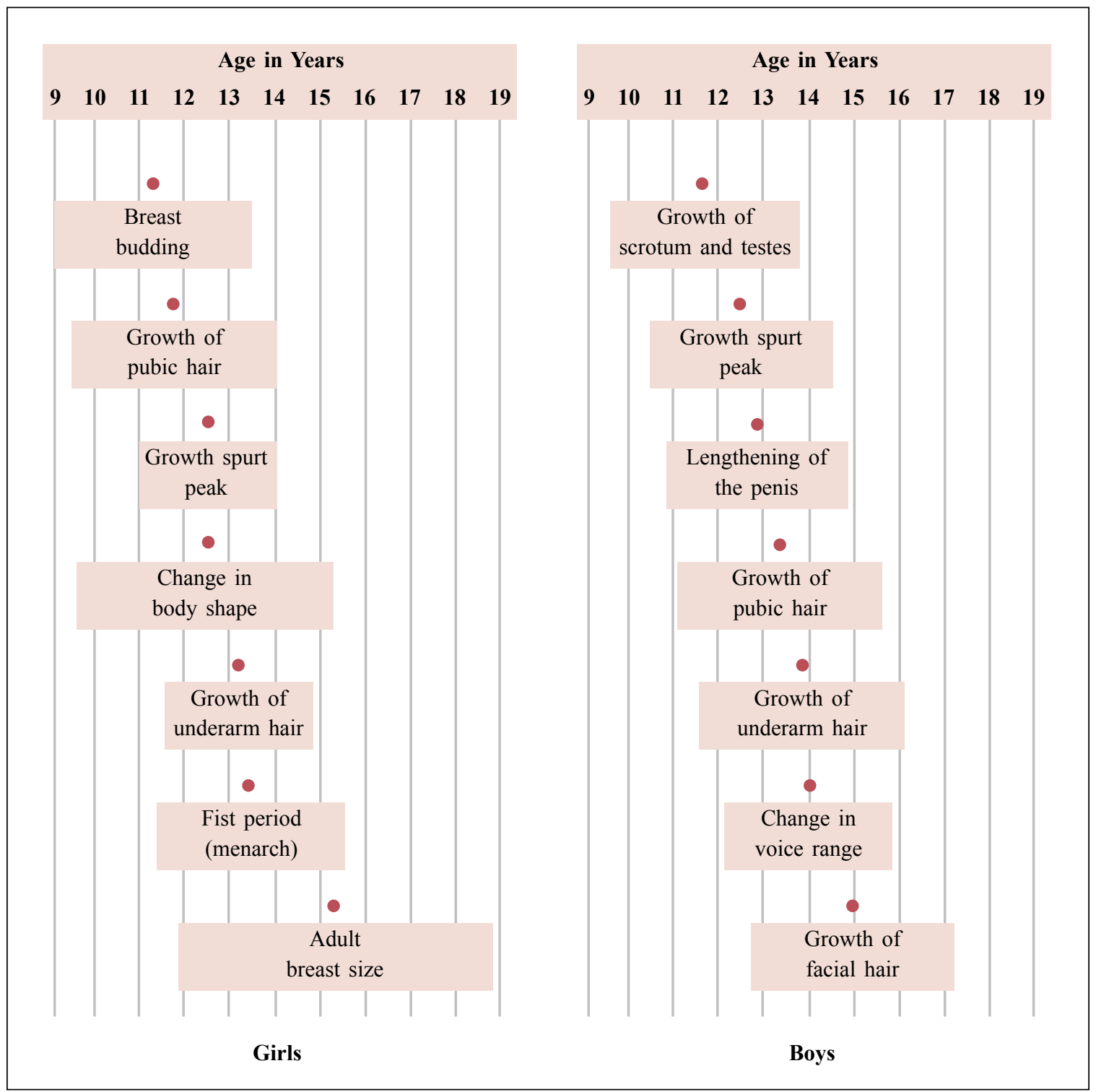

- Climacteric and menopause: The physiological and psychological changes in our sexual and reproductive functioning that occur in midlife in both men and women.

o Climacteric in men not so clear/evident and occurs later (60-70 years)

o Menopause in women occurs when menstruation stops (45-55 years). This includes the period leading up to menopause.

3. Body image: Attitudes and feelings about one's own body, appearance and attractiveness that affect one's mental well-being, comfort with, and expression of one's sexuality.

4. Sexual orientation/identities: The direction of one's romantic and sexual attraction - to the opposite, the same, or both sexes. Includes heterosexual, homosexual and bisexual orientations.

5. Gender identity and roles: Gender identity is one's internal sense of being either male or female, usually but not always the same as one's biological sex. Gender roles are the set of socially prescribed behaviours and characteristics expected of females and males. 


\section{B. Relationships and emotions}

All people need to have relationships with others through which they experience emotional closeness. This can be through families (a social unit which usually includes people who are related by blood, marriage, or affection) or friendship. The emotions include:

1. Loving, liking, and caring: Feelings that are the basis of emotional bonds and positive connections and relationships between people.

2. Attraction and desire: Emotional and physical feelings that draw someone to another person; these feelings may include emotional and sexual longing and passion.

3. Flirting: Playful romantic or sexual interactions that communicate attraction. Flirting can cross the line and become harassment if the recipient perceives it to be unwelcome or offensive.

4. Dating/courtship/engagement: Meeting, spending time together, and going out as a part of the process of getting to know and love someone, sometimes with the purpose of deciding whether or not to marry.

5. Intimacy: Emotional closeness to others characterised by feelings of connectedness, openness, sharing, and reciprocity.

6. Marriage and lifetime commitments: The union, usually legal, of two people who make a commitment to love and care for each other and share their lives and family responsibilities over the long term.

7. Raising children: Bringing up, providing for, and nurturing children, usually as a part of a family.

\section{Sexual behaviour}

Sexuality is a natural and healthy part of life from birth to death, which individuals express through a variety of behaviours. This includes:

1. Masturbation: Giving oneself sexual pleasure, usually by touching or rubbing one's own genitals. It could be mutual when partners touch and rub each other's genitals for sexual stimulation.

2. Shared sexual behaviour: Includes, but is not limited to:

- Kissing: Touching and caressing someone with one's lips to express affection and love.

- Caressing, touching and massaging: Stroking gently to express affection and love; being in physical contact with someone.

- Sexual Intercourse: Vaginal, oral, or anal intercourse.

- Abstinence: Not having sexual intercourse. Abstinence may include other types of sexual touching.

3. Pleasure and human sexual response: The enjoyable response of the body to sexual touching, which may or may not include orgasm, a highly pleasurable release of built-up sexual tension.

4. Fantasy: Sexual or erotic thoughts, dreams, and imaginings that are sexually arousing but are not necessarily acted on or even desired in reality.

\section{Sexual health}

Sexual health includes having the knowledge and attitudes and taking the actions necessary to actively maintain the health of one's reproductive system and to avoid unwanted consequences of sexual behaviour. This component includes:

1. Contraception: The use of various methods to intentionally prevent pregnancy; these methods include devices, agents, drugs, sexual practices, and surgical procedures.

2. Abortion: Induced termination of pregnancy.

3. Reproductive tract infections, sexually transmitted infections (STIs), and HIV/AIDS: Reproductive tract infections are those that occur in the reproductive tract (such as yeast infections or vaginitis) due to poor genital hygiene, un-sterile procedures performed on the reproductive tract or untreated sexually transmitted infections (STIs). STIs are those infections that can be acquired through sexual intercourse or intimate sexual contact (such as 
gonorrhoea, chlamydia, herpes, syphilis chanchroid and HIV/AIDS). Many can be transmitted in other ways as well, such as during childbirth.

4. Reproductive health includes:

- Genital care and hygiene: Caring for and keeping one's genitals clean, healthy and free from injury.

- Breast self-exam: A simple self-help technique in which women feel their breast tissue in a prescribed manner every month to check for changes or lumps that may indicate a problem.

- Testicular self-exam: A simple self-help technique in which men feel their testicles in a prescribed manner every month to check for changes or lumps that may indicate a problem.

- Prevention of HIV/STIs and unwanted pregnancy: Decisions and actions taken to reduce the risk of infection with an STI or HIV and the risk of an unwanted pregnancy; includes abstinence, seeking advice and preventive care, open and honest communication between sexual partners, and the use of condoms and contraception. Unwanted pregnancy could also mean having a safe abortion so that the health of the mother is conserved.

- Prenatal care, safe child birth and early child care: Regular check-ups with a trained health care provider during pregnancy to monitor the health of the woman and the foetus and to help to identify any problems early. It includes ensuring a safe delivery so that the health of the mother and the baby is preserved.

- Infertility: The continuing inability to bear a child.

5. Sexual dysfunction: A psychological or physical problem that interferes with a person's ability to express or enjoy his or her sexuality to the fullest degree. Includes lack of desire, inadequate lubrication, and difficulties in maintaining erections or achieving orgasm.

\section{E. Sexual violence}

Sexual violence is any violence (i.e. abusive or unjust use of power) that has a sexual aspect or element. It includes the use of sexuality to influence, control, or manipulate others. This includes:

1. Child sexual abuse: Any sexual contact or interaction between an older or more powerful person and a child or minor; this may or may not involve touch. The abuser is usually someone known to the child. It could also include verbal sexual abuse.

2. Incest (non-consensual): A sexual relationship between two people who are too closely related to get married by law or custom.

3. Rape: Forced or non-consensual sexual intercourse or other intimate sexual contact. The force may be physical or psychological (that is, through threats or coercion). Sexual intercourse constitutes rape if one of the parties is not capable of giving consent for whatever reason.

4. Sexual manipulation: Using sex to indirectly influence, control, force/coerce, or exploit someone to one's own advantage.

5. Sexual harassment: Persistent unwelcome verbal or physical sexual advances or conduct of a sexual nature, or demand for sexual activity in exchange for benefits, for example in a school or work setting.

6. Partner or domestic violence: Physical or sexual violence against a partner with whom one is in a romantic and/or marital relationship.

7. Gender discrimination: Showing preference or prejudice or denying equal treatment to someone based solely on his or her gender.

8. Harmful practices: A range of practices, whether traditional or modern, that decreases a person's sexual wellbeing or ability to experience his or her sexuality safely and pleasurably (Examples in India: Devadasi in North Karnataka, women insubordination, wife sharing in Rajasthan etc).

\section{Adapted from Source:}

- $\quad$ INSA India. 1998. Divine Sexuality. Bangalore: Ash Design and Print Unit.

- Irvin, A. 2004. Positively Informed-Lesson Plans and Guidance for Sexuality Educators and Advocates. New York: International Women's Health Coalition (IWHC). 


\section{Handout 1.2: Facts about Girls and Boys}

\section{Facts about girls}

\section{The menstrual cycle}

All women have menstrual periods from puberty (ages 9 to 16 years) to menopause (ages 45 to 55 years) unless they have had a complete hysterectomy (the removal of the uterus). Periods generally last from three to seven days.

- The time between the periods, are approximately 28 days, with great variation among individuals.

- Some girls and women have cycles as short as 21 days or as long as 34 days; others have periods at irregular intervals.

- When girls first start having their periods, it is not unusual for them to be irregular, at least for the first year or two. This is perfectly normal and usually means that the ovaries are not releasing an egg every month.

- The average menstrual discharge is approximately one half cup in volume, consisting of four to six table spoons of blood, other fluids and mucus.

NOTE: Women who have very little body fat due to sports activities or eating disorders sometimes do not have menstrual periods.

\section{What happens during a menstrual cycle?}

1. Pituitary gland: At puberty, the pituitary gland, located at the base of the brain, releases a hormone that signals the ovaries to start producing other hormones. These hormones regulate the menstrual cycle.

2. Ovaries: Once a month, an egg ripens and is released from the ovary. This process is called ovulation.

3. Uterus: Each month, in preparation for a fertilised egg, the uterus builds up a thickened lining made up of blood and body tissue to nourish the egg. If the egg is not fertilised, this lining is not needed and is shed through the vagina during menstruation. The first time a girl gets her menstruation is referred to as menarche.

4. Pregnancy: In most cases, menstruation ceases during pregnancy. However some women experience a brief period after becoming pregnant. During pregnancy, the tissue and the blood that usually form the menstrual flow provide nourishment to the developing foetus. Since the woman is pregnant, her pituitary gland stops sending its hormonal message.

Women who have too much bleeding (more than 7 to 10 days, extremely heavy periods with clots, or requiring more than one pad or tampon every two hours); or who go more than two or three months without a period should have a medical check-up. Hormones or birth control pills are safe ways to make the periods more regular.

Menstrual hygiene: A woman/girl needs to keep her vagina and surrounding area clean at all times but especially during periods, otherwise she may have infection, itching and burning and bad odour. A girl should practice the following during this period.

- $\quad$ Bathe daily.

- Wash the genital region with soap.

- Change sanitary napkins/cloth frequently (at least 3 to 4 times a day) in order to prevent bad odour and infection. The used napkins must be placed in a paper or a plastic bag before throwing them in a closed dustbin.

- If using a cloth, wash the cloth in hot water with detergent soap and dry it in the sunlight in order to prevent infection.

- When the blood stained pad or cloth rubs against the thigh, the skin of the thigh gets sore. It becomes difficult to walk. Hence, applying cream, oil/powder in that area is helpful. It is not advisable for girls to engage in heavy physical activity (running, manual labour) during menstruation as there is loss of blood and the various reproductive parts are under strain due to the process of menstruation. Moderate work is allowed. 
Sanitary napkins: Gauze-covered cotton pads or clean soft cotton cloth worn during menstruation to absorb the flow of blood:

- $\quad$ Pads come in many sizes and shapes to accommodate the lightness or heaviness of the menstrual flow.

- $\quad$ Pads should be changed several times a day and before one goes to bed.

- Most pads are made with an adhesive strip on the underside, designed to stick to regular underwear.

- Pads have a plastic layer on the underside to keep blood from coming through and staining clothes. The side that lies against the body is usually plain white.

- Since the pad stays close to the body, no one can say it is being worn even if a woman is dressed in slacks.

Tampons: Thin rolls of cotton and/or other fibres, with a string attached to one end.

- Although there are no medical prohibitions, some people believe it is better for young girls to wear pads than tampons during the first years of menstruation. Girls should talk to their mothers or other caretakers about tampon use.

- How to use a tampon:

- Relax and take your time.

- Stand with legs apart and knees slightly bent; sit with knees apart; or place one foot on the toilet or a chair.

- To make insertion easier, gently hold applicator with thumb and middle finger.

- Insert the tip of the tampon into the vagina and slant toward lower back until your fingers touch your body.

- Use forefinger or other hand to gently push the inner tube until flush with outer tube.

- Withdraw applicator, being sure both tubes are removed.

- Gently tug on removal strings until you feel slight resistance to make sure the tampon is properly positioned.

- Avoid using deodorant tampons; they may irritate the vagina.

- Change tampons every four to eight hours. Scientific studies have shown that tampons that have not been changed for more than 6-8 hours contribute to the cause of Toxic Shock Syndrome (TSS). TSS is a rare but serious disease that may cause death.

\section{To reduce risk of TSS}

- Each woman should use the minimum absorbency needed to control her flow-preferably regular or junior tampons unless the menstrual flow is too heavy.

- Alternate using tampons and sanitary napkins during the menstrual period.

- Know the warning signs of TSS - sudden fever, vomiting, diarrhoea, fainting, dizziness, or a rash that looks like sunburn

Dealing with cramps: Menstrual discomfort varies. Some women experience cramps before and during their periods. Cramps are caused by the tightening and relaxing of muscles around the uterus. Cramps can be treated with a variety of remedies:

- Apply a hot-water bottle to abdomen.

- Take a walk or a warm bath.

- Drink a hot beverage.

- Take medications such as ibuprofen or acetaminophen for severe cramps. Make sure you do not have allergies or other reasons to avoid using particular medications and always consult with your doctor before using any medication.

- Exercise, drink lots of water, and get plenty of sleep.

○ If severe cramps persist, see a doctor. 
Some girls and women also experience premenstrual syndrome (PMS) symptoms such as blotting, pimples, tender breasts, food cravings, headaches, constipation, and feeling irritable, sensitive or tired. Non prescription methods of dealing with PMS include getting regular exercise, taking vitamin B, drinking lots of fluids and avoiding caffeine. Young women with PMS can check with a health practitioner for further advice.

The body may retain more water than usual at this time. Cutting down on salty foods (such as cheese, soda, canned vegetables and canned soups) will help prevent this. These premenstrual symptoms end when menstruation begins.

\section{Normal vaginal lubrication and discharge}

Beginning at puberty, all girls and women have a certain amount of clear or cloudy discharge that may dry to yellowish colour on underclothes and give off a mild odour. This normal discharge is created when droplets of mucus are secreted by the cervix. The mucus cleans and moistens the vagina and helps protect the uterus from infection. Just after menstruation, a girl produces very little vaginal discharge and has the sensation of dryness. As she approaches ovulation, the cervix produces more mucus and its consistency changes as the body prepares for the next menstrual discharge.

A girl will also produce more vaginal discharge when she is taking antibiotics or birth-control pills, when she is sexually excited or nervous, or when she is pregnant.

Note: Without proper instruction, monitoring vaginal discharge is not an accurate way to determine ovulation.

\section{Sexual arousal}

- Girls have physical feelings when they get sexually excited or "turned on" either with a partner or alone. The vagina lubricates (gets wet) to prepare for sexual activity. This is entirely normal.

- Girls and women also have orgasms - emotional and physical sensations that occur at the peak of sexual excitement. Orgasm is an individual experience and could vary on different occasions for the same woman. In most cases, women experience a series of rhythmic muscle contractions near the opening of the vagina, accompanied by feelings of warmth, relaxation and pleasure.

\section{Facts about boys}

\section{Common experiences}

Erections: During an erection, the penis gets hard and stands out stiffly from the body. The penis has three spongy canals, which fill with blood and make the penis larger and stiffer. Erections start happening at birth and continue through old age. They can be caused by:

- Any sexual stimulation (this can include pictures, television, touch, books, thoughts).

- $\quad$ Other common events (lifting heavy loads, straining to move bowels, dreaming, exposure to cold, tight clothing, fright, excitement, taking a shower, waking up).

- No apparent cause, especially during puberty.

- $\quad$ Erections are the first stage of sexual excitement in males.

- Muscles at the base of the bladder prevent men from urinating while they have an erection.

- Erections will go away by themselves. It is not necessary for a male to orgasm or ejaculate to make the erection go away. No harm will result from having an erection without ejaculating-testicles will not turn blue. 
Ejaculations: When sexual stimulation and excitement increase to a certain level, a white milky, "globby" fluid comes out of the penis accompanied by a pleasurable feeling and overall relaxation. This ejaculation is sometimes called having an orgasm or "coming". Before puberty, a boy can "come" and will have a pleasurable feeling, but no fluid will come out of his penis. Facts about ejaculation:

- During ejaculation, muscles surrounding the base of the penis contract and relax and spurt semen through and out of the penis. Afterwards the penis gradually loses its erection.

- One ejaculation consists of 150 to 600 million sperm in one teaspoon of fluid. The sperm can live inside the woman for two to seven days.

- A full erection in not necessary for ejaculation. Ejaculation may occur during intercourse, masturbation, or wet dreams. However boys can and do have many erections without ejaculating.

\section{Nocturnal emissions or wet dreams}

- $\quad$ Pubescent boys and men regularly get erections while sleeping, often coinciding with periods of dreaming (REM sleep). Occasionally they may also ejaculate and may awaken immediately or in the morning with wet clothes and bedding.

- Boys and men have nocturnal emissions (wet dreams); they are especially common during early adolescence.

- If a boy has another regular outlet for sperm, such as masturbation, he usually won't have wet dreams. This is normal.

- Many boys who have wet dreams worry that they are wetting the bed and may be too embarrassed to discuss their experience. However, wet dreams are completely normal experiences that boys are encouraged to discuss with their parents and other trusted adults. If a boy is embarrassed about semen on his sheets, he can change the sheets and wash them or take a wet cloth, clean the spot on his sheet and allow it to dry before making his bed.

\section{Cleanliness}

- Wash and dry the penis and testicles daily.

- If uncircumcised pull back skin to wash away odour-causing smegma (accumulated dirt, lint and oily substances under the foreskin of the penis).

- Dry the penis completely; otherwise you risk chapping. Such chapping is not usually serious but can be quite uncomfortable.

\section{Circumcision}

- This is removal of the foreskin covering the glans (head) of the penis, usually when the boy is an infant.

- Circumcision is an individual decision that each parent will make, preferably after gaining the information on the pros and cons.

- It is a cultural practice amongst certain religious communities e.g. amongst the Muslims and Jews.

- It is medically indicated sometimes e.g. in the case of Phimosis (infection that causes pain when the foreskin of the penis is pulled back)

- It has received a lot of focus in the context of prevention of HIV but scientific evidence is not enough to recommend it as a method for the prevention of HIV infection

\section{Adapted from source:}

- Irvin, A. 2004. Positively Informed-Lesson Plans and Guidance for Sexuality Educators and Advocates. New York: International Women's Health Coalition (IWHC). 


\section{Handout 1.3: Basic information about sexuality through life (Only For Facilitator)}

Physical and physiological changes occur in the body as people age. Several factors can affect these changes such as:

- Income

- Nutrition

- $\quad$ Stress

- Responsibilities

- Health

\section{Sexuality through the various physiological changes}

\section{Menarche}

- Even today in many parts of the world, menarche is marked as a significant coming of age event for girls. This is often accompanied by rituals and celebrations.

- Sadly many, even those in the urban areas, are not prepared by their mothers, caretakers or teachers for menarche.

- Restrictions are placed on the girl with the onset of menarche - on what she should wear; whom she can speak to; where and when she can go out. This could cause confusion and shame for the young girl.

- It is important to recognise that menarche by itself does not pose a danger. It is prevailing perceptionse.g. 'It is good to have sex with a virgin, to be rid of a sexually transmitted infection' etc. that pose the danger.

- During this stage girls might become aware of sexual feelings towards the opposite or same sex.

- Girls need to be educated - on the changes that happen in their bodies; the possible manner in which they may be perceived and preyed on by others; and how they can protect themselves from any sexual violence.

\section{Menstruation}

- In some cultures menstruation is still considered as dirty, and rituals of purity are practiced. Women are considered unfit to take part in social and religious activities when menstruating.

- People may thus consider it dirty to have sex during this time. However, it is important to remember that menstruation is a normal physiological process and if a couple wishes to have sexual intercourse there is no medical indication to avoid it.

- Some women with irregular periods may also be ovulating during menstruation. Hence if such women want to plan a pregnancy, this must be informed to them as many consider menstruation as a safe period, i.e. they are unlikely to get pregnant.

\section{Peri menopause, menopause and post menopause}

- The period before a woman reaches menopause (few years before menopause) is called peri-menopause. During this period oestrogen levels fall and could lead to hot flushes, changes in libido or sexual desire, and vaginal dryness.

- Menopause is the time when a woman does not menstruate for at least a year. It occurs in woman between the ages of 40 and 60 years. However due to circumstances such as a medical intervention e.g. hysterectomy, auto immune deficiencies that may result after chemotherapy or HIV/AIDS or genetic conditions, a woman may experience menopause before the age of 40 years.

- Both peri-menopause and menopause are often thought of as a time when women experience diminished sexual desire. However this is often due to social attitudes that look down on a woman's expression of sexuality. Many believe that if a woman has fulfilled her reproductive responsibilities, she should not express any sexual desire. 
- Other physical changes that are likely during the post menopausal period include decrease of fat in the genitals, thinning and drying of the vaginal mucus membranes and decrease in firmness of breasts. Although libido may decrease, the idea has more to do with prevailing social attitudes that look down upon post menopausal women's expression of sexuality. This does not take into consideration the woman's desire itself.

- There is no medical contraindication for sexual relationships during this period. However a woman is at greater risk of HIV if exposed through the sexual route (vaginal intercourse) due to thinning of the vagina.

\section{Climacteric}

- Just like in the female menopausal process the male has decreased testosterone levels

- This is often not accompanied with decreased sexual desire

As both men and women get, older their physical conditions such as health status may affect their sexual interest and performance. This does not mean that they will not have sexual desire. However it is important for nurses to recognise that sexual desire and expressions of sexuality could vary with health status. It is important to remember the definition of sexual health and the need to address sexual health with a positive and respectful attitude.

\section{Adapted from source:}

- TARSHI. 2006. Basics and Beyond. New Delhi: TARSHI.

\section{Handout 1.4: Facts about sexual relationships}

Intimate relationships occur in different situations, irrespective of caste, religion, class, colour, race etc. However there are some controls that guide the development of intimate relationships such as religious teachings, legal rights, and laws with regards to how and when they could occur. People begin exploring their ideas and feelings about sexual relationships in early adolescence. They may experience infatuations, crushes, attractions, or even their first love. In many societies, the process of developing relationships that lead to marriage begins at this time as well. But few adolescents have thought clearly about the qualities that are important to them in a long-term partner or even what they would consider a healthy relationship, how to begin one, or how to get out of a relationship that is not healthy. And they usually receive very little adult guidance about it.

Some relationships are not healthy. Assessing a relationship objectively and concluding that it should end is difficult for everyone, but it can be especially confusing for adolescents and young people. Young people often misinterpret or ignore signs of serious relationship problems, making them vulnerable to emotional or physical abuse or exploitation. Power imbalances frequently go unquestioned - they may even be socially sanctioned or encouraged — and very often affect young girls. In many countries, poverty leads young women to develop relationships with older men of means - so-called sugar daddies - which are usually highly unequal. In the context of the HIV/AIDS epidemic, older men may also seek out young girls because they believe that they are free from infection or even that sex with a virgin will cure HIV. Unhealthy, unequal relationships put young women in particular at high risk of physical abuse, forced sex, unwanted pregnancy, STIs and HIV. Participants should learn how to recognise the signs of an unhealthy relationship and develop the communication skills necessary to avoid or end it.

When two people intend to start a sexual relationship it is important that they consider the various aspects of the relationship:

- What do they want of this relationship? Is it for fashion? Or are they serious?

- Would they want to talk about it with someone whom they trust?

- How far would they want to go in the relationship?

- Would they be free to discuss their feelings and desires with each other?

- Is the relationship equal? Is there respect between each other?

- Would something help them in deciding about the relationship? 
Relationships could be at the emotional level or may move into the physical level. Below are some behaviours that may occur when two people decide on a physical intimate relationship.

\section{Outer course}

- All sexual activities that exclude intercourse and are safe, yet give pleasure to both partners depending on their comfort levels, their attitudes and readiness for the activity

- Behaviours could include the following but this list is not exhaustive

o Hugging

o Kissing

- Touching, caressing

o Manual stimulation of the genitals/masturbation

- Some of these behaviours could lead to orgasm or release of sexual tension

- $\quad$ Remember the just like the whole body can experience pain, the skin could be erogenous. Thus

- Both partners need to be able to discuss what they are comfortable with, to be able to have a healthy life time of positive relationships

- Couples considering outer course must be able to decide what is considered as off limits

- It is important to respect each other and to keep their commitments to each other

\section{Sexual intercourse}

- According to the dictionary 'intercourse' involves 'exchange and communication'. Hence in sexual intercourse there is a mixing of body fluids (semen/vaginal secretions)

Intercourse of any type is a serious behaviour. It is ideally put off until two partners are mature and fully committed to their relationship. It has been governed by cultural norms, laws, and personal ethics.

\section{Vaginal intercourse}

- Can be part of sexual behaviour between man and woman.

- In unprotected sexual intercourse (without a barrier e.g. latex condom) there is exchange of body fluids (semen/vaginal secretions) which can result in

- Pregnancy

- Diseases if either partner is infected (STIs/HIV)

- When a man becomes sexually excited, his penis becomes erect. When the woman becomes sexually excited her vagina becomes lubricated in preparation for comfortable penetration by the penis. Either the man or the woman places the penis into the vagina. The man moves the penis in and partially out of the vagina. This friction creates pleasure. Both partners move their bodies to increase the pleasure. Without lubrication, intercourse can cause pain

\section{Oral sex}

- Oral sex or oral-genital sex is another form of sexual intercourse that involves the exchange of fluids. The term refers to two behaviours

- Mouth contact with vulva called cunnilingus

- Mouth contact with penis is called Fellatio. It can be practiced between homosexuals (MSM, lesbian) or heterosexuals

- It is a scientific and medical fact that oral sex in and of itself does not lead to disease, or pregnancy. But it is important to remember that the mouth contains more bacteria than the genitals when they are free of disease. Therefore oral sex can be a mode of transmitting disease.

- Diseases are transmitted through semen. Partners should avoid ingesting any fluid from the penis, including semen. It is also essential that men use a condom if they have oral sex performed on them.

- Similarly since disease can be transmitted from vaginal secretions, dental dam or a latex female condom must be used when performing oral sex on a woman 
- Myths:

- Only white people practice oral sex

- Oral sex is unsanitary/unclean

- A man who wants oral sex performed on him is probably gay

o Penis-vagina intercourse is the only normal form of having sex

\section{Anal sex/intercourse}

- Anal sex means various acts that could stimulate and cause feelings of pleasure and or sexual intercourse in the anus, penis in the anus.

- $\quad$ Can be practiced between men having sex with men (MSMs) and heterosexuals but may require a KY jelly or lubricant before penetration since the anus is dry and tight.

- Very risky sexual behaviour. Various intestinal infections such as hepatitis, STIs (gonorrhoea, syphilis and herpes) can spread from oral/anal contact. HIV can easily be transmitted if there is injury to the anal mucosa. It never leads to pregnancy.

- Must use a condom if it is practiced when you are unsure of the presence of STIs or a monogamous relationship

(Source: http//:www.sexuality.org for more details or more information on sexual behaviours)

Age of consent: The minimum age for engaging in sexual intercourse. This is different depending on factors such as:

- Type of sexual intercourse: vaginal, anal or oral intercourse/penetration; other acts

- Male vs. female actor

- Same-sex vs. male/female behaviour

- Sex in marriage/outside marriage

- Behaviour involving institutional power relations or money, or not

- Behaviour involving age-differences between people, or not

\section{What does the law say with regards to age of consent in India?}

\begin{tabular}{l|l} 
Laws on age of consent & Reference
\end{tabular}

According to Section 375 of I.P.C., sexual intercourse with one's own (Aggrawal, 2000) wife, even with her consent, is rape if she was below 15 years...13 years for the state of Manipur'

'India's age of consent for heterosexual sex is 16 except in Manipur, where it is 14. If the partners are married then a lower age of consent applies (13 in Manipur and 15 elsewhere).'

(Avert. 2008. 'Worldwide Ages of Consent' http://www.avert.org/ aofconsent.htm

(Aggrawal, 2000)

Age of Majority 18 (Indian Majority Act 1875); 'Child' in law means under 16 (Bombay Children Act 1948); 'Minor' is under 18 (The Hindu Minority and Guardianship Act 1956, section 4 a); Age of Marriage 18 for female, 21 for male-Hindu Marriage Act 1955, section 5 (iii)

\section{Adapted from source:}

- Irvin, A. 2004. Positively Informed-Lesson Plans and Guidance For Sexuality Educators and Advocates New York: International Women's Health Coalition (IWHC). 


\section{Handout 1.5: Statements on sex-correct responses to give to participants for}

worksheet 1.5

1. It is my right to experience sexual pleasure-(Statement 1-2)

Fact: All individuals (irrespective of health, ability/disability status, mental illness etc) have the right to experience and express sexual pleasure in any manner they feel comfortable, as long as they do not break or disregard another person's rights. Individuals have sex for several reasons. The gender of a person has nothing to do with it. It is also important to remember that both men and women have a right to say no to sexual activity any time. The decision needs to be made each time a person is thinking of having sex with someone. A person has the right to say no to a sexual relationship even if he/she previously had shared such a relationship.

Fact: Young people have the right to experience sexual pleasure and should have access to information (about safe sex, when they are ready for sexual relationships) and contraception to protect them. Fantasies and desires are individual and experienced differently. They are not 'wrong' as long as they do not violate other people's spaces or rights in any way. However there are laws that govern at what age and with whom a person can engage in sexual activities.

2. The aim of sex is just to have pleasure. Too much of it could lead to multi-partner sexual relationships (promiscuity) - (Statement 3)

Opinion: Pleasure is essential to well being, whether it is sexual, emotional, physical or mental. Pleasure can be experienced in many different ways. Through sexual intercourse, kissing, hugging, lying next to each other etc. Pleasure is not only through physical experiences, but mental and emotional ones also. Some people have sex to experience pleasure, while others may enjoy it for the feeling of intimacy or for procreation. People can also experience sexual pleasure from acts other than sex, for example touching each other or watching movies or reading sexually explicit books.

There are several reasons for a person engaging in multi partner sexual relationships. Multi partner sexual relationships also have gender implications. In some societies it is acceptable for men to have multiple partners, but if a woman engages in the same she is called 'loose' and other derogatory terms.

3. Pleasure can be experienced between people of the same sex-(Statement 4)

Fact: All people irrespective of their sexual identities (homosexual, heterosexual etc) can experience sexual pleasure. People can choose to practice and experience pleasure differently with people of the same gender within their own personal ethic or values. It is sometimes the socio-cultural pressures and conditioning that emphasises one dominant sexual identity as well sexual relationship. But it is essential to recognise that several identities exist and people do experience and give pleasure to each other in different ways. Details of different types of sexual orientation is given in Handout 1.6.

4. Sexual intercourse is really the best way to express your love for someone-(Statement 5) Myth: There are hundreds of ways to show you care about or love someone without physical intimacy. In addition sexual activity includes a range of physical acts such as holding hands, hugging, kissing, touching, caressing to sexual intercourse etc. Sexual intercourse is only one type of sexual activity and only one way to express love.

5. Men always get aroused by the idea of sex-(Statement 6)

Myth: In the same way that sexuality is an individual experience, desire is experienced differently by each person and even for the same person at different times, depending on various factors (the circumstances, health, stress levels, relationship issues etc). Men are not always sexually aroused. Even if men are aroused they may not get an erection immediately. This does not mean there is something wrong or that they do not desire their partner.

Fact: Several people have the misconception that once a man/boy gets really excited and gets an erection, he has to go all the way and have intercourse or he will not fulfil his sexual pleasure. The fact is that an erection does not have to end in sexual intercourse. Occasionally, a boy/man might feel some discomfort if he is sexually excited for an extended period of time. This will disappear when he is able to relax, or if he masturbates. 
Fact: In some societies it is wrongly believed that men's desires should be considered before women's and that only men should experience sexual pleasure. However all people regardless of their gender can have sexual pleasure/desires and have a right to express themselves sexually. It is also said that wet dreams are usually triggered by sexual dreams and fantasies. Wet dreams occur due to involuntary ejaculation of semen during sleep. They are normal and are not related to how sexually active a person is or how often they have thoughts of sex.

Fact: Remember, it is normal and healthy for both males and females to have sexual feelings and the desire to express them, but neither males nor females need to have sex with each other to have an orgasm or to be healthy

6. Women do not have orgasms so when the male reaches orgasm, sex is finished-(Statement 7-8)

Myth: Women do have orgasm. It may be necessary that some sensitivity and patience is shown by her partner to ensure that the female experiences orgasm; especially if he is extremely excited. Males generally achieve orgasm faster than females, so it is important that the male knows how to arouse the female and wait till she reaches orgasm. Communicating likes and dislikes is important to ensure that sexual relations are satisfying for both the male and the female.

Fact: Women are known to experience orgasms through other sexual activities such as clitoral stimulation and stimulation of other parts of the body, not just through sexual intercourse (vaginal, anal or oral).

7. It is possible to sustain a marriage or relationship with sexual pleasure and if you are in a monogamous relationship-(Statement 9-10)

Opinion: For some people, sexual pleasure must be a part of a healthy relationship. Others feel this is not essential to maintain a marriage or a relationship. Again this varies for people at different times of their lives. Many people experience pleasure in a variety of sexual situations, not all within a marriage or a monogamous relationship or in a physical sexual relationship. There should not be moral judgments on those choices and experiences. This is governed by a personal ethics, social expectations and several other factors.

8. It is not good to have sex during pregnancy or menstruation-(Statement 11)

Opinion: Though vaginal intercourse is sometimes not advisable in the first three months and the last two months of pregnancy, pleasure can be given and received through activities other than intercourse. The sexual desire of a pregnant woman and her partner is not governed by the pregnancy. The purpose of sex is not just reproduction but also to experience pleasure.

It is important that sexual activity is consensual (agreed up on by both partners) and safe. Unless there are clear instructions from the health care professional to abstain, as in the case of a difficult pregnancy, there is no reason a couple cannot be sexually active throughout the woman's pregnancy. Activities like mutual masturbation and other activities can be engaged in until the end of term.

Opinion: Certain cultures believe that menstruation is dirty and thus it is not a good time to have sex. However, this is often based on social and religious teachings and has nothing to do with a woman's desire. Menstruation is a normal physiological process and sex activity during that period would not in any way be harmful to the woman.

9. Alcohol and other addicting drugs make it easier to get sexually aroused-(Statement 12)

Myth: They have exactly the opposite effect. Alcohol and other drugs may increase desire and reduce inhibitions (make you feel freer) but they decrease the flow of blood to the genital area and make it more difficult for males to have an erection; and for both males and females to experience orgasm. More importantly, they can make people feel like it is okay to do things they would not ordinarily do-such as not protect themselves against pregnancy, STIs and HIV.

Adapted from source:

- TARSHI. 2006. Basics and Beyond. New Delhi: TARSHI. 


\section{Handout 1.6: Sexual orientation/identity/preference}

Sexual orientation refers to deep seated direction of one's romantic and erotic attraction-towards the same sex (homosexual); other sex (heterosexual); or both sexes (bisexual). Sexual orientation is a continuum, not a set of absolutely distinct categories. People do not choose their sexual orientation; they discover their feelings of attraction. The only choice is whether or not to act on those feelings. Some people's feelings vary over time. The alternative terms sexual preference and sexual inclination have similar meanings.

Typically a person may be identified in many ways as seen below:

\begin{tabular}{|c|c|c|}
\hline Identity & Meaning & $\begin{array}{l}\text { How would you feel when dealing } \\
\text { with a person who expresses the } \\
\text { following identities/orientations? }\end{array}$ \\
\hline Heterosexual & $\begin{array}{l}\text { - Romantic and sexual attraction to and/or behaviour } \\
\text { with members of the other gender } \\
\text { - Commonly thought of as 'attraction to the opposite } \\
\text { sex' } \\
\text { - It is normal, not an illness and has no known cause }\end{array}$ & $\begin{array}{l}\text { - Comfortable } \\
\text { - OK } \\
\text { - Uncomfortable }\end{array}$ \\
\hline Homosexual & $\begin{array}{l}\text { - A person who has sexual, emotional, and/or has romantic } \\
\text { attraction to a person of the same gender/sex } \\
\text { - It is normal, not an illness and has no known cause } \\
\text { - Lesbian: the term of preference for most homosexual } \\
\text { women because it offers an identity independent of men. } \\
\text { The term originates from the island of Lesbos in the } \\
\text { Aegean Sea, which was the home of the Greek woman } \\
\text { poet Sappho, who was a lover of women } \\
\text { - Gay: Men attracted to men. The label gay is often used } \\
\text { as an umbrella term for both gay men and lesbians } \\
\text { - It is normal and has no definite cause. }\end{array}$ & $\begin{array}{l}\text { - Comfortable } \\
\text { - OK } \\
\text { - Uncomfortable }\end{array}$ \\
\hline Bisexual & $\begin{array}{l}\text { - Also called 'bi' } \\
\text { - A person who is attracted to both the genders, but not } \\
\text { necessarily simultaneously or equally } \\
\text { - It is normal, not an illness and has no known cause }\end{array}$ & $\begin{array}{l}\text { - Comfortable } \\
\text { - OK } \\
\text { - Uncomfortable }\end{array}$ \\
\hline An Intersex & $\begin{array}{l}\text { - Is an individual who has underdeveloped male/female } \\
\text { sexual organs. Used to be called hermaphrodite (a } \\
\text { scientific term used primarily for animals) } \\
\text { - Hijra (exact size of the community is unknown) } \\
\text { - Chaka, Ombhodhu, Channapatna, Sanga (Derogatory } \\
\text { terms) } \\
\text { - Primarily, the Hijra is a castrated male, who willingly } \\
\text { undergoes such a procedure. Usually they feel that they } \\
\text { are females who are trapped in a male body }\end{array}$ & $\begin{array}{l}\text { - Comfortable } \\
\text { - OK } \\
\text { - Uncomfortable }\end{array}$ \\
\hline Asexual & - No sexual attraction for either sex & $\begin{array}{l}\text { - Comfortable } \\
\text { - OK } \\
\text { - Uncomfortable }\end{array}$ \\
\hline
\end{tabular}




\section{Myth and Fact Statements-Answers}

1. Homosexual behaviour is unnatural-myth

Anthropologists Ford and Beach found that homosexual behaviour is present in every species of mammal that has been carefully studied. Since human beings in all cultures, animals and insects engage in sexual behaviour with the same gender frequently and in significant numbers, it cannot be considered as unnatural.

2. Gay and lesbian people can be identified by the way they look and act-myth

While some people who are gay do fit a stereotype, most do not. There is no way to know for sure if someone is gay unless he or she tells you. The way a person carries herself or himself is not what makes a person gay. What make a person gay are the strong internal feelings of romantic and sexual attraction to members of the same sex.

3. People choose their sexual orientation-myth

People do not choose whom they are attracted to. Feelings of attraction are discovered rather than chosen.

4. Parents are the major influence on whether their child is homosexual or heterosexual or bisexual-myth Heterosexual, gay, lesbian, and bisexual children are raised in all kinds of families. Studies have been unable to show that any particular style of parenting leads a child to be gay or straight or that the sexual orientation of the parent is a factor. More than $90 \%$ of children who live with a gay parent have a heterosexual orientation. Likewise, the vast majority of gay people have been raised by heterosexual parents who wanted and expected their children to be heterosexual. The fact is children seem to develop their sexual orientation independent of their parents.

5. There is no such thing as a true bisexual. Bisexuals are generally confused about their sexuality or they are exploring-myth

Bisexuality is a legitimate sexual orientation. Some people have the potential to achieve sexual and emotional satisfaction and fulfilment with members of both genders/sexes. Bisexuality is a lifelong orientation, although relating sexually to both sexes may be limited to a particular period in the person's life. Some experts believe that the majority of human beings are bisexual. Many people never tune into the homosexual side of their attractions. Some people have bisexual feelings but do not identify themselves as bisexual. Bisexuals tell us that they feel like they are in two closets because they are often not accepted in either the gay or the straight community.

6. The majority of people in the world with AIDS are heterosexual-fact

As of 2007, this is true in India. According to the National AIDS Control Organisation (NACO) draft-Policy Guidelines for Mainstreaming Gender in HIV programmes that came out in 2008, women in monogamous relationships are becoming infected with HIV because their husbands have had multiple sexual partners and unprotected sex. The virus has expanded the circle of infected populations to include adolescent girls (married and single); married women of reproductive age; sexually active single women; pregnant women; and women survivors of sexual abuse and rape. Heterosexual relationships have been the documented risk factor in $85 \%$ of HIV positive cases.

7. In a lesbian or gay relationship, one partner plays the male (butch) role and other the female (femme) role-myth

In same gender relationships, the partners do not play roles; they do not try to mimic heterosexual relationships. One person is typically more outgoing than the other. Either person is likely to initiate sexual activity, although as in any relationship, one person may be more interested than the other. Even in heterosexual relationships, couples are getting away from playing rigid roles based on gender.

8. Gay people can't have children-myth

Gay men and lesbians are very capable of having children, although not as a result of having sex with their same gender partner. Many gay people are parents as a result of an earlier heterosexual relationship or marriage. Some lesbian women choose to artificially inseminate or to become pregnant by a male friend (sometimes gay men also want to be parents). Other gay people adopt children or raise a child who needs a home. Parenting is a very important life experience for many gay men and lesbian women.

Adapted from source:

- Irvin, A. 2004. Positively Informed-Lesson Plans and Guidance For Sexuality Educators and Advocates. New York: International Women's Health Coalition (IWHC).

- $\quad$ NACO. 2008. Policy guidelines for mainstreaming gender in HIV programmes. (Draft copy). New Delhi: NACO. 


\section{Slides}

\section{Module 1}

Talking about ourselvesexploring the concept of Sexuality

\section{\#1.2 \\ Objectives}

By the end of this module participants will:

- discuss the need for training on sexuality and gender

- define 'human sexuality'

- examine one's perceptions to the sexuality and sexual identities

- express views and perceptions to body parts, sexual behaviours, and sexual orientation

- explore one's attitudes to sexual behaviours and expressions

\section{$\# 1.3$ \\ What is the Definition of Health?}

Health is a state of complete physical, mental \& social well being, not merely the absence of disease or infirmity (WHO)

\section{\#1.4}

How would you Define Sexual Health?

- Sexual health is a state of physical, emotional, mental and social well- being (WHO)

- Addressing sexual health requires a positive and respectful approach to sexuality and sexual relationships

Activity $1.1 \mathrm{Pg} 59$

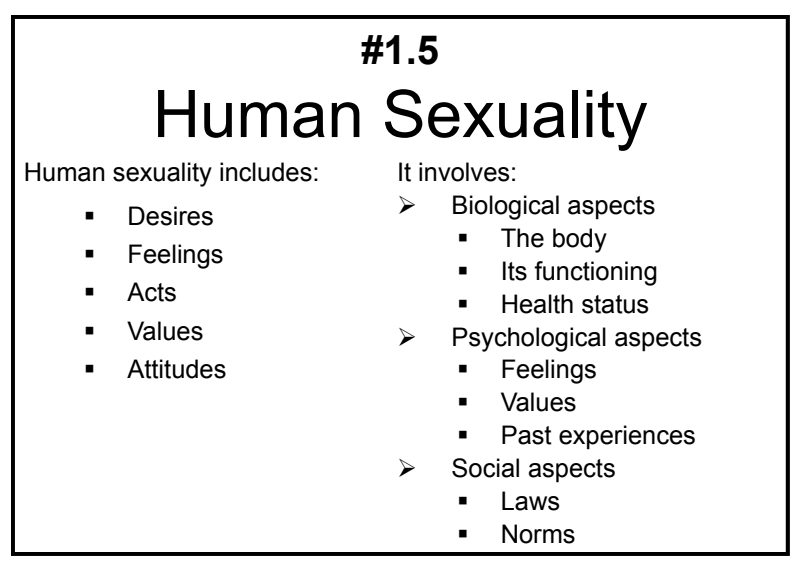




\section{\#1.7}

Components of Human Sexuality

- Human development

- Relationships and emotions

- Sexual behaviour

- Sexual health

- Sexual violence

Activity 1.2

Worksheet 1.1\&1.2

Handout 1.1-1.2

Activity 1.3

Worksheet 1.3 (only facilitator)
\#1.8

Perceptions of our Body

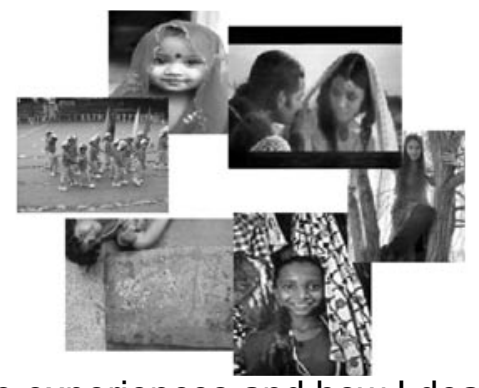

My life experiences and how I deal with it

\section{$\# 1.9$}

Remember that Sexuality includes our....

Awareness and feelings about our own body and other people's bodies through out life;

- Ability and need to be emotionally close to someone else;

- Understanding of what it means to be female or male or the third sex (gender identity);

- Feelings of sexual attraction to other people within the context of rights;

- Capacity to maintain sexual and reproductive health

\section{$\# 1.10$}

Why must we Talk about Sex?

- Humans are sexual beings

- It constitutes a personal right of the individual

- It has an important impact on life and health

- There is a definite link between sex and HIV, STIS

- People face discrimination based on sexual behaviours or identities

WHO Training module

\section{\#1.11 Barriers-Talking about Sex}

- Socio cultural: It is considered bad to talk about sex openly

- Personal: Lack of awareness, religious background etc

- Stigma: 'Will I be misunderstopd becaûse I talk about sex?'

- It's natural so every one will get to know about it without being taught

\section{\#1.12 \\ What is Sex?}

- It is the behaviour shared between two or more persons

- Principles of

- Respect

- Autonomy

- Justice

Handout 1.4 


\section{\#1.13 \\ What is the Purpose of Sex?}

- For pleasure and sharing intimacy

- For reproduction or procreation

Activity 1.7

Worksheet 1.5

Handout 1.5

\section{\#1.14}

\section{Sexual Orientations/Identities}

- What is my perception of varied sexual orientations?

- Would I be comfortable with people with sexual orientations different from mine?

- Myth or fact exercise

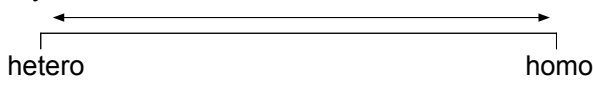

Handout 1.5

Activity 1.7

Worksheet 1.5

Refer to Glossary of Terms

\section{\#1.15}

\section{Sexual Behaviours and Identities}

\begin{tabular}{|l|c|c|c|}
\hline \multirow{2}{*}{ All behaviours } & M/F & MSM/Gay & Lesbians \\
\cline { 2 - 4 } & $\sqrt{ }$ & $\sqrt{ }$ & $\sqrt{ }$ \\
\hline \multicolumn{4}{|l|}{ Sexual intercourse } \\
\hline Oral sex & $\sqrt{ }$ & $\sqrt{ }$ & $\sqrt{ }$ \\
\hline Vaginal sex & $\sqrt{ }$ & $\times$ & $\times$ \\
\hline Anal sex & $\sqrt{ }$ & $\sqrt{ }$ & $\times$ \\
\hline
\end{tabular}

\section{\#1.16 \\ Key Messages}

- There are many different ways to define the term 'sexuality'

- Sexuality is an integral part of being human

- Sexuality is essential to the continued existence of humanity. But it is not just about the process of reproduction. Sexual behaviour is only one part of sexuality

\section{\#1.17}

\section{Key Messages}

To simplify the term "human sexuality," it can be split into the following five components all of which are interconnected:

- Human development

- Relationships and emotions

- Sexual behaviour

- Sexual health

- Sexual violence
Worksheet 1.7 Review of the Module 


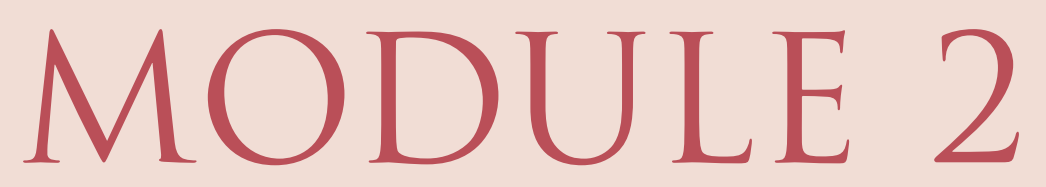

\section{DISCOVERING WHO I AM-BASIC CONCEPTS OF GENDER}




\section{Facilitators Guide}

\section{Content Considerations}

1. Build awareness amongst the participants that gender affects all walks of life and that they could face gender role and/or stereotyping in their own professional and personal lives.

2. Focus on issues of concern for all genders and try to be neutral. Avoid showing your own values towards the different topics.

3. Discuss power, oppression, and internalised oppression. This usually makes those who face oppression or discrimination believe in the stereotypical or derogatory characteristics ascribed to them. Emphasise that because gender-role stereotypes are learned, they can be challenged, unlearned, and changed.

4. Help sensitise the group that gender-role, stereotyping and discrimination affects everyone and systematically deprives girls and women of power. It is essential to discuss the devastating consequences of such discrimination. It is also important that boys and men understand the benefits they could have if they help in changing genderroles and stereotypes.

5. Acknowledge that it can be difficult to change gender roles - that it requires courage and persistence. People who do not conform to gender roles may be teased, bullied, harassed, attacked or punished by the community. This is, however, not acceptable.

6. Emphasise that working to end gender discrimination and stereotyping is easier if people support each other and work together.

\section{Aim}

The aim of this Module is to help participants understand, appreciate and apply the concept of gender to the expression of sexuality, health status, as well as, development.

\section{Objectives}

By the end of the module participants will

1. Differentiate between concepts of gender and sex.

2. Explore gender role expectations and how they can limit life options.

3. Define terms, including gender, gender roles, gender stereotypes, and gender discrimination.

4. Describe how gender issues can affect sexuality, development and health.

5. Explore ways in which these issues could be addressed in their own setting.

\section{Duration: 4.5 hours}

\section{Key Messages}

1. Gender varies by culture, but it begins influencing social development from birth; we already have a strong sense of gender by age three.

2. Gender affects every aspect of life - from how we see and value ourselves to how we learn to communicate and interact with one another.

3. Gender affects how we express and experience our sexuality, how we initiate romantic relationships, and what we feel about giving and receiving pleasure.

Sexuality education can and must do its part to correct injustices. A gender perspective should be included in all topics. 
Module 2: Topic, time, activity/method and resources needed

\begin{tabular}{|c|c|c|c|}
\hline Topic & Time & Activity/Method & Resources Needed \\
\hline Introduction & 5 minutes & & $\begin{array}{l}\text { - Black/white board or flip chart or OHP/LCD Projector } \\
\text { - Plain paper } \\
\text { - Duster } \\
\text { - Chalk/marker pens/OHP transparencies } \\
\text { - Slides: } 2.1-2.2\end{array}$ \\
\hline \multirow[t]{2}{*}{$\begin{array}{l}\text { A. Basic } \\
\text { concepts of } \\
\text { Gender }\end{array}$} & 20 minutes & $\begin{array}{l}\text { Activity 2.1: } \\
\text { Characteristics of } \\
\text { men/male and women/ } \\
\text { female (group); gender } \\
\text { terminology }\end{array}$ & $\begin{array}{l}\text { - Black/white board or flip chart or OHP/LCD Projector } \\
\text { - Plain paper } \\
\text { - Duster } \\
\text { - Chalk/marker pens/OHP transparencies } \\
\text { - Review handout } 1.1-1.2 \text { and Glossary of terms } \\
\text { - Handout } 2.1 \\
\text { - Slides: } 2.3-2.6\end{array}$ \\
\hline & 60 minutes & $\begin{array}{l}\text { Activity } 2.2: \text { Gender } \\
\text { roles, relations and life } \\
\text { choices }\end{array}$ & $\begin{array}{l}\text { - Black/white board, or flip chart or OHP/LCD Projector } \\
\text { - Chalk/marker pens/OHP transparencies } \\
\text { - Duster } \\
\text { - Worksheet } 2.1 \\
\text { - Handout } 2.2\end{array}$ \\
\hline \multirow[t]{2}{*}{$\begin{array}{l}\text { B. Gender Roles, } \\
\text { Discrimination } \\
\text { and Stereotyping }\end{array}$} & 30 minutes & $\begin{array}{l}\text { Activity 2.3: Gender } \\
\text { Roles and expectations } \\
\text { (group) } \\
\text { Self Reflection } \\
\text { (individual) }\end{array}$ & $\begin{array}{l}\text { - Black/white board or flip chart or OHP/LCD Projector } \\
\text { - Chalk/marker pens/OHP transparencies } \\
\text { - Duster } \\
\text { - Worksheet } 2.2 \\
\text { - Slides: } 2.7-2.8\end{array}$ \\
\hline & 30 minutes & $\begin{array}{l}\text { Activity } 2.4: \text { My } \\
\text { perceptions of } \\
\text { gender roles/gender } \\
\text { discrimination/gender } \\
\text { stereotyping }\end{array}$ & $\begin{array}{l}\text { - LCD/OHP projector } \\
\text { - Review of Handout } 2.1 \\
\text { - OHP transparencies } \\
\text { - Chart paper } \\
\text { - Marker pens }\end{array}$ \\
\hline \multirow[t]{3}{*}{$\begin{array}{l}\text { C. Exploring } \\
\text { how gender } \\
\text { impacts on } \\
\text { sexuality and } \\
\text { health }\end{array}$} & 30 minutes & $\begin{array}{l}\text { Activity } 2.5: \text { Gender } \\
\text { and reproductive health }\end{array}$ & $\begin{array}{l}\text { - Flip chart or OHP or LCD Projector } \\
\text { - Chits of paper } \\
\text { - Markers, tape } \\
\text { - OHP transparencies } \\
\text { - Candy or other small size sweet } \\
\text { - Handout } 2.3 \text { and } 2.4\end{array}$ \\
\hline & 20 minutes & $\begin{array}{l}\text { Activity } 2.6 \text { : Gender } \\
\text { and sexuality }\end{array}$ & $\begin{array}{l}\text { - LCD/OHP projector } \\
\text { - OHP transparencies } \\
\text { - Video is enclosed in the CD_avseq07wmv; } \\
\text { avseq11wmv and avseq12wmv } \\
\text { (Source: Ahmed A \& S. } \\
\text { Menon-Rights and Desire, Breakthrough) } \\
\text { - Review Handout } 2.2 \\
\text { - Video player } \\
\text { - Speakers } \\
\text { - Worksheet } 2.3 \\
\text { - Slides 2.9-2.12 }\end{array}$ \\
\hline & 20 minutes & $\begin{array}{l}\text { Activity } 2.7 \text { : Gender } \\
\text { equity in health- } \\
\text { Wonder drug }\end{array}$ & $\begin{array}{l}\text { - Black/white board or OHP/LCD Projector } \\
\text { - Chalk/marker pens/OHP transparencies duster } \\
\text { - Slides 2.13-2.14 }\end{array}$ \\
\hline Conclusion & 10 minutes & Summary & $\begin{array}{l}\text { - Worksheet } 2.4 \\
\text { - Slides: } 2.15-2.16\end{array}$ \\
\hline
\end{tabular}




\section{Introduction}

\section{Slide 2.1-2.2}

It is important to teach about Gender early in the undergraduate curricula, because it deeply influences all aspects of life, particularly sexuality and health. For the purposes of this module, gender is defined as the cultural characteristics, behaviours and roles that are considered to be male or female, not the obvious biological differences.

Explain to participants that they may sometimes be asked to share personal memories and experiences related to gender issues during the course of the module. Assure participants that while some memories could be pleasant and others may be painful, embarrassing or difficult to discuss, the group will adhere to the ground rules. Get participants to recall the ground rules. Emphasise that while the module gains its richness and meaning from the sharing, no one who feels uncomfortable sharing a memory will be required to do so. Reiterate that whatever is shared in the room will remain within the classroom.

Project the objectives of the module to the participants. Enquire if they have any clarifications (slide 2.2).

\section{A. BASIC CONCEPTS OF GENDER}

\section{Note for Facilitators: Activity 2.1-2.2}

Activity 2.1 will help participants review the characteristics of males and females. It is important that you help the participants focus on the psychosocial characteristics of a boy/male or a girl/female and not just the biological characteristics. Do remember that biological characteristics have been covered in the pre-university portions and later in the nursing curricula too, under Anatomy and Physiology. Therefore what is likely to be required is clarification of any misconceptions on the biological aspects.

Encourage participants to review Handout 1.1-1.2 from Module 1 as well as Handout 2.1 as it would help them to recollect what they have learnt in the past. Encourage questions from participants on all the aspects covered in the Handouts, and make time to clarify such questions.

\section{Activity 2.1: Characteristics of men/male and women}

Purpose: The participants will

- Differentiate between the concepts 'gender' and 'sex' using their own perceptions of what characterises male and female.

- Review the biological characteristics of the male and female by themselves.

\section{Materials:}

- Black/white board, or flip chart or OHP/LCD projector

- Chalk/marker pens/OHP transparencies

- $\quad$ Plain paper

- Duster

- Review Handout 1.1-1.2 of Module 1

- Glossary of terms

- $\quad$ Slides 2.3-2.6

- $\quad$ Handout 2.1 


\section{Process:}

1. Ask the participants to form their own groups of 5 to 8 persons depending on the size of the class. This is to ensure that participants are comfortable sharing personal experiences with group members.

2. Instruct participants to have a 5-minute discussion in their groups on the following:

- What are some typical characteristics of men Men are...

- What are some typical characteristics of women women are...

3. Give participants a clue that characteristics need not be just the physical characteristics but also other characteristics (mental, social, spiritual etc). Instruct participants to come up with as many characteristics as they can.

4. Divide the board/flip chart/OHP transparency in to two halves. Write 'man' on one side and 'woman' on the other side. Then encourage the group coordinator for each group to come forward and write down the characteristics they discussed on the board/flip chart/OHP transparency. Ensure there is no repetition of any characteristic on the board.

5. Once they have completed:

- Highlight the biological characteristics first by drawing circles around any that are listed. Highlight that these characteristics are parts of the male and female reproductive system. These are the biological characteristic/s of being either male or female or third sex. They help identify the sex of the person. They could be sex characteristics (vagina, vulva, penis or any of the internal reproductive organs) or secondary sex characteristics (breasts, auxiliary hair, pubic hair etc).

- Tell participants to review the content given in Handout 1.1: Components of human sexuality (human development) and Handout 1.2: Facts about girls and boys which was covered in Module 1. Questions on the subject can be answered in the next class.

- Some examples of psychosocial characteristics that you could use to prompt participants, if they are not forth coming from participants are given in the Box 2.1.

\section{Box 2.1: Examples of characteristics of women and men as perceived by society}

\begin{tabular}{|l|l|l|l|}
\hline \multicolumn{2}{c|}{ Women are: } & \multicolumn{2}{c}{ Men are: } \\
\hline Dependent & Passive & Self-reliant & Independent \\
\hline Weak & Followers & Active & Powerful \\
\hline Incompetent & Spectators & Leaders & Competent \\
\hline Less important & Modest & Doers & Strong \\
\hline Emotional & Subjective & Ambitious & Logical \\
\hline Implementers & Soft-spoken & Objective & Decision-makers \\
\hline Housekeepers & Caring & Out-spoken & Breadwinners \\
\hline Supporters & Nurturing & Bosses & Leaders \\
\hline Fragile & Gentle & Assertive & Protectors \\
\hline Fickle & Excitable & Strong & Consistent \\
\hline Fearful & Patient & Stoic & Brave \\
\hline Peace-makers & Cheerful & Impetuous & Aggressive \\
\hline Cautious & Caretakers & Forceful & Adventurous \\
\hline Flexible & Cooperative & Achievers & Focused \\
\hline Sensitive & Warm & Competitive & Bold \\
\hline
\end{tabular}

\section{Adapted from source:}

- Simons, G. F and G. D. Weissman. 1990. Men and Women: Partners at Work. CA, USA: Crisp Publications. 
6. Initiate a discussion about these psychosocial characteristics or attributes. Remind the group that these have been socially constructed i.e. assigned to people by society. This is referred to as 'gender'.

7. Ask the participants the following question:

- What are your observations in comparing these two lists?

- What do these lists show you?

- Could the characteristics that were listed under the men column be evident in women and vice versa?

Change the heading of each column by writing 'women' where 'men' was written and 'men' where 'women' was written. The reason you are doing this is because you need to show participants that the characteristics they had listed under 'men' could be true for 'women' and that which was listed for 'women' could be written under 'men'.

8. Explain, by projecting slides 2.3-2.6 the difference between the concepts 'Gender' and 'Sex'. Give them the reason why we need to discuss the issue of gender with special reference to the nursing curricula (slide 2.4).

9. Distribute Handout 2.1 to the participants and ask them to refer to it later. It only contains information that has been presented in the slides 2.3-2.6.

10. Tell participants to go through the Glossary of Terms given to them with Module 1 and help them to identify various terminologies related to gender. Ask that they should read this in preparation for the next class; to come with one or more questions related to the topic. Questions could be written on small chits of paper without any identification. Make time (at least half an hour) in the next class to answer the questions. Alternatively, you could conduct a short quiz on the terms to see if they have understood it.

11. Conclude by saying that

- Gender is socially constructed, and differences that are evident among men and women have been designed socially. The concept is well established by the age of three. This happens through socio cultural conditioning and rearing practices.

- Since these characteristics are learnt, they can be unlearnt. But the process is not easy due to strong socio-cultural foundations. However building awareness is the first step in getting rid of these differences slowly.

- Reinforce that when we talk gender, it refers to both women and men. The focus of talking about gender is to reduce the differences that have been constructed between the genders in all walks of life including health and sexuality.

\section{Adapted from source:}

- $\quad$ INSA India. 2003. Experiencing Options. Bangalore: Books for Change. 


\section{Activity 2.2: Gender roles, relations and life choices}

Purpose: The participants will

- Identify the roles, activities and tasks of men and women in their communities.

- Discuss the effect of these different roles, activities and tasks on relationships between men and women and the life choices of men and women.

\section{Materials:}

- Black/white board, or flip chart or OHP/LCD Projector

- Newsprint, sheets of paper

- Chalk/marker pens/OHP transparencies

- Duster

- Worksheet 2.1

- $\quad$ Handout 2.2

\section{Process:}

1. Divide participants into four groups. Assign each group one of the following categories :

- Male farm worker

o Female farm worker

- Male top executive

- Female top executive

2. Ask each group to:

- Draw a large circle and divide it into sections, as though you were slicing a cake or pie. Each section in the circle will signify activities typical to the category of worker assigned to the group. The size of each section will signify the time spent doing each activity in a typical 24 hour period.

3. Reconvene in the large group. Post the diagrams and lead a discussion based on the following questions:

- What was your feeling when you first saw your completed chart?

- Which of the activities are considered work?

- How do you define work?

- What differences do you notice in the way in which men and women spend their day? Their spare time?

- What are some of the consequences of these differences for women? What are the health implications? What are the implications regarding income?

- What are some of the consequences of these differences for men?

- What are some of the consequences of these differences for society?

4. Distribute Handout 2.2: Gender roles and ask for a volunteer to read it aloud. Summarize the key lessons learned from the activity.

A key lesson is that many of the activities that consume women's time - cooking, childcare, cleaning-are not considered "work" because they do not involve earning an income. Women's time is therefore considered less valuable than men's because they may not earn cash. When women are involved in earning income for the family, they generally continue to perform all the additional responsibilities within the home. The perception of women's activities as not being valuable and women's limited ability to earn an income results in women having less power in the family and the community. Refer to women's triple roles: reproductive, productive and community.

5. Now divide participants into single sex groups. Distribute Worksheet 2.1, (Gender Roles and Relationships Matrix). Give the women's matrix to the women's group(s) and the men's matrix to the men's group(s). Allow the groups about 30 minutes to complete the matrix. 
6. Allow each group to present its findings. After the presentations, lead a discussion using the following questions:

What differences did you observe in men's and women's roles?

- What did you notice about relationships of men and women in terms of power?

- What is the impact of these roles and relationships on life choices?

7. Ask participants to return to their groups to complete the following task:

- Identify specific items you have listed in your matrix under the headings "Roles" and "Relationships" which you believe need to be changed in order to achieve equity in gender relationships.

- Identify strategies for implementing these changes.

8. Allow each group to present its findings. Ask each person to identify one change they would like to make in their own life and make a note of it. Explain that this is a topic they will return to later in the workshop.

\section{Adapted from source:}

- CEDPA. 2000. Gender, Reproductive Health and Advocacy Training Manual. Washington DC: CEDPA.

\section{B. GENDER ROLES, DISCRIMINATION AND STEREOTYPING}

\section{Note for Facilitators: Activity 2.3-2.4}

Remember to conduct a quiz on all the terminology on 'Gender' found in the Glossary of Terms before you begin Activity 2.3. Encourage participants by rewarding the group that scores the highest marks.

Activity 2.3 will make participants reflect on their own lives and/or may remind them of past painful experiences. It is important that you are sensitive to any participant who shows signs of being affected. Take time to counsel the participant, if needed. Also inform the participants who want help, that help is available. This is all part of the responsibility of facilitating such a topic with the participants. If you feel unsure of your own ability to handle any of the concerns or issues raised by the participants, do not hesitate to get more expert help. Remind participants that confidentiality will be maintained at all costs.

Activity 2.4 primarily helps to clarify all the concepts that they have learnt: sex role, gender role, gender discrimination and gender stereotyping. Inform participants that sometimes the distinguishing line between gender role and gender discrimination is grey. It is important that nurses are able to recognise that discrimination can occur based on gender and gender identity. As a result of this discrimination, people may not access health care services when they need it. Typically, for example, a person who is discriminated against may not come to the hospital on time, leading to a delay in diagnosis and the burden would then be on the health care system.

Make all attempts to clarify any misconceptions of the participants.

\section{Activity 2.3: Gender Roles and Expectations}

Purpose: The participants will

- Distinguish between concepts such as gender roles, sex roles, gender discrimination and gender stereotyping.

- Display recognition of how gender concepts could affect all walks of life and thus one's progress in life.

\section{Materials:}

- Black/white board or flip chart or OHP/LCD Projector

- Chalk/marker pens/OHP transparencies

- Duster

- $\quad$ Slides-2.7-2.8

- Worksheet 2.2 


\section{Process:}

1. Write on the board/flip chart/OHP transparency for all to see 'As a human being certain basic needs that I want....' Tell participants to take two minutes to complete the statement in their note book. After two minutes ask participants to volunteer and call out what they have written, and write these on the board/flip chart/OHP transparency for all to see. If there are males and females in the class, get the responses from an equal number of males and females. You will find that basic needs do not depend on the gender of a person. Point out that 'gender' has nothing to do with basic needs of individuals. In the discussion, be sure to highlight that human beings want similar things and that these basic needs and wants are often unrelated to being male or female.

2. Let participants remain in the same groups. It is preferable for this part of the activity that the participants are from the same cultural background. However if this is not possible, tell participants to give reference to each of the different cultures they are representing. Instruct them to choose a person from their group who will document/record what they discuss. Give them 5 minutes for discussing the following statements:

- In my culture, women must. and must not do.

- In my culture, men must and must not do.

3. Call the group recorders to share the groups' responses to the two statements. Write the responses on the board/ flipchart. Explain the concepts 'gender roles', 'sex roles' and 'gender stereotyping' and 'gender discrimination' as given in the slide 2.7 (slide is animated) and slide 2.8 .

- Explain that gender stereotypes emerge from the confusion between sex roles and gender roles.

- One example of a gender stereotype is the belief that women are shy and gentle because of their biology rather than because of societal expectations.

- Gender stereotypes categorise men and women according to rigid constructs and promote the belief that these differences are biological. Some examples of socially determined characteristics are stereotypes, ideologies, values, attitudes, beliefs, and practices.

- Gender roles are established through the influence of family, community, schools, religious institutions, culture/tradition/folklore/history, media, policies, peer groups and the workplace.

4. Discuss the responses of the participants to the two statements using the following questions:

- What are your observations while comparing these two lists? What do these lists show you?

- How do people view the characteristics/activities on the two lists? Do women and men have to be or do the things that you wrote down?

- Can women and men do things expected of the opposite sex? What are the consequences?

- How do these different roles, responsibilities, and expectations affect the life choices of women? Of men?

- Remind them of Activity 2.2. Ask them 'What could happen in your community if the girl asks the boy to come out for a picnic? Would it be acceptable? How would the community view it?'

5. Emphasise that all people are restricted in their behaviours, responsibilities, and life choices because of culturally assigned roles and stereotypes. Explain to participants how the social construction of gender restricts women's ability to achieve their basic human wants in many societies. This is why it is often said that gender issues are human rights issues. Encourage participants to come out with any examples they have seen of this in their own setting.

6. Narrate the story of the Father and the Son as given in Box 2.2. (Important: when narrating the story do not mention the gender of the neurosurgeon at all, but refer to the neurosurgeon as a neurosurgeon or 'famous doctor' at ALL times). 


\section{Box 2.2: Story of 'The Father and Son'}

There was this father who was always busy. One day, the father had an unexpected holiday. So, he decided to take his son for a picnic. The son was very excited, as he loved going out with his father and this had not happened for a long time. They packed their bags and then got into the car.

As the father drove, the son in his excitement kept yelling, 'Faster, faster.' And the father kept increasing the speed of the car. The father was so engrossed in his son's excitement that he did not notice a vehicle coming in the opposite direction at one turn in the road until it was too late. He tried to swerve but crashed into a tree.

This happened near a junction that had a famous neurosurgery super-specialty hospital. A neurosurgeon who belonged to this area and had come up in life made this hospital. This famous hospital was established as that turn was a dangerous one and several fatal accidents happened there in a year. The people from the nearby villages had all been trained on emergency management of trauma by the neurosurgeon's team. So, when they heard the crash, some people rushed to the accident site. They saw that the father was not moving. And then they heard a small cry from the child. They immediately got the child out and rushed him to the hospital.

At the hospital the neurosurgeon was called immediately to attend to the child. Just before the surgery, the neurosurgeon went in to see the child. One look at the child and the neurosurgeon said 'Oh no! I can't operate, he is my son!'

Then ask participants: "How could this be?"

- Wait for responses to the question, and list the participant's responses on the board. Some usual responses are-the neurosurgeon is lying; may be the child was adopted; may be the father was a priest or was the step-father or the first father of the child. Rarely and only if you make a mistake when narrating the story will participants come out with the right answer at the first instance. The answer is 'The neurosurgeon is the mother!!'

- The story could sensitise the participants on how we are conditioned by cultural factors and upbringing about gender roles. Bring to the notice of the participants that cultural conditioning and ideas about the physical capacities of the male or female body, often leads to misconceptions about roles that can be performed only by men and roles that can be performed only by women.

- Distribute Worksheet 2.2: Self Reflection. Ask participants to complete the Worksheet in 5 minutes and then debrief:

- What are your expectations and aspirations (dreams/ambitions) for yourself? Do your expectations match with your family's expectations of you? Your community's expectations for you?

- What are some factors that may help you get your aspirations/expectations?

o Why did you choose nursing? Do you think it had anything to do with your gender?

7. Encourage participants to volunteer to share what they have written with the rest of the class.

8. Conclude by asking whether they have understood the meaning of the terms. Do a quick review of the concepts by asking them some questions to ensure they have understood it. Ask participants if they could share situations they may have faced that reflect gender discrimination or stereotyping. 


\section{Activity 2.4: My understanding of the concepts}

Purpose: The participants will

- Be clear about the concepts gender roles, discrimination and stereotyping.

- Differentiate between concepts such as gender roles, gender discrimination.

- Be able to recognise gender discrimination and stereotyping if it occurs in their daily professional or personal lives.

\section{Materials:}

- $\quad \mathrm{LCD} / \mathrm{OHP}$ projector

- $\quad$ Review of Handout 2.1

- OHP transparencies

- Chart paper

- Marker pens

- $\quad$ Handout 2.2

\section{Process:}

1. Tell participants that you will be conducting a quiz to examine if they have understood the concepts of gender role, sex role, gender discrimination.

2. Allow students to continue to sit in their groups. Tell them that you will be reading out a statement. They will discuss the statement in their groups for a minute and then when you clap your hand the participant who puts up the hand first will be given a chance to answer whether the statement denotes 'sex roles' 'gender roles', 'gender discrimination' or 'gender stereotyping'. If the answer is right, two marks will be given to the group. If the answer is wrong then the question will be passed to the next group for one mark. If you do not have access to the LCD you could read the statements out. You may need the help of a co-facilitator to do this or you could ask one of the Group Coordinators to volunteer to help you. The list of statements is given in Box 2.3. Correct responses are given in parenthesis against each statement.

3. Clarify with the participants any doubts they may have. Reinforce that it is sometimes difficult to differentiate between gender discrimination and gender stereotyping. Tell participants to refer to Handout 2.1 for the meaning of the various terms.

4. Conclude by saying that

- The distinction between gender discrimination and gender stereotypes is not always clear.

- Gender roles are usually based on gender stereotyping; for example, the belief that nursing is an occupation for women is based on the gender stereotype that women are caring and nurturing by nature.

- Gender roles can be challenged by building awareness and changing attitudes amongst people to recognise that gender biases exist in every environment and it is only through positive action some measure of equity can be reached. 


\section{Box 2.3: List of statements to clarify gender terminology}

1. Women give birth to babies, men do not. (sex roles)

2. Girls are gentle, and boys are tough. (gender roles)

3. Women cook and clean the house; men earn an income through paying jobs outside the house. (gender roles)

4. Amongst Indian agricultural workers, women are paid 40-60 percent of the male wage. (gender discrimination)

5. Women can breastfeed babies; men can bottle feed babies. (sex roles)

6. Most business people in India are men. (gender roles/stereotyping)

7. Most building site workers in India are men. (gender roles/stereotyping)

8. Men are better than women at math, physics, and science. (gender stereotyping)

9. In Nair customs, women inherit the property. (gender roles)

10. According to UN statistics, women do 67 percent of the world's work, but their earnings amount to only 10 percent of the world's income. (gender discrimination)

11. Nurses are generally women since they are to be subservient to the physician. (gender stereotyping)

12. Men's voices break at puberty, women's voices do not. (sex roles)

13. In one study of 224 cultures, there were five in which men did all the cooking and 36 in which women did all the house building. (gender roles)

14. Nurses are usually women since they are naturally caring, gentle, and sensitive. (gender roles/stereotyping)

15. Women are soft-spoken and gentle; men are assertive and strong. (gender roles)

16. Men do not make good nurses. (gender stereotyping)

17. Men make decisions about family planning and the number of children a couple will have. (gender roles/gender discrimination)

\section{Adapted from sources:}

- Ahmed, A. and S. Menon. 2006. Rights and Desire-A Facilitator's Manual to Healthy Sexuality. New Delhi: Breakthrough.

- Irvin, A. 2004. Positively Informed-Lesson Plans and Guidance for Sexuality Educators and Advocates. New York: International Women's Health Coalition (IWHC). 


\section{EXPLORING HOW GENDER IMPACTS SEXUALITY AND HEALTH}

Note for Facilitators: Activity 2.5-2.7

Activity 2.5-2.7 will help participants be sensitised to the issues of gender discrimination and stereotyping in the context of health and sexuality. As nurses, it is important that we are aware of our subconscious thoughts and how this may impact the way we deal with others.

Highlight that controversies may arise during and after all these three activities. Some may feel that sexual orientation and gender identity are not issues; others may believe that their own communities are populated only by 'straight' people i.e. people with the dominant sexual and gender identity; still others may believe that it is immoral and inappropriate to be of a different sexual orientation. There may be some who question your own sexual orientation. Remember while you may face resistance when you talk about the issues of gender, you will also be taking a step toward creating a more just and welcoming environment for all genders and sexual orientations.

Please be well prepared for the session with all the materials required. If you do not have all that is required then prepare participants ahead of time so that they can come ready with advertisements that they commonly see on television that they believe have gender implications. Remember the focus must be to draw from participants that gender discrimination and stereotyping can be changed. Once people become aware of the strengths they possess, the resources available, and have a clear goal in mind, they can pave the way for a positive change.

Keep in mind that Activity 2.6 can generate a lot of noise. It is important that you check that this noise is permissible in the premises when you are doing this activity. Use the game to draw the link between gender and sexuality as well as health.

Activity 2.7 helps to draw the link between gender and health care service provision. Help participants recognise that everyone faces situations in their professional lives, where they make conscious choices, to be non-discriminatory and non-judgmental in providing care for the clientele. Remind them that there are universal ethical principles that could guide them when dealing with their clientele. These include respect for human dignity; to do good and never harm anyone; and the freedom from injury. Reinforce that it is important to be unbiased when caring for clientele.

\section{Activity 2.5: Gender and reproductive health}

Purpose: The participants will

- Understand reproductive health and its components.

- Realize the effect of gender roles, relationships and stereotypes on the factors that impact reproductive health.

\section{Materials:}

- $\quad \mathrm{LCD} / \mathrm{OHP}$ projector

- $\quad$ Flipchart and paper, markers, tape

- Note cards

- OHP transparencies

- Candy or other small prize

- $\quad$ Handout 2.3 and 2.4

\section{Process:}

1. First, review the learner objectives you wrote on the flipchart. Next, initiate a quick brainstorm to get participants' understanding of the term 'Reproductive Health'. Record their input on a flipchart. Using an overhead projector, present the definition of Reproductive Health that emerged from ICPD: 
"Reproductive Health is a state of complete physical, mental and social well being and not merely the absence of disease or infirmity, in all matters related to the reproductive system and to its functions and processes. People are able to have a satisfying and safe sex life and they have the capability to reproduce and the freedom to decide if, when and how often to do so. Men and women have the right to be informed and have access to safe, effective, affordable and acceptable methods of their choice for the regulation of fertility, as well as access to health care for safe pregnancy and childbirth."

2. Ask the participants how people in their communities understand the term 'Reproductive Health'. How does their understanding compare to the definition shown on the overhead projector? Does their understanding encompass the issue of reproductive rights?

3. Ask participants to add any elements or components of reproductive health based on the previous discussions. Record their responses.

Reproductive health as described in the ICPD Programme of Action includes the following elements:

- Family planning education, counselling and services

- Education and services for prenatal (antenatal) care, safe delivery and post natal care and infants' and women's health care

- Prevention and management of abortion complications

- Treatment of reproductive health conditions

- Prevention and treatment of reproductive tract infections, including STDs and HIV/AIDS.

- Information, education and counselling on human sexuality and responsible parenthood.

4. Explain that in order to better understand the meaning of this quote, the participants are going to create a mind map of reproductive health. The purpose of the mind map is to explore the range of factors that can affect reproduction.

A mind map is a variation on the traditional brainstorm. Participants are asked to focus on a central conceptin this case reproductive health- and brainstorm related concepts. This methodology generates a visual map of interrelated themes and ideas. The map is developed with synapses, similar to the way our brains work.

Write the term 'Reproductive Health' in the centre of the blank paper, enclosed in a circle. Invite the group to identify the key factors that affect reproductive health.

Write each response in a new circle and draw a line connecting this circle back to reproductive health. For example, if the first factor identified is culture, it is helpful to ask probing questions to identify the specific cultural issues. Once culture is fully developed as an influencing factor on reproductive health, move on and ask participants for a new factor. Continue adding to the map until such time that all the possible factors have been identified.

Once the mind map is complete, ask a volunteer to copy each of the factors and sub-factors onto index cards, one factor per card. These will be used later in the "Name that Gender Issue" game.

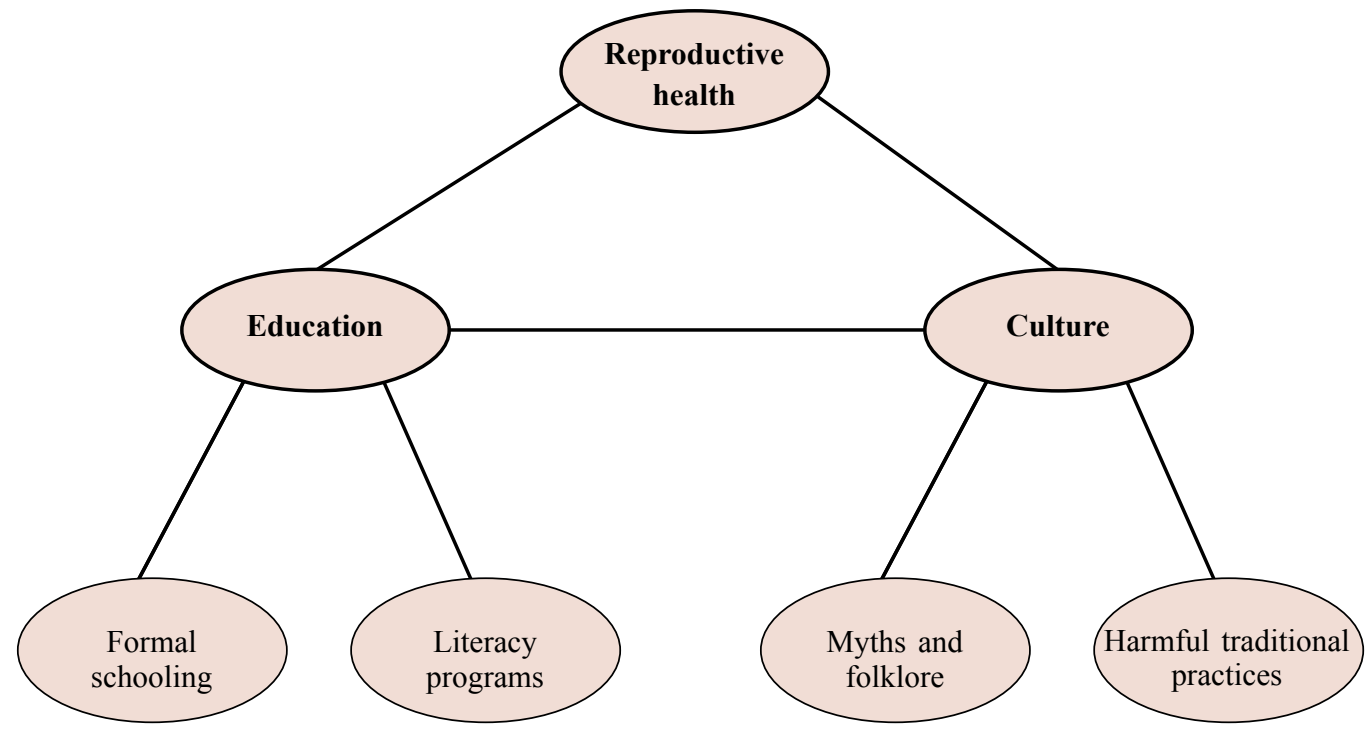


5. Ask participants whether they think gender related roles, relationships and stereotypes shape any of the factors identified on the mind map. Ask for examples in the context of one or two factors on the mind map. For example, if education was identified as a factor that affects reproductive health, a gender issue related to education is that boys are often given preference over girls to attend school if the family cannot afford to send all the children to school. If income was identified as a factor, a related gender issue is that men are more often in the productive (income generating) sector than women and earn more money than women for the same work.

6. Divide participants into 3 to 4 teams to play "Name that Gender Issue". Explain the rules as follows: Team 1 will pick one of the cards generated by the mind map (the set prepared by the volunteer) from a hat or large bowl. The team then has 15 seconds (or an agreed upon amount of time) to come up with gender issues related to that factor. Award one point for each accurate gender issue identified. If Team 1 cannot think of any gender issues, the remaining teams will each have an opportunity to name one issue. After Team 1 has completed its turn, have Team 2 pick a card from the bowl and repeat the process. Keep track of points on a flipchart.

7. After several rounds, tally the scores and award a prize to the winning team. Ask participants to share what they learned from the game. Summarize the activity by pointing out that gender has an impact on nearly everything we do. Often the obstacles that prevent people from exercising their reproductive rights and protecting or controlling their reproductive health are related to gender and gender inequities.

8. $\quad$ Distribute Handout 2.3 and 2.4

\section{Activity 2.6: Gender and sexuality}

Purpose: The participants will

- Be sensitised to their own prejudices and assumptions about people when delivering health care.

\section{Materials:}

- $\quad \mathrm{LCD} / \mathrm{OHP}$ projector

- OHP transparencies

- Video is enclosed in CD-avseq07wmv; avseq11wmv and avseq12wmv (Source: Ahmed A. \& S.Menon Rights and Desire Breakthrough: Delhi)

- $\quad$ Review Handout 2.2

- Video player

- Speakers

- $\quad$ Slides-2.9-2.11

- $\quad$ Worksheet 2.3

\section{Process:}

1. Project the video trigger clippings from 'Rights and Desire' that have been copied on the CD, in the order given on slide 2.11. If you do not have access to a video player, ask participants to role play examples of advertisements shown on television that have gender implications. Initiate a small discussion on other advertisements of a similar nature that they have seen.

2. Remind them to review Handout 2.2 thoroughly, as it will help them recognise how 'being a woman' could have a negative impact. The section of the Handout-Crimes Against Women, typically show how most of the crimes against women mentioned in the Handout, are directed against the sexuality of the woman.

3. Project slide 2.9-2.11 and discuss the impact of gender on sexuality with special focus on the imbalanced role between the genders.

4. Brainstorm : What would be some signs of positive gender change? 
5. Explain to participants that currently there are many gaps and inequalities between expectations of men and women. To create a better balance the following steps would need to be taken (slide 2.12):

- Develop a positive identity and self-image for women

- Create a space for women and other minorities to explore, speak and develop strength and thus build relationships with other women. E.g. to form and build self help groups, women sanghas etc.

- Mobilise and build a collective identity with other women through self help groups etc to advocate and to meet their needs

- $\quad$ Support women and other minorities in social leadership by increasing the number of women in meaningful, community level leadership roles; building capacity to fight for change within existing structures.

- Facilitate cultural change by redefining gender rules and norms; recreating cultural practices, customs, rituals, symbols, etc.

- Support women and other minorities' personal autonomy and ability to resist abuse and violence; allocate responsibilities to others in the family, have open and respectful communication with spouse, influence decision-making with spouse and other family members

- Improve women and other minorities' economic security by assisting women's access to and control over credit, safe and rewarding sources of employment, and food security

- Build Institutional support of women and other minorities through fostering effective linkages with agencies that support women's interests, developing and promoting of gender/women friendly services.

- Increase access of women and other minorities to political power by including protection of human rights, representation in government at all levels, capacity to exercise legal rights.

6. Conclude by telling the participants the same could be applied in their own personal and professional lives when faced with these challenges. Give them Worksheet 2.3 and ask them to identify the resources that are available to help them, for each of the points listed on the slide. Some examples could be professional bodies, faculty members who are supportive as well as good role models and links with other organisations, influential people and others that they come across in their clinical postings.

\section{Adapted from source:}

- $\quad$ Ahmed, A. and S. Menon. 2006. Rights and Desire-A Facilitator's Manual to Healthy Sexuality. New Delhi: Breakthrough.

- Alphonse, X. 2004. We Shall Overcome-Textbook on Life Coping Skills. Bangalore: SKIP Publication.

\section{Activity 2.7: Gender equity in health-wonder drug}

Purpose: The participants will

- Recognise how one's perceptions could affect delivery of care to clientele.

- Be able to identify issues that reflect gender equity or inequity in health care system.

\section{Materials:}

- $\mathrm{LCD} / \mathrm{OHP}$ projector

- Black/white board

- Chalk/marker pens/OHP transparencies

- Duster

- $\quad$ Slides-2.13-2.14

- $\quad$ Worksheet 2.4

\section{Process:}

1. Tell participants that you will narrate a story. Narrate the story given in Box 2.4. 


\section{Box 2.4: The wonder drug}

- There was a scientist in your community who discovered a drug that would cure a person of HIV. He had money just enough to make only one drug. He gave you the drug and told you to give it to any person whom you felt needed it most.

- Three people come to you because they heard about the drug. One is a 30 year old business man, another a 10 year old child and the third a 23 year old sex worker.

- To whom would you give the drug?

2. Wait for responses.

- In all likelihood most would respond "the child"; a few may answer "the business" man or "the sex worker".

- Then ask participants to give reasons for their response using this question "Why did you choose the child (or the man, or the woman) and not the others?" (Possible responses: The child is innocent, he did not do anything to get the infection; the sex worker if cured, would not infect others; the business man could afford to buy the medicine himself \{Probe further\})

3. Once you are sure that participants have given enough reasons for their choice tell the participants that 'the story is not over'. Continue the story as given below:

- The child has been diagnosed with a cancer that is in the late stages and expert doctors believe he has only 3 months to live. Now who would you give the drug to?

4. Wait for responses.

- Remember that often participants, who opted for the child, are likely to change their response to either the business man or the sex worker.

- Ask the participants to sit in groups according to their newly made choice. Note the difference in the group numbers now.

- Then ask those who changed their initial response "Why did you change your response (the child for the man or the woman)?"

- Possible responses could be:

o We will still give it to the child. The child is innocent; so even if he is going to die it would be for a good cause. (Probe: Don't you think that the drug is wasted?)

o Now that I know the child is going to die I will give it to the business man or the sex worker (Probe further).

o Is there any more information that we need to have before we make a decision?

5. Then tell them, 'The business man got HIV when he was 18 years old after a blood transfusion. He gives charity to an HIV support group every year and he spends a lot of his free time with children who have HIV. The sex worker was sold by her parents at the age of 12 years. She was taken to a brothel. She was forced in to sex work.' Now what would you say?

- Wait for responses.

- Ask participants whether they have seen similar situations in the clinical setting. Encourage those who answer in the affirmative to share their experiences.

- Project slides 2.13-2.14 that will highlight the meaning and aim of gender equity in health.

6. Conclude by telling participants that sometimes making decisions while providing health care may not be easy. However, when such decisions have to be made, the universal ethical principles of justice, respect and autonomy are useful guides in the process. It is also important to remain non-judgemental and non-discriminatory in the provision of care.

7. Request all participants to come with at least one question written on a slip of paper on module 2 .

- Ask participants to complete Worksheet 2.4 which is an evaluation of the module and to return it to you. 


\section{CONCLUSION}

Project slides 2.15-2.16, and highlight the key messages of the module. Encourage each participant to look for any paper cuttings that reflect gender issues, and bring it to the next class. You could read a few of the cuttings or paste it on a board in the class, so that all can read it.

\section{Adapted from source:}

- St. John's College of Nursing. 2005. Facilitators Manual-STI and HIV /AIDS; Prevention, Care and Support. Bangalore: KSAPS and ICHAP. 


\section{Worksheets}

Worksheet 2.1: Gender roles \& relationships matrix-Women

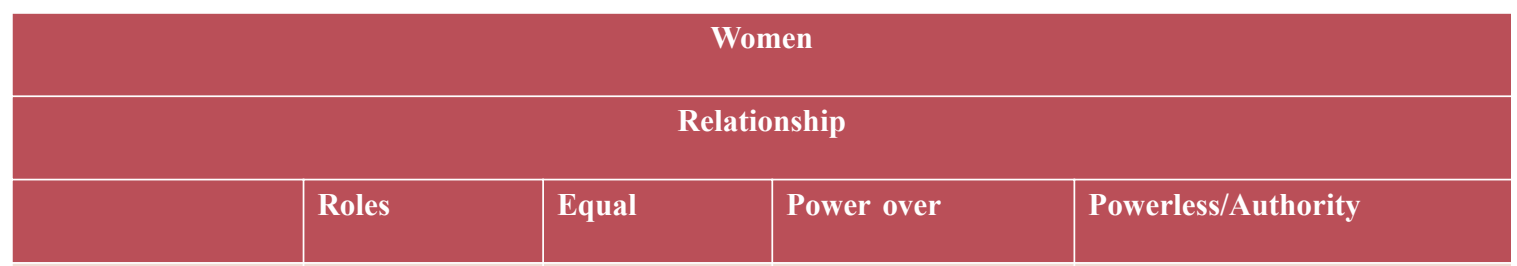

Home

Community

Organization 
Worksheet 2.1: Gender roles \& relationships matrix-Men

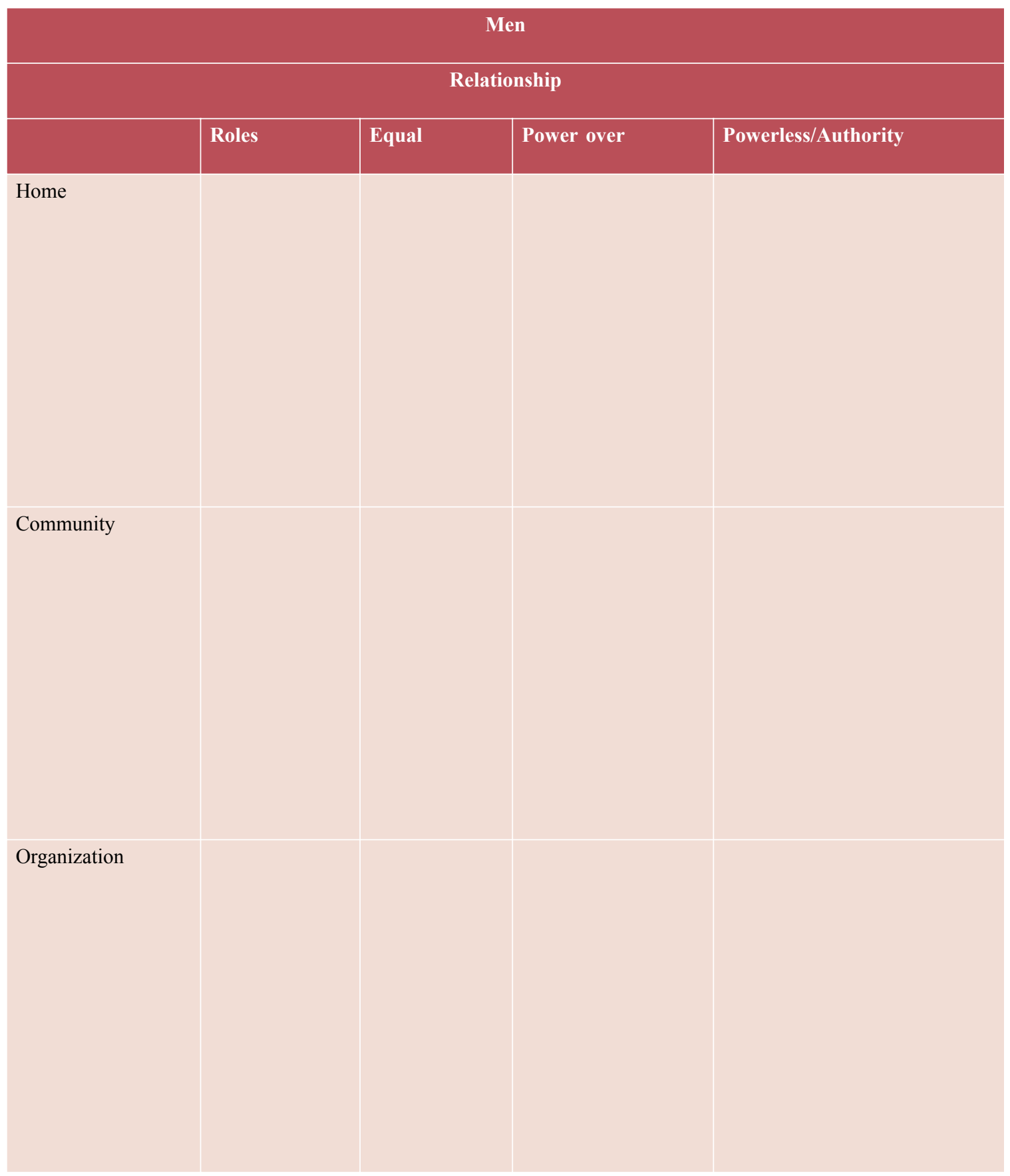




\section{Worksheet 2.2: Self reflection (Individual)}

What are your expectations and aspirations (dreams/ambitions) for yourself?

What are your family's and society's expectations of you?

What are some factors that may help you get your aspirations/expectations?

Why did you choose nursing? Do you think it had anything to do with your gender? 
Worksheet 2.3: Gender inequalities-How can I balance it in my personal and professional life?

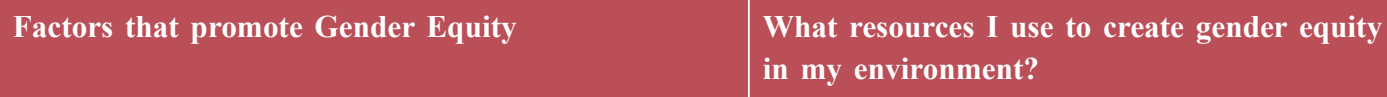

Develop positive identity and self-image

Create space for women to explore, speak and develop strength and build relationships

Mobilise and build collective identity

Support women in social leadership

Facilitate cultural change

Support women's personal autonomy and ability to resist abuse and violence

Improve economic security

Build institutional support

Increase access to political power 


\section{Worksheet 2.4: Review of the module}

Kindly take 5 minutes to complete the following and hand the paper over to me. You need not write your name anywhere but it is important to give me your response, since this will help me know whether this session was useful or not. You have the freedom to write your own thoughts in the space that is provided.

Write at least three things you learnt from the module:

Write down at least one thing you never thought of in relation to gender and sexuality:

What did you feel was not necessary for this module?

Write any three suggestions for this module: 


\section{Handouts}

\section{Handout 2.1: Gender and sex}

\section{What is the difference between the concepts 'Sex' and 'Gender'?}

\begin{tabular}{l|l}
\hline \multicolumn{1}{|c|}{ Sex } & \multicolumn{1}{c}{ Gender } \\
$\begin{array}{l}\text { Refers to the biological differences between } \\
\text { men and women. }\end{array}$ & $\begin{array}{l}\text { Gender refers to the socially constructed roles and responsibilities of } \\
\text { women and men in a given culture or location. }\end{array}$ \\
$\begin{array}{l}\text { These differences are generally universal } \\
\text { and unchanging. }\end{array}$ & $\begin{array}{l}\text { These roles are influenced by perceptions and expectations arising } \\
\text { from cultural, political, environmental, economic, social and religious } \\
\text { factors, as well as from custom, law, class, ethnicity and individual } \\
\text { or institutional biases. }\end{array}$ \\
& Gender attitudes and behaviours are learned and can be changed.
\end{tabular}

\section{What are some of the situations in which we see gender differences?}

\begin{tabular}{ll}
\hline Social differences & In perceptions of men's and women's social roles: \\
- The man is seen as head of the household and chief breadwinner \\
- While the woman is seen as nurturer and caregiver
\end{tabular}




\section{Why are gender roles not good for us?}

- Women feel less respected and less valued and have lower self-esteem.

- Women and men are discouraged from certain goals and career paths, e.g. for women - becoming a bus driver/ professor/occupying positions of authority over men; for men-becoming a nurse/kindergarten teacher/playing nurturing, care-giver roles.

- Women are made to feel useless without a man.

- Inheritance and property laws exclude women from access to family resources.

- Men feel pressure to "be strong," cannot show emotions or ask for support.

\section{Why have gender roles not changed?}

- They have developed over a long period-implicit in the structure of the laws.

- Culture takes a long time to change.

\section{How to overcome gender discrimination? The 5 E's}

- Education and building awareness about one's rights.

- Education of people and thus, removing ignorance.

- Economic independence for women.

- Empowerment of women through ability and authority to act.

- Engagement in issues where the rights have been violated-advocacy.

\section{Adapted from source:}

- $\quad$ Ahmed, A. and S. Menon. 2006. Rights and Desire-A Facilitator's Manual to Healthy Sexuality. New Delhi: Breakthrough.

- $\quad$ American Centre for International Labour Solidarity. 2007. "Module 2: HIV/AIDS, Gender and Sexuality-Trade Union Capacity Building”. HIV/AIDS Prevention and Care Project. USA: Solidarity Centre.

- $\quad$ Kim, J and M. Mosei. 2007. Sisters for Life-Gender and HIV Training Manual. Intervention with Micro enterprise or AIDS and Gender Equity (IMAGE) Study; Rural AIDS and Development Action; Research (RADAR) Program School of Public Health, University of the Witwatersrand. South Africa: Small Enterprise Foundation. 


\section{Handout 2.2: Gender roles}

The biological differences between men and women do not normally change; people are either male or female. However, the characteristics they are perceived to have, and the roles and responsibilities assigned to them, differ among societies, cultures and historical periods.

Gender roles are the activities ascribed to men and women on the basis of perceived differences. "Division of labour" is a term used in gender literature to mean the roles and tasks assigned to women and men on the basis of perceived gender characteristics and attributes, instead of ability and skills.

\section{Men's roles}

Today, as the world moves towards greater industrialization the lines of demarcation between men's and women's occupations have become fainter. However, when the world was less industrialized, all work that was not domestic or household related was considered the work of men. Since it was visible, recognition and productive value was given to it largely because it was men who did the work and were paid for it. To a large extent this differentiated practice continues. Even today the community management roles played by men are those that tend to involve political organization and leadership and therefore greater visibility—not community organization and social security networking, which continues to be considered the women's domain.

\section{Women's triple roles}

Women's roles in most societies fall into three categories: productive (relating to production of goods for consumption or income through work in or outside the home), reproductive (relating to domestic or household tasks associated with creating and sustaining children and family), and community management (relating to tasks and responsibilities carried out for the benefit of the community). Women must balance the demands of these three different roles and should be recognized for their contributions.

The tasks women usually perform in carrying out their different roles do not generally earn them an income. Women are often defined exclusively in terms of their reproductive roles, which largely concern activities associated with their reproductive functions. These reproductive roles, together with their community management roles, are perceived as natural. But because these roles do not earn income, they are not recognized and valued as economically productive. Women's contributions to national economic development are, therefore, often not quantified and remain invisible.

In many societies, women also carry out productive activities such as maintaining small holder agricultural plots in farming systems. These tasks are often not considered work and are therefore often unpaid. While women may also perform many roles which attract wages in both the formal and informal economic sectors, But women's economically productive roles, in contrast to men's, is often undervalued or given relatively little recognition.

Gender roles and responsibilities vary among cultures and can change over time. For example, in India, unskilled labour is considered "women's work" while in Africa it is "men's work". In Europe and the United States, the contribution men make to domestic activities is becoming increasingly important and visible. 


\section{Handout 2.3: Reproductive health and women's status}

Reproductive Health is a state of complete physical, mental and social well-being and not merely the absence of disease or infirmity, in all matters related to the reproductive system and to its functions and processes. People are able to have a satisfying and safe sex life and they have the capability to reproduce and the freedom to decide if, when and how often to do so. Men and women have the right to be informed and have access to safe, effective, affordable and acceptable methods of their choice for the regulation of fertility, as well as access to health care for safe pregnancy and childbirth.

\section{Adapted from Source:}

- $\quad$ CEDPA. 2000. Gender, Reproductive Health and Advocacy, Training Manual Washington DC: CEDPA.

\section{Status of women globally-A summary}

Women and Poverty

- $70 \%$ of the 1.2 billion people living in poverty are female

\section{Women as Workers}

- Women do more than $67 \%$ of the hours of work done in the world. But earn only $10 \%$ of the world's income and own only $1 \%$ of the world's property

- The value of unremunerated work was estimated at about \$16 billion, from which \$11 billion represents the invisible contribution of women

- Women are paid 30-40\% less than men for comparable work on an average

- $60-80 \%$ of the food in most developing countries is produced by women

- Women hold between 10-20\% managerial and administrative jobs

- Women make up less than $5 \%$ of the world's heads of state

\section{Women and Education}

- $60 \%$ of the 130 million children in the age group of 6-11 years who do not go to school, are girls

- Approximately $67 \%$ of the world's 875 million illiterate adults are women

\section{Women and Health}

- Women account for $50 \%$ of all people living with HIV/AIDS globally

- In the year 2000, there were 80 million unwanted pregnancies, 20 million unsafe abortions, and 5 lakhs maternal deaths. $99 \%$ of these cases were reported in developing countries

\section{Crimes against women}

Police records show high incidence of crimes against women in India. The National Crime Records Bureau reported in 1998 that the growth rate of crimes against women would be higher than the population growth rate by 2010. Earlier, many cases were not registered with the police due to the social stigma attached to rape and molestation cases. Official statistics show that there has been a dramatic increase in the number of reported crimes against women.

\subsection{Sexual Harassment}

Half of the total number of crimes against women reported in 1990 related to molestation and harassment at the workplace. Eve teasing is a euphemism used for sexual harassment or molestation of women by men. Many activists blame the rising incidents of sexual harassment against women on the influence of "Western culture". In 1987, the Indecent Representation of Women (Prohibition) Act was passed to prohibit indecent representation of women through advertisements or in publications, writings, paintings, figures or in any other manner. 
In 1997, in a landmark judgment, the Supreme Court of India took a strong stand against sexual harassment of women in the workplace. These commonly came to be known as the 'Vishakha Guidelines'. The Supreme Court's definition of sexual harassment includes 'such unwelcome sexually determined behaviour (whether directly or by implication) such as

- $\quad$ physical contact and advances;

- a demand for sexual favours;

- $\quad$ sexually coloured remarks;

- $\quad$ showing pornography;

- $\quad$ any other unwelcome physical, verbal or non verbal conduct of sexual nature'.

The Court also laid down detailed guidelines for prevention and redressal of grievances. The National Commission for Women subsequently elaborated these guidelines into a Code of Conduct for employers.

\subsection{Dowry}

In 1961, the Government of India passed the Dowry Prohibition Act, making the dowry demands in wedding arrangements illegal. However, many cases of dowry-related domestic violence, suicides and murders have been reported. In the 1980s, numerous such cases were reported.

In 1985, the Dowry Prohibition (maintenance of lists of presents to the bride and bridegroom) Rules were framed. According to these rules, a signed list of presents given at the time of the marriage to the bride and the bridegroom should be maintained. The list should contain a brief description of each present, its approximate value, the name of the person who has given the present and his/her relationship to the person. However, such rules are hardly enforced.

A 1997 report claimed that at least 5,000 women die each year because of dowry deaths, and at least a dozen die each day in 'kitchen fires' thought to be intentional. The term for this is bride burning and is criticised within India itself. Amongst the urban educated, such dowry abuse has reduced dramatically.

\subsection{Female infanticides and sex selective abortions}

India has a low sex ratio, the chief reason being that many women die before reaching adulthood. Tribal societies in India have a better sex ratio than all other caste groups put together, in spite of the fact that tribal communities have far lower levels of income, literacy and health facilities. It is, therefore, suggested by many experts, that the low sex ratio in India can be attributed to female infanticides and sex-selective abortions.

All medical tests that can be used to determine the sex of the child have been banned in India, due to incidents of these tests being used to get rid of unwanted female children before birth through the Prenatal Diagnostic Techniques Act (PNDT) 1994. Female infanticide (killing of girl infants) is still prevalent in some rural areas. The abuse of the dowry tradition has been one of the main reasons for sex-selective abortions and female infanticides in India.

\subsection{Domestic violence}

The incidents of domestic violence are much lower. The Act Against Domestic Violence is one of the most recent attempts of the government to safeguard the rights of women in their homes.

\subsection{Trafficking}

The Immoral Traffic (Prevention) Act was passed in 1956. However, many cases of trafficking of young girls and women have been reported. These women are either forced into prostitution, domestic work or child labour.

Every year, an estimated 4 million women and girls are bought and sold worldwide, either into forced prostitution, slavery or forced marriage.

About 45,000 to 50,000 women are trafficked annually to the United States.

An estimated 200,000 Bangladeshi women have been trafficked to Pakistan over the last 10 years, the majority are whom are young women. 
Between 5,000 and 7,000 Nepali girls are trafficked every year across the border to India. Most end up as sex workers in brothels in Bombay and New Delhi. An estimated 200,000 Nepali women, most of them girls under 18, are sex workers in Indian cities.

In Western Europe alone, about 500,000 women and girls from developing countries and countries with economies in transition are entrapped in the slave trade each year.

In the last 30 years, trafficking in women and children in Asia for sexual exploitation alone has victimised over 30 million people.

Girls as young as 13 (mainly from Asia and Eastern Europe) are trafficked as "mail-order brides". In most cases, these girls and women are powerless, isolated, and at great risk of violence.

Large numbers of children are being trafficked in West and Central Africa, mainly for domestic work but also for sexual purposes.

Nearly 90 percent of trafficked workers are girls, who work at less than subsistence wages in shops or on farms, or as scavengers and street hawkers. UNICEF estimates that every year trafficking of 1,000 to 1,500 Guatemalan babies and children occurs for adoption by foreign couples in North America and Europe.

Gender discrimination places girls at greater risk of being trafficked than boys. Girls are usually trafficked for their labour. Examples of exploitative and illegal work that trafficked girls are subjected to include: bonded sweatshop labour, forced prostitution, and domestic servitude.

\subsection{Rape}

There has been a eight fold increase of rapes cases in India since 1971. Overall the violent crimes under the IPC have actually declined. According to the latest report of the National Crime Review Board (NCRB), between 1971 and 2006 murder incidents just about doubled, kidnapping and abduction cases went up by 149\%, while cases of dacoity and rioting declined. In general, violent crimes showed a decline of $16 \%$ during the period. In this context, the seven times increase in rape cases is shocking.

\section{Other special concerns in women}

\subsection{Health}

The average female life expectancy today in India is low compared to many countries, but it has shown gradual improvement over the years. In many families, esp. rural ones, the girls and women face nutritional discrimination within the family, and are anaemic and malnourished.

The maternal mortality in India is the second highest in the world. Only $42 \%$ of births in the country are supervised by health professionals. Most women deliver with help from women in the family who often lack the skills and resources to save the mother's life, if it is in danger. According to UNDP's Human Development Report (1997), the proportion of pregnant women (age 15-49) with anaemia was found to be as high as $88 \%$.

\subsection{Family planning}

The average Indian woman has little control over her own fertility and reproductive health. Women, particularly those in rural areas, do not have access to safe and self-controlled methods of contraception. The public health system emphasises permanent methods like sterilisation, or long-term methods like IUDs that do not need followup. Sterilisation accounts for more than $75 \%$ of total contraception, with female sterilisation accounting for almost $95 \%$ of all sterilisations. 
Handout 2.4: Examples of factors which affect risk and vulnerability to HIV for men and women

\section{Men}

\section{Physiological and behavioural factors}

Lower physiological risk/vulnerability for men than women. High risk for men who have unsafe sex with men

Usually infected at later age $(>30)$

Having multiple sex partners is accepted or even the norm

\section{Socio-Cultural factors: Prevailing norms and expectations}

Sexual domination as image of manhood, sexual relations outside marriage

Emphasis on virginity, monogamy, modesty, motherhood as image of womanhood

Presumption of knowledge, which prevents Culture of silence on sexual matters - it is inappropriate to be aware seeking information, contraception or of sexuality or to suggest condom use treatment

Violence in combination with drugs/alcohol against women, men

Dealing and using (injected) drugs

Cultural practices: female genital cutting, ritual cleansing, widow inheritance, practice of "dry" sex

Socialising together with alcohol use

Imbalance of sexual power (including Not supposed to decide about their own body, having sex violence)

Lack of responsibility for own sexuality

Vulnerability to coerced sex, including rape and other sexual abuse - at home, school, workplace, in conflict situations

Stigma attached to HIV/AIDS discourages Stigma attached to HIV/AIDS discourages testing, knowledge sharing testing, knowledge sharing and leads to and leads to ostracism

ostracism

\section{Socio-Economic factors}

Economic power

Economic dependency/insecurity

Responsible for income generating, even at large distances

Responsible for reproductive tasks, including the burden of caring of ill relatives

Less or no responsible for caring

Control over resources

Legal rights

Less access to and control over economic assets, and fewer options for income/asset creation

Lack of legal recourse and discrimination in legal rights and protections, e.g. property grabbing

Male occupations involving mobility, migration Resort to sex work by migrant or refugee women or in case of and family disruption (e.g. truck driving, poverty/despair military)

\section{Adapted from source:}

- Africa Region Gender Team. 2001. The gender discriminations of HIV/AIDS: Putting gender on the MAP. (Working draft). Washington DC: World Bank. 


\section{Slides}

\section{Module 2 \\ Discovering who am I? \\ Basic concepts-Gender}

\section{\#2.3}

What is Sex? What is Gender?

That which is obviousbiological characteristics of being male or female
That which is socially learnt and considered to be male or female behaviours or roles

Activity 2.1

Review Handouts 1.11.2 in Module 1

\section{\#2.4}

\section{Why Talk about Gender?}

- It brings the context of unequal relations between the sexes (male / female / third sex)

- It affects all walks of life

- It has implications on development, sexuality, health and health care services

\section{\#2.5}

\section{Differences in Concepts}

Sex and Gender

SEX

- Biological

- Universal

- Born with

- Generally unchanging

- Does not vary GENDER

- Socially made

- Cultural

- Learned

- Changes over time

- Varies within and between cultures
\#2.6

Remember

Gender is not just 'Sex'

\section{Gender is not just 'Women'}

Review Glossary of Terms Identify terms that are relevant to gender Come with a question each / Quiz for next class Activity 2.2 Worksheet 2.1 


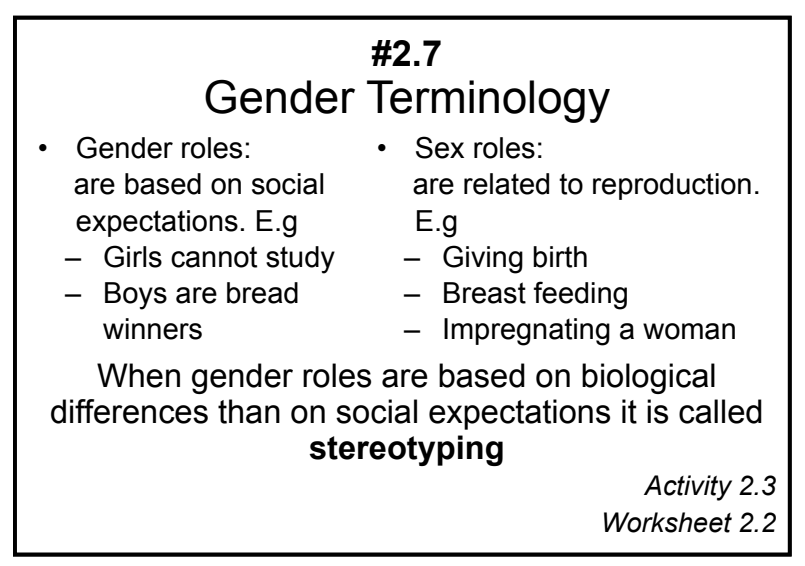

Activity 2.6 Video clippings on $C D$

\section{\#2.9} Gender and Sexuality

- Issues that may arise

- Trafficking

- Rape

- Sexual harassment (more with women and transgenders)

- Sexual abuse (all genders)

- Female foeticide/infanticide

- Domestic violence

\section{\#2.8 Gender Discrimination}

- Gender discrimination is

- The unequal or unfair treatment of men or women

- Based solely on the biological aspects-sex

- Gender discrimination does not consider the individual skills, talents, and capabilities.

Activity 2.4

\begin{tabular}{|c|c|}
\hline $\begin{array}{l}\text { Gender and } S \\
\text { - Inadequate } \\
\text { information } \\
\text { - Early marriage } \\
\text { - Lack of experience } \\
\text { of pleasure } \\
\text { - Stigma and } \\
\text { discrimination* } \\
\text { - Violence* } \\
\text { * This could refer to women } \\
\text { intersex etc. }\end{array}$ & $\begin{array}{l}\text { Tality__impact } \\
\text { - Lack of self esteem } \\
\text { - Emotional problems } \\
\text { - Stress } \\
\text { - } \text { Not able to access } \\
\text { - health care } \\
\text { - HIV risk } \\
\text { - STI/STD risk } \\
\text { nsgender, cross-dressers, }\end{array}$ \\
\hline
\end{tabular}

\section{\#2.10}

\section{Gender and Sexuality-Relationship}

- Government programs: Family planning program initially focused on women-sterilisation

- Media: Women only have bodies and are vehicles of pleasure

- Laws and regulations: Affects the way sexuality is controlled-number of children / Laws against homosexuality (Sec 377 )

- Societal influences: Emphasis of society on 'natural'/ 'straight' relationships

- Discrimination against homosexuals, bisexuals, hijras, intersex, etc. 


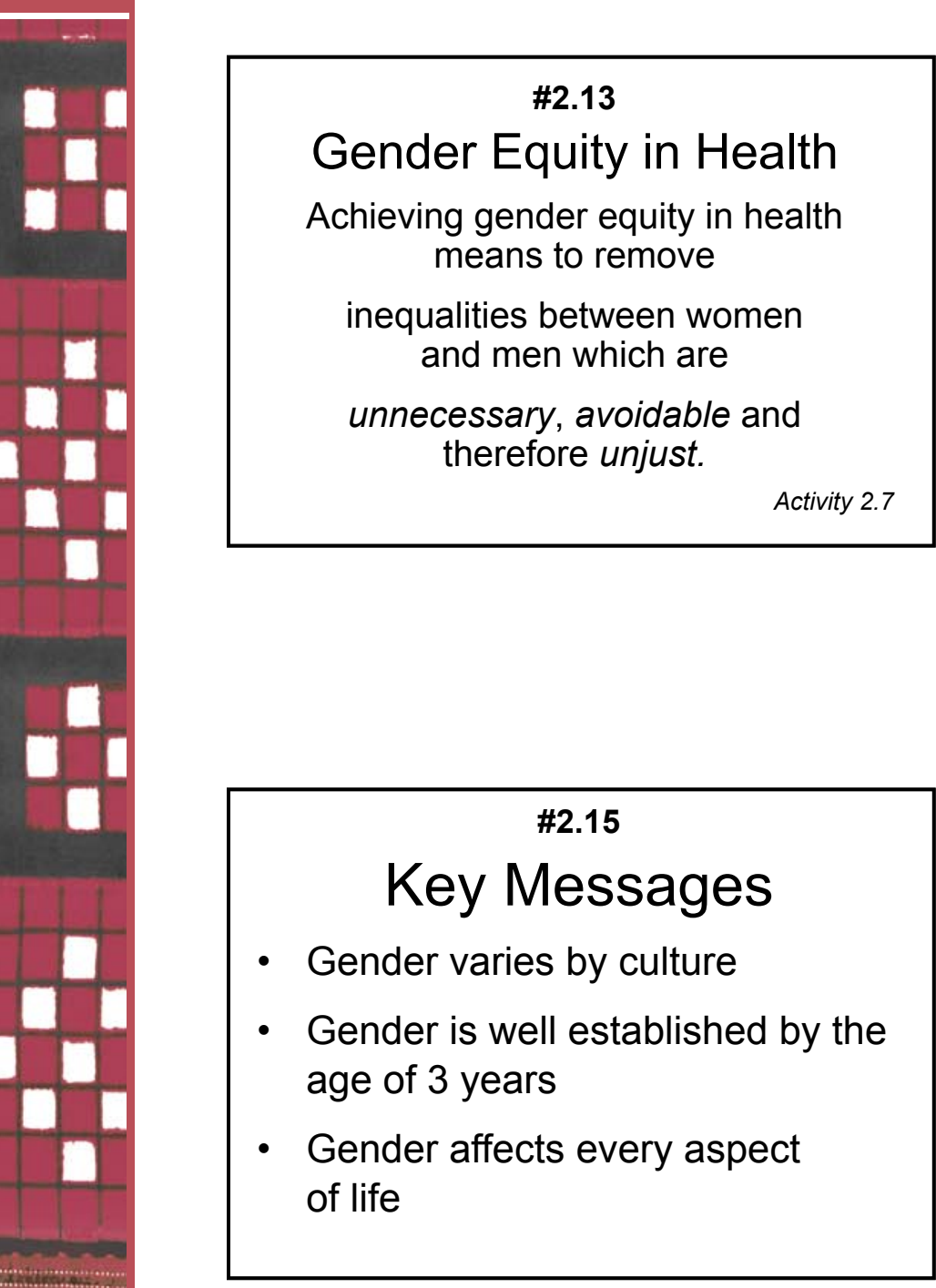

\section{\#2.14}

\section{Aim: Gender Equity in Health}

- All have equal rights

- To enjoy good health

- To participate in health related activities and production of health

- To have equal access to health care services 


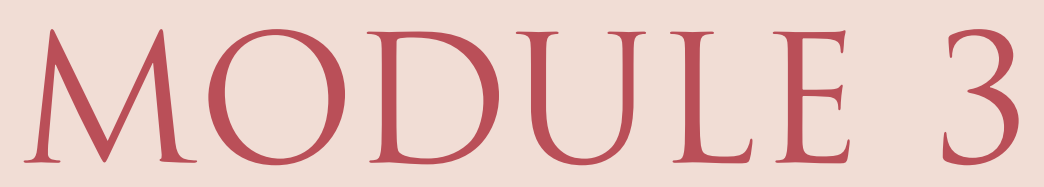

\author{
KNOWING MY RIGHTS-SEXUAL AND \\ REPRODUCTIVE HEALTH AND RIGHTS
}




\title{
Facilitators guide
}

\section{Content Considerations}

1. Review basic human rights and help participants put sexual and reproductive health rights within the context of human rights.

2. Explore with participants through case scenarios how skills, such as, effective decision making, feelings of self worth, positive relationships and problem solving can be fostered.

3. Bring out the predominant cultural values around sexual behaviour. Remember that the main purpose is to help participants clarify their own values.

4. Consider providing basic information about sexual concerns and dysfunctions. Many of the most common are related to sexual pleasure. Address both the positive and negative aspects of sexual relationships. The positive aspects include the experience of intimacy, pleasure, caring, loving, and getting pregnant if desired. While the negative aspects that need to be addressed include sexual violence, infections (e.g. STIs, HIV), unwanted pregnancy and abortion.

5. Make use of the anonymous question box to solicit and answer participants' specific questions.

\begin{abstract}
Aim
At the end of this module, participants will understand the dimensions of sexual and reproductive health and rights; appreciate and demonstrate skills in addressing these issues with themselves, their peers, colleagues and their clientele.
\end{abstract}

\section{Objectives}

By the end of the module, participants will

1. List sexual and reproductive health and rights within the framework of human rights.

2. Discuss the positive aspects of sexual relationships.

3. Explore various issues concerning sexual relationships, including unprotected sex.

4. Examine one's views with regards to abortion, use of contraceptives, STIs and HIV.

5. Analyse case scenarios with regards to sexual relationships and sexual and reproductive health.

\section{Duration: 8 hours}

\section{Key Messages}

- Sexual and reproductive health can be influenced by gender.

- Healthy and equal relationships could reduce the risk of physical abuse, forced sex, unwanted pregnancy, STIs and HIV.

- Gender also requires a discussion of rights. Inequality between the sexes often limits girls' and women's access to information and health services, depriving them of their right to control their bodies and to decide on matters related to sexuality and fertility. Gender discrimination can also generate and perpetuate sexual violence, forced marriage, and harmful practices that may affect the sexual and reproductive health of a person.

- Introspection and recognition within the group of individual attitudes and perceptions towards sexual violence, abortions and use of contraceptives, could help young professionals be open to the variations that exist amongst and within their own as well as in other groups/communities.

- A healthy individual is a product of physical wellness and has the mental and emotional skills and strength needed to know, develop and maintain good and healthy relationships. 
Module 3: Topic, time, activity/method and resources needed

\begin{tabular}{|c|c|c|c|}
\hline Topic & Time & Activity/Method & Resources Needed \\
\hline Introduction & 5 minutes & & $\begin{array}{l}\text { - } \text { Black/white board or flip chart or } \mathrm{OHP} / \mathrm{LCD} \\
\text { projector } \\
\text { - Chalk/marker pens/OHP transparencies } \\
\text { - Slides } 3.1-3.2\end{array}$ \\
\hline $\begin{array}{l}\text { Human Rights } \\
\text { review }\end{array}$ & 20 minutes & $\begin{array}{l}\text { Activity } 3.1 \text { : Review } \\
\text { of human rights with } \\
\text { case scenarios } 3.1-3.3\end{array}$ & $\begin{array}{l}\text { - } \text { Black/white board or flip chart or OHP/LCD } \\
\text { projector } \\
\text { - Chalk/marker pens/OHP transparencies } \\
\text { - Duster } \\
\text { - Handout } 3.1 \\
\text { - Slides } 3.3-3.4\end{array}$ \\
\hline \multirow[t]{2}{*}{$\begin{array}{l}\text { Sexual Health and } \\
\text { Rights }\end{array}$} & 10 minutes & $\begin{array}{l}\text { Activity } 3.2 \text { : Sexual } \\
\text { health discussion- } \\
\text { meaning and rights }\end{array}$ & $\begin{array}{l}\text { - } \text { Black/white board or flip chart or OHP/LCD } \\
\text { projector } \\
\text { - Chalk/marker pens/OHP transparencies } \\
\text { - Duster } \\
\text { - Handout } 3.2 \\
\text { - Slides } 3.5-3.10\end{array}$ \\
\hline & 90 minutes & $\begin{array}{l}\text { Activity } 3.3 \text { : Sexual } \\
\text { health-analysis } \\
\text { of case scenarios, } \\
\text { worksheets, self } \\
\text { reflection and role } \\
\text { plays }\end{array}$ & $\begin{aligned} & \text { - } \text { Black/white board or flip chart or OHP/LCD } \\
& \text { projector } \\
& \text { - Chalk/marker pens/OHP transparencies } \\
& \text { - Duster } \\
& \text { - Worksheet } 3.1-3.4 \\
& \text { - Handout } 3.3-3.4 \\
& \text { - Trigger tapes-ITECH mentoring tool kit } \\
& \text { - DVD player } \\
& \text { - Speaker } \\
& \text { - Review of Incomplete story-second part } \\
& \text { (Worksheet } 2.1 \text { that you had collected) } \\
& \text { - Slide 3.11-3.3.16 }\end{aligned}$ \\
\hline \multirow[t]{2}{*}{$\begin{array}{l}\text { Reproductive } \\
\text { Health and } \\
\text { Rights }\end{array}$} & 60 minutes & $\begin{array}{l}\text { Activity } 3.4 \text { : } \\
\text { Reproductive health } \\
\text { issues - my views on } \\
\text { contraception }\end{array}$ & $\begin{array}{l}\text { - } \text { Black/white board or flip chart or } \mathrm{OHP} / \mathrm{LCD} \\
\text { projector } \\
\text { - Chalk/marker pens/OHP transparencies } \\
\text { - Duster } \\
\text { - Worksheet } 3.5-3.6 \\
\text { - Review Handout } 3.2 \\
\text { - Handout } 3.5 \\
\text { - Slide } 3.17-3.20\end{array}$ \\
\hline & & $\begin{array}{l}\text { Activity } 3.5 \text { : } \\
\text { Reproductive health } \\
\text { issues-contraception } \\
\text { and safe pregnancy }\end{array}$ & $\begin{aligned} \text { - } & \text { Black/white board or flip chart or } \mathrm{OHP} / \mathrm{LCD} \\
& \text { projector } \\
\text { - } & \text { Chalk/marker pens/OHP transparencies } \\
\text { - } & \text { Duster } \\
\text { - } & \text { Worksheet } 3.7 \\
\text { - } & \text { Review Handout } 3.4 \text { when } \\
& \text { doing role plays }\end{aligned}$ \\
\hline
\end{tabular}


Cont'd $\ldots$

\begin{tabular}{|c|c|c|c|}
\hline & 40 minutes & $\begin{array}{l}\text { Activity } 3.6 \text { : } \\
\text { Reproductive health } \\
\text { issues-safe abortion }\end{array}$ & $\begin{array}{l}\text { - } \text { Black/white board or flip chart or OHP/LCD } \\
\text { projector } \\
\text { - Chalk/marker pens/OHP transparencies } \\
\text { - Duster } \\
\text { - Worksheet } 3.7 \text { to continue } \\
\text { - Worksheet } 3.8 \\
\text { - Handout } 3.6-3.7 \\
\text { - Slides } 3.21-3.22\end{array}$ \\
\hline & 30 minutes & $\begin{array}{l}\text { Activity } 3.7 \text { : } \\
\text { Reproductive health } \\
\text { issues-STIs/HIV }\end{array}$ & $\begin{aligned} & \text { - } \text { Black/white board or flip chart or OHP/LCD } \\
& \text { projector } \\
& \text { - } \text { Chalk/marker pens/OHP -transparencies } \\
& \text { - } \text { Duster } \\
& \text { - } \text { Worksheet } 3.9 \\
& \text { - Handout } 3.8 \\
& \text { - Slides 3.23-3.24 }\end{aligned}$ \\
\hline Summary & 10 minutes & $\begin{array}{l}\text { Activity } 3.8 \text { : You are } \\
\text { precious }\end{array}$ & $\begin{array}{l}\text { - Glass } \\
\text { - Box of dot pins } \\
\text { - Bottle with water } \\
\text { - LCD projector } \\
\text { - Rings of participants that must be returned } \\
\text { - Worksheet } 3.10 \\
\text { - Slides: } 3.25-3.26\end{array}$ \\
\hline
\end{tabular}

\section{Introduction: Slide 3.1-3.2}

This module attempts to cover the most important issues with regards to sexual and reproductive health. Inform participants that while several sexual and reproductive health issues will be covered in the regular curricula, the focus in this module is to contextualise these issues within the present socio-cultural demands and understand its impact on the overall well being of an individual. The module also focuses on increasing the individual's awareness of her/his own perceptions towards these issues, with the assumption that it will aid in openness to differences and foster acceptance of these differences.

It is important that you are aware of your own perceptions on these issues and are able to present them in a neutral manner. Also make sure that you emphasise the main principles of respect, autonomy and justice.

Project slide 3.2 and list the objectives of the Module. 


\section{A. HUMAN RIGHTS REVIEW}

Note for Facilitators: Activity 3.1

Activity 3.1 will sensitise the participants to various human rights, which could then be used to introduce the concept of sexual and reproductive health rights. The purpose of the three case scenarios which form part of the activity is to help participants reflect on human rights that are likely to be violated on a daily basis. This could help them get familiar with at least some of the commonly addressed human rights violations. Draw the attention of participants to the fact that sexual and reproductive health and rights could be an underlying or an unspoken agenda when these rights are violated as is seen in the case scenarios presented for discussion.

\section{Activity 3.1: Review of human rights with case scenarios}

Purpose: The participants will

- Discuss the most common Human Rights.

- Describe how human rights could be violated in day to day situations.

- $\quad$ Link sexual and reproductive health rights with human rights.

\section{Materials}

- Black/white board or flip chart or OHP/LCD projector

- Chalk/marker pens/OHP transparencies

- Duster

- $\quad$ Slides 3.3-3.4

- Handout 3.1

\section{Process:}

1. Project slide 3.3 (the slide is animated) and brainstorm with these questions:

- What is the meaning of 'needs' and 'rights'? Do you think there are any differences between them?

- What are some of the human rights you know of?

- Wait for responses and write them on the board/flip chart. Reaffirm that sexual and reproductive health is a human right.

- $\quad$ Explain how human rights are developed as given in Slides 3.3-3.4.

- Human Rights refer to those rights which accrue to an individual by virtue of being born as a human being. They are essential for living a life with dignity and self respect, for self development, to create one's own identity and to be treated with equality.

- They are universal, inherent and intrinsic; based on being born human; inalienable (cannot be taken away); indivisible (equally enjoyed) and non hierarchical. The State has an obligation to respect, protect and fulfil rights.

- Needs refer to the need for shelter, food, clothing, education, health, work, security, liberty, decision making, expression, security and love.

- We need to recognise need to fulfil rights. In talking about needs, no one is duty bound to fulfil them. But in rights there is a core content which details out the minimum needs that need to be fulfilled to be able to live with dignity.

- Give them Handout 3.1. This contains a list of some of the human rights but not all of them.

2. Ask participants to sit in groups of 6-8. Tell them that you will be reading aloud three case scenarios one by one and discussing them in the context of human rights. The case scenarios are given in Box 3.1. Participants should refer to the Handout 3.1 while the case scenarios are being discussed. Read the first case scenario, and ask participants the 
questions given after the case scenario. Possible responses for the questions are given within parentheses. Wait for responses from the participants and facilitate any discussion on this. Do the same for the next two case scenarios.

3. Conclude by saying that sexual and reproductive health is also a human right.

\section{Box 3.1: Case scenarios for Activity 3.1}

1. Case scenario: Hari is 25 years old and is from a remote village. He discovered that he was HIV+ 3 years ago. He was seeking treatment in one clinic near his home. One day when he went to the clinic, the clinic was closed and a notice said that it had shifted. Hari asked his friend about the clinic and told him the reason why he wanted to go to the clinic. The next day at work, he was called in by his boss and told to leave the job.

\section{Discussion questions:}

- Why do you think the boss threw him out of the job? (Possible responses: HIV status, fear that HIV would spread, ignorance about HIV and its modes of transmission)

- What assumptions were made about Hari? (Possible responses: Bad character that would spoil others)

- What rights of Hari are being violated? (Possible responses: Social security, right to live, right to a job, right to access to health care etc.).

- What do you think he could do? (Possible responses: Get help-lawyers consortium/social organization to help him get his job back etc.).

2. Case scenario: Rita is 25 years. She lives in a community that believes that women must be married at 18 years and not work. With a friend, she leased a single room apartment, owned by a bank manager. She feels she could apply for a house loan at the same bank where her landlord works. The bank manager tells her that she cannot apply for a loan unless she shows that she is married.

\section{Discussion questions:}

- What did the bank manager assume about Rita? (Possible responses: She is modern, she is not yet married, something is wrong with her etc.).

- What are her rights? (Possible responses: Right to freedom from discrimination, fair public hearing, adequate standard of living).

- What do you think she could do? (Possible responses: Get help, be aware of her rights: if she shows capacity to pay back the loan then she cannot be denied a loan).

3. Case scenario: One of your friends says that she has met someone and is really excited that she is going to be married. Six months after the wedding, she came to the hospital with a fracture and lot of bruises. On seeing her you suspect that something is wrong. She is no longer the carefree person you knew her to be during her engagement period and you learn that the fracture was not an accident but was done intentionally by her spouse.

\section{Discussion questions:}

- What issues could be addressed here? (Possible responses: Forming intimate relationships, sexuality, sexual violence and sexual rights).

- What do you think you could do for her? (Possible responses: Seek professional help, counseling for both, link her to others/support groups, make her aware of her rights, help her recognize signs of unhealthy relationships). 


\section{B. SEXUAL HEALTH AND RIGHTS}

Note for Facilitators: Activity 3.2-3.3

Activity 3.2 will help to review the meaning of Sexual Health and Sexual Rights. Allow enough time for participants for discussion on sexual rights to facilitate participants understanding. Encourage them to ask questions.

Activity 3.3 consists of several case scenarios that build up into a story, to build awareness on sexual health and bring into context the various challenges in a relationship. Participants are likely to ask for your opinion so remember to check your own perceptions on these issues before you take the session. It is important, however, that participants develop their own opinions on each of the case scenarios. Avoid giving them any ready-made answers. Encourage them to reflect on what their own responses would be to these issues. Make them aware that knowing the range of opinions that exist in the room could help them address these issues more openly with their clientele.

Remember to take time to complete all activities since one flows into the next. The activities would help in informing participants about the subject and in introspecting on their views and reactions in similar situations. Review with participants what is expected of them when they enact a role play.

\section{Activity 3.2: Sexual health discussion—meaning and rights}

Purpose: The participants will

- Explore the concept of sexual health.

- Become aware of the various sexual rights.

- Gain contextual information on sexual rights through review of case scenarios.

\section{Materials:}

- Black/white board or flip chart or OHP/LCD projector

- Chalk/marker pens/OHP transparencies

- Duster

- $\quad$ Slides 3.5-3.10

- $\quad$ Handout 3.2

\section{Process:}

1. Project slide 3.5. The slide is animated. Brainstorm "What is the meaning of sexual health?" Wait for responses and then highlight the meaning of sexual health.

2. Discuss the key elements of sexual health and what we need to fulfil each of these elements (slides 3.6-3.8).

3. Project slide 3.9-3.10 and list the Sexual Health Rights. Reinforce that sexual health is a basic human right. Ask participants to introspect and check whether they feel these rights have been their rights too.

4. Read the third case scenario that was used in Activity 3.1 again to discuss sexual rights. Ask them "Which sexual health rights were violated for your friend, as given in the case scenario?"

5. Distribute Handout 3.2. Tell them that it contains the same information on sexual health, as was projected.

6. Conclude by asking them whether they have any questions on these issues. Remind them of the anonymous question box that is available to ask any questions they want. 


\section{Activity 3.3: Sexual relationships in the context of sexual health and rights}

Purpose: The participants will

- Explore the various aspects of relationships.

- Become aware of the differences in approaches according to gender, as well as, based on their own cultural backgrounds.

- Explore the purposes of sexual relationships.

- Identify common behaviours that signal an unhealthy relationship.

- Determine what they would do if they were confronted with a partner's behaviours that warn of problems in the relationship.

- $\quad$ Practice skills for helping a friend end an unhealthy relationship.

\section{Materials:}

- Black/white board or flip chart or OHP/LCD projector

- Chalk/marker pens/OHP transparencies

- Duster

- $\quad$ Worksheet 3.1-3.4

- $\quad$ Slides $3.11-3.16$

- $\quad$ Handout 3.3-3.4

- Trigger tapes-ITECH Mentoring tool kit

- DVD player

- $\quad$ Speaker

\section{Process:}

1. Ask participants to form small groups of 6-8 members-preferably of the same sex. Ask them to analyse each part of the case scenario (3.1a-3.1c) and respond to the questions given in Worksheet 3.1. Give them 10 minutes for the exercise.

2. Call the first group coordinator to read the case scenario 3.1a and the questions aloud for all to hear. Then invite participants to respond to the questions based on their group discussion. Write the responses on the board/OHP transparency/flip chart for all to see. In all probability you may get different responses from each group. Highlight this to participants.

3. Complete the next two parts of the case scenario (3.1b-3.1c) in a similar manner. Then:

- Distribute and review Worksheet 3.2 with the participants. Highlight that healthy relationships have codes of behaviour. The behaviours mentioned in Worksheet 3.2 are all unhealthy, but it is important to recognise the response of either partner to them. The partner's response could be either of the following: 'do nothing'; 'discuss the behaviour/try to change the behaviour'; or 'end the relationship'. Inform participants that the purpose of giving them this worksheet is for them to become aware of behaviours that signal an unhealthy relationship. The most ideal way to handle the relationship would be to 'discuss the behaviour/try to change the behaviour'. However if the two do not see any way to repair the relationship, the next alternative would be 'end the relationship'. The option 'do nothing' would not help in building a healthy relationship.

- Ask participants to answer the question:

- What do you think of Raju and Seema's relationship.

- Is it healthy or unhealthy?

- Why would you say it is healthy or unhealthy?

(Appropriate responses: It is an unhealthy relationship because Raju did not show respect to Seema's decision about where the relationship should move. He made fun of her and was indifferent to her. Seema herself was 
not able to discuss and resolve the indifference shown by Raju. Instead she continued the relationship probably due to the fact 'they seemed the ideal couple of the campus!')

4. Reiterate the characteristics of a healthy relationship as given in slide 3.11. Divide the participants into three main groups. Give them possible role plays they could do (See Box 3.2) and leave the choice of actors for the role play to the group.

5. Then discuss the last part of the case scenario $3.1 \mathrm{~d}$ in the same manner that the previous case scenarios were discussed. Refer to Handout 3.2 on sexual rights to aid in the discussion.

6. Distribute Worksheet 3.3 and ask them to complete it individually and then in groups. The purpose of the Worksheet is for them to introspect on their own values and perceptions on sexual intercourse. After 10 minutes:

- Read out and ask participants the questions given in Worksheet 3.3 (see Box 3.3). Possible responses for the questions are given in parenthesis after each question. Encourage responses and remind participants of the ground rules.

- $\quad$ Refer to Slide 3.11 which highlights some important aspects of forming a sexual relationship.

\section{Box 3.2: Role plays that participants could enact to demonstrate how they could repair or end a relationship}

1. Role play: A 15-year-old high school girl has been in a relationship with a 20-year old college student for five months. Last night he made a joke about her being young and revealed he's cheating on her at college.

The characters: the 15-year-old girl and her two high school friends

2. Role play: A 17-year-old girl tells her cousin brother and aunt about the 18-year-old guy she has been going out with. She tells them that of late he demands to know where she is all the time and yells at her whenever he finds her talking with other guys.

The characters: the 17-year-old girl, her 18-year-old cousin brother, and her 36-year-old-aunt.

3. Role play: A 17-year-old guy met a 44-year-old man at a restaurant 4 months ago. This man is very popular, handsome, and has a reputation for being with young men. He has just asked the 17-year-old to come live with him.

The characters: the 17-year-old guy and two other gay friends

\section{Adapted from source:}

- Irvin, A. 2004. Positively Informed-Lesson Plans and Guidance for Sexuality Educators and Advocates. New York: International Women's Health Coalition(IWHC).

\section{Box 3.3: Discussion questions as given in Worksheet 3.3}

1. What are the best reasons for having sexual intercourse? What are the best reasons for waiting or deciding not to have sexual intercourse?

(Possible responses: Being able to feel good about oneself, being assertive, possibly not being so popular and combating peer pressure).

2. Can someone who has decided to wait change his/her mind? Why? What about the reverse: can some one who has previously had sexual intercourse decide to stop for now?

(Possible responses: Introspection, priorities change, peer pressure, wanting to be like others).

3. What would happen to someone who says he/she wants to wait? What does someone need to know if he/she is going to say no to intercourse?

(Possible responses: Knowledge about sexual and reproductive health, how to make decisions, problem solving, communicate assertively, know one's values and what is important to them, being unpopular, etc.). 
7. Reiterate that it is ideal that decisions on sexual relationships be made collaboratively so that the rights of a person are maintained. Distribute handout 3.3 that shares tips on decision making in sexual relationships (Slide 3.12).

8. Distribute handout 3.4 to participants to read about the facts of adolescence. Inform them that:

- One of the main reasons for this Module is to make them aware of the challenges that young people and adolescents face.

- That $21.4 \%$ of the population of India is between the ages $10-19$ years and more than $30 \%$ of people infected with HIV are in the age bracket $15-30$ years.

- As young health professionals they could do a lot to enhance the awareness among young people and adolescents about sexual and reproductive health issues, and thus help in creating a healthy population.

9. Project slide 3.13 and brainstorm, "When could sexual violence occur in a relationship? What forms of sexual violence are you aware of?" Link their responses to those they gave for the questions in case scenario 3.ld. Then list the various forms of sexual violence as given in slide 3.14.

10. After this, ask the participants the question given below and write their responses on the board:

- "If Seema approaches you as she is your neighbour and knows you are studying to be a nurse, what information will you collect from her?"

11. Tell participants that you will show them a video/enact role plays that demonstrate the communication skills needed while addressing sensitive issues. Show them the Trigger tapes (ITECH-Mentoring Toolkit) on provider centred and client centred assessment. You will require a DVD player. Alternatively, if you are not able to use the video, then enact the same as a role play with another facilitator. It is advisable to review the DVD so that you are prepared for the role play. The guidelines for the role play are given in Box 3.4:

- Divide the participants into 2 groups based on their seating arrangements.

- Show the first video/enact the role play. Get a feedback from the participants of the first group immediately. Tell them to focus on the communication.

- The second groups members are then invited to comment on the second video/the role play.

- Both groups are asked to focus on the communication between the characters in the film/play.

12. Project slide 3.15 that gives them key points to be observed when addressing the sexual health of a client. Inform participants that when collecting sexual history from a client it is important they follow certain guidelines. Hence, you will be projecting a video to highlight these.

13. Slide 3.16 focuses on the main points to keep in mind when assessing the sexual and reproductive health of a client. (For further information refer online or to International Planned Parenthood Federation and WHR Trainers' Guide in Sexual Health: Chapter 1: Counseling).

14. Remind participants that when they collect sensitive information from their clients, it is important they still maintain the same principles of :

- Respect: the dignity of the person-maintain confidentiality.

- Autonomy: self determination - ability to make decisions after being provided with all the information possible.

- Justice: fair treatment - being non-judgmental and unbiased when providing care to the client, even if the clients perceptions, behaviours and values differ from yours. 


\section{Box 3.4: Role play to be enacted by two facilitators demonstrating provider centred and client centred sexual health assessment}

1. Role Play: An 18 year old girl comes to visit the community health nurse in the PHC. The nurse is busy on the phone and recording something. The girl tells the nurse hesitantly that she has a headache. The nurse tells her she will give her a tablet (Paracetamol). The nurse receives a phone call, and immediately attends to it and while talking on the phone the nurse looks at the girl and asks her, "Any other problems?" After that the girl says, "I have some discharge down there (vaginal discharge)". The nurse immediately starts bombarding her with questions such as "When did you have sex last? How many partners have you had in the last three months? Did you use condoms? Don't you know you have an STI (without even examining her)? Does your mother know you have sex?" The nurse concludes by telling her, "If I were you, I would not be doing this. You have more important things to do." The girl appears worried and answers in monosyllables. During the whole process the nurse is distracted with phone calls, does not maintain eye contact, appears to be in a hurry and always seems to be recording something in some document.

2. Role Play: The situation is the same. An 18 year old girl comes to visit the community health nurse. The nurse is busy on the phone and is recording something. The girl tells the nurse that she has a headache. The nurse first greets the girl and then tells her she will give her something for it. Then the nurse says, before that do you have any other problems/concerns. The girl then hesitatingly mentions that she has white discharge. The nurse tells her she will examine her, but would need to find out more information from her before that. She goes through the same list of questions to be asked when eliciting the sexual concerns of a client given below:

- What are your main concerns (prioritize according to client's perception)? Do you have any other problems? Which is most important for you right now?

- Are you sexually active? If yes, what behaviors are presently practiced?

- What do you know about HIV or STIs? Do you know how you could prevent these?

- Where do you live? Who can you go to for help? What are you presently doing? (support systems for the person)

- If you have had any problems before how have you solved them?

- What do you know about your partner/s?

- Any history of ulcers/warts/abnormal discharge/swelling/pain in the past 3 months - STI?

- $\quad$ Does he/she use condoms? If no why?

15. Give participants Worksheet 3.4-which is a questionnaire that encourages self reflection. It will help them identify their own attitudes and values on sexual health. Ask participants to go through it individually. The first section of questions is focused on sexual relationships and the second section of questions focuses on the use of contraceptives. Then initiate a discussion on the first two questions in Worksheet 3.4 using the questions given below:

- What are some ways that a typical client might answer these questions?

- In your community, how might men's answers differ from women's?

- Might young adults answer these questions differently from older adults?

- Which answers or opinions might cause conflict or controversy among wives and husbands, parents and children, students and teachers, or other key groups in the community?

16. Conclude by enquiring whether they have any questions. Remind them about the question box that is available. If no questions are forthcoming ask participants to read the Handouts and let them know you will clarify any doubts in the next class. 


\title{
C. REPRODUCTIVE HEALTH AND RIGHTS
}

\author{
Note for Facilitators: Activity 3.4-3.5
}

Tell participants that you will be discussing reproductive health issues such as contraception in Activity 3.4 and 3.5. While they are most likely already well informed about contraception by nature of their work, this activity is about making them sensitive to their own perceptions about this issue. This is to help them manage clients who may ask questions that are challenging, effectively and appropriately.

Activity 3.4 is a series of small activities such as introspection, self examination, and open discussion. It is assumed that these activities will help participants become sensitised to their own ideas and attitudes towards contraceptives.

Activity 3.5 is role plays that focus on situations where contraception and/or safe pregnancy will have to be addressed. Share guidelines on doing a role play with the group and encourage them to participate actively in this activity, as it would help them know how to handle such situations in real life. The Handouts are a useful source of for information on the topic.

\section{Activity 3.4: Reproductive health issues-My views on contraception}

Purposes: The participants will

- Define reproductive health.

- List the reproductive health rights.

- Examine own perceptions of contraception.

\section{Materials:}

- Black/white board or flip chart or OHP/LCD projector

- Chalk/marker pens/OHP transparencies

- Duster

- Worksheet 3.5-3.6

- $\quad$ Slides 3.17-3.20

- $\quad$ Review Handout 3.2

- $\quad$ Handout 3.5

\section{Process:}

1. Project slide 3.17. Review with participants the meaning of reproductive health. Project slide 3.18 and ask one Group Coordinator to read out the Reproductive Health Rights. The rights are also given in Handout 3.2.

- As the Rights are being read, encourage participants to check whether they feel they could genuinely claim all or any of them

o The Right to decide whether to marry, and to decide if, when and how many children to have

o The Right to well being through life, for all matters relating to the reproductive system

o The Right to a responsible, healthy, safe and satisfying sex life

o The Right to unrestricted access to information in order to make informed choices

o The Right to have available safe, effective, affordable and acceptable family planning methods of choice

o The Right to safe pregnancy and birth

o The Right to be free from sexual violence and assault

o The Right to privacy in relation to reproductive health 
- Brainstorm with participants: "When claiming any of these rights, do you think you will face any difficulty? If so, what difficulties and why?"

- Explain that there are several issues that could come under the umbrella of reproductive health and rights, this module covers those issues that are socially pressing (slide 3.19). The aim of covering these issues (contraception, abortion and HIV infection) is to sensitise them to these issues and help them recognise that there could be differences in attitudes and values about them. Since you will not be covering all of the issues under reproductive health and rights, you could encourage them to clarify doubts on any of the issues that have been listed on the list of Reproductive Rights.

2. Brainstorm with participants the question given in Box 3.5. The answer and further details is also given in Box 3.5.

3. Emphasise that perceptions towards contraceptives could be individual, based on upbringing, early experiences, religious background, knowledge on the topic and experience in the field. It could also depend on their values as well as laws (slide 3.20). However, as health care professionals it is essential that they be aware of their own views on contraception - so that they give unbiased information to people who require such information and thus can enable them to make informed choices about it.

\section{Box 3.5: Correct answer for question 'Which kind of birth control works $100 \%$ of the time?' Listed below are just some birth control methods used.}

Which kinds of birth control works $100 \%$ of the time?

- Abstinence

- Sterilization

- IUD and implant

- Injection

- Oral contraceptive pill

- Condom

Answer (with rationale)

1. Only abstinence: Note, especially, that abstinence is only $100 \%$ effective when it is used consistently and when it is defined as not just abstaining from vaginal intercourse, but also avoiding any chance of ejaculation on the woman's genitals (for pregnancy prevention).

2. Sterilization is about $99.5 \%-99.9 \%$ effective. That means if one person has had his or her tubes tied, they have only a four in 1,000 (one in 250) chance, or less, of becoming pregnant. But there is still some chance.

3. The IUD and the Implant are highly effective methods (less than $1 \%$ chance of becoming pregnant with the IUD and no pregnancies have been reported so far with the new implant). They are both placed in the body of a woman by a health care provider (a doctor or a nurse practitioner). The method is not dependent on the behavior of the person using the method (such as remembering to take a pill) as much as the other hormonal methods (pill, shot etc).

4. The Injection (Depo-Provera) is also highly effective (less than 3\% chance of pregnancy in a typical user). This is less dependent on the person using this method than the following hormonal methods, but there is still room for failure (for example forgetting about an appointment for the next shot and getting it late).

5. The oral contraceptive pill is about $92 \%$ effective among typical users (more effective if used perfectly [99.7\%] - never forgotten, etc.—but few people use any method perfectly). That means if a woman uses the pill, the couple has about an eight percent (eight out of 100) chance of starting a pregnancy in a year's time. But there is still some chance.

6. Condom is about $85 \%$ to $98 \%$ safe if used correctly and consistently. It also protects against STI. It is inexpensive and available over the counter.

\section{Adapted from source:}

- Irvin, A. 2004. Positively Informed-Lesson Plans and Guidance for Sexuality Educators and Advocates. New York: International Women's Health Coalition(IWHC). 
4. Distribute Worksheet 3.5 .

- Ask participants to complete the first statement in 3 minutes. After that, ask participants to volunteer with their responses for each of the options. Stress on the likelihood that there could be differences in opinions amongst participants and the need to adhere to the ground rules.

- Then give them 5 minutes to complete the rest of the Worksheet. Statements 2-4 have four options. They will have to choose the best option according to their perception.

- Once they have completed it, ask one of the group volunteers to read aloud the second statement. Designate four areas of the room for each of the options and ask participants to move to the respective side of the room depending on their responses. Permit participants to debate the issue, at least for 5 minutes.

- $\quad$ Repeat the same for all the statements.

5. Close this exercise by giving the participants Handout 3.5. It contains information on contraceptives. Since they have probably learnt a lot of this in their regular curricula you will not be discussing it. However, if there are any questions you will be available to answer them.

6. Conclude by giving them Worksheet 3.6 that will help them identify their own risks levels and the need for contraception. This is personal; and they should do it in their own time. Encourage them to clarify their doubts and to use the question box for questions they are embarrassed to ask.

\section{Activity 3.5: Reproductive health issues-Contraception and safe pregnancy}

Purpose: The participants will

- Examine own views about contraception and safe pregnancy.

- Through role plays learn how to address these issues in their daily lives.

\section{Materials:}

- Black/white board or flip chart or OHP/LCD projector

- Chalk/marker pens/OHP transparencies

- Duster

- Worksheet 3.7

- $\quad$ Review Handout 3.4 when doing role plays

\section{Process:}

1. Divide participants into five groups. Give them Worksheet 3.7 and give them 10 minutes to plan the role plays. If possible, identify the groups and give the role plays in the previous class to allow time for preparation. Guidelines for the role play are given in the Worksheet. The first two role plays are focused on contraception and safe pregnancy while the remaining two are focused on safe abortions which are used in Activity 3.6.

2. Call the group assigned the first role play forward. Ask the Group Coordinator to first read the case scenario aloud for all to hear. Allow five minutes for the role play. Give positive feedback to the participants who took part in the role play. Clarify any doubts.

3. Repeat the procedure for the second and third role plays. After that give them information as given in the Box 3.6 on why it is important to give accurate information to young women on contraception. It is common practice in our country to marry off girls as young as $14-15$ years - who then become sexually active. Handout 3.4 gives information on risks the adolescent girls face. The information could help them recognise that it is possible to have a sexual relationship without having the fear of conception. You could ask them to review Handout 1.4 from Module 1, which gives information on various sexual behaviours that could be pleasurable without resulting in pregnancy. 


\section{Box 3.6: Need for information about contraception among young women}

Why is it necessary to give young women information about contraception?

1. It is their right. Information about contraception would empower them to plan and decide when they want to have a pregnancy; and when it is biologically, psychologically and socio-economically safe to have a baby.

2. Pregnancy at a young age (18 or under) increases health risks and thus should be avoided:

- The young woman's bone structure may not be fully developed, increasing the risk of complications at birth.

- If the young woman is still growing, pregnancy may deprive her body of nutrients which are needed to complete her growth.

- The baby may also be under-nourished.

- Teenage pregnancy often affects the education and employment prospects of the mother if she is still at school, by putting an end to her formal education.

- In some societies a single mother may face additional social problems if there are no structures to give her social and economic support; especially if the pregnancy is disapproved of.

What are some measures you can take to avoid pregnancy in under 18s?

- Teach comprehensive sexuality education in schools, beginning before students reach puberty. Many young people become sexually active before receiving any education or information.

- Assist parents to teach their children about sexual health.

- Provide confidential health and counselling services for young people. Where young people's confidentiality is not respected, they are not likely to seek health advice.

- Facilitate peer education. This has been effective in reducing teenage pregnancy.

- Remove restrictions on supply of contraceptives to unmarried people. Many restrictions still exist on the supply of contraceptives and condoms. Be non judgmental when a young person approaches you for information on contraception.

- Educate young people to avoid high-risk situations-for example alcohol consumption which increases risk-taking behaviour such as unsafe sex.

- Encourage responsible behaviour in men and young males.

4. Conclude by telling participants to be thorough with information on contraceptives. As young health care professionals who go to the clinical field, they may be seen as peers by the youth. It is important that they do not miss the opportunity of providing accurate information on these issues, so that the youth can make informed choices.

\section{Note for Facilitators: Activity 3.6-3.7}

Activity 3.6 will help participants examine their own values and perceptions on abortion. The activity consists of several sub-activities that include introspection, role plays and discussion. Remind participants about the ground rules.

Activity 3.7 is focused on discussing HIV infection. Help participants to recall the game 'Tailing the Cow' (Module 2: Activity 2.7). The purpose of the game was to help them reflect on their own values, attitudes and perceptions towards various sexual expressions and behaviours as well as to specific sexual and reproductive health issues. Specifically it is important to remember people affected and infected with HIV have the right to live their lives as positively as is possible. Since this module is long, case scenarios in this activity are restricted to discussion. However, it would be ideal if the participants could actually role play the situations. 


\section{Activity 3.6: Reproductive health issues: Safe abortion}

Purpose: The participants will

- Explore the various issues surrounding abortions.

- Discuss the Medical Termination of Pregnancy (MTP) Act and Pre-Natal Diagnostic tests (PNDT) Act.

- Through role play learn how to possibly address these issues in their daily lives.

\section{Materials:}

- Black/white board or flip chart or OHP/LCD projector

- Chalk/marker pens/OHP transparencies

- Duster

- $\quad$ Worksheet 3.7 to continue and Worksheet 3.8

- $\quad$ Slides 3.21-3.22

- $\quad$ Handout 3.6-3.7

\section{Process:}

1. Brainstorm with participants what they know about abortion and what is their awareness about the MTP Act, 1971.

2. Distribute Handout 3.6 and 3.7 that gives brief information on the MTP Act and the Prenatal Diagnostic Technique (PNDT) Act; and on the scenario with regards to abortions.

3. Divide the room into three areas and designate each area as 'Agree'; 'Unsure' and 'Disagree'. Tell participants that you will be calling out some statements (see Box 3.7) and they should respond to the statement as either 'Agree', 'Unsure' or 'Disagree' and move to the respective part of the room. Tell them to avoid the 'unsure' section as far as possible. Follow the same procedure for all the statements:

\section{Box 3.7: Statements to be used in Activity 3.6}

- Abortion should be a woman's choice (correct response: agree)

- Abortion should be legal and free (correct response: agree)

- If a woman is raped, it is okay for her to have an abortion (correct response: the woman's choice)

- Sex selective abortion should be a woman's choice (correct response: law against it. It is no one's choice)

- It is okay to have an abortion if tests indicate the possibility of defects in the foetus (correct response: agree)

- Young people have a right to an abortion without parental consent (correct response: laws governing it)

4. Once the participants have moved to a particular designated area in the room, ask a few representatives from each group to give reasons why they chose a particular option. Again, give them the guidelines of the MTP Act. However, do not hesitate to reinforce that each individual may be entitled to her/his own views based on the ground principles of respect, autonomy and justice.

5. Brainstorm with participants, "Why is abortion a health issue?" (Possible responses: due to the number of unsafe abortions that occur in the country, the number of unwanted deaths due to unsafe abortions, lack of awareness of the target group on how to prevent pregnancy, lack of awareness on where to access safe abortion services, etc.). Ask the participants "What do you think are the reasons for abortions?" After getting a list of responses project slide 3.21-3.22 (it is animated). These are the facts based on multiple studies done in various countries.

6. Give them Worksheet 3.8 to be completed individually-give them an option-either they could complete it now or later in their own time. 
7. Discuss any issues that may arise the next day when you check if they have completed the Worksheet 3.8 . Remind them of the anonymous question box where they could place any question they would like to ask and make time to clarify any doubts.

8. Call the respective groups that had to perform the fourth and fifth role play from Worksheet 3.7. All these role plays will help to reinforce information on reason for abortions and the PNDT Act given in Handout 3.7. Ensure that they have covered all the points given under the Act. Clarify any issues. To review information that has already been covered in Module 1 and to ensure that participants are reading Handouts, ask participants the questions given in Box 3.8. Answers are given in parenthesis after each question.

9. Conclude by telling them that they are likely to have strong and different opinions about abortion and on each of the reasons for abortion. What is important is that they get in touch with their own feelings towards abortion. Remind them that whatever their own feelings, the guiding principles of respect, autonomy and justice are foremost when dealing with clients.

\section{Box 3.8: Questions to review understanding on abortions}

- Is it legal for a girl who is 17 years to have an abortion?

(Possible response: Yes; as the age of consent is 16, but with the consent of the guardian as she is a minor under the provisions of the IPC, 1875).

- If the girl tells you she is raped then, what could she do?

(Possible response: File an FIR; seek help from supporting agency; determine her options and help her make a choice; if needed, offer her emergency contraception if she is within the period of 72 hours; reinforce the need to be counseled and tested for HIV).

- If the girl is unsure about the need for an abortion, what could you do?

(Possible response: Help her come to a decision by letting her know the pros and cons of either continuing with the pregnancy or having an abortion; reinforce that her choice will be kept confidential and she will be supported).

\section{Activity 3.7: Reproductive health issues-STIs and HIV}

Purpose: The participants will

- $\quad$ Review the main factors that pre dispose individuals to STIs and HIV.

- Examine their perceptions towards HIV.

- Be aware of how STIs and HIV can be prevented and managed.

- Analyse case scenarios to learn how to address similar issues in their daily lives.

\section{Materials:}

- Black/white board or flip chart or OHP/LCD projector

- Chalk/marker pens/OHP transparencies

- Duster

- Worksheet 3.9

- $\quad$ Slides 3.23-3.24

- $\quad$ Handout 3.8

\section{Process:}

1. Brainstorm "Why do we need to address STIs and HIV". Review the modes of transmission of HIV with participants (slide 3.23). Distribute Handout 3.8 which provides information on the vulnerability of girls and women to STIs and HIV due to various gender issues and prevailing socio cultural practices. Tell participants to read it and come for the next class with questions on it. 
2. Give Worksheet 3.9 to participants and allow them 5 minutes to complete it individually. Review the statements given in the Worksheet 3.9 by asking participants to give their views individually. (The correct responses are given in parenthesis against each statement) Reinforce the ground rules.

- Mandatory HIV testing for couples planning to get married is a good policy. (Appropriate response: depends on one's views. Presently this is not mandatory in India, although some states have recommended it. Counselling for voluntary testing is more Rights-oriented than mandatory. Moreover, even if both partners are in the window period during this test, mandatory pre-marital testing does not guarantee that both partners will practise fidelity after marriage).

- Women who are HIV positive could be allowed to have children. (Appropriate response: Women who are HIV positive have the right to bear children. It is important that the woman is explained the risks of transmission of HIV to the baby, and the measures to prevent transmission. Details of the Preventing Mother to Child Transmission (PMTCT) or Prevention of Parent to Child Transmission (PPTCT) programme needs to be explained to her. She could then make an informed choice).

- All people entering the country/migrating from different parts of the country should be screened for HIV (Appropriate response: This is presently not mandatory in India. It is important to recognise that HIV infection is prevalent in all population groups today. What is required are methods of prevention more than screening of people from outside).

- Homosexuals are the reason why HIV infection in our country is so high. (Appropriate response: HIV infection has spread in India primarily through sexual contact, injecting drug use, blood and blood products, mother to baby, occupational exposure. Unsafe sex is what makes people vulnerable).

- Women are to blame for HIV infection in our country since they are the ones who primarily infect men. (Appropriate response: Fact is that women are more susceptible to HIV infection than men. The proportion of men and women who are infected with HIV is more or less balanced and the statistics does not show a big difference in proportions).

- $\quad$ All STIs could become HIV infection. (Appropriate response: No, however, STIs could increase the risk for HIV transmission by $5 \%$ to $9 \%$ depending on several factors).

- A person with HIV infection and who is asymptomatic is also said to have AIDS. (Appropriate response: No. HIV infection is the stage where a person looks normal and healthy. AIDS is clinically classified as presence of one major opportunistic infection, CD4 count of less than 200 and HIV positive status).

- Persons living with HIV infection must be encouraged to disclose their status for the good of others. (Appropriate response: It is advisable they disclose their HIV status to their sexual partner, or those with whom they share injecting drugs, as also to their primary treating physician. However, due to stigma associated with the infection many people fear to do so. They would need counselling and support to help them make such a decision).

- A doctor has a right to disclose the HIV status of a person to the partner/spouse. (Appropriate response: If after several counselling sessions and if the person continues to refuse to disclose status to his/her partner and the physician knows that the partner is at risk for HIV infection, the physician is bound by law to do so, after informing the concerned person).

- All patients who are admitted in the hospital must be tested for HIV infection. (Appropriate response: Not needed. If standard precautions are practiced diligently, the risk for occupational exposure to HIV infection could be reduced. Remember that risk for Hepatitis $B$ and $C$ infections is higher than that of HIV in the health care setting).

- Needle exchange programmes that are used to reduce the chance of needle reuse amongst intravenous drugs use will encourage drug-use behaviour. (Appropriate response: This risk does exist, but whenever a public health programme is put in place, the risk-benefit ratio is determined. Here, the benefits outweigh the risks and thus, it has been used as preventive method).

- Women who are HIV positive could breast feed their child. (Appropriate response: Women who are HIV positive must be counselled on the options available for feeding the baby. The options include: exclusive breast feeding for months or exclusive alternative feeding. The risks and benefits must be informed to the mother and thus she should be helped to make her decision).

- All healthcare personnel should wear gloves, mask, and gowns whenever they are in contact with a HIV positive patient only. (Appropriate response: All nurses and other health care personnel are taught universal 
precautions. The use of protective personal equipment will depend on the procedure and thus the chance of exposure to infectious body fluids, not based on the diagnosis of HIV status).

- We can make out if a person has HIV infection by just looking at a person. (Appropriate response: HIV status can only be determined by diagnostic tests. However one could suspect HIV status by the physical appearance of a person, and the presence of particular illnesses. This must be confirmed with diagnostic tests).

- Women who are living with HIV infection and found to be pregnant must be encouraged to have an abortion. (Appropriate response: The woman should have been counselled on the risk of transmission of $H I V$ infections and the risk of her own status before becoming pregnant. If not, and she has come to the health facility for the first time and has been diagnosed to be living with HIV infection, then she would need to be counselled on the preventive methods, as well as the risks of transmission to the baby. Explain about the Prevention of Mother to Child Transmission Centres, which are established for women like her. She could then make an informed choice. Remember that the woman has a right to have children and HIV positive status does not come under the MTP Act).

- It is best for health care personnel to use all personal protective equipment, if they know they are going to be in contact with infectious body fluids when taking care of any patient. (Appropriate response: Yes).

- If a patient is recommended for surgery, HIV testing must be mandatory (Appropriate response: No, what is important is that standard or universal precautions are followed. HIV positive status does not change the surgical procedure at all. It is however good, that if a person is aware of his/her status he/she informs the treating physician or surgeon).

- HIV infection is seen only in specific groups of people. (Appropriate response: No, today HIV infection has been detected in the general population in India and it is not restricted to a particular group in the population).

3. Project slide 3.24 and review with participants the various methods that are available to reduce the risk of transmission of and thus prevention of HIV infection.

4. Divide the class into four groups. Give each group a chit with one case scenario. Ask each of the respective groups to give answers for the questions in the case scenario. The case scenarios and possible responses for questions given for each case scenario are given in parenthesis in Box 3.9. Take 5 minutes for each case scenario. Clarify any doubts.

5. Conclude by encouraging questions. Clarify their doubts. You could inform them that they will learn more details about HIV and STIs in their regular curricula.

\section{Box 3.9: Case scenarios for Activity 3.7}

1. Case scenario: A 20 year old man who is HIV positive asks you, 'Do I have AIDS? Can I continue to do all that I was doing before?'

- What information will you collect from him? (Possible responses: present health status; when was the diagnosis made; any risk factors such as multiple sexual partners, IDUs etc).

- What can you tell him? (Possible responses: if asymptomatic and with no opportunistic infection, he could continue with his daily activities of living; he should have the opportunity to live positively, join the positive support groups, etc.; he should not donate blood or any organs; should not share needles, if using drugs and should use a condom correctly and consistently every time he has sexual intercourse with his partner/s).

2. Case scenario: A 20 year old girl goes to donate blood for her sister. She is a leading designer professional. The doctor tells her she is HIV-positive. She says, 'How can I have HIV, I have had sex with only one man before.'

- What information will you collect from her? (Possible responses: support her, reaffirm that she is presently healthy, she could look after her health as well as take medicines that could help when needed, assess any risk factors, support system).

- What can you do for her (Possible responses: refer for further support, refer for treatment if needed, and encourage her to continue her work while she is healthy).

Cont'd on next page... 
Cont'd $\ldots$

3. Case scenario: A couple who is HIV positive wants to have a baby. They approach you.

- What information will you collect from them? (Possible responses: present health status; when was the diagnosis made; any risk factors such as multiple sexual partners, IDUs etc).

- What can you do for them? (Possible responses: inform about risk of HIV transmission to baby, inform them about the possibility of bearing a healthy child if certain precautions are taken, refer for further support, refer for treatment if needed, and encourage them to continue safe sex, report any infections early, encourage her to continue her work while she is healthy).

4. Case scenario: A 25 year old man diagnosed with HIV asks you, 'I have never had alcohol, nor taken drugs. I have had sex only with my wife. How did this happen?'

- What information will you collect from him? (Possible responses: support him, reaffirm that he is presently healthy, he could look after his health as well as take medicines that could help when needed, assess any risk factors, support system).

- What can you tell him? (Possible responses: "sometimes it is hard to know how one got infected", refer spouse for testing, refer for further support and encourage him to continue to work while healthy, encourage him to join the positive support group for more information and resources to live a positive life with dignity).

\section{Note for Facilitators: Activity 3.8}

Activity 3.8 is an important one and will help participants become aware of how 'precious' they and other people are. To conduct this activity properly you must recognise and believe this of yourself. When participants come forward to take part in the activity, you may see them placing the dot pins in the glass of water very gently. Draw a parallel with this observation. If we can be so gentle with a glass of water, how much more gentle will we need to be with a person in need, to ensure that the person reaches his/her full potential.

\section{Activity 3.8: You are precious}

Purpose: The participants will

- Recognise the inherent worth of their own life.

- Recognise the importance of another person's life irrespective of their background, their values, their attitudes and behaviours.

\section{Materials:}

- Glass

- Box of pins

- Bottle with water

- Worksheet 3.10

- $\quad$ Slides 3.25-3.26

- $\quad$ LCD projector

\section{Process:}

1. Project slides 3.25-3.26 and give participants the key messages of the module.

2. Inform participants that you will be conducting a game for them. Take a glass that is empty and place it on the table for all participants to see.

3. Call any participant to come forward and fill the glass with water. Once the participant says that the glass is full, ask all the other participants whether they agree that the glass is full. You may get varied responses. 
4. Then ask the participants if anyone could fill some more water in the glass. If someone says 'Yes', then this participant is invited to fill the glass with few more drops of water until the whole group agrees that any more water will create a spill.

5. Take a box of pins and ask participants how many pins can be put into the glass without making the water spill over. Participants give their own estimates. Some of them may say that it is not at all possible for even one pin to be put into the water because the glass is full to its maximum capacity, while others may offer different numbers.

6. Invite those who gave a number to come to the table. They are given their specified number of pins. The participants are invited to drop those pins into the glass without spilling the water. Caution participants from shaking the table on which the glass is kept or from touching the water.

7. One of the group coordinators is invited to count the cumulative number of pins dropped into the water and check that if any water has spilled over.

8. After the participants have dropped the number of pins they estimated, the facilitator could drop the remainder of the pins. Even after this participants will find that the water from the full glass did not spill over. The facilitator could then ask for some smaller objects (rings, hair slides and clips) from the participants and gently slide them also into the water in the full glass.

9. Ask participants for the total number of pins dropped into the water (the box gives an estimated number on its side label)

- Explain that due to the surface tension of water, even a glass is full to the brim, can take in several pins. The trick is to drop or slide the pins very gently and without shaking the glass, the table or touching the water.

10. Then discuss the following:

- Why did we underestimate the number of pins, which could be dropped into the glass? Do we similarly underestimate our abilities?

- Why did we presume that the glass is full? Draw the similarity. "If a small thing such as a glass could be seen to hold more than what we assume, how much more can human beings absorb?"

- Conclude this activity by reinforcing that this module could have brought out some positive memories as well as negative memories. Use the learning's from the Activity 2.5 of Module 2 . Remind them that being aware of one's goals, using all the possible resources available, and determination could help one move forward.

\section{CONCLUSION}

- $\quad$ End with emphasising that EACH PERSON IN THE ROOM IS PRECIOUS!

- Ask participants to complete Worksheet 3.10 to review their opinions about the module. Encourage them to be as frank as possible as it would help in improving the module. Collect the same for your evaluation.

- Reinforce the fact that since everyone is precious, it is important that we assert that everyone is also entitled to all the rights irrespective of caste, religion, health or socioeconomic status. It is only when the importance of every person is recognized that rights take their correct place in our society.

\section{Adapted from Source:}

- $\quad$ INSA India. 2003. Experiencing Options. Bangalore: Books for Change. 


\section{Worksheets}

\section{Worksheet 3.1: Case scenario}

\section{Case scenario 3.1a:}

Raju and Seema are in college and have been looking at each other for some time. They like each other too. Of late, every time Raju sees Seema, he asks her to come out with him. Seema does not know what to do. She likes him, and she does not want him to think that she is not interested in him.

- What do you think Raju can do?

- How do you think Seema can respond?

\section{Case scenario 3.1b:}

Seema finally agrees to go out with Raju. It has been one year now that Raju and Seema have been seeing each other. Lately, every time Raju meets Seema he has some gift to give her. Seema feels like saying 'No' to Raju. She is wondering what to do.

- What do you think Seema can do?

- What do you think of Raju's behaviour? 


\section{Case scenario 3.1c:}

Seema and Raju are going out for 3 years now. One day, when they decide to meet with each other, Raju tells Seema that he wants to have a closer relationship with her. This will really prove her love for him. Seema refuses, and Raju begins to act differently. He also begins to crack jokes about her/puts her down in front of her friends.

- What do you think Seema should do?

- What do you think about Raju's action?

- What factors would help Seema to respond to/make a decision about this situation?

\section{Case scenario 3.1d:}

Raju and Seema, however, continue to meet once in a way but their relationship is not the same. On his birthday, Raju asks Seema out. They are known as the best couple in college. Raju is handsome, athletic and typically liked by all the girls.

Seema is the girl who is very popular in the college campus, and she feels she is very lucky to have known Raju though he has been behaving differently to her.

Seema agrees, they first go for a movie, and then he takes her to a friend's place where there is a party going on.

Both enjoy the party. They are dancing and love the music, and while dancing Raju takes her to a corner where there are not many people. He starts kissing her, and then when Seema realises what is happening she shouts 'no'. But the music is loud and no one hears her, and she struggles but Raju is stronger than her. He has sex with her. She comes to you the next day.

- What rights are violated in this situation?

\section{Adapted from source:}

- Irvin, A. 2004. Positively Informed-Lesson Plans and Guidance for Sexuality Educators and Advocates. New York: International Women's Health Coalition(IWHC).

- World Health Organization. 1995. Teaching Modules for Basic Education in Human Sexuality. Manila: WHO Regional Office of the Western Pacific. 


\section{Worksheet 3.2: Warning signals of an unhealthy relationship}

A healthy relationship is honest, equal, respectful and responsible. Some people have identified the behaviours listed in the table below as warning signs that a relationship is not honest, equal, respectful and responsible. Check what you would probably do in each of the following situations.

\begin{tabular}{l|c|c|c|} 
Imagine your partner or the person you are & \multicolumn{3}{|c}{ Your response would be? } \\
\cline { 2 - 4 } \begin{tabular}{l} 
interested in \\
\cline { 3 - 4 }
\end{tabular} & Do nothing & $\begin{array}{c}\text { Discuss } \\
\text { relationship/ } \\
\text { Try to change } \\
\text { behaviour }\end{array}$ & End relationship \\
& &
\end{tabular}

- Makes negative remarks about your clothes, body or hair.

- Reveals that there is a much greater age difference between you than you had been led to believe.

- Always decides where you will go.

- Makes you hide things from your friends.

- Puts you down in public.

- Accuses you of fooling around with someone when you are not.

- Calls or turns up unexpectedly to check on you.

- Ignores what you want to do.

- Makes you feel guilty when you go out with your friends.

- Keeps you away from home.

- Hits you and then apologises.

- Refuses to use a condom.

- Will not let you get or use any protection.

- Demands you have intercourse when you do not want to.

- Refuses to get tested for a sexually transmitted infection.

\section{Adapted from source:}

- Irvin, A. 2004. Positively Informed-Lesson Plans and Guidance for Sexuality Educators and Advocates. New York: International Women's Health Coalition(IWHC). 


\section{Worksheet 3.3: Self reflection-Reasons for sexual intercourse}

- What are the best reasons for having sexual intercourse?

- What are the best reasons for waiting or deciding not to have sexual intercourse?

- $\quad$ Can someone who has decided to wait change his or her mind? Why?

- What about the reverse: can some one who has previously had sexual intercourse decide to stop for now?

- What would happen to someone who says that she/he wants to wait?

- What does someone need to know if he or she is going to say no to intercourse?

\section{Adapted from source:}

- Irvin, A. 2004. Positively Informed-Lesson Plans and Guidance for Sexuality Educators and Advocates. New York: International Women's Health Coalition(IWHC). 


\section{Worksheet 3.4: Self reflection-My attitudes and values on sexual health}

1. Read the following questions and silently consider how you might answer each one for yourself:

- Under what circumstances did your (will your) first sexual experience occur?

- If yes, was it a positive or negative experience?

- Did (Has) anyone pressurize/d or coerce/d you to have sex before you were ready, either peers or a partner?

- $\quad$ Did (Will) you or your first partner use protection against unwanted pregnancy or STIs/HIV? If not, why not?

- Are you (Will you be) able to communicate with your partner about your sexual life, needs and desires?

- In your sexual experiences, have you ever wanted to use contraception/condoms, but were not able to do so for some reason? If so, what were the reasons?

- Have you or your partner ever experienced an unplanned pregnancy? If so, what was that like?

- Have you ever felt (Will you ever feel) at risk of getting an STI?

- Have you ever been tested or sought treatment for an STI? Were you satisfied with the service?

- Do you know anyone who has been infected with HIV or who has developed AIDS symptoms?

2. If you have used contraception and/or condoms (only if relevant):

- How did you decide to use contraception/condoms?

- What method did you use? How did you get the supply (if applicable)?

- Have you ever switched methods? If so, why?

- How do you feel about contraceptives/condoms?

- How do you think contraceptive/condom use affects sexual pleasure?

- Have you ever experienced any side-effects?

- Have you discussed contraceptive/condom use with your partner?

- Do you know whether your partner uses contraceptives/condoms?

- How do you feel about your partner using contraceptives/condoms?

3. As a group, review the questions above in light of the following:

- What are some ways that a typical client might answer these questions?

- In your community, how might men's answers differ from women's?

- How might young people answer these questions differently than older adults?

- Which answers or opinions might cause conflict or controversy among wives and husband, parents and children, students and teachers, or other key groups in the community?

\section{Adapted from source:}

- Irvin, A. 2004. Positively Informed-Lesson Plans and Guidance for Sexuality Educators and Advocates. New York: International Women's Health Coalition(IWHC). 


\section{Worksheet 3.5: Self reflection-Contraceptives and my views}

\section{Complete the following statements:}

1. If I ever become a parent,

I hope my children will wait to be married until

I hope my children will wait to have sexual intercourse until

I hope my children will wait to have children of their own until

Take time and respond to each of the statements given below. For each statement you would need to make a single choice from amongst the options. Choose and place a check mark on the option you would choose in the given situation. REMEMBER THERE IS NO RIGHT OR WRONG ANSWER HERE. This exercise will help you get in touch with your own perceptions, attitudes and views on contraception.

2. The law allows a minor to get birth control without his or her parents' consent.

- I think the law should be changed; minors should not be allowed to obtain birth control, even with a parent's permission.

- I think the law should be changed; parents should have the legal right to say "no".

- In my opinion, parents should at least have the legal right to be notified, but not to veto the decision.

- I agree with the law; there should be no age limit on the legal right to privacy.

3. The law allows a married person to be sterilised without his or her spouse's consent.

- I agree with this law; no one should have to get a spouse's permission.

- I think the law should be changed; a man should be allowed to veto his wife's decision to have her tubes tied.

- I think the law should be changed; either spouse should be allowed to veto his or her spouse's decision

- I think the law should be changed; sterilisation should be illegal.

\section{I believe that}

- In a heterosexual couple, birth control is the man's responsibility.

- In a heterosexual couple, birth control is the woman's responsibility.

- $\quad$ Both people should take responsibility for birth control.

- Birth control is wrong; neither person should "take responsibility" for it.

\section{I believe that}

- It's morally wrong to use any form of birth control except abstinence, even if you are married.

- Some forms of birth control are immoral, even for married couples.

- As long as the couple is married, I would not call any form of birth control "wrong" or "immoral"

- Regardless of whether the couple is married, I would not call any form of birth control "wrong" or "immoral"

\section{Adapted from source:}

- Irvin, A. 2004. Positively Informed-Lesson Plans and Guidance for Sexuality Educators and Advocates. New York: International Women's Health Coalition(IWHC). 


\section{Worksheet 3.6: Self reflection-Contraceptive options chart and your risk levels}

\section{Self reflection:}

1. Considering your own behaviour now, where on the continuum of risk (no risk/very low risk/some risk/high risk) would you place yourself.

a. For an unplanned pregnancy?

$\begin{array}{ll} & \text { No risk } \\ & \text { Very low risk } \\ & \text { Some risk } \\ & \text { High risk }\end{array}$

b. For a sexually transmitted infection?

No risk

Very low risk

Some risk

High risk

c. For HIV infection?

No risk

Very low risk

Some risk

High risk

2. Do you think you would want to change your location on the continuum? Yes/No. If yes, one thing that you may change is/If no, one thing that may make you change your location is: 


\section{Worksheet 3.7: Role play for contraceptives, safe pregnancy and abortions}

You are given a case scenario. What you are expected to do is to role play the situation based on information that is given in the case scenario. Try and be as creative as possible. Think about how you would face the situation in real life and bring out the context appropriately. You will be given 10 minutes to prepare and 5 minutes for acting out the situation. Role plays 1-2 are focused to review content on contraception and safe pregnancy. Role plays 3-4 are focused to review content on abortion and the PNDT Act.

\section{Role play}

A young lady comes to the OPD where you are posted. She does not know much about contraception but is enthusiastic about not having a pregnancy. The receptionist does not pay much attention to her. Everyone seems busy in the OPD. She spots you and approaches you. She tells you 'I need to talk to you before I go to the doctor. I want to know how I can avoid pregnancy.'

\section{Demonstrate how would you approach the situation?}

- How would you collect information on her sexual history? (See Handout 3.4 for details on how to collect information on sexual history. Remember the role plays/videos you saw when collecting sensitive information from clientele. Following this, find out awareness about contraceptives. You could use the respective handout for it. Give unbiased information to the woman and find out what her choice would be and why. Be positive in your approach and encourage her with positive messages).

\section{Role play}

A young girl studying in college approaches you when you go to the community with questions about the pill, the IUD, and the condom.

\section{Demonstrate the following:}

- How would you find out her knowledge and feelings on contraceptive methods, her sexual relationship, her fears, etc. (Use open ended questions. See the Handout 3.4 that has some examples. Use techniques of active listening. Summarise what you hear from her, identify your own feelings on such a topic before you attempt giving information, and provide the needed unbiased information. Remember to be neutral).

\section{Role play}

An 18 year old comes to you saying that she feels she is pregnant. She does not know what to do. She has not consulted anyone.

\section{Demonstrate how you would deal with the situation keeping in mind her rights and her partner's rights?}

- What information will you find out from her? (Remember to collect a sexual history as already highlighted; assess pregnancy status; make sure that you find out what she wants to do if she is pregnant. Assist her in identifying her options - to prevent a pregnancy if she is early enough i.e. within the first three months of missing her last period; to continue the pregnancy; or to terminate it, Assess her support system and who she would like to inform).

- What information will you give her? What can you do for her? (Give information in an unbiased manner. Find out what her choice would be. Allow her to go through the decision making process by looking at the advantages and disadvantages of each option. Then help her to make a choice. Please remember not to make the choice for her. If needed refer her for further help or for further services). 


\section{Role play}

Varsha is 17 years, comes to the OPD. She seems obviously distressed. You ask her what brings her there and she says "I need an abortion. Please do not tell anyone but tell me what to do?"

\section{Demonstrate how you would deal with such a situation:}

- What specific information you would collect from her? (Get a thorough sexual history; reasons for wanting an abortion; number of children, if any; has she taken any previous medication or attempted to abort on her own before coming to the facility; and do an obstetrical assessment: since when she has missed her periods, any bleeding PV, any fever, swelling or pain in the abdomen, burning when voiding, etc).

- What information would you give her? (Give information in an unbiased manner. Find out her choice of method for abortion. Allow her to go through the decision making process by looking at the advantages and disadvantages of each option or method. Then help her to make a choice. Please remember not to make the choice for her. If needed refer her for further help or for further services).

\section{Role play}

Suma, a 24 year old married woman, comes to the OPD with a history of missing her periods for the last two months. She has three children 6, 4 and 2 years. All are girls. She says her husband wants to have a son and she wants to check if the baby is a girl. If the child is female then she will have an abortion.

\section{Demonstrate the following:}

- What other information would you collect from her? (Get a thorough sexual history, use of contraceptives etc. find out what her support system is, find out the obstetrical history as given in role play 3.7(1) also do a physical exam to assess her medical condition).

- How could you help her? (Find out whether she has any main support system; enquire whether she could get her husband for further counselling. Help her explore the advantages and disadvantages of the her decision. Give her unbiased information on abortions as well as the PNDT Act, Refer her for further counselling). 


\section{Worksheet 3.8: My views on abortion}

\begin{tabular}{|c|c|c|c|c|}
\hline \multirow{2}{*}{$\begin{array}{l}\text { Possible reasons for } \\
\text { an abortion }\end{array}$} & \multirow{2}{*}{$\begin{array}{l}\text { Responses given by those who want } \\
\text { to seek abortion }\end{array}$} & \multicolumn{3}{|c|}{ What I feel about the reason } \\
\hline & & Agree & Unsure & Disagree \\
\hline To stop child bearing & $\begin{array}{l}\text { - I have already had as many children I want } \\
\text { - I do not want any children } \\
\text { - My contraceptive method failed }\end{array}$ & & & \\
\hline $\begin{array}{l}\text { To postpone } \\
\text { childbearing }\end{array}$ & $\begin{array}{l}\text { - My most recent child is too young } \\
\text { - I want to delay having another child } \\
\text { - I am presently studying and cannot find the } \\
\text { time to look after a child } \\
\text { - I am presently too busy }\end{array}$ & & & \\
\hline Socioeconomic reasons & $\begin{array}{l}\text { - I cannot afford a baby now } \\
\text { - I want to finish my education } \\
\text { - I need to work full time to support (myself/ } \\
\text { my family) or my children } \\
\text { - My children go to bed hungry almost every } \\
\text { night }\end{array}$ & & & \\
\hline Relationship problems & $\begin{array}{l}\text { - I am having problems with my husband or } \\
\text { partner } \\
\text { - I don't want to raise a child alone } \\
\text { - I want my child to grow up with a father } \\
\text { - I should be married before I have a child }\end{array}$ & & & \\
\hline Age & $\begin{array}{l}\text { - I think I am too young to be a good mother } \\
\text { - My parents do not want me to have a child } \\
\text { - I do not want my parents to know I am } \\
\text { pregnant } \\
\text { - I am too old to have a child }\end{array}$ & & & \\
\hline Health & $\begin{array}{l}\text { - The pregnancy will affect my health } \\
\text { - I have a chronic illness } \\
\text { - The foetus may be deformed } \\
\text { - I am infected with HIV }\end{array}$ & & & \\
\hline Coercion or force & $\begin{array}{l}\text { - I have been raped } \\
\text { - My father (or other male relative) made me } \\
\text { pregnant } \\
\text { - My husband (or partner or parent or relative) } \\
\text { insists that I have an abortion }\end{array}$ & & & \\
\hline
\end{tabular}

\section{Adapted from source:}

- Irvin, A. 2004. Positively Informed-Lesson Plans and Guidance for Sexuality Educators and Advocates. New York: International Women's Health Coalition(IWHC). 


\section{Worksheet 3.9: My views on HIV}

State whether you Agree/are Unsure/or Disagree with the following statements. Avoid unsure as far as possible.

- Mandatory HIV testing for couples planning to get married is a good policy.

- Women who are HIV positive should be allowed to have children.

- All people entering the country/migrating from different parts of the country should be screened for HIV.

- Homosexuals are the reason why HIV infection in our country is so high.

- Women are to blame for HIV infection in our country since they are the ones who primarily infect men.

- All STIs could become HIV infection.

- A person with HIV infection and who is asymptomatic is also said to have AIDS.

- HIV positive persons must be encouraged to disclose their status for the good of others.

- A doctor has a right to disclose the HIV status of a person to the partner/spouse.

- All patients who are admitted in the hospital must be tested for HIV infection.

- Needle exchange programs that is used to reduce the chance of needle reuse amongst intravenous drugs use will encourage the risky behaviour.

- Women who are HIV positive can breast feed their child.

- I should wear gloves, mask, and gown whenever I am in contact with a HIV positive patient.

- We can make out if a person has HIV infection by just looking at that person.

- Women who are HIV positive and found to be pregnant must be encouraged to have an abortion.

- It is best for me to use all personal protective equipment, if I know I am going to be in contact with infectious bodily fluids when taking care of a any patient.

- If a patient is recommended for surgery, HIV testing must be mandatory.

- HIV infection is seen only in specific groups of people. 


\section{Worksheet 3.10: Review of the module}

Kindly take 5 minutes to complete the following and hand the paper over to me. You need not write your name anywhere. Please do respond, since this would help me know whether this session was useful or not. If you have additional thoughts, please share them in the space that is provided

Write at least three things you learnt from the module:

Write down at least one thing you had never thought of in relation to sexual and reproductive health and rights:

What did you feel was not necessary for this module?

Write any three suggestions for this module: 


\section{Handouts}

\section{Handout 3.1: Universal declaration of human rights}

Some of the human rights are given below

\begin{tabular}{|c|c|}
\hline Article 1 & Right to equality \\
\hline Article 2 & Freedom from discrimination \\
\hline Article 3 & Right to Life, liberty and personal security \\
\hline Article 4 & Freedom from slavery \\
\hline Article 5 & Freedom from torture and degrading treatment \\
\hline Article 6 & Right to recognition as a person before the law \\
\hline Article 7 & Right to equality before the law \\
\hline Article 8 & Right to remedy by competent tribunal \\
\hline Article 9 & Freedom from arbitrary arrest and exile \\
\hline Article 10 & Right to fair public hearing \\
\hline Article 11 & Right to be considered innocent until proven to be guilty \\
\hline Article 12 & Freedom from interference with privacy, family, home \& correspondence \\
\hline Article 13 & Rights to free movement in and out of the country \\
\hline Article 14 & Right to asylum in other countries from persecution \\
\hline Article 15 & Rights to nationality and freedom to change it \\
\hline Article 16 & Right to marriage and family \\
\hline Article 17 & Right to own a property \\
\hline Article 18 & Freedom of belief and religion \\
\hline Article 19 & Freedom of opinion and information \\
\hline Article 20 & Right to peaceful assembly and association \\
\hline Article 21 & Right to participate in government and free elections \\
\hline Article 22 & Right to social security \\
\hline Article 23 & Right to desirable work and to join trade unions \\
\hline Article 24 & Right to rest and leisure \\
\hline Article 25 & Right to adequate living standard \\
\hline Article 26 & Right to education \\
\hline Article 27 & Right to participate in cultural life of community \\
\hline Article 28 & Right to social order that articulates this document \\
\hline Article 29 & Community duties essential to free and full development \\
\hline Article 30 & Freedom from state or personal interference in the above rights \\
\hline
\end{tabular}

\section{Adapted from source:}

- $\quad$ Ahmed, A. and S. Menon. 2006. Rights and Desire-A Facilitator's Manual to Healthy Sexuality. New Delhi: Breakthrough. 


\section{Handout 3.2: Sexual and reproductive health rights}

More than a decade ago, at the International Conference on Population and Development (ICPD) in Cairo, 179 countries agreed that:

- All couples and individuals have the right to decide freely and responsibly the number, spacing, and timing of their children and to have the information and means to do so and that all decisions concerning reproduction should be made free from discrimination, coercion, and violence.

- The Fourth World Conference on Women in Beijing in 1995 further agreed that the human rights of women include their right to decide freely and responsibly on matters related to their sexuality:

- The human rights of women include their right to have control over and decide freely on matters related to their sexuality, including sexual and reproductive health, free of coercion, discrimination and violence. Equal relationships between women and men in matters of sexual relations and reproduction, including full respect for the integrity of the person, require mutual respect, consent and shared responsibility for sexual behaviour and its consequences.

- At Beijing, governments also recognised that entrenched patterns of social and cultural discrimination are major contributors to sexual and reproductive ill health, along with lack of information and services.

Reproductive rights and sexual health are necessary. ICPD put human needs, both individual and social, and specifically those of women, at the centre of population and development policies. (ICPD, Principle $2 \& 3$, Para. 3.4 and 3.16) The human rights approach adopted in Cairo is the guarantor that those needs will remain central to the way polices, services, and programs are developed and delivered.

- Rights protect against coercion, discrimination, and violence. Reproductive rights also include the right of individuals and couples to make decisions concerning reproduction free of discrimination, coercion, and violence as expressed in human rights documents.

- Rights require access. A human rights approach recognises that all individuals have equal rights and entitlements irrespective of who they are and where they live.

- Rights cannot be divorced from needs. Reproductive and sexual health and other basic human needseducation, sanitation, clean water, and nutrition - are equally important and interdependent; all are human rights. Especially for women, good pre-natal and obstetric care, safe contraception, and other aspects of health are inseparable from such basic amenities as reliable transportation, hygienic conditions, and clean water. At the same time, their rights to liberty, security of the person, and development are unattainable without comprehensive, accessible, and affordable reproductive and sexual health services and the freedom to make decisions about their fertility and sexuality. These rights form a seamless web, and all are grounded in basic human needs. To rank them denies the realities of women's lives, especially for poor women.

- Rights require a comprehensive approach. Since the individual's varied and changing needs are always at the centre of a human rights based approach, comprehensive services are required.

The ICPD Programme of Action calls for and defines reproductive and sexual health care to include:

- Family planning

- Antenatal, postnatal, delivery and postpartum care

- Access to safe abortion and post abortion care

- Prevention, care and treatment for HIV/AIDS and other STIs

- Prevention, surveillance and care for violence against women and other action to eliminate traditional harmful practices 
1. Sexual health: The dynamic state of physical, mental, emotional and social well being (WHO, 2005)

\subsection{Elements of sexual health:}

1.1.1. Capacity to enjoy and control sexual and reproductive behaviour in accordance with a social and personal ethic

1.1.2. Freedom from fear, shame, guilt, false beliefs and other psychological factors that inhibit sexual response and impair sexual relationships

- $\quad$ Respect

- Love

- Commitment

1.1.3. Freedom from organic disorders, diseases and deficiencies that interfere with sexual and reproductive functions

\subsection{Sexual rights:}

1.2.1. The right to sexual information (facts, something that deals with misconceptions)

1.2.2. The right to comprehensive sexuality education

1.2.3. The right to sexual autonomy (decision making) and safety of the sexual body

1.2.4. The right to sexual pleasure (no harm, injury, guilt, shame, false beliefs that may inhibit the sexual response)

1.2.5. The right to sexual health care, which should be available for prevention and treatment of all sexual concerns, problems and disorders

1.2.6. The right to sexual freedom, excluding all forms of

- Sexual coercion (force)

- Exploitation (taken advantage of)

- $\quad$ Abuse

2. Reproductive health and rights: State of physical, mental and social wellbeing in all matters relating to reproductive system in all stages of life

- $\quad$ Satisfying and safe sex life

- Capacity to reproduce: if, when and how often

- Access, effective, affordable and acceptable methods of family planning

- Safe pregnancy and child birth care

\subsection{Reproductive health rights}

2.1.1. The right to decide whether to marry and to decide if, when and how many children to have

2.1.2. The right to well being through life, for all matters relating to the reproductive system

2.1.3. The right to a responsible, healthy, safe and satisfying sex life

2.1.4. The right to unrestricted access to information in order to make informed choices

2.1.5. The right to have available safe, effective, affordable and acceptable family planning methods of choice

2.1.6. The right to safe pregnancy and birth

2.1.7. The right to be free from sexual violence and assault

2.1.8. The right to privacy in relation to Reproductive health 
We must ensure universal access for young people to comprehensive sexuality education, within and outside of schools, which:

- Includes abstinence as one important option

- $\quad$ Provide full and accurate information

- Gives social support and helps young people to:

o Build skills to establish equality within their relationships

o Respect the right to consent in sex and marriage and end violence and sexual coercion

- $\quad$ Provide girls with

o Safe spaces, free from harassment and discrimination

o Alternatives to early marriage

o Activities to help build their self-esteem and confidence

- Help boys to be

o Responsible for their own behaviour

o Able to understand that violence and coercive sex are not their birthright

- Such programs have been mandated at ICPD and have been reaffirmed many times

- Have guaranteed young people access to health services, not necessarily through separate services, which will often be impractical, but at least through appropriately trained staff, adjusted hours of service and "youth-friendly" outreach

- Provide basic services and referral can also be developed in many places where young people congregate

\section{Adapted from source:}

- International Women's Health Coalition. 2001. Sexual Health-Fact Sheet. New York: IWHC.

- SPC/UNFPA.1998. "Population Advocacy and Reproductive Health". IEC Projects. Reproductive Health Fact Sheets. 1-12. Noumea: Secretariat of Pacific Community.

- UNDP/UNFPA/WHO/World Bank Special Programme of Research Development and Research Training in Human Reproduction-HRP 2004. "Sexual health—a new focus for WHO". Progress in Reproductive Health Research. No 64.

- Women's Coalition for the International Conference on Population and Development (ICPD) 2001. Health, Empowerment, Rights and Accountability Action Sheets. New York: International Women's Health Coalition

\section{Handout 3.3: Your right to information-Tips for sexual decision making}

\section{Remember that a sexual relationship calls for:}

- Knowledge and awareness of one's body

- Factual information about sexual and reproductive health issues

- $\quad$ Respect for self and others

- Commitment to one's values

- Control of sexual and reproductive behaviour based on personal and social ethics/values 


\section{Points to keep in mind when making a decision with regards to a sexual relationship}

1. Share about your relationship with someone who is able to help you in your choices and whom you can trust. This person must know you well, be able to help you and want the best for you. Share any concerns you may have with the person.

2. Weigh the pros and cons of entering into a relationship. Do not rush into a sexual relationship just because you are attracted or it feels socially good or you are pressurised. Ask yourself questions: 'Why would I want to get in to this kind of a relationship?'; 'What next?'; 'Where would I want to be after this relationship?'

3. Get to know the person. Share your values and thoughts with the person you are interested in. Talk about potentially sexual situations and what each would do in such a situation. This will help you clarify your own and your partner's values. Remember the potential impact of your sexual decisions. It may be too late to think about pregnancy, STIs and HIV/AIDS after you have put yourself and another person at risk for these.

4. Spend some time alone thinking about your values and ask yourself 'would my sexual behaviour reflect my values?' Whenever you are with peers or friends who try to influence you make a sexual decision which goes against your values, or what you feel uncomfortable with, stay true to yourself and don't do anything against your own values. Trust yourself!

5. Anticipate situations where you may have to make a sexual decision. You may already know what times and places you may find yourself needing to make a sexual decision. Do not wait until that time to decide! Go into a potentially sexual situation with your thoughts and values in mind. If needed, share these thoughts with your confidante. For example, you could tell the person in whom you have been confiding, 'I have decided to go out with my friend to his/her home. But he/she told me no one else is there at home in that part of the day. I am uncomfortable, but I am not sure how I can refuse to go.'

6. You are not the only one making the decision about your sexual activity; one half of the decision belongs to the person you are thinking of being sexual with, so talk with that person and listen to the other person's thoughts and feelings: you are not weak if you say "no", you are actually much stronger.

7. Do not be afraid to question others who try to change your mind about your sexual decisions. Talk to your friends and peers about what you feel. You can be a positive influence on your friends by getting them to question their own values and sexual decisions.

\section{Adapted from source:}

- Alphonse X, 2004. We Shall Overcome-Text Book On Life Coping Skills. Bangalore: SKIP Publication.

- $\quad$ INSA India. 2003. Experiencing Options. Bangalore: Books for Change.

- Irvin, A. 2004. Positively Informed-Lesson Plans and Guidance for Sexuality Educators and Advocates. New York: International Women's Health Coalition(IWHC).

- $\quad$ NACO and UNICEF. 2006. Facilitators' Handbook for Training of Trainers. Adolescents Education Programme. New Delhi: NACO.

\section{Handout 3.4: Ensuring the sexual and reproductive health of adolescents}

Today, about 1 billion people worldwide are between 10 and 19 years of age, $85 \%$ of them in developing countries. In India, adolescents (10-19 years of age) comprise $24.1 \%$ of the total population. The Programme of Action of the International Conference on Population and Development recognised that adolescents have a special need for sexual and reproductive health information, education and services and that these services must respect the right of adolescents to privacy.

\section{FACT: Many women around the world marry as adolescents.}

Across Sub-Saharan Africa, at least half of young women enter their first marriage or union by age 18 (e.g. Mali, Niger-more than $75 \%$ of young women; Cameroon, Malawi, Uganda, Nigeria-more than 50\%). In Egypt and the Sudan, the proportion is $27 \%$, but in Yemen, it is $49 \%$. In Latin America and the Caribbean, between 20 and $40 \%$ of adolescent women in countries such as Brazil, the Dominican Republic, Mexico, El Salvador, Guatemala and 
Trinidad and Tobago are married before age 18 . Across Asia, the likelihood of early marriage varies: $73 \%$ of women in Bangladesh enter a union by age 18, compared with $14 \%$ in the Philippines and Sri Lanka and 5\% in China.

\section{FACT: Many adolescents who are sexually active do not use contraception.}

Of the roughly 260 million women aged 15-19 worldwide, married and unmarried, about $11 \%$ (29 million) are sexually active and do not want to become pregnant, but are not using a modern method of birth control. Of these 29 million, approximately $59 \%$ are married.

\section{FACT: Pregnant adolescents are at grave risk of death and injury.}

Each year, about 14 million (married and unmarried) young women aged 15-19 give birth. These adolescents are about twice more likely to die from pregnancy and childbirth than women in their twenties and their children face a higher risk of infant and child death. Each year, an estimated 1-4 million young women aged 15 to 19 have induced abortions, many of which are unsafe.

\section{FACT: Adolescents are at great risk of contracting sexually transmitted infections (STI) and HIV/AIDS.}

Of the 30 million people living with HIV in 1998, at least one-third were aged 10 to 24 . Each year, there are about 2.6 million new HIV infections in this age group. Worldwide, each year, approximately one in 20 adolescents contracts an STD.

FACT: Sexuality education for adolescents does not lead to promiscuity.

A WHO-sponsored review of 35 studies of sex education programs found: a) there is no evidence that sex education in schools leads to earlier or increased sexual activity in adolescents; b) those programs which promoted both postponement of sex and protected sex were more effective than those which promoted abstinence alone; and c) sex education is most effective when given before a young person becomes sexually active. UNAIDS reported similar conclusions based on an assessment of 68 reviews of sexual health education.

Condoms and Disease Prevention programmes: education about sexual health and/or HIV/AIDS does not encourage increased sexual activity. In fact good quality programmes help delay first intercourse and protect sexually-active youth from STIs, including HIV and from pregnancy; responsible and safe behaviour can be learned; and sexual health education is best started before the onset of sexual activity.

\section{FACT: Sexual abuse, incest and rape affect young people in most countries.}

National surveys from Canada, the Netherlands, New Zealand, Norway and the United States indicate that roughly $30 \%$ of women were abused as children. A study of Guatemalan street youth indicates that all have been sexually abused: $53 \%$ by their family members, $6 \%$ by friends, $3 \%$ by neighbours and $46 \%$ by people they did not know. In Uganda, half of sexually active primary school girls report being forced to have sexual intercourse and $22 \%$ anticipate receiving gifts or money in exchange for sex. Each year around the world about 2 million adolescents and girls between the ages of 5 and 15 enter or are forced into commercial sex.

As a health care professional, it is important then to be able to get a valid sexual history, so that you could help your clientele make informed choices. Below is a list of questions that could use to elicit information on sexual and reproductive health:

- What are your main concerns? (prioritise according to client's perception)

- Are you sexually active? (Have you had sex with anyone?)

- Who is/are the partner/s? (Whom do you have sex with? How many partners have you had in the last three months?)

- What behaviours are presently practiced? (What behaviours do you have with your partner? Do you make use of any contraceptives? What discussion have you had about contraception with your partner?)

- What is your awareness on sexual pleasure, safe behaviours, HIV or STIs? (Why do you practice various sexual behaviours? What do you know of safe sex behaviours? Have you heard of HIV and STIs? What do you know about HIV? About STIs?) 
- Any history of ulcers/warts/abnormal discharge/swelling/pain in the genital area in the past 3 months- STI?

- Does he/she use condoms? If no why?

- What are strengths and weaknesses of the person? (What would you do when you face a problem? Who all form your close network for communication? Who would you trust most with something confidential?

\section{Adapted from source:}

- Women's Coalition for the ICPD. 2001. Reproductive Health and Rights are Human Rights, New York: IWHC.

- $\quad$ ITECH. 2008. Empowering Nurses to Deliver HIV Nursing Care and Education (ENHANCE) Training Curriculum. Tambaram Sanatorium, Government Hospital of Thoracic Medicine, Chennai: International Training and Education Center on HIV (ITECH).

- St. John's College of Nursing. 2005. Facilitators Manual-STI and HIV/AIDS; Prevention, Care and Support. Bangalore: KSAPS and ICHAP.

\section{Handout 3.5: Contraceptive options}

\begin{tabular}{|c|c|c|c|}
\hline Method & Main advantages & Some possible problems & Effectiveness \\
\hline Abstinence & $\begin{array}{l}\text { - No physical side effects } \\
\text { - Can be used anytime } \\
\text { - Nothing to purchase } \\
\text { - Excellent protection } \\
\text { against sexually } \\
\text { transmitted infections } \\
\text { (STI) }\end{array}$ & $\begin{array}{l}\text { Requires commitment } \\
\text { and self control by both } \\
\text { partners } \\
\text { - Social pressure to engage } \\
\text { in intercourse } \\
\text { - Many people fail to use } \\
\text { protection when abstinence } \\
\text { ends }\end{array}$ & $\begin{array}{l}100 \% \text { if used consistently } \\
\text { AND if ejaculation on a } \\
\text { woman's genitals is avoided. }\end{array}$ \\
\hline $\begin{array}{l}\text { Birth Control } \\
\text { Pill }\end{array}$ & $\begin{array}{l}\text { - Continuous protection } \\
\text { against pregnancy } \\
\text { - Nothing to apply or insert } \\
\text { at time of intercourse } \\
\text { - More regular, shorter } \\
\text { periods } \\
\text { - Ability to become } \\
\text { pregnant returns quickly } \\
\text { when use is stopped } \\
\text { - Protects against painful, } \\
\text { heavy, or irregular } \\
\text { periods, ovarian and } \\
\text { endometrial cancer and } \\
\text { infections of the fallopian } \\
\text { tubes }\end{array}$ & $\begin{array}{l}\text { Must remember to take } \\
\text { daily } \\
\text { - Possible side effects: } \\
\text { nausea, breast tenderness, } \\
\text { weight gain or loss } \\
\text { - Rare, but serious health } \\
\text { risks (blood clots, heart } \\
\text { attack and stroke-these } \\
\text { risks are higher for women } \\
\text { over } 35 \text { who smoke) } \\
\text { - No protection against STI }\end{array}$ & $\begin{array}{l}92 \% \text { to } 99+\% \text { if } \text { used } \\
\text { correctly and consistently }\end{array}$ \\
\hline Implant & $\begin{array}{l}\text { Continuous protection } \\
\text { against pregnancy for } \\
5 \text { years (Norplant) or } 3 \\
\text { years (Implanton) } \\
\text { - Nothing to apply or insert } \\
\text { at time of intercourse } \\
\text { - Minor surgical procedure }\end{array}$ & $\begin{array}{l}\text { - Irregular menstrual } \\
\text { bleeding } \\
\text { - Possible weight gain or } \\
\text { loss } \\
\text { - Visible - can be seen under } \\
\text { skin } \\
\text { - No protection against STI }\end{array}$ & $99+\%$ \\
\hline
\end{tabular}


Cont'd...

\begin{tabular}{|c|c|c|c|}
\hline Method & Main advantages & Some possible problems & Effectiveness \\
\hline Injection & $\begin{array}{l}\text { - Continuous protection } \\
\text { against pregnancy for } 3 \\
\text { months (Depo Provera) or } \\
1 \text { month (Lunelle) } \\
\text { - Nothing to apply or insert } \\
\text { at time of intercourse } \\
\text { - Menstruation stops for } \\
\text { over half of women who } \\
\text { use Depo Provera (some } \\
\text { may not consider this an } \\
\text { advantage) } \\
\text { - Private-no visible sign } \\
\text { that person is using this } \\
\text { method } \\
\text { Other physiological } \\
\text { advantages similar to } \\
\text { those of the pill }\end{array}$ & $\begin{array}{l}\text { - Requires injection } \\
\text { Must remember to get the } \\
\text { shot } \\
\text { - Availability of Lunelle may } \\
\text { be limited } \\
\text { - Possible side effects (Depo } \\
\text { Provera): irregular period, } \\
\text { weight gain, headaches. } \\
\text { Other side effects and } \\
\text { risks for Depo Provera and } \\
\text { Lunelle similar to those of } \\
\text { the pill } \\
\text { - Return to fertility may } \\
\text { take several months (Depo } \\
\text { Provera) } \\
\text { Increased spotting/bleeding } \\
\text { in first month of use } \\
\text { (Lunelle) } \\
\text { No protection against STI }\end{array}$ & $\begin{array}{l}97 \% \text { to } 99+\% \text { if used } \\
\text { consistently }\end{array}$ \\
\hline $\begin{array}{l}\text { Intrauterine } \\
\text { device (IUD) }\end{array}$ & $\begin{array}{l}\text { Two types-one offers } \\
\text { continuous protection } \\
\text { against pregnancy for } 5 \\
\text { years, the other for } 10 \\
\text { years } \\
\text { - Nothing to apply or insert } \\
\text { at time of intercourse } \\
\text { - IUDs with hormones may } \\
\text { reduce menstrual cramps } \\
\text { and bleeding } \\
\text { - Non hormonal IUDs are } \\
\text { an alternative for women } \\
\text { who cannot use hormonal } \\
\text { methods }\end{array}$ & $\begin{array}{l}\text { - Must be inserted and } \\
\text { removed by clinician } \\
\text { - Heavier periods } \\
\text { - Rare, but serious health } \\
\text { risks (uterine expulsion } \\
\text { or perforation, pelvic } \\
\text { inflammatory disease) } \\
\text { - No protection against STI } \\
\text { - Not typically recommended } \\
\text { for adolescents }\end{array}$ & $98 \%$ \\
\hline Male condom & $\begin{array}{l}\text { - Excellent protection } \\
\text { against STI and HIV } \\
\text { - May help delay } \\
\text { ejaculation } \\
\text { - Male involvement } \\
\text { - Inexpensive, available } \\
\text { over the counter }\end{array}$ & $\begin{array}{l}\text { - May leak or break if used } \\
\text { incorrectly } \\
\text { - May interfere with } \\
\text { spontaneity }\end{array}$ & $\begin{array}{l}85 \% \text { to } 98 \% \text { if used } \\
\text { correctly and consistently }\end{array}$ \\
\hline Female condom & $\begin{array}{l}\text { - Available over the counter } \\
\text { Alternative for people } \\
\text { with latex allergies } \\
\text { - Good protection against } \\
\text { STI }\end{array}$ & $\begin{array}{l}\text { - May be difficult to insert } \\
\text { - Requires high level of } \\
\text { comfort with one's body } \\
\text { - May become dislodged } \\
\text { during intercourse } \\
\text { - May interfere with } \\
\text { spontaneity }\end{array}$ & $\begin{array}{l}79 \% \text { to } 95 \% \text { if used } \\
\text { correctly and consistently }\end{array}$ \\
\hline
\end{tabular}




\begin{tabular}{|c|c|c|c|}
\hline Method & Main advantages & Some possible problems & Effectiveness \\
\hline $\begin{array}{l}\text { Diaphragm or } \\
\text { Cervical cap }\end{array}$ & $\begin{array}{l}\text { Can be inserted in } \\
\text { advance of intercourse } \\
\text { - Can remain in place } \\
\text { for multiple acts of } \\
\text { intercourse (diaphragm- } \\
24 \text { hours; cervical cap } \\
48 \text { hours) }\end{array}$ & $\begin{array}{l}\text { - Requires high level of } \\
\text { comfort with one's body } \\
\text { - Requires fitting by } \\
\text { clinician } \\
\text { - May be difficult to insert } \\
\text { - Limited STI protection, but } \\
\text { also possibility of irritation } \\
\text { (by spermicide) that could } \\
\text { facilitate STI transmission }\end{array}$ & $\begin{array}{l}84 \% \text { to } 91 \% \text { (cap) or } 94 \% \\
\text { (diaphragm) if used } \\
\text { correctly and consistently }\end{array}$ \\
\hline Spermicides & $\begin{array}{l}\text { Available over the counter } \\
\text { in a variety of forms } \\
\text { (creams, films, foams, } \\
\text { gels, suppositories) } \\
\text { - Adds lubrication (creams, } \\
\text { foams, gels) }\end{array}$ & $\begin{array}{l}\text { - Timing: must insert close } \\
\text { to each intercourse } \\
\text { - May cause allergic reaction } \\
\text { - Possibility of irritation that } \\
\text { could facilitate } \\
\text { - STI transmission }\end{array}$ & $\begin{array}{l}71 \% \text { to } 85 \% \text { if } \text { used } \\
\text { correctly and consistently }\end{array}$ \\
\hline Withdrawal & $\begin{array}{l}\text { - Nothing to purchase } \\
\text { - Available as a last resort } \\
\text { - Dependent on male } \\
\text { partner } \\
\text { - Requires great control }\end{array}$ & $\begin{array}{l}\text { - } \text { May affect pleasure } \\
\text { - No protection against STI }\end{array}$ & $\begin{array}{l}\text { Effectiveness varies:failure } \\
\text { rate increases if the male } \\
\text { does not predict and control } \\
\text { ejaculation correctly }\end{array}$ \\
\hline $\begin{array}{l}\text { Fertility } \\
\text { awareness } \\
\text { methods }\end{array}$ & $\begin{array}{l}\text { - Nothing to purchase } \\
\text { Permitted by some } \\
\text { religious groups that } \\
\text { prohibit the use of other } \\
\text { methods }\end{array}$ & $\begin{array}{l}\text { - Requires commitment } \\
\text { - No intercourse for much of } \\
\text { menstrual cycle } \\
\text { - No protection against STI }\end{array}$ & $\begin{array}{l}75 \% \text { to } 99 \% \text { if used } \\
\text { correctly and consistently: } \\
\text { combined use of calendar, } \\
\text { basal temperature and } \\
\text { cervical mucous methods }\end{array}$ \\
\hline No method & $\begin{array}{l}\text { - No protection against } \\
\text { pregnancy } \\
\text { - Nothing to purchase }\end{array}$ & - No protection against STI & $15 \%$ \\
\hline $\begin{array}{l}\text { Vasectomy \& } \\
\text { tubectomy }\end{array}$ & $\begin{array}{l}\text { - Permanent protection } \\
\text { against pregnancy } \\
\text { - Nothing to apply or insert } \\
\text { at time of intercourse } \\
\text { - Requires surgery }\end{array}$ & $\begin{array}{l}\text { - Reversal has relatively low } \\
\text { success rate } \\
\text { - No protection against STI } \\
\text { - Usually available only to } \\
\text { older individuals }\end{array}$ & $99+\%$ \\
\hline $\begin{array}{l}\text { Emergency } \\
\text { contraception } \\
\text { (E.C.) }\end{array}$ & $\begin{array}{l}\text { - Can be used up to } 72 \\
\text { hours after unprotected } \\
\text { intercourse } \\
\text { - Good for emergency } \\
\text { situations }\end{array}$ & $\begin{array}{l}\text { May cause nausea and } \\
\text { vomiting } \\
\text { - Not for regular use } \\
\text { - No protection against STI } \\
\text { - Effectiveness depends on } \\
\text { timing. The sooner E.C. } \\
\text { is taken after unprotected } \\
\text { intercourse, the higher the } \\
\text { success rate. }\end{array}$ & $\begin{array}{l}\text { Used within } 24 \text { hours- } \\
\text { reduces risk of pregnancy } \\
\text { by up to } 95 \% \text {; used within } \\
72 \text { hours-reduces risk of } \\
\text { pregnancy by } 75 \% \text { to } 89 \%\end{array}$ \\
\hline
\end{tabular}

Note: If a method is 99\% "effective," 99 women in 100 having sexual intercourse regularly for one year are expected not to become pregnant. If a method is $15 \%$ "effective," 15 women out of 100 would be expected not to become pregnant. (Lower percentages indicate "typical user" rates; higher percentages indicate "perfect user" rates.)

\section{Adapted from source:}

- Irvin, A. 2004. Positively Informed-Lesson Plans and Guidance for Sexuality Educators and Advocates. New York: International Women's Health Coalition(IWHC). 


\section{Why is it necessary to give young women information about contraception?}

This is important because pregnancy at a young age (18 or under) increases health risks:

- The young woman's bone structure may not be fully developed, increasing the risk of complications at birth.

- If the young woman is still growing, pregnancy may rob her body of nutrients which are needed to complete her growth.

- The baby may also be under-nourished.

- Teenage pregnancy often affects the education and employment prospects of the mother if she is still at school, by putting an end to her formal education.

- In some societies a single mother may face additional social problems if there are no social structures to give her social and economic support; and in particular if the pregnancy is disapproved of.

What are some solutions that you can take an active part in to avoid pregnancy in under 18 age group?

- Teach comprehensive sexuality education in schools, beginning before students reach puberty. Many young people become sexually active before receiving any education or information.

- Assist parents to teach their children about sexual health.

- Provide confidential health and counselling services for young people. Where young people's confidentiality is not respected, they are not likely to seek health advice.

- $\quad$ Facilitate peer education. This has been effective in reducing teenage pregnancy.

- Remove restrictions on supply of contraceptives to unmarried people. Many restrictions still exist on the supply of contraceptives and condoms. Be non judgmental when a young person approaches you for information on contraception

- $\quad$ Encourage responsible behaviour in men and young males.

\section{Emergency contraception is just that...emergency contraception isn't abortion}

Emergency contraception is used by women to protect against unwanted pregnancy after, rather than before, unprotected sex. It has one specific purpose: to give women an opportunity to prevent unintended pregnancy-women who have been raped, who have no access to contraception or who fear the method they used has failed. Names by which it appears in the media are: I-pill, Unwanted 72, Morning after pill etc.

Fact: Emergency contraception refers to contraceptive methods that can be used by women within 72 hours following unprotected intercourse to prevent an unwanted pregnancy.

Fact: Emergency contraceptives work before implantation and not after a woman is already pregnant. Medical science defines the beginning of pregnancy as the implantation of a fertilised egg in the lining of a woman's uterus. Implantation occurs five to seven days after fertilisation.

Fact: Once implantation has occurred and pregnancy is established, emergency contraceptive treatment using hormone pills is not effective in interrupting pregnancy.

Fact: Taking the results of the studies with high-dose oral contraceptives (which are similar to emergency contraceptive pills) into account, experts believe there is no harm to a pregnant woman or foetus if emergency contraceptive pills are inadvertently used during early pregnancy.

Fact: Although frequent use of emergency contraceptive pills is not recommended, repeated use poses no health risks and should never be cited as a reason for denying women access to treatment.

Fact: Estimates show that increased use of emergency contraceptive pills could reduce the number of unintended pregnancies and abortions by half annually.

Fact: Emergency contraception is not new. It is the same contraceptive compound used by millions of women the world over since the 1970s.

\section{Adapted from source:}

- Women' Coalition for the ICPD. 1998 Emergency Contraception Is Just That-Emergency Contraception, Not Abortion. USA Health, Empowerment, Rights and Accountability (HERA). 


\section{Handout 3.6: The Medical Termination of Pregnancy Act, 1971}

\section{(Act No. 34 of 1971)-10 ${ }^{\text {th }}$ August 1971 and PNDT Act}

An Act to provide for the termination of certain pregnancies by Registered Medical Practitioners and for matters connected therewith or incidental thereto.

Be it enacted by Parliament in the Twenty-second Year of the Republic of India as follows:

\section{Short title, extent and commencement}

(1) This Act may be called the Medical Termination of Pregnancy Act, 1971.

(2) It extends to the whole of India except the State of Jammu and Kashmir.

(3) It shall come into force on such date as the Central Government may, by notification in the Official Gazette, appoint.

2. Definitions - In this Act, unless the context otherwise requires,

(a) "Guardian" means a person having the care of the person of a minor or a lunatic;

(b) "Lunatic" has the meaning assigned to it in section 3 of the Indian Lunatic Act, 1912 (4 of 1912);

(c) "Minor" means a person who, under the provisions of the Indian Majority Act, 1875 (9 of 1875), is to be deemed not to have attained his majority;

(d) "Registered medical practitioner" means a medical practitioner who possesses any recognised medical qualification as defined in clause (h) of section 2 of the Indian Medical Council Act, 1956, (102 of 1956), whose name has been entered in a State Medical Register and who has such experience or training in gynaecology and obstetrics as may be prescribed by rules made under this Act.

\section{When pregnancies may be terminated by registered medical practitioners}

(1) Notwithstanding anything contained in the Indian Penal Code (45 of 1860), a registered medical practitioner shall not be guilty of any offence under that Code or under any other law for the time being in force, if any pregnancy is terminated by him in accordance with the provisions of this Act.

(2) Subject to the provisions of sub-section (4), a pregnancy may be terminated by a registered medical practitioner,

(a) Where the length of the pregnancy does not exceed twelve weeks if such medical practitioner is, or

(b) Where the length of the pregnancy exceeds twelve weeks but does not exceed twenty weeks, if not less than two registered medical practitioner are, of opinion, formed in good faith, that

(i) The continuance of the pregnancy would involve a risk to the life of the pregnant woman or of grave injury to her physical or mental health; or

(ii) There is a substantial risk that if the child were born, it would suffer from such physical or mental abnormalities to be seriously handicapped.

Explanation 1-Where any pregnancy is alleged by the pregnant woman to have been caused by rape, the anguish caused by such pregnancy shall be presumed to constitute a grave injury to the mental health of the pregnant woman.

Explanation 2-Where any pregnancy occurs as a result of failure of any device or method used by any married woman or her husband for the purpose of limiting the number of children, the anguish caused by such unwanted pregnancy may be resumed to constitute a grave injury to the mental health of the pregnant woman.

(3) In determining whether the continuance of a pregnancy would involve such risk of injury to the health as is mentioned in sub-section (2), account may be taken of the pregnant women's actual or reasonable foreseeable environment.

(4) In the event of a minor or a major with mental illness

(a) No pregnancy of a woman, who has not attained the age of eighteen years, or, who, having attained the age of eighteen years, is a lunatic, shall be terminated except with the consent in writing of her guardian. 
(b) Save as otherwise provided in clause (a), no pregnancy shall be terminated except with the consent of the pregnant woman.

4. Place where pregnancy may be terminated-No termination of pregnancy shall be made in accordance with this Act at any place other than

(a) A hospital established or maintained by Government, or

(b) A place for the time being approved for the purpose of this Act by Government.

\section{Sections 3 and 4 when not to apply}

(1) The provisions of section 4 and so much of the provisions of sub-section (2) of section 3 as relate to the length of the pregnancy and the opinion of not less than two Registered Medical Practitioners, shall not apply to the termination of a pregnancy by a Registered Medical Practitioner in a case where he is of opinion, formed in good faith, that the termination of such pregnancy is immediately necessary to save the life of the pregnant woman.

(2) Notwithstanding anything contained in the Indian Penal Code (45 of 1860), the termination of a pregnancy by a person who is not a Registered Medical Practitioner shall be an offence punishable under that Code and that Code shall, to this extent, stand modified.

Explanation-For the purposes of this section, so much of the provisions of clause (d) of section (2) as relate to the possession, by a Registered Medical Practitioner, of experience or training in gynaecology and obstetrics shall not apply.

6. Power to make rules-Refer for details at http://mohfw.nic.in/MTP\%20Act\%201971.htm

7. Power to make regulations

(1) The State Government may, by regulations:

(a) require any such opinion as is referred to in sub-section (2) of section 3 to be certified by a Registered Medical Practitioner or practitioners concerned, in such form and at such time as may be specified in such regulations and the preservation or disposal of such certificates;

(b) require any Registered Medical Practitioner, who terminates a pregnancy, to give intimation of such termination and such other information relating to the termination as may be specified in such regulations;

(c) prohibit the disclosure, except to such purposes as may be specified in such regulations, of intimations given or information furnished in pursuance of such regulations.

(2) The intimation given and the information furnished in pursuance of regulations made by virtue of clause (b) of sub-section (1) shall be given or furnished, as the case may be, to the Chief Medical Officer of the State.

(3) Any person who wilfully contravenes or wilfully fails to comply with the requirements of any regulation made under sub-section (1) shall be liable to be punished with fine, which may extend to one thousand rupees.

\section{Protection of action taken in good faith}

No suit or legal proceedings shall lie against any Registered Medical Practitioner for any damage caused or likely to be caused by anything, which is in good faith done or intended to be done under this Act.

\section{Pre Natal Diagnostic Techniques (Regulation and Prevention of Misuse) Act, 1996}

\section{The Pre Natal Diagnostic Techniques (PNDT) Act and Rules}

The Pre-Natal Diagnostic Techniques (Regulation and Prevention of Misuse) Act, 1994, was enacted and brought into operation from $1^{\text {st }}$ January, 1996, in order to check female foeticide. Rules have also been framed under the Act. The Act prohibits determination and disclosure of the sex of foetus. It also prohibits any advertisements relating to pre-natal determination of sex and prescribes punishment for its contravention. The person who contravenes the provisions of this Act is punishable with imprisonment and fine.

Recently, PNDT Act and Rules have been amended keeping in view the emerging technologies for selection of sex before and after conception and problems faced in the working of implementation of the Act and certain directions of 
Supreme Court after a PIL was filed in May, 2000 by CEHAT and others, a group of NGOs on the slow implementation of the Act. These amendments have come into operation with effect from $14^{\text {th }}$ February, 2003

Refer for further details http://mohfw.nic.in/THE\%20PNDT

- $\quad$ The PNDT (PRINCIPAL) ACT 1994

- $\quad$ The PNDT (PRINCIPAL) RULES 1996

- The PNDT Advisory Committee Rules, 1996

- $\quad$ The PNDT Amednment Act, 2002

- $\quad$ The PNDT Amendment Rule, 2003

\section{Handout 3.7: Basic information on safe abortion}

\section{What is an induced abortion and a spontaneous abortion?}

\section{Induced abortion}

Involves surgical or medical procedures to terminate the pregnancy

These could be safe or unsafe
Spontaneous abortion

Pregnancy terminates without any surgical or medical intervention

\section{What is meant by unsafe abortion?}

- The World Health Organization defines unsafe abortion as a procedure for terminating an unintended pregnancy carried out either by persons lacking the necessary skills or in an environment that does not conform to minimal medical standards, or both.

- Worldwide, $48 \%$ of all induced abortions are unsafe. However, in developed regions, nearly all abortions (92\%) are safe, whereas in developing countries, more than half (55\%) are unsafe.

- More than $95 \%$ of abortions in Africa and Latin America are performed under unsafe circumstances, as are about $60 \%$ of abortions in Asia (excluding Eastern Asia).

- The worldwide unsafe abortion rate was essentially unchanged between 1995 and 2003 (15 and 14 abortions per 1,000 women aged 15-44, respectively). Because the overall abortion rate declined during this period, the proportion of all abortions that are unsafe increased from $44 \%$ to $47 \%$.

\section{What are the consequences of unsafe abortion?}

- Worldwide, an estimated five million women are hospitalized each year for treatment of abortion-related complications, such as haemorrhag e and sepsis.

- Complications due to unsafe abortion procedures account for an estimated $13 \%$ of maternal deaths worldwide, or 67,000 per year.

- Almost all abortion-related deaths occur in developing countries. They are highest in Africa, where there were an estimated 650 deaths per 100,000 unsafe abortions in 2003, compared with 10 per 100,000 in developed regions.

- Approximately 220,000 children worldwide lose their mothers every year from abortion-related deaths. In India it has been reported that 20,000 women die every year due to unsafe abortions.

- Additional consequences of unsafe abortion include loss of productivity, economic burden on public health systems, stigma and long-term health problems, such as infertility.

\section{Overview of the abortion situation}

\section{Globally}

- More than one-third of the approximately 205 million pregnancies that occur worldwide annually are unintended and about $20 \%$ of all pregnancies end in induced abortion. 
- Of the 23 million pregnancies that occur in developed countries, more than $40 \%$ are unintended and $28 \%$ end in induced abortion.

- Of the 182 million pregnancies that occur in developing countries, more than one-third are unintended and 19\% end in induced abortion ( $8 \%$ are safe procedures and $11 \%$ are unsafe).

- The average woman must use some form of effective contraception for at least 20 years if she wants to limit her family size to two children and 16 years if she wants four children.

- Two-thirds of unintended pregnancies in developing countries occur among women who are not using any method of contraception.

- More than 100 million married women in developing countries have an unmet need for contraception, meaning they are sexually active; are able to become pregnant; do not want to have a child soon or at all; and are not using any method of contraception, either modern or traditional.

- The reasons why women (married and unmarried) do not use contraceptives most commonly include concerns about possible health and side effects and the belief that they are not at risk of getting pregnant.

\section{India}

A fairly significant proportion of women in the community-based survey (13\%) experienced at least one abortion. Abortion levels were particularly high among urban women (17\%), as well as those who were literate $(18 \%)$ or residing in a household with a high standard of living (19\%). Abortions occurred largely to limit (77\%) or space (22\%) childbearing. Very few women (3\%) reportedly had abortions because they desired a child of a different sex. Besides those women who underwent abortions, a fair number of others experienced unwanted pregnancies that were carried to term.

Examples of unsafe abortion methods used

- Drinking turpentine, bleach or tea made with livestock manure

- Inserting herbal preparations into the vagina or cervix

- Placing foreign bodies, such as a stick, coat hanger or chicken bone, into the uterus

- Jumping from the top of stairs or a roof

\begin{tabular}{|l|c|c|c|c|}
\hline \multirow{2}{*}{ Region and Sub region } & \multicolumn{2}{|c|}{ No. of abortions (millions) } & \multicolumn{2}{|c|}{ Abortion rate* } \\
\cline { 2 - 5 } & $\mathbf{1 9 9 5}$ & $\mathbf{2 0 0 3}$ & $\mathbf{1 9 9 5}$ & $\mathbf{2 0 0 3}$ \\
\hline World & 45.6 & 41.6 & 35 & 29 \\
\hline Developed countries & 10.0 & 6.6 & 39 & 26 \\
\hline Excluding Eastern Europe & 3.8 & 3.5 & 20 & 19 \\
\hline Developing countries* & 35.5 & 35.0 & 34 & 29 \\
\hline Excluding China & 24.9 & 26.4 & 33 & 30 \\
\hline Estimates by region & & & & \\
\hline Africa & 5.0 & 5.6 & 33 & 29 \\
\hline Asia & 26.8 & 25.9 & 33 & 29 \\
\hline Europe & 7.7 & 4.3 & 48 & 28 \\
\hline Latin America & 4.2 & 4.1 & 37 & 31 \\
\hline Northern America & 1.5 & 1.5 & 22 & 21 \\
\hline Oceania & 0.1 & 0.1 & 21 & 17 \\
\hline
\end{tabular}

*Abortions per 1000 women aged 15-44 years.

**Those within Africa, the Americas, excluding Canada and the United States of America, Asia, excluding Japan and Oceania excluding Australia and New Zealand.

\section{Adapted from source:}

- Guttmacher Institute \& World Health Organisation. 2007. In Brief-Facts on Induced Abortion Worldwide. Geneva: WHO.

- Population Council \& Parivar Seva Sanstha. 2004. Understanding Induced Abortions: Findings from a programme of research in Rajasthan, India. New Delhi: Population Council. 


\section{Handout 3.8: HIV fact sheet}

\section{What is HIV and what is AIDS?}

\begin{tabular}{|c|c|}
\hline HIV & AIDS \\
\hline $\begin{array}{l}\text { - HIV: Human Immunodeficiency Virus } \\
\text { - Causes AIDS } \\
\text { - Person may be asymptomatic and can do normal activity } \\
\text { for many years once infected with the virus }\end{array}$ & $\begin{array}{l}\text { - AIDS: Acquired immunodeficiency Syndrome } \\
\text { - HIV infection progresses to AIDS } \\
\text { - Person is symptomatic and may not be able to do normal } \\
\text { activity. May be presented with serious infections (called } \\
\text { Opportunistic infections that may be caused by either } \\
\text { viruses, bacteria, protozoa or fungi that are residing in } \\
\text { the body or outside) of the skin, respiratory, nervous } \\
\text { or gastrointestinal system mainly }\end{array}$ \\
\hline
\end{tabular}

\section{Who is at risk of having HIV infection?}

- History of having unsafe sex with multiple sex partners, men having sex with men

- History of sexually transmitted infections, TB, Hepatitis B, Hepatitis C

- History of receiving blood transfusions, organs

- History of having partners who had multiple sex partners, STIs

- History of injecting drug use (IDUs), sharing needles

- History of being born of a woman who is HIV positive

- History of needle stick injury or exposure of non intact skin or mucosa to infectious body fluids (blood, semen, vaginal secretions, CSF, peritoneal fluid, pleural fluid, synovial fluid, pericardial fluid, interstitial fluid)

\section{How is HIV transmitted?}

- Unprotected sexual contact (Anal intercourse-highest risk; vaginal intercourse-next most risky although it is the commonest route of infection in India; oral intercourse-low risk)

- Transfusion of untested blood or blood products, organ transplant (By law all donors have to be tested for 5 infections: Malaria, Hepatitis B, Hepatitis A, VDRL, HIV)

- $\quad$ Sharing of used needles and syringes amongst IDU

- From mother to child during pregnancy or during delivery or when breast feeding if the mother has not been a part of PPTCT programme

- Occupational exposure (risk of health care professionals getting the infection when exposed to body fluids)

\section{How can I know if I have HIV?}

- You could be tested for HIV. The test is called an antibody test. The test is available in all district hospitals and in some private labs or hospitals (costly, sometimes no counselling done)

- Before testing, you will be counselled about what is HIV, the modes of transmission, you could be assessed for risk factors and the need for testing

- You have to sign a consent form for getting the test

- $\quad 3-5 \mathrm{ml}$ of blood is drawn and the blood is tested on 3 antigens to look for reaction. This is called the rapid test and you could get the result on the same day within 45 minutes.

- You don't have any signs of infection: all three antigens have tested negative

- You have symptoms: only 2 antigens need to test positive for you to be diagnosed HIV+

- If the first HIV test is negative it could indicate either of the two-a) that you are negative; or b) in the window period i.e. the period between the time the virus enters the body till the appearance of antibodies in the blood. This window period is usually 6-12 weeks but may extend to 6 months in a very small proportion of the population. 


\section{What happens when a person has HIV?}

HIV requires some of the body cells called the CD4 (i.e. T-lymphocytes part of the WBC) to multiply. It uses the nuclei of these cells to increase in number therefore destroying the cells. In many years, as more CD4 cells get destroyed the body's capacity to fight off infections reduces. The person then begins to present with infections very easily and becomes sick.

\section{How can HIV be prevented?}

- Practicing safe sex

- Not sharing needles/using fresh needles and syringes

- Seeing that blood/blood products and organ donors are tested for HIV

- Practicing standard precautions in the hospital setting

- Taking PEP in the event of occupational exposure

- Reducing risk through harmful cultural practices

- Reducing mother to child transmission of HIV

\section{What should a person once infected with HIV do to prevent the spread of it?}

A person could reduce the chance of spreading the virus by:

- Practicing safe sex

- Use condoms whenever the person has sexual intercourse

- Practice outer course methods

- Abstain from having sex

- Not donating blood or any other organs including semen, breast milk

In the case of a pregnant woman:

- Take medicines as prescribed by the doctor

- Get treated for any infections

- Visit the doctor regularly

- Ensure a good diet

- Avoid any invasive procedure on the uterus

- Come to the hospital for delivery

- Learn about how to feed the baby safely given the socioeconomic status

The effort should be to slow down the HIV infection in the body to help an HIV positive person live longer. This could be through any of the following methods:

- Try and stay as healthy as possible by taking a good nutrition

- Eat food that is freshly prepared, in a clean manner

- Get any infection treated by a doctor

- Have regular follow up with the doctor to check if the CD4 cell count is reducing or not

- Take prophylaxis to prevent some infections (this will be prescribed by the treating doctor)

- Take Antiretroviral treatment when prescribed by the doctor

\section{Facts: Realities of girls' and women's lives}

HIV/AIDS epidemics in India and around the world are primarily driven by heterosexual sex. HIV/AIDS is thus essentially a sexual and reproductive health and rights issue, especially for girls and women. The realities of girls' and women's lives that violate their sexual and reproductive rights and undermine their health are the same realities that put them at serious risk of HIV/AIDS - and these impose disproportionate burdens on them once they are infected and/or caring for others who are. Some of the realities that are most harmful are given below: 
1. Marriage of young girls to older, usually sexually experienced men: Of the 331 million girls currently aged 10-19 in the developing world (excluding China) 163 million will be married by their twentieth birthday. In many countries, girls are still married before their fifteenth birthdays. In Mozambique, for example, 21\% of women currently aged 20-24 were married before age 15 , and $57 \%$ before age 18 . One-quarter (24\%) of young women in Mali were married by age 15, and two-thirds by 18 . In Nicaragua, $13 \%$ of young women were married or living with their partners by age 15 , and $43 \%$ by 18 . In South Asian countries such as Bangladesh and India, a child bride is sexually inexperienced, knows little or nothing about contraception or HIV, and is expected to demonstrate her fertility immediately, i.e., she is required to have frequent and unprotected sex, resulting in high-risk pregnancies. Marriage, far from being a safe space, can be very dangerous.

2. Sex between young girls and older men outside of marriage: Girls in some social settings are driven to transactional sex through an array of needs-family survival, transportation, school fees, food - and sometimes enticements - clothes, a night out, or a cell phone. Transactional sex crosses income groups, but everywhere seems to be primarily between older men and younger women, including girls. In a study conducted in Soweto, South Africa, for example, among nearly 4,000 pregnant women ages 15 to 44 years, transactional sex was associated with HIV sero positivity. Girls and young women who are sold, or enticed, or tricked into transactional sex end up not only in brothels or red light districts, but also in countless informal settings impossible to track or to reach with protective information and services.

3. Violence and sexual coercion inside and outside marriage: Girls and women are biologically twice as likely as men to become infected with HIV during sexual intercourse with an infected partner. A violent partner dramatically increases the woman's risk and obliterates any protective action she might otherwise take. Rape as a weapon of war, or even of lesser conflicts such as family or tribal feuds, is all too common. In some countries, between 20 and 48 per cent of young women aged 10-25 years have experienced forced sex. And today we witness the horrors of international and national sex trafficking in young women and in children of both sexes.

4. Husbands or primary partners who engage in extramarital affairs or visit commercial sex workers: Premarital and extramarital sexual activity are widely condoned, or even encouraged, for adolescent boys and men as a demonstration of masculinity. Men who work far from home often have sex with women in brothels, along truck routes, or on construction sites. They return home and infect their wives and, in turn, their babies, with a range of sexually transmitted infections. In Thailand, this is clearly an emerging challenge: In 1991, 90\% of HIV transmission in Thailand was through sex work, and 5\% through heterosexual transmission of cohabiting partners. By the end of 2002, 15\% was through sex work, and 50\% through heterosexual partners. In even the most outwardly sexually conservative societies, such as India and Indonesia, boys and men have casual sex with each other-secretly - and then marry.

5. Taboos against giving girls factual information about sexuality and reproduction before, and even after, marriage: All too often, social norms dictate that girls remain not only virginal, but also ignorant of sexuality, reproduction, HIV, contraception, and even condoms when they enter marriage. UNAIDS reports that in 24 subSaharan African countries, including Cameroon, Kenya, Nigeria, and Uganda, more than two thirds of young women aged 15-24 years, lack comprehensive knowledge of HIV.

6. Lack of condom use in marriage or long-term relationships: By now it is common knowledge that few men use condoms with their primary female partners. And most women who are primary partners either do not perceive that they are at risk from their boyfriends or husbands, or they do not ask them to use condoms for fear of violence or rejection, or because they want to get pregnant. Dr. Paulo Teixeira, Senior Adviser to the HIV/AIDS program in Sao Paulo, Brazil, has repeatedly expressed concern that adult middle class women in stable relationships do not perceive that they are at risk for infection. Those in what they perceive to be a monogamous relationship - that is, $92 \%$ of Brazilian women - use condoms only $21 \%$ of the time. Yet the epidemic in Brazil is spreading 9 times faster among women than men. In India, Dr. Suniti Solomon sums up the plight of women in her country: 'A sex worker can tell a client, 'Use a condom or get lost.' A housewife in India can never do that."

\section{Adapted from source:}

- Germain, A. 2005. Making Progress: An International Agenda to Secure and Advance Sexual and Reproductive Rights and Health New York: IWHC. 


\section{Slides}

\section{Module 3 \\ Knowing my Rights \\ Sexual and Reproductive Health Rights}

\section{\#3.2 \\ Objectives}

- List sexual and reproductive health rights within the framework of human rights

- Discuss the positive aspects of sexual relationships

- Explore various issues concerning sexual relationships including unprotected sex

- Examine one's views with regards to abortions, use of contraceptives and STIs / HIV

- Analyze case scenarios with regards to sexual relationships and sexual as well as reproductive health

\section{\#3.3}

How are Human Rights Formed?

- Identify the need

- Establish the need (express it at public level and get group consensus)

- Stake a claim with appropriate authority (applications, appeals, morchas, creating awareness, advocacy, dailogue with state)

- Convince the State about the existence of the need and demanding the need to be a Right

- Take procedural steps (State)

- Make laws and implement schemes

\section{\#3.4}

\section{Key Features of Human Rights}

- Are those rights which accrue to an individual by virtue of being born as a human being

- Attributes of human rights:

- Universal

- Inherent and intrinsic: born with them

- Inalienable: cannot be taken away

- Indivisible: equally enjoyed

- Non hierarchical: no hierarchy

- Obligation of State to

- Respect

- Protect

- Fulfill

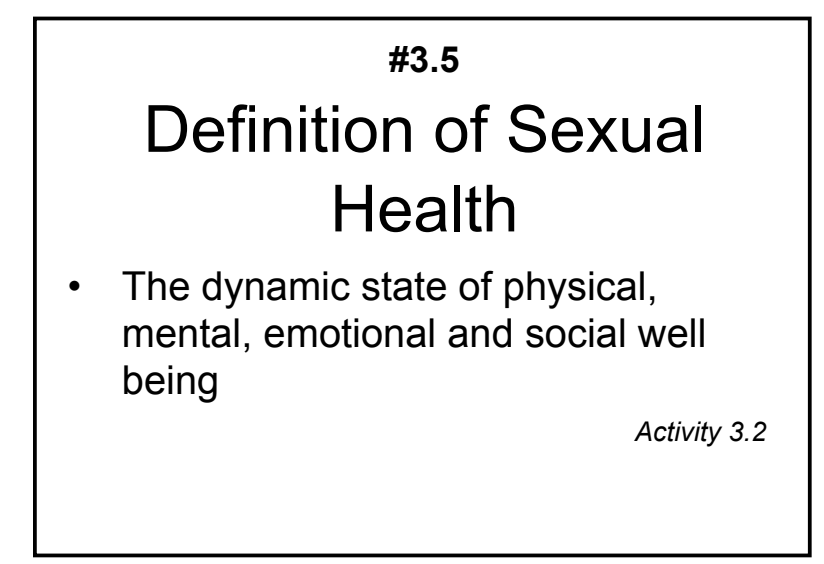

\begin{tabular}{|c|c|}
\hline \multicolumn{2}{|c|}{ Sexual Health-Basic Elements } \\
\hline $\begin{array}{l}\text { Capacity to enjoy } \\
\text { and control sexual } \\
\text { and reproductive } \\
\text { behaviour in } \\
\text { accordance with a } \\
\text { social and personal } \\
\text { ethic. }\end{array}$ & $\begin{array}{l}\text { What is needed? } \\
\text { - Have knowledge about sexual } \\
\text { and reproductive health } \\
\text { - Be aware of one's values, } \\
\text { desires and goals } \\
\text { - Be aware of one's own body } \\
\text { - Keep in mind ethical principals } \\
\text { of respect, autonomy and justice } \\
\text { when forming a relationship }\end{array}$ \\
\hline
\end{tabular}




\section{\#3.7}

\section{Sexual Health-Basic Elements}

Freedom from fear, What is needed?

shame, guilt, false - Have knowledge about

beliefs and other sexual and reproductive

psychological factors

that inhibit sexual

response and impair

sexual relationships health

- Be aware of one's values, desires and goals

- Get help for past experiences that have negative impact

- Recognize one's rights

\section{\#3.8}

\section{Sexual Health-Basic Elements}

Freedom from organic disorders, diseases and deficiencies that interfere with sexual and reproductive functions
What is needed?

- Have knowledge about sexual and reproductive health

- Take measures to avoid risk factors for sexual and reproductive health concerns

- Protect self and be able to say 'no' when you want to say 'no'
Handout 3.2

\section{\#3.9}

\section{Sexual Health and Rights}

- The Right to Sexual Information

- The Right to Comprehensive Sexuality Education

- The Right to Sexual Autonomy (freedom to make decisions) and Safety of the Sexual body

- The Right to Sexual Pleasure that could be a source of well being

(Cont'd...)

\section{(Cont'd...) \\ \#3.10}

Sexual Health and Rights (cont.)

- The Right to Sexual Health Care, which should be available for prevention and treatment of all sexual concerns, problems and disorders

- The Right to Sexual Freedom, excluding all forms of

- sexual coercion (force),

- exploitation (being taken advantage of due to a more vulnerable position)

- abuse

\section{\#3.11}

\section{Sexual Relationships}

\section{- Characteristics}

- Respect for self and others

- Honesty between partners

- Equality amongst partners

- Responsibility for both partners

- Sexual relationships call for

- Knowledge and awareness of one's body

- Having factual information about sexual and reproductive health issues

- Commitment to one's personal and social values that could help control of sexual and reproductive behaviour

\section{\#3.12}

\section{Sexual Relationships: Tips to make Decisions}

- Share about the relationship with someone you can trust

- Weigh the pros and cons of the relationship

$$
\text { - Is the relationship healthy? }
$$

- Get to know the person

- Introspect on your values and that of your partner

- Anticipate situations that you may be in when you would have to make a decision about sexual behaviour

- Seek advise from a person you trust

Worksheet 3.3 
\#3.13

Sexual Violence in a
Relationship_When Could
it Occur?

- Principles of Respect, Autonomy, Justice are broken.

- What are the forms of sexual violence?

\section{\#3.14}

Forms of Sexual Violence

- Forced or coerced sex in marriage/dating relationships

- Rape, even within marriage

- Sexual harassment

- Sexual abuse of children

- Forced sex work and trafficking

- Child marriage

- Violent acts against the sexual integrity of a woman (Female genital circumcision (FGC) and virginity inspections)

Trigger tapes: I-TECH: Mentoring tool kit

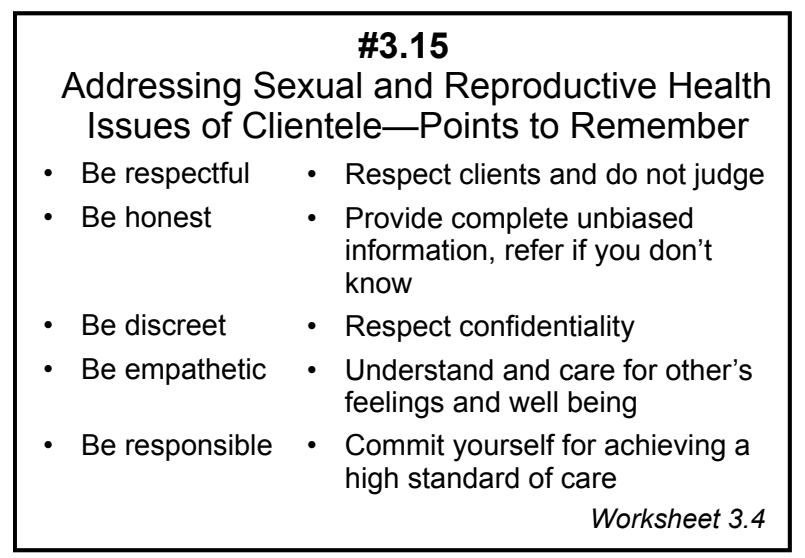

\section{\#3.17 \\ Reproductive Health and Rights}

- State of physical, mental and social wellbeing in all matters relating to reproductive system in all stages of life. This means

- To have a satisfying and safe sex life

- To be able to reproduce: if, when and how often

- To be able to have access to effective, affordable and acceptable methods of contraception

- To have safe pregnancy and child birth care

Refer Handout 3.2

\section{\#3.16 \\ Sexual History}

- What are the main concerns (prioritize according to client's perception)

- Is he/she sexually active? If yes, what behaviours are presently practiced?

- What is his/her awareness on sexual pleasure, safe behaviors, HIV or STIs?

- What are the support systems for the person?

- How has he/she solved problems before?

- What does he/she know about the partner/s?

- Any history of ulcers/warts/abnormal discharge/ swelling/pain in the past 3 months - STI?

- Does he/she use condoms? If no why? 


\begin{tabular}{|c|}
\hline \#3.19 \\
Reproductive Health Issues: \\
What will be covered \\
Contraception-To help participants \\
become aware of the prevailing attitudes \\
Abortion-To highlight safe abortion \\
and prevailing attitudes \\
RTIs/STIs/HIV-To build awareness on it \\
and become aware of prevailing attitudes \\
\hline
\end{tabular}

\begin{tabular}{|l|}
\hline \multicolumn{1}{|c|}{ \#3.21 } \\
Reproductive Health Issues: Abortion \\
- The right to abortion is a reproductive right of all women \\
regardless of age, marital status, disability etc \\
- Women are given higher priority with regards to the right \\
to have a child or not \\
- Abortion is heavily debated: \\
- Pro choice supporters- A woman's body is her \\
responsibility hence it is her choice to continue a \\
pregnancy or not \\
- Pro life supporters-Life begins from conception, \\
hence abortion amounts to taking life
\end{tabular}

\section{\#3.23}

\section{Reproductive Health Issues:} Scenario of STIs and HIV

Routes of HIV transmission:

- Sexual

- Pregnant women: ANC/Intranatal/Feeding options

- IDUs

- Blood and blood products transfusion

- Occupational exposure
\#3.20

Reproductive Health Issues: Factors affecting perceptions on contraception

- Personal experiences

- Upbringing: Cultural and religious background

- Belief in above teachings

- One's own value system

- Information on prevailing conditions, human rights issues, reproductive health

- Laws and universal principles related to it
- To save a woman's life

- To preserve woman's physical health

- To preserve a woman's mental health

- For rape or incest

- When there is a possibility of foetal impairment

- For economic and social reasons

- Upon request for unplanned pregnancy

\section{\#3.24}

Reproductive Health Issues: Prevention of STIs and HIV

\section{- Abstinence}

- Be faithful to partner-avoid multiple partner relationship

- Condom-use correctly and consistently

- Diagnose and treatment-get tested if there is a risk factor and seek treatment when needed

- Educate self and others on prevention

- Harm reduction: reducing risk with risk behavior (multiple partner / IDUs)

- Blood / blood products use: using screened products

- Cultural practices

- Gender issues

- PPTCT: safe pregnancy and delivery, prevention of transmission during pregnancy, delivery and lactation, safe sex 


\section{\#3.25 \\ Key Messages}

- Every person is entitled to sexual and reproductive rights

- $\quad$ All people irrespective of marital status, sexual and gender identity, whether they have a disability or not have the right to make a choice to have a child or not

- Knowledge of contraception is important for the prevention of unwanted pregnancies, making choices for planning children, protecting oneself from STIs including HIV

- Women are given higher priority over men for their reproductive rights

\section{\#3.26 \\ Key Messages}

- Sexual and reproductive health and rights are issues and needs to be dealt with sensitivity

- Learning from Game

- The glass held more than was perceived

- So also as human beings we can do more than we perceive we can. This depends on one's determination, goals, values, resources

Activity 3.8

Worksheet 3.10 


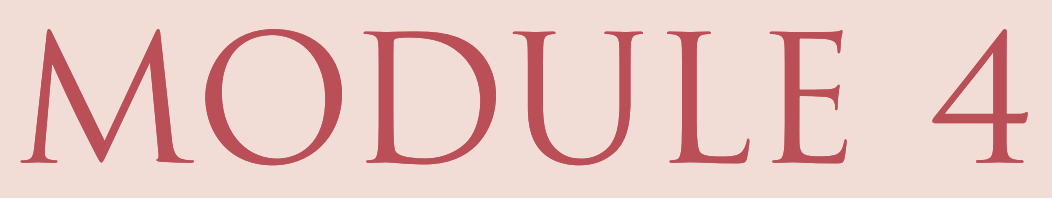

\author{
I AM ABLE! \\ LIFE SKILLS-MY ARMOUR
}




\section{Facilitators Guide}

\section{Content Considerations}

1. "Life skills" is an approach used to bring into context, sexuality and gender issues to facilitate the development of skills needed to make responsible and informed choices.

2. The main objective of the 'I am Able_Life skills Module' is to promote healthy awareness of one's choices.

3. Adaptations of the World Health Organisation's Life Skills are included in this Module, viz.: managing stress, time and emotions; awareness of self; decision-making skills, using critical thinking; empathy; problem solving skills; interpersonal skills; communicating assertively and creatively.

4. The approach in the Module includes elements that could be adapted to different cultures, as appropriate.

\section{Aim}

The participants will be able to understand the importance of developing life skills, appreciate and apply life skills in their day-to-day professional and personal lives to address, specifically, sexual and reproductive health issues.

\section{Objectives}

By the end of this Module participants will:

1. Assess their own life skills.

2. Participate in activities in the class room to know how they could develop their life skills.

3. Explain the need to develop life skills in the context of personal and professional demands.

4. List the various life skills that could be used to address sexual and reproductive health and rights.

\section{Duration: 3-4 hours}

\section{Key messages}

1. One needs to become aware of life skills to know how one could improve these skills to address sexual and reproductive health issues.

2. Development of life skills could help individual nurses, professionally and personally.

3. Practising these skills daily could help one become competent in managing stressful situations and peer pressure. 
Module 4: Topic, time, activity/method and resources needed

\begin{tabular}{|c|c|c|c|}
\hline Topic & Time & Activity/Method & Resources Needed \\
\hline Introduction & 5 minutes & Discussions & $\begin{array}{l}\text { - Black/white board or flip chart or OHP/LCD } \\
\text { projector } \\
\text { - Chalk/marker pens/OHP transparencies } \\
\text { - Duster } \\
\text { - Slides } 4.1-4.2\end{array}$ \\
\hline $\begin{array}{l}\text { The need for } \\
\text { Life Skills } \\
\text { training in } \\
\text { nursing curricula }\end{array}$ & 15 minutes & $\begin{array}{l}\text { Activity 4.1: } \\
\text { Meaning of life skills } \\
\text { assessment of life } \\
\text { skills }\end{array}$ & $\begin{array}{l}\text { - Black/white board or flip chart or OHP/ } \\
\text { LCD projector } \\
\text { - Chalk/marker pens/OHP transparencies } \\
\text { - Duster } \\
\text { - Worksheet } 4.1 \\
\text { - Facilitators key to evaluate } \\
\text { - Slide } 4.3-4.4\end{array}$ \\
\hline \multirow[t]{5}{*}{$\begin{array}{l}\text { Various Life } \\
\text { Skills }\end{array}$} & 20 minutes & $\begin{array}{l}\text { Activity } 4.2 \text { : Stress } \\
\text { management }\end{array}$ & $\begin{aligned} & \text { - } \text { Black board or flip chart or OHP/LCD } \\
& \text { projector } \\
& \text { - } \text { Chalk/marker pens/OHP transparencies } \\
& \text { - } \text { Duster } \\
& \text { - Worksheet } 4.2-4.3 \\
& \text { - Handout } 4.1 \\
& \text { - Review of Worksheet } 2.4 \text { from module } 2 \\
& \text { - Slide } 4.5-4.9\end{aligned}$ \\
\hline & 20 minutes & $\begin{array}{l}\text { Activity } 4.3 \text { : Time } \\
\text { management }\end{array}$ & $\begin{aligned} & \text { - } \text { Black/white board or flip chart or } \mathrm{OHP} / \mathrm{LCD} \\
& \text { projector } \\
& \text { - } \text { Chalk/marker pens/OHP transparencies } \\
& \text { - Worksheet } 4.4-4.5 \\
& \text { - Handout } 4.2 \\
& \text { - Slide } 4.10-4.15\end{aligned}$ \\
\hline & 20 minutes & $\begin{array}{l}\text { Activity } 4.4 \text { : } \\
\text { Managing emotion }\end{array}$ & $\begin{aligned} & \text { - } \text { Black/white board or flip chart or } \mathrm{OHP} / \mathrm{LCD} \\
& \text { projector } \\
& \text { - } \text { Chalk/marker pens/OHP transparencies } \\
& \text { - } \text { Duster } \\
& \text { - } \text { Handout } 4.3 \\
& \text { - Slide } 4.16-4.19\end{aligned}$ \\
\hline & 20 minutes & $\begin{array}{l}\text { Activity 4.5: } \\
\text { Awareness of Self }\end{array}$ & $\begin{aligned} & \text { - } \text { Black/white board or flip chart or OHP/LCD } \\
& \text { projector } \\
& \text { - } \text { Chalk/marker pens/OHP transparencies } \\
& \text { - Duster } \\
& \text { - Plain sheet of paper } \\
& \text { - Dot pins } \\
& \text { - Chart with all participants' finger print } \\
& \text { - Worksheets } 4.6-4.8 \\
& \text { - Handout } 4.4 \\
& \text { - Review of Worksheet } 4.2 \text {; Activity } 3 \text { of module } 1 \\
& \text { and Activity } 8 \text { of module } 3 \\
& \text { - Slide } 4.20-4.21\end{aligned}$ \\
\hline & 20 minutes & $\begin{array}{l}\text { Activity } 4.6 \text { : Decision } \\
\text { making }\end{array}$ & $\begin{aligned} & \text { - } \text { Black/white board or flip chart or OHP/LCD } \\
& \text { projector } \\
& \text { - } \text { Chalk/marker pens/OHP transparencies } \\
& \text { - } \text { Duster } \\
& \text { - } \text { Handout } 4.5-4.6 \\
& \text { - Slide: } 4.22-4.26\end{aligned}$ \\
\hline
\end{tabular}


Cont'd...

\begin{tabular}{|c|c|c|c|}
\hline Topic & Time & Activity/Method & Resources Needed \\
\hline & 15 minutes & Activity 4.7: Empathy & $\begin{array}{l}\text { - Black/white board or flip chart or OHP/LCD } \\
\text { projector } \\
\text { - Chalk/marker pens/OHP transparencies } \\
\text { - Duster } \\
\text { - DVD player } \\
\text { - Speakers } \\
\text { - Video-Amma } \\
\text { - Video-Trigger tape-post-test counselling from } \\
\text { Mentoring tool kit produced by } \\
\text { - ITECH } \\
\text { - Handout } 4.7 \\
\text { - Slide: } 4.27-4.29\end{array}$ \\
\hline & 15 minutes & $\begin{array}{l}\text { Activity } 4.8 \text { : Solving } \\
\text { problems }\end{array}$ & $\begin{array}{l}\text { - } \text { Black/white board or flip chart or } \mathrm{OHP} / \mathrm{LCD} \\
\text { projector } \\
\text { - Chalk/marker pens/OHP transparencies } \\
\text { - Duster } \\
\text { - Handout } 4.8 \\
\text { - Slide } 4.30-4.37\end{array}$ \\
\hline & 20 minutes & $\begin{array}{l}\text { Activity 4.9: } \\
\text { Developing } \\
\text { interpersonal } \\
\text { relationships }\end{array}$ & $\begin{array}{l}\text { - Black/white board or flip chart or OHP/LCD } \\
\text { projector } \\
\text { - Chalk/marker pens/OHP transparencies } \\
\text { - Duster } \\
\text { - Worksheet } 4.9-4.11 \\
\text { - Slide: } 4.38-4.41\end{array}$ \\
\hline & 10 minutes & $\begin{array}{l}\text { Activity } 4.10 \text { : } \\
\text { Communicating } \\
\text { creatively and } \\
\text { assertively }\end{array}$ & $\begin{aligned} & \text { - } \text { Black/white board or flip chart or OHP/LCD } \\
& \text { projector } \\
& \text { - } \text { Chalk/marker pens/OHP transparencies } \\
& \text { - Duster } \\
& \text { - Worksheet } 4.12-4.13 \\
& \text { - Handout } 4.9 \\
& \text { - Slide } 4.42-4.43\end{aligned}$ \\
\hline Conclusion & 5 minutes & Summary and review & $\begin{array}{l}\text { - Worksheet } 4.14 \\
\text { - Slide } 4.44\end{array}$ \\
\hline
\end{tabular}

\section{Introduction}

\section{Slides: $4.1-4.2$}

It is important to teach about life skills because it could help individuals address and cope with the various challenges they may face daily in their personal and professional lives. For the purposes of this module, only psychosocial life skills are considered. Introduce the session by explaining that the module includes self-reflective exercises and group discussion. Emphasise that while the module gains its richness and meaning from the sharing, no one who feels uncomfortable sharing a memory will be required to do so. Reinforce the ground rules. \{Refer to Introduction Module Box 2\}. Emphasise that whatever is shared in this room will be kept confidential and will not be discussed outside the room.

Project the objectives of the module to the participants. Enquire if they have any clarifications (slide 4.2). 


\section{A. THE NEED FOR LIFE SKILLS TRAINING IN NURSING CURRICULA}

\section{Note for Facilitators: Activity 4.1}

Activity 4.1 will introduce the topic of life skills and why it is included in this training guide. It is important to recognise that nursing students do face several challenges in their professional life. If life skills were incorporated early in their professional training it is assumed to that they could be empowered to take on these challenges. The life skills selected in this training guide will focus on the main theme of the package viz., gender and sexuality issues, but some of the examples in the life skills will be from the general life context of a nursing professional. It is, thus, preferable to use Module 4 only after having completed Modules 1 to 3. Most of the examples used in this Activity are taken from real life situations but the identities of people are changed. It would be good if you could ask participants to come out with their own examples, as they will be able to relate to them better.

\section{Activity 4.1: What is the meaning of life skills?}

Purposes: The participants will

- Discuss the meaning and need for life skills

- List the common life skills needed to address the challenges and demands that they are likely to face.

\section{Materials:}

- Black/white board or flip chart or OHP/LCD projector

- Chalk/marker pens/OHP transparencies

- Duster

- $\quad$ Slides $4.3-4.4$

- $\quad$ Worksheet 4.1

\section{Process:}

1. Ask the participants what they understand by the term 'life skills'. Wait for their responses and then give them this information.

- Life skills are not just numeric and literacy skills that are usually learnt in the regular curricula, but also include psychosocial skills that empower individuals to be able to face challenges of their daily lives.

- There is no definite list of life skills. World Health Organisation lists 10 life skills that they assume are required by human beings to manage day-to-day situations.

- These life skills help individuals address the various issues they face. E.g. when dealing with sexuality and gender issues, it is important that a person has skills in decision making, critical thinking, problem solving, value clarification, self-awareness, communication and so on. Many of the skills are applied simultaneously in a given situation. Box 4.1 highlights some of the common life skills. All of these will not be addressed in this Module, but could be learnt over a period of time.

2. Project slide 4.3 (animated); ask participants why they think it is necessary to learn life skills. Wait for their responses. Introduce the reason for teaching life skills as is given in the slide. Brainstorm 'What are the challenges and demands of the nursing profession?' List their responses on the board for all to see and then project the rest of the slide. The reasons for teaching life skills to nursing students are mentioned below:

- Theory and practical demands of the curricula

- Practice on human beings during their training period

- Staying away from home

- Multiple roles: student, spouse, parent, care-giver etc.

- $\quad$ Risk of sexual harassment at workplace. 
3. After this, list the life skills that will be dealt with in this module. Project slide 4.4. The acronym 'STEADY EPIC' is used in this training guide based on the assumption that if these life skills listed are nurtured, nurses who are often confronted with changing and challenging environments, will be able to meet these with the right attitude and in addition will have a steady positive influence on others. Tell participants that while the life skills will be dealt with sequentially in the Module, in real life situations the skills are likely to be used simultaneously.

4. Conclude by asking the participants to individually list two life skills that they use the most and two that they use the least in their day-to-day interactions (both personal and professional). After they have listed the same, ask them to work on the life skills that they use the least, to enable them to deal effectively with the demands of every day life. Handout worksheet 4.1 and ask them to complete it when they are free.

\section{Box 4.1: Some of the common life skills}

\section{Communication and interpersonal skills}

\section{Interpersonal communication skills}

- Verbal/non verbal communication

- Active listening

- Expressing feelings; giving feedback (without blaming) and receiving feedback

\section{Negotiation/refusal skills}

- Negotiation and conflict management

- Assertive skills

- Refusal skills

\section{Empathy}

- Ability to listen and understand another's needs and circumstances and express that understanding

\section{Cooperation and team work}

- Expressing respect for others' contributions and different styles

- Assessing one's own abilities and contributing to the group

\section{Advocacy skills}

- Influencing skills and persuasion

- Networking and motivation skills

\section{Decision making and critical skills}

\section{Decision making/problem solving skills}

- Information gathering skills

- Evaluating future consequences of present actions for self and others

- Determining alternative solutions to problems

- Analytical skills regarding the influence of values and attitudes of self and others on motivation

\section{Critical thinking skills}

- Analysing peer and media influences

- Analysing attitudes, values, social norms and beliefs and factors affecting these

- Identifying relevant information and information sources

\section{Coping and self-management skills}

\section{Skills for increasing internal locus of control}

- Self-esteem/confidence building skills

- Self-awareness skills including awareness of rights, influences, values, attitudes, strengths and weaknesses

- Goal setting skills

- Self-evaluation/self-assessment/self-monitoring skills

\section{Skills for managing feelings}

- Anger management

- Dealing with grief and anxiety

- Coping skills for dealing with loss, abuse, trauma, etc

\section{Skills for managing stress}

- Time management

- Positive thinking

- Relaxation techniques 


\section{B. VARIOUS LIFE SKILLS}

Note for Facilitators: Activity 4.2

Activity 4.2 would sensitise participants to the common factors that cause stress. It is important to inform participants that the factors that cause stress and levels of stress are manifested differently in individuals. Sometimes, however, the same factor could manifest at different levels of stress in the same individual. Hence, it is important to acknowledge that stress is subjectively perceived. For example, for one participant studies may be identified as the chief factor causing stress, while for another, not having enough money or how they look could be the cause of stress. What is considered stress for one may be considered as a challenge for another.

Remind participants of the ground rules and to respect the differences that may exist amongst them. This activity will also help them recognise that stress needs to be faced and managed properly in order to reduce its negative impact on the quality of life.

Participants require a facilitator with whom they can talk freely, trust, and know that they could be guided and helped without any judgement or moralistic attitudes. Inform that everyone could go through stress, but what is important is for each one to recognise it when it exists, acknowledge it and then believe that they could work it out!

While Worksheet 4.2 is a part of this activity, please remember that sometimes participants may not want to complete the worksheet immediately. The Worksheet can be filled at anytime they perceive stress in their friends or in themselves.

\section{Activity 4.2: Stress management}

Purposes: The participants will

- $\quad$ Be able to be examine whether they are facing stress.

- Discuss the factors that cause stress in them.

- Demonstrate ways to manage stress.

\section{Materials:}

- Black board or flip chart or OHP/LCD projector

- Chalk/marker pens/OHP transparencies

- Duster

- $\quad$ Worksheet $4.2-4.3$

- $\quad$ Slides 4.5-4.9

- $\quad$ Handout 4.1

- $\quad$ Review of Worksheet 2.4 from module 2

\section{Process:}

1. Ask participants, "How many of you in this room face stress?" Wait for their response and then tell them you will be exploring the factors that cause stress.

- Divide the participants into smaller groups (6-8 per group). Distribute Worksheet 4.2. Questions 1-2 should be answered individually. This should then be followed by a 5-minute discussion in their group in which they come up with the three most important causes of stress. Alternatively, you could ask them to choose the three causes of stress in their group.

- Call the Group Coordinators forward and ask them to write the list of three most important/common causes of stress their group has identified on the board/flip chart/OHP transparency.

- Reinforce that causes of stress may be similar amongst groups or may be different. 
2. Brainstorm "Why is it important to address the factors that cause stress?" Wait for responses and then explain the following:

- If we do not deal with the factors that cause stress, then stress could build up in a person and cause burnout.

- $\quad$ List the symptoms of burnout as given in slide 4.6.

- Then ask the group, "What do you do when you are stressed?" Remind them to give the responses based on their answer to question 2 in Worksheet 4.1.

3. Project slide 4.7-4.8 and list the ways to 'Cope with Stress'. Distribute Handout 4.2 which has some suggested steps one could use to reduce stress. Remind them to complete questions 4-6 in Worksheet 4.1. This will help them to know whom they could approach when faced with stress. Reinforce that it is important to be able to find someone from whom they could seek help and with whom they can share their difficulties, struggles or challenges.

4. Brainstorm 'If you face a problem in the clinical area, then what would you do?' Project slide 4.9 after getting sufficient responses. Distribute Worksheet 4.2 and $4.2 \mathrm{~b}$. Remind participants that this could be used by them to assess their levels of stress at any time. The scores on the worksheet are a good indicator of the need for help to manage the stress. If the levels are not very high, they could seek help from a person whom they trust and believe could help them. But if the levels of stress are high, it would be better to seek professional help. You could also inform participants that Worksheet 4.3 could help them assess factors that could cause stress in them from the clinical area, and how they can cope with stressful situations.

5. Divide participants in to small groups (6-8 persons) and give them Worksheet 4.3. Ask them to

- Discuss and write the feelings they may encounter in such a situation.

- Examine if the situation would cause stress in them and if so,

- Would it be due to something from within them or from the environment?

- Could they control it?

- What would they do?

- After 10 minutes you could either discuss the various situations by eliciting from participants their responses to each case situation or if time permits ask the participants from each group to role play one situation, showing their reactions/feelings to the situation and what they would do in such a situation

6. Conclude by reinforcing that stress can be managed. What is important is to acknowledge it, face it and address the factors to reduce stress.

\section{Note for Facilitators: Activity 4.3}

It is important that you are able to recognise the value of your time, before you take the session on time management. You could be a role model to the participants' effective use of time while using the training guide, e.g. being on time for class, finishing on time, showing concern for another person's time by listening to what is said, etc.

The purpose of Worksheets 4.4 and 4.5 is to help participants recognise what they want to do with their own lives. Draw connections with their aspirations that were covered in Module 2: You could refer them back to Worksheet 2.4 of module 2, to identify resources. Reinforce how these limitations could be overcome with:

1. Focus on what one wants to achieve

2. Determination to achieve the goal

3. Effective utilisation of all the resources that one has: the social and emotional support, the finances and one's own abilities and skills.

Reinforce that a good way to use their time effectively is to maintain a log of time for a complete working week. Once they have done this ask them to see where they are spending most of their time and where they are spending the least of their time. Tell them to compare this with their aspirations and what is most important for them. Encourage 
them to check if time spent on an activity matches with their aspirations. If it does, commend them on it; if not, remind them that they can control their lives if they want to! Remind them that time management is a tool needed to succeed. It can enable them to achieve what is most important for them in their lives. This will enable them to participate in activities that they enjoy doing. They could thus, lead a balanced life.

\section{Activity 4.3: Time management}

Purposes: The participants will

- Become aware of how they utilise their time.

- Become sensitive to ways in which they could manage their time.

- Examine their aspirations and what is important for them at this point of life.

- Develop a time plan for their own selves based on their own priorities.

\section{Materials:}

- Black/white board or flip chart or OHP/LCD projector

- Chalk/marker pens/OHP transparencies

- Worksheet 4.4-4.5

- Slides 4.10-4.15

- $\quad$ Handout 4.2

\section{Process:}

1. Read aloud the following phrase 'What value does your time have' given in Box 4.2 that could help participants to reflect on the value of time.

\section{Box 4.2: What value does your time have?}

- To realise the value of a year, ask a woman who has just been diagnosed with cancer

- To realise the value of a month, ask the parents of a premature child

- To realise the value of a day, ask a daily wage worker with a family to feed

- To realise the value of an hour, ask two lovers who anxiously wait to meet

- To realise the value of a minute, ask the person who missed the last bus home

- To realise the value of a second, ask the person who just survived a car accident

- To realise the value of a millisecond, ask the athlete who came in second or the one who won the gold!

2. Distribute Worksheet 4.4, and ask participants to complete the questions in 5 minutes. Inform participants that the purpose of this worksheet would be to help them focus on their goals and objectives for their lives. Then allow the participants to choose a close friend and take 5 minutes to share with the friend the following questions

- When did you first decide what you wanted to be?

- Now that you have joined nursing, what is your plan for the next three to four years?

- What can you see yourself doing after you complete the course?

- What factors will guide you in making these decisions?

3. Time management is illustrated through the old fable about the tortoise and the rabbit (slides 4.10-4.13) that has been borrowed for the purpose. The assumption of using these slides in time management is just to highlight the value of time and to relate how effective usage of time is possible only through focusing on one's goals. If you do not have access to the LCD, you may read it out loud, so that it has the necessary impact. Brainstorm 
the questions given in slide 4.14. Wait for their responses and you could write them on the board. Probe till you get the list of responses given in parentheses.

- How did the tortoise win? Why did the hare lose? (Possible responses: The tortoise was steady and focussed while the hare who overestimated his capacities, lost track of time, was distracted, lazy, and most of all lost focus of the goal-to win)

- What could the hare have done to win? (Possible responses: Stayed focussed, finished the race and then slept or ate as much as he wanted after having won the race)

- What are the lessons learnt? (Possible responses: Have a goal, work towards the goal, manage time effectively, worrying about the goal will only waste time, look at the resources, look at the strength and weaknesses)

4. Give the participants Worksheet 4.5: What's most important for me? And ask them to take 5 minutes and complete it. Get a few of the participants to volunteer their answers. Write their responses for all to see. Point out that it is likely that they will have different priorities despite being in the same class, or studying the same course. Tell them that what is most important for them will depend on their values, their goals as well as their stage in life. e.g. 'to study well' may be the most important thing for someone, while for another it may be to have a 'good relationship', for yet another it may be 'to get along with his/her parents' etc. These priorities are likely to change as they complete their nursing course and move on in life.

5. Project slides 4.14-4.15 explaining about ways in which time could be managed. You could ask participants to make out a time plan for themselves for the next one week. Check it with them and if possible, at the end of the week help them to evaluate to what extent they have stuck to the time plan.

6. Give the participants Handout 4.2. This has the information that has been projected in the slides.

7. Tell participants that they will play a game. Instruct them to 'follow you!' You need to face the participants when you do this game. Say aloud:

- All students stand up please

- Follow me! (you need to show actions, as well as, say aloud)

- Put you right hand on top of your head

- Put your left hand on top of your head

- Now put your right hand on your forehead

- Now put your right hand on your nose (but place it on your chin)

- Ask the participants "What did you learn from this game?" Wait for responses and then tell them:

- 'To manage time you need to be able to not only be good at planning but also at visual communication and listening'.

- Give them examples-You are asked to teach something to the patient in the surgical ward, and you plan something because you perceive it as important for the patient. The patient is, however, upset about his family. He will not listen to you and if you get a feedback, you may realise that the patient had not listened. If you were observant enough to notice that the patient was anxious about his family, then you could have intervened to reduce it by addressing that particular need of the patient. This could save your time as well as that of the patient. It could facilitate the provision of appropriate information to the patient and the patient will be alert enough to listen to what you have to say

- Ask participants for similar examples that they could give.

8. Conclude by saying that time when managed well in one situation could pay off with more time in another situation. Tell participants, 'if you learn to manage your time well, you could do $80 \%$ of your work in $20 \%$ of time, which is your resource'. (Pareto's principle: $80 \%$ of work can be done using $20 \%$ of resources). This could mean that you could have time for all the fun things you want to do-watch movies, read, garden, form a relationship or spend more time with your family! 


\section{Note for Facilitators: Activity 4.4}

Activity 4.4 will help participants get in touch with their own emotions. Acknowledge what the participants share through the various activities. Be sure to reaffirm to participants that they are likely to go through different emotions for the same situation. This is based on one's perception of the situation and one's previous experience. Tell participants it is okay to have different emotions for similar situations. However, what is important is to recognise whether the emotion is a negative emotion or a positive emotion. Negative emotions (fear. anxiety, anger, jealousy, bitterness etc) affect us physically, mentally, emotionally, as well as, affect the way we would relate to others. They could also negatively affect the way we think of ourselves. Positive emotions, on the other hand, have a positive influence on the mind, body and our social relationships.

Do not hesitate to share your own personal experiences with the participants, as this could enhance their ability to share experiences. Reinforce the need to adhere to the ground rules and to maintain confidentiality.

\section{Activity 4.4: Managing my emotions}

Purposes: The participants will

- Get in touch with the different emotions they feel in different situations.

- Learn skills to manage emotions in their personal and professional lives.

- Analyse various situations in the context of their emotional responses and its management.

\section{Materials:}

- Black/white board or flip chart or OHP/LCD projector

- Chalk/marker pens/OHP transparencies

- Duster

- $\quad$ Slides $4.16-4.19$

- $\quad$ Handout 4.3

\section{Process:}

1. Say aloud the statements given in Box 4.3, one by one. Ask participants what they understand by it. Wait for response1s. If the meaning does not come out, use what is in the parentheses to explain the two statements:

\section{Box 4.3: Statements that could be used to introduce the life skill 'Managing your Emotions'}

\section{Statement 1:}

- "Manage your emotions or they will manage you" (Explain that it is important that our minds are able to take control over a situation rather than the emotions. In any stressful situation, it is important to separate the emotion from logical reasoning; then one will be able to manage the situation objectively)

\section{Statement 2:}

- "You can't manage your life until you manage your emotions." (Explain that life comes with its struggles and joys. What is important is to be able to cherish the joys and to manage the struggles. With struggles one will have various emotional responses. Some positive, while others will be negative. If we are able to cope with these emotional changes, separate it from the struggle that we are facing, then we are more likely to manage the struggle successfully) 
2. Project slide 4.16. Explain the meaning of emotions. Reinforce that emotions usually force us into action, unless the energy that comes from the emotion is so low (like in the case of depression) that the person will not be able to act. Brainstorm on "Why is it important to manage emotions?" Wait for responses and then explain:

- Emotions can affect the physical state (increase or decrease heart rate; increase or decrease breathing etc).

- $\quad$ Project slide 4.17. The slide is animated and shows two different pictures. The first picture is an angry lioness and the second is a kitten. Ask them, "Suppose you come face to face with this animal, what emotions you would feel?" Wait for responses (Most likely responses: fear, scared, terrified. The body gets tense, mouth dry, heart rate increases, breathing deepens etc.).

- Then ask them "What changes could you feel happening in your body?"

- Repeat the same question when the kitten is projected. Wait for responses (most likely responses: lovely feeling, cuddly feeling etc. The body feels relaxed, have a rush of positive energy etc.).

- Tell participants that it is important to manage one's emotions, as it could affect the emotional quotient. Emotional quotient is the way we understand ourselves; manage ourselves; understand others; and connect with others.

- Inform the participants that emotions could vary depending on the situation, the person and the past experiences of individuals.

3. Instruct participants to get into smaller groups (6-8 members) of their own choice. You would need to use the case situations 4.1-4.6 given in Box 4.4. These are situations that the participants are likely to experience during their training period. Read aloud each situation and brainstorm "What are the emotions you are likely to experience in such a situation and what are you likely to do if faced with such a situation?"

- Repeat the same with all the case situations. Do not spend more than 10-15 minutes for this part of the activity. It is important that participants recognise that they are likely to have different emotions for the same situation. Remember there is no correct or wrong emotions in any given situation, as situations are perceived differently by individuals.

- Remind them of the ground rules. Highlight that in all case situations you are likely to get responses that are negative rather than positive.

- Emphasise what is important is for them to recognise if the emotion evoked has a pleasant or a negative physical, behavioural and social effect. If it is negative, then it is essential that they take steps to reduce the impact of such emotions. since, it is these negative emotions that evoke negative physical effects that are similar to what we see in stress. 


\section{Box 4.4: Case situations to be used for recognising the different emotions people experience with the same situation}

\section{Case situation 4.1}

A patient has revealed his HIV status to you. He has not revealed his status to anyone else in the hospital, neither is it recorded anywhere in the medical record. He tells you to keep it confidential, but the information is worrying you.

\section{Case situation 4.2}

You are facing a serious relationships problem. You find that you cannot sleep, you are irritable and you are not getting your assignments done on time. What do you think you can do?

\section{Case situation 4.3}

You are giving bath to a patient. After the bath, you and the patient's attendant are clearing all things. For a brief while you are alone with the patient. In those short moments the patient catches hold of your hand and tries pulling you closer. It is obvious that the patient wants to get physically close to you. What do you think you could do?

\section{Case situation 4.4}

You are returning alone from the ward. It is $8.30 \mathrm{pm}$ and there is one corridor you have to walk through that is very lonely. While you are walking in that corridor you hear the footsteps of someone. What do you think you could do?

\section{Case situation 4.5}

You are going to take the history of a 21 year old man to write the admission notes. You go and ask him, 'What is your medical complaint?' and he replies 'I have kidney failure. And now you just leave me alone!!!' What do you think you could do?

\section{Case situation 4.6}

You have been taking care of a patient for the last 5 days. One day you find that you have been getting messages that you do not like from someone that you do not know. In the messages, the person always refers to the patient whom you were looking after.

4. Project slide 4.18 and discuss 'three sources of strength' each person could have, to help the person overcome situations that are difficult or challenging. Ask participants to complete Handout 4.3 individually. It will help them become aware of where they stand with regard to the 'three sources of strength'. Reinforce the need for each person to take personal responsibility to self-regulate emotions. Very often, we blame another for the emotions we feel, e.g. we may say, "It is because of you, I feel sad or angry or happy etc." Instead, one must learn to say the following:

- I am sad that....

- I am afraid that....

- I am angry that....

- My hope is....

- My joy has been..., is..., will be....

5. Remind participants that they need to be careful, especially with the negative emotions. Project slide 4.19 and list the various steps they could take to manage emotions.

6. Conclude by saying that emotions experienced by people will be different for the same situation. It is important to acknowledge the difference and be able to accept a person. Reinforce that when participants learn this, they may become more tolerant to differences in and amongst themselves as well as in their clientele. 


\section{Note for Facilitators: Activity 4.5}

Activity 4.5 requires considerable moving around. Do not hurry through this phase. It is essential that adequate time is spent on this part so that participants may be able to acknowledge that 'yes, there is good in each one'. Encourage participants to move around the class. All participants must be able to get at least 10 of their own peers to write one good quality they have seen in them. They might be hesitant initially. As they continue you will the find the energy levels of the participants increase and this reaches a crescendo when they actually read the good points written about them.

Reinforce that just like participants may feel good when they read about their good qualities from their peers, it would be good if they could develop this habit. Tell them to make an effort everyday to compliment someone or say something nice about them. You could probably also ask them to write out those good points in the Worksheet 4.6 so that they could then keep acknowledging these good points to themselves. Remind them that becoming aware of one's weaknesses could only help to make changes within so that these turn to strengths.

Be aware of how you conduct yourself. Be a good role model to the participants by showing that you are aware of your good qualities and are not embarrassed by your negative qualities. Do not hesitate to show that that you are making efforts to improve on them. Ensure to participants that just like in a pencil, mistakes could be erased; negative qualities of a person could be worked upon to become strengths of a person.

\section{Activity 4.5: Awareness of self}

Purposes: The participants will

- Become aware of their qualities.

- Acknowledge qualities in others through the activity.

- Become sensitised to the need of developing a positive self-image.

- Recognise how positive self-image could impact on expressions of sexuality.

\section{Materials:}

- Black/white board or flip chart or OHP/LCD projector

- Chalk/marker pens/OHP transparencies

- Duster

- $\quad$ Plain sheet of paper

- Dot pins

- Chart with all participants' finger print

- Worksheet 4.6-4.8

- $\quad$ Slides $4.20-4.21$

- Handout 4.4

- $\quad$ Review of Worksheet 4.2, Activity 1.3 of Module 1 and Activity 3.8 of Module 3

\section{Process:}

1. Tell participants that you will now be discussing the next life skill, 'Awareness of Self'. Distribute plain sheets of paper to each participant and instruct them to write out 'the best qualities' they feel that they possess in 5 minutes:

- Once they have completed this, give each participant a pin and ask them to turn this paper, and pin it on their backs with the help of other participants, so that the plain side is exposed to others.

- Tell them to move around and have at least 10 of their classmates/peers write a good quality they have seen in that person. 
- Encourage them to write something different on the paper, and not to repeat what someone else has already been written on the sheet of paper.

- Remind participants that they must only write one good quality, not a bad quality on the paper.

- Give them 10 minutes for the activity, at the end of which everyone must have at least 10 good points written by someone else on their sheets.

- Tell participants to sit down, take the sheet from their backs and read what was written by their friends.

2. Then brainstorm

- "How many of you felt good with the exercise?"

- "How many of you believe what is written on the sheet by your own batch mates?"

- "How many of you had written some similar qualities that your own batch mates had written about you?"

3. Reiterate that just like it felt good to read so many nice things about themselves, it would be good to practice this everyday with their peers. They could develop the habit of complimenting or saying something good to a friend every day.

4. Distribute Worksheet 4.6 and tell participants to fill it with what their peers had listed on the sheet of paper, when they have time. Encourage them to keep this Worksheet in a place where they can see every day. It could help reinforce their good qualities to themselves. You could tell them to add more to the list each day as they discover new qualities about themselves or if someone pays them a compliment.

5. Ask them to complete the third and fourth questions in Worksheet 4.6, "What are your worst qualities? What do you think you could you do with them? What can make you feel good about yourself? Then ask them to sit in the same groups as for Activity 4.4 and share with their group members at least one of their worst points. Give them 5 minutes for the activity. Brainstorm with participants, "what was easier to do- to write something nice about themselves and others or to share some of their worst points?"

- Give them this explanation:

- We are all made up of parts/qualities. Some parts/qualities we like - and others we do not.

- We can learn to like the parts we do not like—or change them!

- We have a choice. By remembering the parts we like we become surer of ourselves and more able to accomplish things.

- By focussing on the concept of liking ourselves we feel good around other people and better at anything we are doing. Remind them of the lessons they learnt through Activity 1.3 (Module 1): "What do I perceive of my body?" and link it to this activity.

- Tell them to review the Worksheet 4.2, and write down whom they would contact to share their negative points. Remind them that it is important to find a person whom they could trust and share their fears, worries, aspirations with so that they can get the needed guidance and help to improve themselves.

- Project slide 4.20 and explain the need for self-awareness.

6. Read aloud case situations 4.7-4.8 given in Box 4.5 and then brainstorm:

- Do you think you would have similar experiences?

- How do you think you could overcome such situations? (Possible responses: Becoming aware of the feelings, acknowledging the feeling exists, talking to someone who can be trusted to help, recognising the good qualities in self, etc)

- What is the danger of not taking care of feelings that arise in such situations? (Possible responses: One may begin to feel extremely negative about oneself. It is known that people with a low self-esteem can be self-destructive. It is important to think positively and have a good body image or else it could lead to the person engaging in activities that are risky for their health, viz., smoking, drinking, drugs, and multiple sexual relationships just to feel good. Remind participants that the feelings they may have when engaging in such activities are usually temporary) 


\section{Box 4.5: Case situations for reflection: Awareness of self}

\section{Case situation 4.7}

I am a girl studying in nursing school and I have always been feeling low as I have a dark complexion. This has been my situation since I can remember. My mother made me use curd, milk, turmeric, but nothing seems to have had an effect. My friends and my sister are fairer than me and I can't help feeling uneasy going out with them. Is it my fault that I am dark? Is there any possible way to become fair? Is it a crime to be dark?

\section{Case situation 4.8}

These are the questions that bother me day and night. I am a boy of 18. My problem is that I have never had a girlfriend - all my friends who study in other colleges call me "Bookworm". When I am in the midst of people I feel they are looking at me as a bookworm. This embarrasses me a lot and I lose self-confidence and can't concentrate fully on my studies. I feel I am the only one who does not have a girl-friend, I feel unattractive, I have lost interest in everything, my family my surroundings, my friends. I sometimes even ask God, why was I born? And I get so discouraged that I would like to commit suicide as I think it is the best way.

7. Distribute Worksheet 4.7-4.8. Tell the participants to complete it in 5 minutes. This will help them focus on who they are, their values, their aspirations, and what they would like to change. Awareness of one's values comes in useful when making decision; also an individual's values may not be the same as those of their own families or their communities.

8. Narrate the 'Story of the pencil' slowly as given in Box 4.6.

\section{Box 4.6: Reflective story: Story of the pencil}

The Pencil maker took the pencil aside, just before putting him into the box.

'There are 5 things you need to know," he told the pencil, "Before I send you out into the world. Always remember them and never forget, and you will become the best pencil you can be.'

'One: You will be able to do many great things, but only if you allow yourself to be held in someone's hand.'

'Two: You will experience a painful sharpening from time to time, but you'll need it to become a better pencil.'

'Three: You will be able to correct any mistakes you might make.'

'Four: The most important part of you will always be what's inside.'

'And Five: On every surface you are used on, you must leave your mark. No matter what the condition, you must continue to write'

The pencil understood and promised to remember, and went into the box with purpose in its heart.

9. Brainstorm the following questions. Wait for responses and write those on the board for all to see:

- Whose hand would that be? (Possible responses: a friend, parent, teacher, someone who wants the best for me, etc.).

- What is meant by painful sharpening? (Possible responses: difficulty, failure, challenges, something that we do not like etc.).

- Is it possible to correct your mistakes? (Possible responses: yes, if we acknowledge that we can, sometimes we may need help).

- What is the most important part of you? (Possible responses: character, what is inside, my values, etc.).

- Do you have a vision? What do you want to achieve? (Possible responses: Refer back to Worksheet 4.8). 
10. Conclude by asking participants what they learnt from the last 4 activities. Remind them that,

- Each one of them is UNIQUE with no carbon copy (Direct their attention to the chart, where they had all imprinted their finger prints), and that is reason enough to be proud. Reinforce the ways in which self esteem could be built (slide 4.21).

- Their perception of themselves is influenced by their relationships and experiences (as has already been discussed in Module 1-Activity 3). This could be changed with positive reinforcement.

\section{Note for Facilitators: Activity 4.6}

Activity 4.6 will help in bringing to focus all the previous life skills that have been dealt with, so far. It is also focussed on decision making with regards to sexual decision making and negative peer pressure. The whole activity is through a single case scenario. Take time to discuss each part in detail.

You may have to give participants enough time to practise the role plays on how to make a decision for negative peer pressure. If need be, and depending on the ability of the participants, give them a day to practise and then ask them to enact the role play in the next class. Be positive in your approach and when debriefing focus on the positive aspects.

\section{Activity 4.6: Decision making}

Purposes: The participants will

- Describe their own decision making process.

- Review the Professional Code of Ethics that could guide them in their professional work.

- Act out and analyse case situations that demonstrate how to apply the decision making model.

\section{Materials:}

- Black/white board or flip chart or OHP/LCD projector

- Chalk/marker pens/OHP transparencies

- Duster

- $\quad$ Slides $4.22-4.26$

- Handout 4.5-4.6

\section{Process:}

1. Project slide 4.22 and tell participants that as young health care professionals there are several situations they are likely to face where decision making is crucial. It could be for simple things such as going out for a movie to bigger ones such as committing to a relationship, or giving in to negative peer pressure or with regards to care of a client. It is important therefore that decision making is discussed with a focus on forming relationships and countering negative peer pressure. Highlight that sometimes in the clinical situation they may be faced with situations that are challenging. It is important that they learn to make valid decisions on these occasions.

2. Then ask the participants to read Handout 4.5; brainstorm the following questions. Wait for responses.

- How are most decisions made in reality? (Possible responses: without thinking, just like that, we think and we make a decision)

- How often have you drifted into making a decision, or let other people/someone else lead you into a decision? (Possible responses: always/very often/sometimes/rarely/never)

- What were the consequences? (Possible responses: good/bad/OK-it did not matter)

- Is it difficult to make good decisions? What makes it difficult? What makes it easier? (Appropriate response: Yes especially when the decision is crucial. It would become difficult if we do not follow a systematic process to make the decision. Using a systematic process can guide in making the decision good) 
3. Then, explain the points in the POWER model for decision making as is given in slide 4.23.

- Ask the participants for an example where they would have to make a decision. If none is forthcoming, give them the same example 'Raju and Seema' of Activity 3.3 from Module 3 with regards to a relationship

- P: What is the problem? (Possible responses: The relationship does not seem to be healthy)

- O: What are the options possible? (Possible responses: The possible options are restore the relationship, break the relationship or just do nothing)

- W: Weigh the options-What are the pros and cons of each option? (Possible responses: look at the positive [pros] and the negative [cons] aspects of each of the three options

- E: Which is the best option? (Possible responses: Choice was made based on your value system, you may take assistance provided by someone who you trust, or some past experiences you have had etc.)

- R: Reflect-What was the effect of your decision? (Possible responses: The decision was effective, there could have been a better option, let me learn from this mistake and be careful next time

4. Inform participants that the focus of the next part in this activity would be how to make decisions with regards to sexual relationships. Read aloud the case situation 4.9 given in Box 4.7 and then brainstorm the various issues that arise from each part of the case situation.

\section{Box 4.7: Case situation to discuss sexual decision making}

\section{Case situation 4.9}

PART A: Priya, a 19 year old nursing student is assigned to Rahul who is 20 years. He is admitted for de-addiction in the psychiatry ward. She begins to take care of him. He is in the ward for 4 weeks and is discharged. He maintains contact with her, and she likes him. The relationship deepens and they have sex one day. She realizes that she is pregnant. She is staying in the hostel, and is afraid of what the authorities would do. She goes out with a class mate and has an abortion.

PART B: Priya, however, continues to see Rahul. She feels she is in love with him and cannot be happy without continuing the relationship. She does not disclose to him that she had an abortion. Rahul lives alone in Bangalore and is studying law. His parents live abroad. He has never been close to them. He is the only son.

PART C: One day Priya comes to college. She is posted in the rural area for three months. Her supervisor notices her to be withdrawn. The teacher asks her if all is well with her. She says yes. But that night she is brought to the casualty having taken an overdose of sleeping pills.

PART D: In the hospital Priya then reveals to her supervisor, who had shown concern for her, that she did so because Rahul had committed suicide. She could not live without him. Priya comes from an orthodox family, and is loved by her parents. She was apprehensive about her parent's reaction once they heard what had happened

PART E: Priya is in the last month of her studies. Her parents come to meet her in the hospital. They support her. She goes home after that month. When she returns, she comes and reveals to the teacher that her marriage is arranged to a person who is abroad. She is confused whether she should tell him what had happened to her, and if so what might happen to her. She asks the teacher for help.

- Wait for the responses. Ask the participants to refer to Handout 4.6: "Code of Ethics and Professional Conduct of Nurses". What are the issues that arise from this Case Scenario? (Answer this question for each of the parts in the case scenario)

- Which life skills will come into play to help Priya?

- Ask participants which of the Code of Ethics and Professional Conduct were violated in the case situation.

- It is important that you draw the link of sexual and reproductive health rights in each part of the case situation. Do not give your personal opinion but provide facts. Remind participants about the ground rules, as they are likely to have differences of opinions.

- Ask participants to suggest what Priya could have done. Give them references of studies that show how adolescents and young adults could reduce risky sexual behaviours. Most of them emphasise the need for giving unbiased sexual and reproductive health information, using the rights based approach to adolescents and youth, so they could make informed choices. 
- Crosby and Miller showed that parental, especially maternal influence could reduce female sexual risk behaviours through monitoring, warmth, support and sexual risk communication

- Other studies have shown that healthy maternal influence could protect adolescent females from unhealthy peer influences. For both sex and condom use, the peer norm - behaviour relationship was moderated by parental communication: Peer norms were more strongly related to behaviour among adolescents who had not discussed sex or condoms with a parent.

- R.A. Crosby, R.J. DiClemente, G.M. Wingwood \& S. Davies showed that adolescent's ambivalence about becoming pregnant was associated with comparatively less frequent use of contraceptives.

- Project slide 4.24-4.25 and review the points to keep in mind in making decisions with regards to sexual relationships.

- Brainstorm with participants, "What are some similar situations that you face where decisions would have to be made?"

5. Project slide 4.26 and explain the points to keep in mind when making decisions in situations where there is negative peer pressure. Divide the participants into 5 groups and tell them they will each be given one case situation (See Box 4.8). You could write a case situation on a slip of paper and distribute it to each group. They could take 10 minutes to plan a role play, showing how they have made a decision to overcome negative peer pressure.

\section{Box 4.8: Case situations for role plays to be enacted}

\section{Case situation 4.10}

Your friends are forcing you to buy something that you cannot afford.

\section{Case situation 4.11}

Your friends are calling you out to go for a movie show that you know your parents will not be happy about.

\section{Case situation 4.12}

Your friends say why are you so good and doing everything for the patient? Any way what is the use, nobody bothers!

Case situation 4.13

All your friends are going out for a party. You know your family does not like you to go out for such parties.

Case situation 4.14

Your friends tell you there is nothing wrong in smoking and drinking. 'Everyone is doing it, so why don't you?'

6. Conclude by reinforcing the ways to counter negative pressure. Ask them "Do you think your life is precious? If yes, what are ways in which you would preserve it?" Draw their attention to Worksheet 4.6 and ask them to check if they are focused on what is important to them in their decisions. Clarify any issues.

\section{Note for Facilitators: Activity 4.7}

Please note that for Activity 4.7 you will need to check your preparedness-a DVD player and speakers should be available; check the videos to see if they are working. The first video 'Amma' is a short story of a girl who loses her mother. The movie is a very good example of empathy. Both the child and the Health Care Worker demonstrate empathy. E.g. the child says "Paavam amma! She will get injection in the hospital. Why are people saying that you and appa are bad people?" etc.

The second video is a trigger tape from the International Training and Education Centre on HIV (I TECH) Mentoring Toolkit. You could highlight how important empathy could be to facilitate behaviour change. The video is about a young man who comes for HIV test result. The Health Care Provider is very empathetic and demonstrates qualities of respect, active listening, acknowledging the strengths of the client and guides him into making appropriate choices.

It is important to highlight to participants that we are all born with empathy but we are generally not aware of it. Tell participants that it is time that we start understanding and being empathetic. 


\section{Activity 4.7: Empathy}

Purposes: The participants will

- Describe the steps to develop empathy.

- List the benefits for developing empathy with clientele.

- Practise skills of empathy in client interactions.

\section{Materials:}

- Black/white board or flip chart or OHP/LCD projector

- Chalk/marker pens/OHP transparencies

- Duster

- DVD player

- $\quad$ Speakers

- Video-'Amma'-Dept. of Experimental Medicine and AIDS Research Centre of T.N. Dr. M.G.R. Medical University, Chennai

- Video-Trigger tape-'Post-test Counselling' from Mentoring Toolkit produced by International Training and Education Centre on HIV (I TECH)

- $\quad$ Slides 4.27-4.29

- $\quad$ Handout 4.7

\section{Process:}

1. Project slide 4.27 to describe the meaning of empathy. Show participants the video 'Amma'. This is a short video about a 5 year old child whose mother was diagnosed to be HIV positive. It shows the child with the mother when she is well and when she gets sick. The child is put in a home for a while, till one day the Health Worker comes to see the girl. Her mother had written a letter to her. Ask participants

- What were your feelings when you viewed the video?

- Who do you think is showing empathy in the video?

- $\quad$ Give some examples of empathy demonstrated in the video.

2. Project slides 4.28 and 4.29 that highlight how one could develop empathy. Ask the participants, "What do you understand about listening empathetically? Give examples." Inform them about skills of expressing empathy as given in Box 4.9 .

\section{Box 4.9: Tips to show empathy to a client}

- Look at the person

- $\quad$ Listen to what is being said

- Watch for non-verbal clues

- How does the person express his/her feelings?

- What does the person talk about?

- How do they feel about what they talk about?

o Does giving all your attention to the other person improve listening?

- Focus on what is important to the client

- Give information that is relevant 
3. Explain that as nurses, we are trained to look for problems. This means that we may only see what we think is wrong, and try to correct it. We must learn to recognise what a patient is doing right, and praise or show approval of good practices. Accepting what a patient thinks and feels; plus recognising and praising is good practice - it builds a patient's self-confidence, encourages him/her to continue good practices, he/she is more likely to accept any suggestions that you make.

4. Give participants some tips to remember how to demonstrate skills of empathy.

5. Conclude by asking participants, "How do you think you can put this into practice in your daily life?" Get some examples from them. Ask one of the Group Coordinators for the day to write these on the chart that is provided. Give participants Handout 4.7 to read and reflect on points that were discussed under empathy.

\section{Note for Facilitators: Activity 4.8-4.9}

In Activities 4.8 \& 4.9 the story of "The Tortoise and the Hare' is continued. It is used to demonstrate how through problem solving techniques and interpersonal techniques to ultimately become good friends. It is important that you draw comparisons with real life situations. You would have to reiterate how managing stress, valuing time, managing emotions, becoming aware of one's strengths and weaknesses, as well as, demonstrating empathy (all the life skills we have completed so far) helped the hare and tortoise solve their problem of competing and develop a partnership with each other. Emphasise that these same techniques would be required for effective functioning in their professional and personal lives.

\section{Activity 4.8: Solving problems}

Purposes: The participants will

- Identify the meanings of problems.

- Use the steps in the 'POWER' model for solving problems.

- Apply the problem solving steps in analysing 'The Tortoise and Hare' story.

\section{Materials:}

- Black/white board or flip chart or OHP/LCD projector

- Chalk/marker pens/OHP transparencies

- Duster

- $\quad$ Slides 4.30-4.37

- $\quad$ Handout 4.8

\section{Process:}

1. Do this energising yet reflective game for the participants to understand problem solving:

- Ask at least 10 participants to volunteer to go out. Then instruct the rest of the participants to form a circle holding hands, so that they are all turning inwards.

- Make one of the participants to come under the arc formed by two participants in the circle, without breaking the circle. Ask all other participants to follow till the whole circle is now facing outward.

- Tell participants to continue holding each other's hands, whatever the circumstances.

- Call those participants who are outside and ask them to try make the circle face inwards without breaking the chain.

- Give them 5 minutes for the activity. If they are not able to follow the instructions, then ask the participants to form the chain so that all are turning inwards. It is important that they do not unlink their hands in the process. (The best way to do this is such that one person again goes under the arc formed by the participants directly opposite him/her and the rest in the circle follow). 
2. Project slide 4.30-4.31 to highlight the meaning of problems (See Box 4.10) and what they could do when faced with problems. Use the POWER model to make decisions that was highlighted in Activity 4.7. Reinforce the need to stop, reflect, weigh the options and choose the best possible option to solve the problems. Give participants an example of how to apply the POWER model by using any of the situations that have already been discussed or with a new example that someone may share.

\section{Box 4.10: Meaning of the acronym 'PROBLEM'}
P: Predictors
R: Reminders
O: Opportunities
B: Blessings
L: Lessons
E: Everywhere
M: Messages
S: Solvable

3. Tell participants that every problem can be used as an opportunity, a lesson to learn from, and a reminder to see whether we can do better. Then tell them that the story of the 'Tortoise and Hare' is continued from where it was stopped during the session on time management. Narrate the story as given in the slides 4.32-4.33. Remember this is a reflective story. Project slide 4.34, complete the story and ask participants, "What are the lessons learnt?" Wait for responses and then project the rest of the slide. Emphasize:

- Being aware of one's strength and weaknesses;

- Reflecting on one's failures;

- Focussing on the job at hand; and

- Being persistent could help in facing a challenge.

Ask participants if they have any examples in real life where they can apply these lessons. Wait for responses.

4. Then continue to narrate the story using slides $4.35-4.36$

5. Project slide 4.37 and ask participants, "What lessons are learnt now?" Wait for responses. The slide is animated. Click and a picture will come on the screen that looks like a duck/rabbit. Try and encourage discussion by asking the participants what they see in the picture:

- $\quad$ Responses may include 'duck'

- Wait for more response till you get someone saying a 'rabbit'. You will notice participants looking in different directions and changing position to see the rabbit

- Tell them problems could be solved by being creative, reflecting and changing perspective, like the tortoise did with the hare to win the race

- Ask "Do you think this lesson could be applied in real life?"

6. Conclude by giving them Handout 4.8 to read on the points covered under problem solving. Reinforce that if problems are solved on time, it could prevent stress, save a lot of time, and thus prevent burnout as well.

\section{Activity 4.9: Interpersonal relationships (IPR):}

Purposes: The participants will

- Be able to reflect on their interpersonal skills.

- Become aware of who is in their relationship chart.

- Assess their interpersonal skills. 


\section{Materials:}

- Black/white board or flip chart or OHP/LCD projector

- Chalk/marker pens/OHP transparencies

- Duster

- $\quad$ Worksheet 4.9-4.11

- $\quad$ Slides $4.38-4.41$

\section{Process:}

1. Ask participants, "Why do you think we need to develop good IPR?" Wait for responses. Then ask, "What do they understand by the two proverbs given below?"

- It is in the shelter of each other that people live (Irish proverb).

- No man can live like an island (John Donne, English poet and clergyman 1572-1631).

Wait for responses and then tell them, there is value in relationships.

2. Distribute Worksheet 4.9 to participants and ask them to complete it in 10 minutes. Tell them there is no right or wrong answers but that the exercise will show them where they stand with relationships. Remind them of the ground rules and underline that they need not share it with anyone else. However, inform them if they have someone who is like a mentor to share it with the person, as he/she may be able to help in improving their interpersonal relations.

3. Project slide 4.38 and explain about the Relationships chart:

- Most people will have small communities around them. These could include family, friends, and colleagues in college, community where they live and God.

- Ask participants to take Worksheet 4.10 and within 5 minutes write under each of the circles names of the people whom they believe they have a good relationship with. Tell them not to think about it too much. The people who matter will be those who come to mind immediately.

- Highlight that this chart can help them recognise the people who are most important in their lives. Sometimes, this list remains for the rest of their lives, while sometimes, depending on the circumstance or situation, the list of people may change. For example, if they change jobs and go to another country, then they may not have their family with them or their close friends etc. or if they get married they may form more relationships with the members of their spouse's family. Ask them if they can think of any other examples.

- Tell participants that from this relationship chart, they will be able to identify whom they can trust enough to share confidential problems. Remind them to check with what they had written in Worksheet 4.2 (person they could trust)

4. Then inform the participants that the story of the Tortoise and the Hare will continue. Show them slides 4.39-4.41. The last slide 4.41 is animated. Brainstorm - "What are the lessons you have learnt now?" Highlight the key learning's from the story of the Tortoise and the Hare as mentioned in this slide 4.41.

5. Give participants Worksheet 4.11 to complete in 10 minutes and help them to interpret where they stand with regards to their relationships. This Worksheet will help them recognise how good they are at receiving feedback from others as well as disclosing about themselves to others. Inform them the higher their scores in these, the better they are in their interrelationships.

6. Conclude by saying that this session would help participants recognise how important it is to have good interpersonal relations and where they presently are in their interpersonal relations. Reinforce that as nurses, it is important we develop this skill, as it could help us effectively coordinate with the health care team in the hospital, network with various key stakeholders in the community or collaborate with other nurses to enhance the profession. Emphasise that the nurse is the only health care team member who is in the hospital round-theclock. She has to coordinate with all other health care team members for effective delivery of service. This skill would definitely stand good in such a situation. 


\section{Note for Facilitators: Activity 4.10}

Remember, that participants will learn the basics of communication during their regular curricular courses. The purpose of Activity 4.10 is to help participants identify situations when they have to be assertive and how they could be assertive. It is best that participants learn these skills early in their professional course so that they can use these skills effectively in both their personal and professional lives

\section{Activity 4.10: Communicating assertively}

\section{Purpose: The participants will}

- Discuss how to communicate assertively.

- Recognise the ways in which they communicate.

- Practise how to be assertive using the Assertive Discrimination Index sheet.

\section{Materials:}

- Black/white board or flip chart or OHP/LCD projector

- Chalk/marker pens/OHP transparencies

- Duster

- Worksheet 4.12-4.13

- $\quad$ Slides 4.42-4.44

- $\quad$ Handout 4.9

\section{Process:}

1. Ask participants "What factors would help them to communicate assertively?" Give them the meaning of assertiveness, why it is necessary to be assertive, and how one can be assertive by briefly using the information given in Handout 4.9 .

2. Distribute Worksheet 4.12 to participants. They could complete this worksheet in their free time. Tell them that their responses to each of the statements in the worksheet will help them recognise where they need to improve in their communication. Those statements to which they have responded 'rarely' or 'never' would indicate areas that need to be strengthened.

3. In order to clarify what an assertive statement is, use Worksheet 4.13-Assertion Response Index. Clarify with participants what are the various ways of responding:

- Submissive response

- Aggressive response

- $\quad$ Assertive response

Brainstorm with the participants the kind of assertive response they would give. As they respond to the statements, you have to ask them to identify whether it was an assertive response, an aggressive one or a submissive one.

4. Conclude the Module by telling participants that all these life skills, if developed adequately, could help them achieve their goals in life. They could be helpful to them in situations that are challenging. Check if any clarifications are required. Ask participants to complete Worksheet 4.14 and to return it to you. Their responses will help you see what changes would be needed in the respective module.

\section{CONCLUSION}

Inform the participants that you have completed all the Modules. Assure them that you will be available for any help if needed. You may want to follow up with the participants to check the impact of the training on them. You could use any of the Worksheets that have been previously used in the modules, to be able to assess change in knowledge, attitudes or even skills. 


\section{Worksheets}

\section{Worksheet 4.1: Self reflection-Stress management}

1. What are the factors that usually cause stress in you?

2. What do you do when you are stressed?

3. What does trust mean to you?

4. Is it easy for you to trust others? If yes why? If no why? Do you think you could work around this by yourself or with someone's assistance?

5. List three people that you trust enough to tell your feelings

6. If you are staying in the hostel, and you face a problem in the professional or personal area, whom do you think you would trust enough to discuss your feelings?

You could do this when you are free so that in times of stress you know what you could do. Remember you and you alone should be in control of your life. 


\section{Worksheet 4.2: Assess your stress levels}

The Stress Checklist was designed to give you some idea that how stressed you are in life. Check the column that best reflects what is true for you. Go through the list quickly. Your first response is normally the most revealing. Be honest. After all, only you will see the results.

\begin{tabular}{|l|l|l|l|l|} 
Statements & Always & Sometimes & Rarely & Never
\end{tabular}

1. I finish the day feeling satisfied with what I have done.

2. I feel in control of my life.

3. I experience dizzy spells or palpitations.

4. I feel fatigue or lack of anger.

5. I have difficulty getting sleep.

6. I am confident about the future.

7. I have a poor appetite.

8. I lose my temper over minor/small things.

9. I can rely on my family or friends to support me if I need help.

10. I find the amount of work I have exceeds the amount of time available for it.

11. I feel I am as good as anyone else at the job I do.

12. I find people with whom I work with/deal with everyday supportive.

13. I look forward to the next day.

14. I do not know what I'm working for.

15. I am unable to unwind/relax in the evening or at the end of the day.

16. I have more responsibility than I can handle.

17. I drink too much alcohol $/ \mathrm{smoke}$ excessively/chew paan.

18. I can switch off thinking about problems.

19. I think I manage my time well.

20. I know how to refuse to take on additional work if I need to. 


\section{HOW TO ADD UP YOUR SCORE}

- Questions 1, 2, 6, 9, 11, 12, 13, 18, 20: Score 1 for "Always", 2 for "Sometimes", 3 for "Rarely", and 4 for "Never".

- Questions 3, 4, 5, 6, 7, 8, 10, 14, 15, 16, 17: Score 4 for "Always", 3 for "Sometimes", 2 for "Rarely" and 1 for "Never".

\section{Minimum Score 20}

How to interpret your score

\begin{tabular}{|c|c|}
\hline $70-80$ & Very high level stress \\
\hline $60-70$ & Severe Stress \\
\hline $40-60$ & Moderate stress \\
\hline
\end{tabular}

\section{Adapted from source:}

- Beck, D. L. and R. Srivastava. 1991. "Perceived level and source of stress in baccalaureate nursing students". Journal of Nursing Education 30 (3):127-133.

- Luthans, F. 1998. Organisational Behaviour. (8th Edition). Boston: Irwin McGraw-Hill.

- Demerouti, A., A. B. Bakker, F. Nachreiner et al. 2000. "A model of burnout and life satisfaction amongst nurses". Journal of Advanced Education 32 (2): 454-464.

\section{Worksheet 4.2 B: Perceived stress scale for undergraduate student nurses in the clinical area}

Given below are a series of items about stress related to your clinical postings. There are no 'right or wrong answers' for these statements. As you read each item record how stressful you have found the situation on a scale of $0-4$ where ' 0 means no stress and 4 means extreme levels of stress', by placing a check $(\sqrt{ })$ on the appropriate response. Your responses are for you alone, and if you feel you need help, seek help from a person you trust or from a professional.

Please be sure to answer every statement.

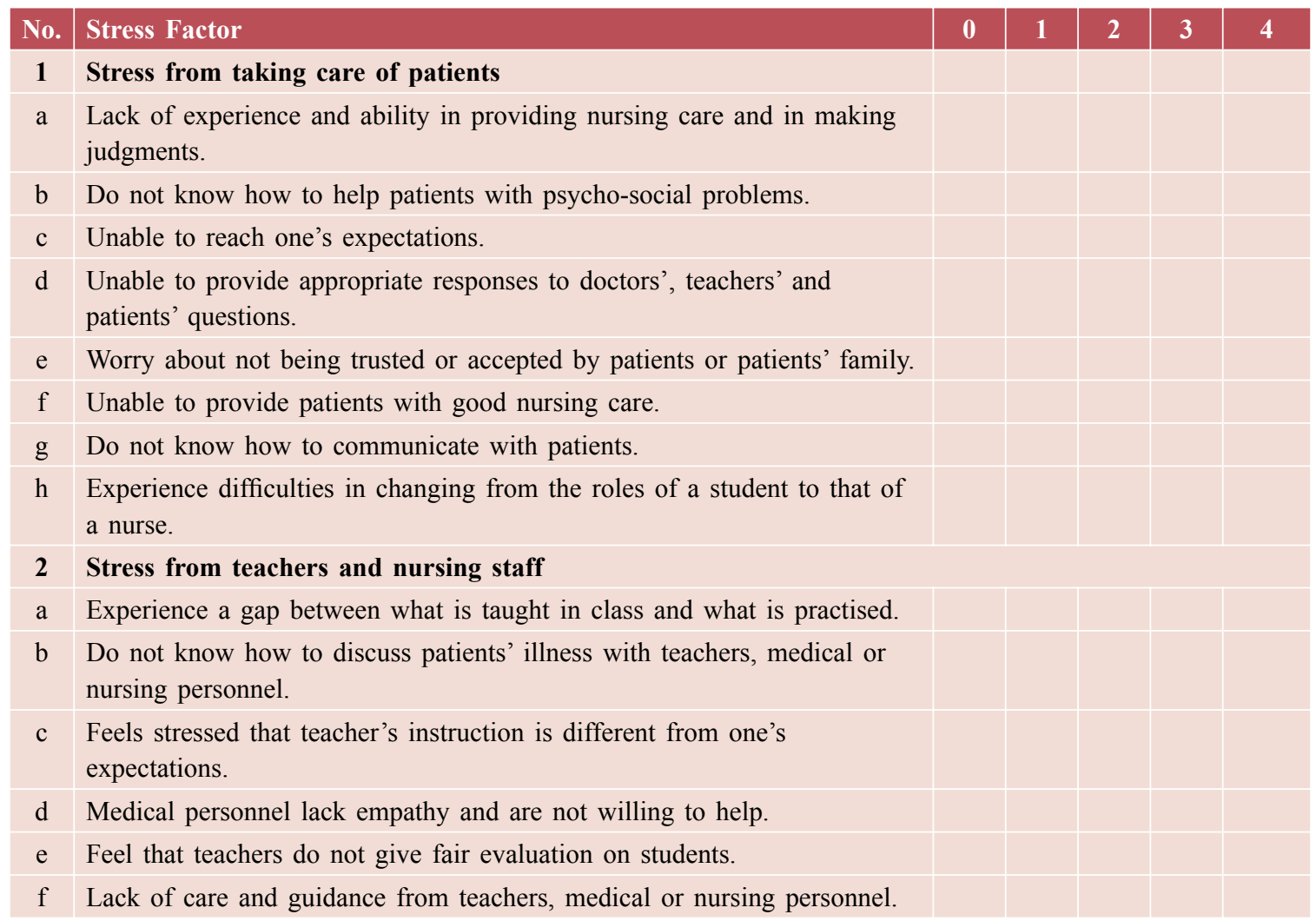

Cont'd on next page... 
Cont'd...

\begin{tabular}{|c|c|c|c|c|c|c|}
\hline No. & Stress Factor & $\mathbf{0}$ & 1 & 2 & 3 & 4 \\
\hline 3 & Stress from assignments and workload & & & & & \\
\hline a & Worry about bad grades. & & & & & \\
\hline $\mathrm{b}$ & Experience pressure from the nature and quality of clinical practice. & & & & & \\
\hline $\mathrm{c}$ & Feel that one's performance does not meet teacher's expectations. & & & & & \\
\hline $\mathrm{d}$ & $\begin{array}{l}\text { Feel that requirements of clinical practice exceed one's physical and } \\
\text { emotional ability to cope. }\end{array}$ & & & & & \\
\hline e & $\begin{array}{l}\text { Feel that dull and inflexible clinical practice affects one's family and } \\
\text { social life. }\end{array}$ & & & & & \\
\hline 4 & Stress from peers and daily life & & & & & \\
\hline a & Experience competition from peers in clinical practice. & & & & & \\
\hline $\mathrm{b}$ & $\begin{array}{l}\text { Feel pressure from teachers who evaluate students' performance by } \\
\text { comparison. }\end{array}$ & & & & & \\
\hline $\mathrm{c}$ & $\begin{array}{l}\text { Feel that clinical practice affects one's involvement in extracurricular } \\
\text { activities. }\end{array}$ & & & & & \\
\hline d & Cannot get along with other peers in the group/class. & & & & & \\
\hline 5 & Stress from lack of professional knowledge and skills & & & & & \\
\hline a & Unfamiliar with medical history and terms. & & & & & \\
\hline $\mathrm{b}$ & Unfamiliar with professional nursing skills. & & & & & \\
\hline $\mathrm{c}$ & Unfamiliar with patients' diagnoses and treatments. & & & & & \\
\hline 6 & Stress from the environment & & & & & \\
\hline a & $\begin{array}{l}\text { Feel stressed in the hospital environment (the people, the way things } \\
\text { happen in the hospital is too formal etc) where clinical practice } \\
\text { takes place. }\end{array}$ & & & & & \\
\hline $\mathrm{b}$ & Unfamiliar with ward facilities. & & & & & \\
\hline $\mathrm{c}$ & Feel stress from the rapid change in patient's condition. & & & & & \\
\hline
\end{tabular}

\section{Physio-psycho-social response scale}

Given below are a series of physio-psycho-social symptoms that may occur during your clinical postings. There are no 'right or wrong answers' for these statements. As you read each item record how often you may have experienced these symptoms on a scale of $0-4$ where 0 means never and 4 means always, by putting a check ( $\sqrt{ })$ on the appropriate response.

Your responses are for you alone, and if you feel you need help, seek help from a person you trust or from a professional.

Please be sure to answer every statement.

\begin{tabular}{|c|c|c|c|c|c|c|}
\hline S. No & Physio-psycho-social Status & $\mathbf{0}$ & 1 & 2 & 3 & 4 \\
\hline 1 & Physical symptoms & & & & & \\
\hline a & I feel giddy. & & & & & \\
\hline $\mathrm{b}$ & I experience nausea and vomiting. & & & & & \\
\hline $\mathrm{c}$ & I have vertigo and feel dizzy. & & & & & \\
\hline d & I feel pressure in the chest. & & & & & \\
\hline e & My fingers and toes feel numb. & & & & & \\
\hline $\mathrm{f}$ & I have stomach ache and diarrhoea. & & & & & \\
\hline $\mathrm{g}$ & I have difficulty in breathing without any reason. & & & & & \\
\hline $\mathrm{h}$ & I catch a cold. & & & & & \\
\hline
\end{tabular}

Cont'd on next page.. 
Cont'd...

\begin{tabular}{|c|c|c|c|c|c|c|}
\hline S. No & Physio_psycho-social Status & $\mathbf{0}$ & 1 & 2 & 3 & 4 \\
\hline 2 & Emotional symptoms & & & & & \\
\hline a & I tend to be worried and nervous. & & & & & \\
\hline $\mathrm{b}$ & I tend to be nervous and anxious lately. & & & & & \\
\hline c & I often feel low in spirits and depressed. & & & & & \\
\hline d & I feel afraid without any reason. & & & & & \\
\hline $\mathrm{e}$ & I feel I am going to have a nervous breakdown. & & & & & \\
\hline $\mathrm{f}$ & I feel more anxious lately. & & & & & \\
\hline g & I cannot calm down. & & & & & \\
\hline 3 & Social behavioural symptoms & & & & & \\
\hline a & I am not optimistic about my behaviour. & & & & & \\
\hline $\mathrm{b}$ & $\begin{array}{l}\text { My life is not colourful (pleasurable, happy, joyful, and positive } \\
\text { feelings). }\end{array}$ & & & & & \\
\hline $\mathrm{c}$ & I cannot work and function as usual. & & & & & \\
\hline d & I have difficulty in making decisions. & & & & & \\
\hline e & I do not feel needed or valued. & & & & & \\
\hline $\mathrm{f}$ & I cannot think clearly. & & & & & \\
\hline
\end{tabular}

Any other stress factor.

Clinical area that you find most stressful

Clinical area that you find least stressful

Any other.

\section{Adapted from source:}

- Shiela, S., Huey-Shyan, Lina and Shiow-Li Hwangb. 2002. "Perceived stress and physio-psycho-social status of nursing students during their initial period of clinical practice and the effect of coping behaviours". International Journal of Nursing Studies. 39: 165-175.

\section{Coping behaviour inventory}

The purpose of this inventory is to find out how you deal with situations that you find stressful in the clinical area or in your life. There are no 'right or wrong answers' for these statements. As you read each statement record how often you use this coping behaviour on a scale of $0-4$ where 0 means never and 4 means always, by putting a check $(\sqrt{ })$ on the appropriate response.

Your responses are for you alone, and if you feel you need help, seek help from a person you trust or from a professional.

Please be sure to answer every statement.

\begin{tabular}{|c|c|c|c|c|c|c|}
\hline S. No. & Factor/Item & $\mathbf{0}$ & 1 & 2 & 3 & 4 \\
\hline 1 & Avoidance & & & & & \\
\hline a & To avoid difficulties during clinical practice or in life situations. & & & & & \\
\hline $\mathrm{b}$ & To avoid teachers/people in authority. & & & & & \\
\hline $\mathrm{c}$ & To quarrel with others and lose temper. & & & & & \\
\hline $\mathrm{d}$ & To expect miracles so one does not have to face difficulties. & & & & & \\
\hline e & To expect others to solve the problem. & & & & & \\
\hline $\mathrm{f}$ & To attribute to fate. & & & & & \\
\hline
\end{tabular}

Cont'd on next page... 
Cont'd...

\begin{tabular}{|c|c|c|c|c|c|c|}
\hline S. No. & Factor/Item & 0 & 1 & 2 & 3 & 4 \\
\hline 2 & Problem solving & & & & & \\
\hline a & To adopt different strategies or ways to solve problems. & & & & & \\
\hline $\mathrm{b}$ & To set up objectives and solve problems. & & & & & \\
\hline $\mathrm{c}$ & To make plans, list priorities, and solve stressful events. & & & & & \\
\hline d & To find the meaning of stressful incidents. & & & & & \\
\hline e & To employ past experiences to solve problems. & & & & & \\
\hline f & To have confidence in performing as well as seniors. & & & & & \\
\hline 3 & Stay optimistic & & & & & \\
\hline a & $\begin{array}{l}\text { To keep an optimistic and positive attitude in dealing with everyday life } \\
\text { situations. }\end{array}$ & & & & & \\
\hline $\mathrm{b}$ & To see things objectively. & & & & & \\
\hline c & To have confidence in overcoming difficulties. & & & & & \\
\hline d & To cry, to feel moody, sad and helpless. & & & & & \\
\hline 4 & Transference & & & & & \\
\hline a & To have a feast. & & & & & \\
\hline$b$ & To sleep for long. & & & & & \\
\hline $\mathrm{c}$ & To save time for sleep. & & & & & \\
\hline d & To maintain good health. & & & & & \\
\hline e & To relax by watching TV and movies. & & & & & \\
\hline f & To relax by taking a bath & & & & & \\
\hline $\mathrm{g}$ & To relax by performing physical exercises like jogging. & & & & & \\
\hline
\end{tabular}

Any other:

\section{Adapted from source:}

- Anderson, P. 1997. "Perceived levels and sources of stress in beginning bachelor of nursing students". Nursing And Midwifery-Victoria University, New Zealand, 15: 101-108.

- Beck, D. L. and R. Srivastava. 1991. "Perceived level and source of stress in baccalaureate nursing students". Journal of Nursing Education 30 (3):127-133.

- Eliot, M. 1996. "The clinical environment: A source of stress for undergraduate nurses". Australian Journal of Advanced Nursing 20(1): 34-38.

- Jone's M.C and D. W. Johnston. 1997. "Distress, stress and coping in first year student nurses". Journal of Advanced Nursing. 26 (3): 475-482. 


\section{Worksheet 4.3:}

\section{Case Situations (Group Work)}

Take 5 minutes to think and write your responses and feelings to various situations. Alternatively the facilitator will have a large group discussion after the smaller groups have had some time to decide.

\begin{tabular}{l|l|l} 
Situation & $\begin{array}{l}\text { What are your } \\
\text { feelings }\end{array}$ & $\begin{array}{l}\text { Is this something from within } \\
\text { you or outside of you? Can you } \\
\text { control it? What can you? }\end{array}$
\end{tabular}

- Your results have come. You really do not know what to expect. What do you think you could do?

- Your friend has told a person something about yourself that you trusted him/her with. The next day you hear everyone else talking about it.

- You have gone to give medicine to a patient in the ward. The patient shouts at you in the centre of the ward.

- A doctor is known to use abusive language with all health care workers. One day when you are in the ward, the doctor just walked in and starts abusing you. You do not know the reason for his use of language and are upset with his behaviour. This has happened for the second time in a week.

- A discharged patient's relative keeps shouting at you because there is a delay in getting the discharge summary.

- You are giving an injection for the first time and your hand is shaking. Your instructor shouts at you for that.

- You have been asked by the staff to go to the laboratory to collect a report for the $4^{\text {th }}$ time today.

- You are missing your family as you are staying in the hostel. You go to the principal and ask permission to go home for the holidays and you are refused permission.

- Your friend is always late for class and nothing happens to her, but today you are 10 minutes late as you had an assignment in the ward. The teacher tells you 'you need not come for the class!' 


\section{Worksheet 4.4: Self reflection on your aspirations}

Take a few minutes and reflect on your life. Complete these questions. Then share this with your close friend.

- When did you first decide what you wanted to be?

- Now that you have joined nursing, what is your plan for the next five years?

- What can you see yourself doing after you complete the course?

- What factors will guide you in making these decisions?

\section{Worksheet 4.5: What's most important for you}

\begin{tabular}{|c|c|c|c|}
\hline $\begin{array}{l}\text { Being independent } \\
\text { emotionally and } \\
\text { financially }\end{array}$ & $\begin{array}{l}\text { Doing very well in my } \\
\text { studies }\end{array}$ & Making a lot of money & $\begin{array}{l}\text { Getting along with my } \\
\text { parents }\end{array}$ \\
\hline $\begin{array}{l}\text { Having a romantic } \\
\text { relationship }\end{array}$ & $\begin{array}{l}\text { Living according to my } \\
\text { religious beliefs }\end{array}$ & $\begin{array}{l}\text { Staying out of trouble } \\
\text { with the authorities }\end{array}$ & $\begin{array}{l}\text { Having a friend I can } \\
\text { always count on }\end{array}$ \\
\hline Getting a job I really like & $\begin{array}{l}\text { Having sex with someone } \\
\text { I love }\end{array}$ & $\begin{array}{l}\text { Being in good physical } \\
\text { condition }\end{array}$ & Being successful in sports \\
\hline $\begin{array}{l}\text { Having time alone with } \\
\text { my self }\end{array}$ & $\begin{array}{l}\text { Having children when I } \\
\text { feel ready to raise them }\end{array}$ & $\begin{array}{l}\text { Avoiding sexually } \\
\text { transmitted infections and } \\
\text { HIV infection }\end{array}$ & $\begin{array}{l}\text { Doing something that } \\
\text { makes a difference in } \\
\text { community }\end{array}$ \\
\hline Being in style & $\begin{array}{l}\text { Having others look up } \\
\text { to me }\end{array}$ & Becoming famous & Having fun \\
\hline \multicolumn{2}{|c|}{3 most important things in life for me } & \multicolumn{2}{|c|}{3 least important aspects of life } \\
\hline \multicolumn{2}{|c|}{ 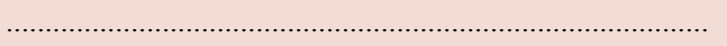 } & \multirow{2}{*}{\multicolumn{2}{|c|}{. }} \\
\hline & & & \\
\hline & & \multicolumn{2}{|c|}{ 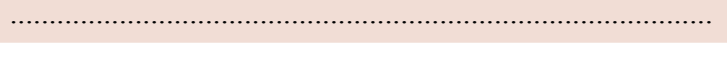 } \\
\hline
\end{tabular}

\section{Adapted from source:}

- Irvin, A. 2004. Positively Informed-Lesson Plans and Guidance for Sexuality Educators and Advocates. New York: International Women's Health Coalition (IWHC). 


\section{Worksheet 4.6: Self awareness-My best points/qualities}

1. Write down all your best qualities/positive qualities

2. Write down all the qualities your friends wrote about you during the exercise

3. What are your worst qualities? What do you think you could do about them?

4. What will make you feel good about yourself?

\section{Adapted from source:}

- $\quad$ Alphonse, X. 2004. We Shall Overcome-Textbook on Life Coping Skills. Bangalore: SKIP Publication. 


\section{Worksheet 4.7: What are your values?}

Please rank each value to how important it is to your society, community, your family and to yourself. Rank them from $1-5$ with 1 being 'least important' and 5 being 'most important'

\begin{tabular}{|c|c|c|c|}
\hline & $\begin{array}{l}\text { In my society/ } \\
\text { community }\end{array}$ & In my family & In myself \\
\hline \multicolumn{4}{|l|}{ Being honest } \\
\hline \multicolumn{4}{|l|}{ Finishing secondary school } \\
\hline \multicolumn{4}{|l|}{ Getting married } \\
\hline \multicolumn{4}{|l|}{ Supporting parents when they are old } \\
\hline \multicolumn{4}{|l|}{ Working as a team } \\
\hline \multicolumn{4}{|l|}{ Marrying a rich husband } \\
\hline \multicolumn{4}{|l|}{ Owning fashionable clothes/jewellery } \\
\hline \multicolumn{4}{|l|}{ Being healthy } \\
\hline \multicolumn{4}{|l|}{ Respecting elders } \\
\hline \multicolumn{4}{|l|}{ Being environment friendly } \\
\hline \multicolumn{4}{|l|}{ Helping the needy } \\
\hline \multicolumn{4}{|l|}{ Having good friends } \\
\hline \multicolumn{4}{|c|}{ Respecting diversity (culture, religion caste etc) } \\
\hline \multicolumn{4}{|l|}{ Respecting each other } \\
\hline \multicolumn{4}{|l|}{ Participating in community activities } \\
\hline \multicolumn{4}{|l|}{ Assisting mother in the house } \\
\hline \multicolumn{4}{|l|}{ Taking care of grandparents } \\
\hline \multicolumn{4}{|l|}{ Assisting father in his work } \\
\hline \multicolumn{4}{|l|}{ Empathising (feeling for ) with others } \\
\hline \multicolumn{4}{|l|}{ Visiting a sick neighbour/friend } \\
\hline \multicolumn{4}{|l|}{ Respecting culture norms of society } \\
\hline \multicolumn{4}{|l|}{ Wanting to be more beautiful } \\
\hline \multicolumn{4}{|l|}{ Extending moral support to friends/family } \\
\hline \multicolumn{4}{|l|}{ Being humble } \\
\hline Being adjusting to other people's needs & & & \\
\hline
\end{tabular}




\section{Worksheet 4.8: My manifesto: Describe yourself as a person}

Take your time now and describe yourself on this page. You could use the Values Worksheet (4.7) to fill 'my values are:

- I am:

- My values are:

- What I want to be:

- What is not working well in my life that $I$ want to change:

200 Module 4: I am Able! Life Skills-My Armour 
Worksheet 4.9: Reflection-How good am I in my interpersonal relationships?

\begin{tabular}{l|l|l|l}
\hline Always & Sometimes & Rarely & Never
\end{tabular}

Am I able to show respect for others?

Am I able to expect less from others?

Am I able to empathise with others?

Am I able to show love and affection?

Am I able to see the good in others?

Am I able to trust others?

Am I able to let others trust me?

Am I able to involve others in my work?

Am I able to be sensitive to the needs of others?

Am I able to change negative attitude towards others into positive attitude?

Am I able to share my feelings and resources with others?

Am I able to have common habits with family, friends and neighbors?

Am I able to avoid insulting people?

Am I able to decline gracefully?

Am I able to forgive and forget?

Note: Those statements which have been marked as rarely or never, would need improvement.

\section{Worksheet 4.10: Reflection-My relationship chart}

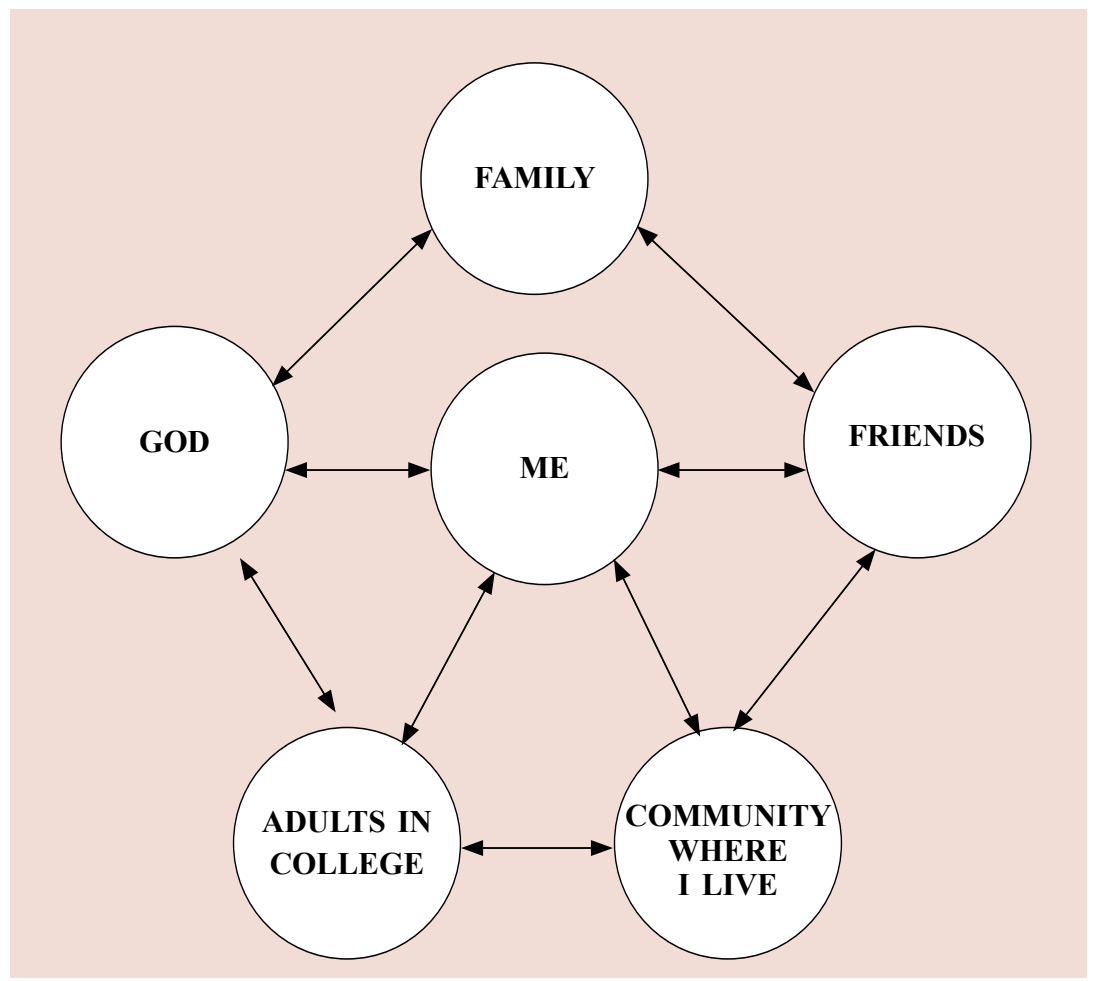




\section{Worksheet 4.11: Friendships relationships survey}

This questionnaire was written to help you assess your understanding of your behaviour in interpersonal relationships. There are no 'right' or 'wrong' answers. The best answer is the one that comes closest to representing your quest for good interpersonal relationships. In each statement, the first sentence gives a situation and the second sentence gives a reaction. For each statement indicate the number that is closest to the way you would handle the question.

$$
\begin{aligned}
& 5 \text { - You always would act this way } \\
& 4 \text { - You frequently would act this way } \\
& 3 \text { - You sometimes would act this way } \\
& 2 \text { - You seldom would act this way } \\
& 1 \text { - You never would act this way }
\end{aligned}
$$

Try to relate each question to your own personal experience. Take as much time as you need to give a true and accurate answer for yourself. There is no right or wrong answer. Trying to give the 'correct' answer will make your answer meaningless to you. Be honest with yourself.

1. You work with a friend, but some of her mannerisms and habits are getting on your nerves and irritating you. More and more you avoid interacting with or even seeing your friend.

$$
\text { Never 1---2----3---4---5 Always }
$$

2. In a moment of weakness, you give away a friend's secret. Your friend finds out and calls you ask about it. You admit to it and talk with your friend about how to handle secrets better in the future.

$$
\text { Never 1---2----3---4---5 Always }
$$

3. You have a friend who never seems to have time for you. You ask him about it, telling him how you feel.

$$
\text { Never 1---2----3---4---5 Always }
$$

4. Your friend is upset with you because you have inconvenienced him. He tells you how he feels. You tell him he is too sensitive and is overreacting.

$$
\text { Never 1---2---3---4---5 Always }
$$

5. You had a disagreement with a friend and now she ignores you whenever she's around you. You decide to ignore her back.

$$
\text { Never 1---2----3---4---5 Always }
$$

6. A friend has pointed out that you never seem to have time for him. You explain why you have been busy and try for a mutual understanding.

$$
\text { Never 1---2----3---4---5 Always }
$$

7. At great inconvenience, you arrange to take your friend to the doctor's office. When you arrive to pick her up, you find she has decided not to go. You explain to her how you feel and try to reach an understanding about future favours.

$$
\text { Never 1---2----3---4---5 Always }
$$

8. You have argued with a friend and are angry with her, ignoring her when you meet. She tells you how she feels and asks about restoring the friendship. You ignore her and walk away.

$$
\text { Never 1---2----3---4---5 Always }
$$

9. You have a secret that you have told only to your best friend. The next day, an acquaintance asks you about the secret. You deny the secret and decide to break off the relationship with your best friend.

$$
\text { Never 1---2---3---4---5 Always }
$$

10. A friend who works with you tells you about some of your mannerisms and habits that get on his nerves. You discuss these with your friend and look for some possible ways of dealing with the problem.

Never 1---2---3---4---5 Always 
11. Your best friend gets involved in something illegal that you believe will lead to serious trouble. You decide to tell your friend how you disapprove of his involvement in this situation.

$$
\text { Never 1---2---3---4---5 Always }
$$

12. In a moment of weakness, you give away a friend's secret. Your friend finds out and calls you to ask about it. You deny it firmly.

$$
\text { Never 1---2---3---4---5 Always }
$$

13. You have a friend who never seems to have time for you. You decide to forget her and to start looking for new friends.

$$
\text { Never 1---2---3---4---5 Always }
$$

14. You are involved in something illegal and your friend tells you of her disapproval and fears that you will get in to serious trouble. You discuss it with your friend.

Never 1---2---3---4---5 Always

15. Your work with a friend, but some of her mannerisms and habits are getting on your nerves and irritating you. You explain your feelings to your friend looking for a mutual solution to the problem.

Never 1---2---3---4---5 Always

16. A friend has pointed out that you never seem to have time for him. You walk away.

$$
\text { Never 1---2---3---4---5 Always }
$$

17. Your best friend gets involved in something illegal that you believe will lead to serious trouble. You decide to mind your own business.

$$
\text { Never 1---2---3---4---5 Always }
$$

18. Your friend is upset because you have inconvenienced him. He tells you how he feels. You try to understand and agree on a way to keep it from happening again.

$$
\text { Never 1---2---3---4---5 Always }
$$

19. You had a disagreement with a friend, now she ignores you whenever she is around you. You tell her how her actions make you feel and ask about restoring your friendship.

$$
\text { Never } 1 \text {---2---3---4---5 Always }
$$

20. A friend who works with you tells you about some of your mannerisms and habits that get on his nerves. You listen and walk away.

$$
\text { Never 1---2---3---4---5 Always }
$$

21. At great inconvenience you arrange to take your friend to the doctor's office. When you arrive to pick her up, you find she has decided not to go. You say nothing but resolve never to do any favours for that person again.

$$
\text { Never 1---2---3---4---5 Always }
$$

22. You have argued with a friend and are angry with her, ignoring her when you meet. She tells you how she feels and asks about restoring the friendship. You discuss ways of maintaining your friendship, even when you disagree.

$$
\text { Never 1---2---3---4---5 Always }
$$

23. You have a secret you have told only to your best friend. The next day, an acquaintance asks you about the secret. You call your friend and ask her about it, trying to come to an understanding how to handle secrets in the future.

$$
\text { Never 1---2---3----4---5 Always }
$$

24. You are involved in something illegal, and your friend tells you of her disapproval and fear that your will get in serious trouble. You tell your friend to mind her own business.

$$
\text { Never 1---2---3---4---5 Always }
$$




\section{FRIENDSHIP RELATIONSHIPS SURVEY ANSWER SHEET}

In the friendship relations survey there are twelve questions that deal with your willingness to self-disclosure and twelve questions that are concerned with your receptivity to feedback. Transfer your scores to this answer key. Reverse the scoring for all questions that are marked with * that is, if you answered 5, record the score of 1; if you answered 4, record the score of 2; If you answered 3, record the score of 3; If you answered 2, record the score of 4 and if you answered 1, record the score of 5 . Then add the scores in each column.

\begin{tabular}{|c|c|}
\hline Willingness to Self-Disclose & Receptivity \\
\hline *1. ------ & 2. ------ \\
\hline 3. ------ & *4. ------ \\
\hline *5. ------ & 6. ------ \\
\hline 7. ------ & *8. ------ \\
\hline *9. ----- & 10. ----- \\
\hline 11. ------ & *12. ------ \\
\hline *13. ------ & 14. ------ \\
\hline 15. ------ & *16. ------ \\
\hline *17. ------ & 18. ------- \\
\hline 19. ------ & *20. ------- \\
\hline *21. ------- & 22. ------ \\
\hline 23. ------ & *24. ------ \\
\hline
\end{tabular}

Remember: the higher your score in both the columns, the better you will be in your interpersonal relations.

\section{Worksheet 4.12: Reflection-How good a communicator am I?}

\begin{tabular}{|c|c|c|c|c|}
\hline & Always & Sometimes & Rarely & Never \\
\hline \multicolumn{5}{|l|}{ I can recognise my own feeling. } \\
\hline \multicolumn{5}{|l|}{ I can recognise another's feelings. } \\
\hline \multicolumn{5}{|l|}{ I can express my own feeling. } \\
\hline \multicolumn{5}{|l|}{ I can accept my own worth and feel happy with myself. } \\
\hline \multicolumn{5}{|l|}{ I can accept my own limitations/weakness with myself. } \\
\hline \multicolumn{5}{|l|}{ I can recognise and express my negative feelings. } \\
\hline \multicolumn{5}{|l|}{ I can accept positive feedback without feeling shy. } \\
\hline \multicolumn{5}{|l|}{ I can accept negative feedback without feeling bad. } \\
\hline \multicolumn{5}{|l|}{ I can read others non-verbal communication well. } \\
\hline \multicolumn{5}{|l|}{ I can show sympathy or identify with other feelings. } \\
\hline \multicolumn{5}{|l|}{ I can express my goals and intensions clearly. } \\
\hline \multicolumn{5}{|l|}{$\begin{array}{l}\text { I can deal effectively with misleading messages (words say } \\
\text { one thing and actions another). }\end{array}$} \\
\hline \multicolumn{5}{|l|}{ I remain calm in high stress situations. } \\
\hline \multicolumn{5}{|l|}{$\begin{array}{l}\text { I can give positive feedback to others so they feel good and } \\
\text { reassured. }\end{array}$} \\
\hline \multicolumn{5}{|l|}{$\begin{array}{l}\text { I can give negative feedback in a helpful way. I can express } \\
\text { my feelings nonverbally. }\end{array}$} \\
\hline \multicolumn{5}{|l|}{ I can accept others as they are. } \\
\hline I can describe another's behaviour. & & & & \\
\hline
\end{tabular}

Note: Areas where you have marked rarely or never would need improvement.

\section{Adapted from source:}

- St. John's College of Nursing. 2005. Facilitators Manual-STI and HIV /AIDS; Prevention, Care and Support. Bangalore: KSAPS and ICHAP. 


\section{Worksheet 4.13: Assertion response-Discrimination index}

Indicate which of the following are assertive, non-assertive and aggressive in each situation.

\section{SITUATION 1}

Your friend has just arrived an hour late for dinner. He/She did not call to let you know that he/she would be detained. You are annoyed about his/her late arrival. You say:

1. Come on in. Dinner is on the table.

2. I have been waiting for an hour. I would have appreciated your calling to let me know you would be late.

3. You've got a lot of nerve coming late. That's the last time I will invite you.

\section{SITUATION 2}

A friend has just complimented you on your new suit. It's the first time you've worn it and you really like it. You say:

1. Thank you.

2. This? It's nothing special.

3. Well... I picked it up at a sale....

\section{SITUATION 3}

You're out with a group of friends. You're all deciding which movie to see. One person has just mentioned a movie you don't want to see. You say:

1. You always pick movies I don't like. You only think about yourself. You're very selfish.

2. I don't want to see that one. How about a movie over at a Plaza Theatre?

3. Well, I don't know much about that movie. But, I guess, if you want to, we can see it.

\section{SITUATION 4}

You are returning a faulty item to the department store. You bought a shirt/blouse. When you took it home, you found a small tear in it. You do not want the item as it is torn. The clerk has just said no one will ever notice it. You say:

1. Well, I'd still like to return it or exchange it. I do not want this one.

2. Look, give me my money. I don't have all day for you to waste my time.

3. Well, are you sure no one will notice it?

\section{SITUATION 5}

You'd like your child to go down the block and pick up a package at your friend's house. You say:

1. Bunty, I would like if you would go to Mrs. Kumar's and pick up a package for me. I would appreciate it if you could do it by 3 o'clock.

2. If you aren't too busy, well...... will you be going to Mrs. Kumar's today?

3. Hey, it's about time you did something worthwhile. Go down to Mrs. Kumar's and pickup a package for me. No back talk. Stop being such a lazy thing. Go on. 


\section{SITUATION 6}

A co-worker keeps giving you all of his/her work to do. You've decided to put an end to this. Your co-worker has just asked you to do some more of his/her work. You say:

1. I'm kind of busy. But if you can't get it done, I guess I can help you.

2. Forget it. It's about time you do it. You treat me like your slave. You're an inconsiderate teacher.

3. No, Reena/Ramesh, I'm not going to do anymore your work. I am tired of doing both my work and your work.

\section{Adapted from source:}

- Crosby, R. A, R. J. Di Clemente, G. M. Wingwood et al. 2002. "Adolescents ambivalence about becoming pregnant predicts infrequent contraceptive use: A Prospective Analysis of Non pregnant African American females". American Journal of Obstetrics and Gynaecology 186 (2): 251-252.

\section{Worksheet 4.14: Feedback on module}

Kindly take 5 minutes to complete the following and hand the paper over to me. You need not write your name anywhere but it is important to give me your responses, since this would help me know whether this session was useful or not. You have the freedom to write your own thoughts in the space that is provided

- Write at least three things you learnt from the module:

- Write three things that you liked about the module:

- What did you feel was not necessary for this module?

- Write any three suggestions for this module: 


\section{Handouts}

\section{Handout 4.1: Coping with stress}

\section{Coping with stress in personal areas}

- Acknowledge that there is stress when it exists

- $\quad$ Try and assess your level of stress (you could use the Worksheet 4.1)

- Look into yourself and examine what are the factors that cause the stress

- Be aware of what usually causes stress in you

- $\quad$ Remember you can cope with stress, by focussing on something that you can control, help change or improve. Ask yourself these questions:

o Is there something within you that is causing stress? Or within the environment?

- What are specific things you can do within yourself and within the work environment to reduce stress and avoid burnout?

- Will you do this alone or with the help of others?

- Find someone whom you can trust to talk about it

- Use different approaches to reduce stress. Check out what really helps you relax:
- Yoga
○ Jog
- Listen to music
- You know what can calm you down
○ Manage your time effectively

- Take professional help if none of these work

\section{Coping with stress in the professional area}

- Acknowledge that there is stress and assess your level of stress

- Examine the factors that cause the stress, and focus on something that you can control, help change or improve. Ask yourself these questions:

- Is there something within you that is causing stress? Or within the environment?

- What are specific things you can do within yourself and within the work environment to reduce stress and avoid burnout?

Will you do this alone or with the help of others?

- Evaluate the effects of stress on an ongoing basis:

- Are things out of balance?

- Become self-aware

- Get help from colleagues, family, and friends

- Work with other nurses to create a supportive environment: plan for a meeting, just to informally discuss with each other how they are and what was happening with each one of them

- $\quad$ Find something outside of work that you enjoy

- If you are a spiritual person, seek spiritual guidance

- Take time to reflect on a difficult situation \& acknowledge the difficulty

- Take professional help if none of these work 


\section{Handout 4.2: Managing time-Know your priorities}

What is most important for you depends on your values and your view of life.

This may change depending on the period of your life.

\section{How to utilise your time?}

- Do not procrastinate (delay).

- Goals - what do you have to finish and by when? Know what is important for you at the particular time of your life. Acknowledge it. Tell a person you trust how much this means to you.

- Log of activities - know where you are now.

- Categorise activities: A, B, C, D; complete D (e.g. an assignment that has to be submitted on time but does not carry marks) first and then C (e.g. an assignment that is urgent and yet also carries a lot of marks...you need to be alert, fresh when doing such activities).

- Review: goals with the person you trust and who wants the best for you.

- $\quad$ Give yourself feed-back.

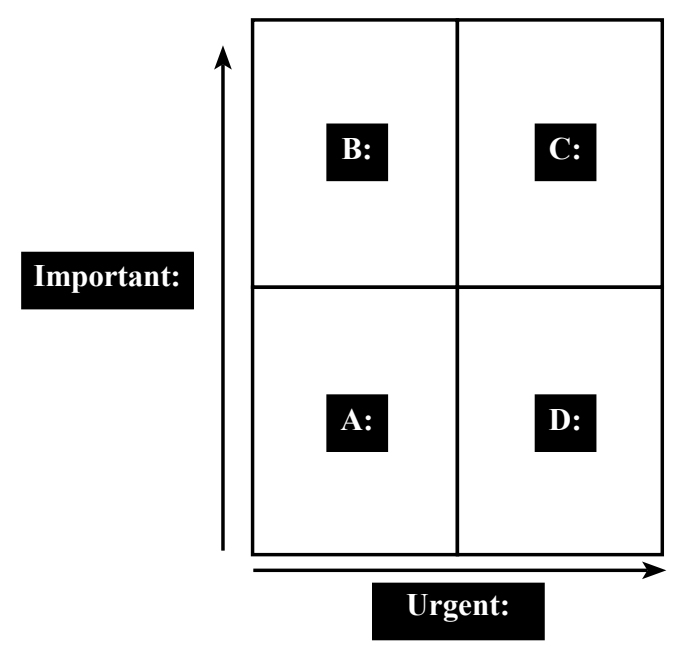

Please note:

A: Not urgent or not important. Do it when your levels of energy are low

- B: Not urgent but important. Do it in your time, however, do not procrastinate. Keep a deadline for it. But you should be having high levels of energy for doing this activity

- C: Very important and very urgent: You need to have high levels of energy as well as keep any other urgent work out of your mind when attempting to do such activities. That is why it is important to complete the D activities first and then start with $\mathrm{C}$

- D: Not important but very urgent. You do not need high levels of energy. This is usually accomplished fast

To realise the value of a year...
Ask a woman who was just diagnosed with cancer
To realise the value of a month...
Ask the parents of a premature child
The value of a day?
Ask a daily wage worker with a family to feed
The value of an hour?
Ask two lovers who anxiously wait to meet
The value of a minute?
Ask the person who missed the last train home
To realise the value of a second...
Ask the person who just survived a car accident
To realise the value of a millisecond...
Ask the athlete who came in second...
Or the athlete who won the gold!!




\section{Handout 4.3: Managing my emotions}

\section{Manage your emotions or they will manage you.}

\section{You can't manage your life until you manage your emotions.}

1. What you need to do when you go through situations that may cause you to have negative emotions

- Recognise that emotions are inner messages

- Acknowledge the emotion you are feeling

- Remember negative emotions are not good for you physically, emotionally or even socially

- Wait for a while till you can control the emotion

- Separate emotion from logic

2. What you could do in specific instances:

- In case a friend presents with a negative emotion: Do not try to problem solve with your friend's negative emotion. It is also important that you do not ignore the negative emotion. Instead try to help your friend look at the situation objectively and say

○ 'You seem upset; do you want to talk about it now?'

- 'You seem worried; do you think I could help you?'

- When you are unjustly dealt with by another person: Remember you have the right to be treated with respect. You do not have to tolerate others' bad behaviour. Assertively say what you feel

- I feel that you are upset with me for something I do not know anything about

- Could you please lower your voice

- I feel that what you are saying is not acceptable. I would not like to be spoken to like that again

3. Remember that everyone has an inner source of strength. This inner source of strength could be strengthened by people who live around us. Take 5 minutes to tick the sources of your own strength. By doing this exercise, you may become aware of your own strengths, and this could hold good for you in situations that are stressful.

\section{What are my sources of strength?}

\section{I have}

- People around me I trust and who love me, no matter what.

- People who set limits for me so I know when to stop before there is danger or trouble.

- People who show me how to do things right by the way they do things.

- People who want me to learn to do things on my own.

- People who help me when I am sinking, in danger, or need to learn.

I am

- Likable and lovable.

- Glad to do nice things for others and show my concern.

- Able to respect others and myself.

- Willing to be responsible for what I do.

- A person who can manage my emotions even when faced with severe challenges or difficulties.

\section{I can}

- Talk to others about things that frighten or bother me.

- Control myself when I feel like doing something not right or dangerous.

- Figure out when it is a good time to talk to someone or take action.

- Find someone to help me when I need it. 


\section{Handout 4.4: Developing self awareness-Its importance}

\section{Benefits of becoming aware of ourselves and qualities and liking ourselves}

- We are all made up of parts. Some parts we like - and others we do not.

- We can learn to like the parts we do not like - or change them we have a choice.

- By remembering the parts we like we are surer of ourselves and more able to accomplish things.

- By focussing on the concept of liking ourselves we feel good around other people and better at anything we are doing.

\section{What is Self-Esteem?}

- It's your self-image or HOW YOU FEEL ABOUT YOURSELF

- Your self-esteem is made up of THOUGHTS AND FEELINGS you have about yourself.

- These may be: negative/positive

- Remember that

- YOU'RE A UNIQUE INDIVIDUAL.

o There is no one else in the world like you.

- That's reason enough to be proud.

- This is influenced by your relationships and experiences

\section{How would having positive self esteem help you?}

- Helps you to accept responsibility for your actions

- Makes you positive in your attitude to anything

- Makes you more sensitive to others needs

- Makes you self-motivated and ambitious

- Makes you open to new opportunities and challenges

- Improves your performance and increases risk-taking ability

- Helps you give and receive both criticism and compliments tactfully and easily

\section{Handout 4.5: Decision making-The POWER model (Self-Reflection)}

- How are most decisions made in reality?

- How often have you drifted into a decision, or let other people/someone else lead you into making a decision?

- What were the consequences? Do you think you could repair such decisions?

- Is it difficult to make good decisions? What makes it difficult? What makes it easier? 


\section{The POWER model for decision making}

\begin{tabular}{|l|l|}
\hline $\mathrm{P}=$ PROBLEM & $\begin{array}{l}\text { Stop and state (or identify) the problem. } \\
\mathrm{O}=\text { OPTIONS }\end{array}$ \\
$\begin{array}{l}\text { Think of different things you can do. The more options you have, the } \\
\text { better. }\end{array}$ \\
\hline $\mathrm{W}=$ WEIGHT & $\begin{array}{l}\text { Think of each option as a 'yes' or 'no', weigh good versus bad for all } \\
\text { options. } \\
\text { The things you value should guide you in your decision making. }\end{array}$ \\
\hline $\mathrm{E}=$ ELECT & $\begin{array}{l}\text { Choose the best option, talk to a person you respect, then take the best action. } \\
\text { Choose the option which obtains what is important to you (values). }\end{array}$ \\
\hline $\mathrm{R}=$ REFLECT & Think or reflect about what happened because of your decision.
\end{tabular}

\section{Handout 4.6: Decision making-Negative peer pressure and code of ethics and professional conduct of nurses in India}

\section{Make your own decisions and take charge of your life}

The five Cs of decision making: There are five factors in the process of making decisions. These could be used best in decisions that are important. Some examples could be those with regard to choice of profession, family life, career, relationships, marriage, friendship, countering negative peer pressure etc. They are not steps in the decision making process. Very often, in making a decision, you will be engaged with more than one factor at a time: consulting while considering, communicating tentatively before committing, checking the previous decision as part of considering the next decision and so on.

- Considering: identifying alternatives, exploring alternatives, eliminating alternatives etc. Considering is iterative i.e. it is a process that we may need to repeat several times. We may have to use the decision model several times before we arrive at a decision that satisfies us

- Consulting: Involving those affected in exploring the issue, in making the decision and in implementing the solution. Using others to enrich your own thinking, in conversations and meetings. Appointing teams as part of the process. Consulting often forms part of considering

- Committing: At the very heart of the process. Taking responsibility for the decision, managing the external and the emotional risks of the decision without blaming it on others, finding your own inner commitment and making it real by announcing the decision

- Communicating: Letting others know in word and writing your decision

- Checking: Monitoring the progress to ensure that the decision actually works

\section{Tips on how to say 'No' to negative peer pressure}

- Know what is important for you and know your values

- Be aware of your strengths

- Be sure of your goals in life

- Talk to someone you respect and trust

- Think ahead and do not put yourself in the situation or place, where you find the pressure is beyond what you can handle

- Be assertive and stand-up to your decision. Take responsibility for it

- Avoid potentially threatening situations

- Get out of the situation, if you had not anticipated it before

Code of Ethics and Professional Conduct: The Code of Professional Conduct for nurses is critical for building professionalism and accountability. Ethical considerations are vital in any area dealing with human beings because they represent values, rights and relationships. This list does not have all the information available in the code of 
ethics and professional conducts as prescribed by the Indian Nursing Council (INC). Only those that are relevant to the main issue being dealt with are presented:

\section{A. Code of Ethics for Nurses in India}

\section{The Nurse respects the uniqueness of individuals in the provision of care}

a. Provides care for individuals without consideration of caste, creed, religion, culture, ethnicity, gender, socioeconomic and political status, personal attributes or any other grounds

b. Individualised care considering the beliefs values and cultural sensitivities

c. Appreciates the place of individual in the family and community and facilitates participation of significant others in the care

d. Develops and promotes trustful relationship with individuals

e. Recognises uniqueness of response of individuals to interventions and adapts accordingly

\section{The Nurse respects the rights of individuals in making informed choices}

a. Appreciates individuals' right to make decisions about their care and therefore gives adequate and accurate information for enabling them to make informed choices

b. Respects the decisions made by the individual regarding their care

c. Protects the public from misinformation and interpretations

d. Advocates special provisions to protect vulnerable individuals and groups

\section{The Nurse respects individuals' right to privacy, maintains confidentiality and shares information} judiciously

a. Respects the individuals' right to privacy of their personal information

b. Maintains confidentiality of privileged information except in life-threatening situations and uses discretion in sharing information

c. Takes informed consent and maintains anonymity when information is required for quality assurance/academic and legal reasons

d. Limits access to all personal records - written and computerised — to authorised persons only

\section{B. Code of Professional Conduct for Nurses in India}

\section{Professional Responsibility and Accountability}
a. Appreciates self-worth
b. Maintains standards of personal conduct reflecting credit upon the profession
c. Carries out responsibilities within the framework of professional boundaries
d. Is accountable for maintaining standards set by INC
e. Is accountable for own decisions and actions
f. Is compassionate
g. Is responsible for continuous improvement of current practice
h. Provides adequate information to individuals that allow them informed choices
i. Practices healthful behaviour

\section{Nursing Practice}

a. Provides care in accordance with set standards of practice

b. Treats all individuals and families with human dignity in providing physical, psychological, emotional, social and spiritual aspects of care

c. Respects individuals and families in the context of traditional and cultural practices, promoting healthy practices and discouraging harmful practices 
d. Presents realistic picture truthfully in all situations for facilitating autonomous decision making by individuals and families

e. Promotes participation of individuals and significant others in the care.

f. Ensures safe practice

g. Consults, coordinates, collaborates and follows up appropriately when individuals' care need exceeds the nurses' competence

\section{Communication and Interpersonal Relationships}

a. Establishes and maintains effective interpersonal relations with individuals, families and communities

b. Upholds the dignity of team members and maintains effective IPR with them

c. Appreciates and nurtures the role of team members

d. Cooperates with other health professionals to meet the needs of individuals, families and communities

\section{Valuing Human Beings}

a. Takes appropriate action to protect individuals form harmful unethical practice

b. Considers relevant facts while taking conscience decisions in the best interests of individuals

c. Encourages and supports individuals in their right to speak for themselves on issues reflecting their health and welfare

d. Respects and supports choices made by individuals

\section{Handout 4.7: Empathy}

The ability to communicate and lead by understanding other's thoughts, views and feelings

To Empathise

Is to see with the eyes of another

To hear with ears of another

And to feel with the heart of another A

\section{How to develop empathy-SAD RULE}

- Self-awareness: how would you feel in a situation

- Accepting a person: accept a person as he or she is, do not try to change the person as you would want the person to be

- Develop it: It is present from birth

- Respect: others for their view points and simply because they are human beings

- Understand others: listen not only to words but the feelings

- Listen: actively

- Expressions: be aware of non verbal expressions as well as verbal expressions

\section{How to empathise with your patients}

- This means showing that you understand his/her feelings from his/her point of view.

- Empathy differs from sympathy. When you sympathise, you look at things from YOUR point of view.

- Building a patient's self-confidence helps him/her make his/her own decisions and resist pressure from other people:

- Accept what a patient thinks and feels.

- Recognise and praise what a patient is doing right.

- As Health Workers, we are trained to look for problems. This means that we may only see what we think is wrong, and try to correct it. 
- We must learn to recognise what a patient is doing right, and praise or show approval of good practices.

- Accepting what a patient thinks and feels plus recognising and praising good practice builds a patient's selfconfidence and encourages him/her to continue good practices.

- When a patient feels that you accept his/her ideas and recognise his/her good practices, he/she is more likely to accept any suggestions that you make.

- $\quad$ Give practical help

- Give only relevant information

- Use simple language

- Present one or two suggestions to choose from, not commands

\section{Listen actively to patients. In listening we could try to do the following:}

- Show interest: e.g. 'you were saying that....'

- $\quad$ Express empathy: e.g. 'I understand that you are feeling....'

- Single out the real problem: e.g. 'what are your concerns? worries? which do you think is the most important?'

- Listen for causes of the problem: e.g. 'what do you think of this problem....'

- Help the speaker associate the problem with the cause: e.g. 'do you see why you are facing this.....'

- Encourage the speaker to develop competence and motivation to solve his or her own problems: e.g. 'how do you want to sort out this problem...?'

- Cultivate the ability to be silent when silence is needed.

In listening, do not:

- Argue

- Interrupt

- Pass judgment too quickly or in advance

- Give advice unless it is requested by the other

- Form answers or jump to conclusions

- Let the speaker's emotions influence your own

\section{Handout 4.8: Problem solving}

\section{What are problems?}

$\begin{array}{llll}\text { P: } & \text { REDICTORS } & - & \text { They help mould our future } \\ \text { R: } & \text { EMINDERS } & - & \text { We are not self-sufficient, we need God and others to help } \\ \text { O: } & \text { PPORTUNITY } & - & \text { They pull us out of our rut and cause us to think creatively } \\ \text { B: } & \text { LESSINGS } & - & \text { They open up doors we usually don't go through } \\ \text { L: } & \text { ESSON } & - & \text { Each new challenge will be our teacher } \\ \text { E: } & \text { VERYWHERE } & - & \text { No place or person is excluded form then } \\ \text { M: } & \text { ESSAGE } & - & \text { They warn us about potential disaster } \\ \text { S: } & \text { OLVABLE } & - & \text { No problem is without solution. }\end{array}$




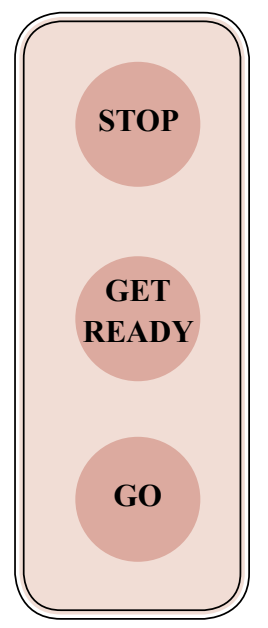

Stop, calm down and think before you act

Think about various things you could do and what the consequences could be

Pick the best one and try it out

\section{How to solve problems?}

Use the POWER model that was mentioned in decision making.

\section{Use the STAR problem solving model}

\section{STOP \& RECOGNISE}

- Do I have a problem?

- What is my problem?

- How is my body affected?

- What feeling am I showing?

- What feelings am I keeping to myself?

\section{THINK \& COMMUNICATE}

- What do I want to happen?

- Who are the other people involved in the situations?

- What do they want to happen?

- What are facts of the situations?

- What are my observed, gathered and remembered facts?

- Have I clearly expressed my feelings and thoughts?

- Have others clearly expressed their feeling and feelings?

- What are some different solutions and their consequences?

- Are the consequences safe for and respectful to others?

- Have I consulted others affected about the range of solutions?

- What is the best solution?

3. ACT

- Use the POWER model: You would have already stated the problem and looked at the options, weighed each option. Choose the best one in sight.

- What is the best situation or solution?

- What action must you take?

- Choose to go back and stop \& recognise again if there is no best solution.

\section{REVIEW}

- Observe the consequences: Use the last step of the POWER model-Reflect.

- If there are no satisfying consequences see what you can do next. 


\section{Handout 4.9: How to communicate assertively}

\section{What does assertiveness mean?}

Assertiveness is the ability to honestly express your opinions, feelings, attitudes, and rights, without undue anxiety, in a way that doesn't infringe on the rights of others.

- It is not aggressiveness; it's a middle ground between being a bully and a doormat.

- It is dependent on a feeling of self-efficacy, a sense that if you behave in a certain way, something predictable will occur.

- Where does non-assertive behaviour come from? Many of us are taught that we should always please and/or defer to others, that it is not nice to consider our own needs above those of others, or that we shouldn't "make waves", that if someone says or does something that we don't like, we should just be quiet and try to stay away from that person in the future.

\section{Why is assertiveness important?}

If you don't know how to be assertive, you might experience:

- Depression: From anger turned inward, a sense of being helpless, hopeless, with no control over your life.

- Resentment: Anger at others for manipulating or taking advantage of you.

- $\quad$ Frustration: How could I be such a stupid person? Why did I let someone victimise me?

- Temper/violence: If you can't express anger appropriately, it builds up until it blows

- Anxiety: This leads to avoidance. If you begin to avoid situations or people that you know will make you uncomfortable, you may miss out on fun activities, job opportunities, relationships, and lots of other good stuff.

- Poor relationships of all kinds: Non-assertive people are often unable to express emotions of any kind, negative or positive. It's murder for a relationship when the partners can't tell each other what they want and need and how the other person affects them. No one is a mind reader. The same is true for friendships and work relationships.

- Physical complaints: Headaches, ulcers, high blood pressure. We all know what stress does to our bodies, and assertiveness, when it becomes a habit, is a great stress reliever.

- Parenting problems: Kids are born knowing how to test the limits their parents set for them. If parents aren't assertive and firm, their kids will walk all over them!

\section{Selective assertiveness:}

Most people find it easier to be assertive in some situations than in others. This makes perfect sense. It's a lot easier to hold your ground with a stranger than with someone you love who might get angry if you express your true feelings. But the more important the relationship is to you, the more important it is to be assertive. Assertive behaviours lead to increased respect from others, their willingness to see you as a person who respects him/herself, a worthwhile person, and a more loveable person!

\section{Is assertiveness always necessary?}

Before you decide to act assertively in a given situation, you have to decide if you can live with the consequences. Although assertive behaviour usually will result in a positive response, some people might react negatively to it. For example, if the other person involved in the relationship is in a higher position than you (teacher, parent, boss), is completely unreasonable and is known to get really angry if anyone dares question their orders, even non-aggressive, respectful, assertive behaviour might set such people off and you could have a lot of problems. If that's your situation, then you may decide you can't afford to be assertive, and learn other stress management techniques. 


\section{Setting the stage:}

If you're planning to try assertive behaviour, remember that the other person is used to your behaving in a certain way, and may be thoroughly confused when you change your communication style. Why not tell the other person upfront what you're trying to do? It helps to choose a peaceful moment for this. Then you might say something like

"I need to tell you something and I'd like you to hear me out before you comment. I've noticed lately that after we've been working on a project together, I find myself feeling frustrated and overwhelmed. I've been thinking about it and I've realised that I often go along with your ideas, without insisting on considering some of my ideas as well, because I'm afraid of upsetting you. From now on I'm going to try something different. When I start to get those frustrated feelings, I'm going to ask that we stop before making a final decision and be sure we have considered all the options. I know that this will be a change for you, but I really think it's fair and I know I'll do a better job and feel better about myself if I can tell you about my ideas." How can anyone argue with that statement?

\section{Techniques:}

Example 'I've noticed that whenever we're preparing to go somewhere, you start rushing me to finish dressing as soon as you're ready, even if it's not yet the time we had planned to leave. I know you get anxious when you're all ready to go and I'm not, but when you do that, I get all flustered and take even more time. By the time we get in the car, we're mad at each other and not much in the mood to have a good time. From now on, let's be sure we know what time we want to leave, and if you're ready before I am, will you please just go to another room and read the paper or watch TV? From now on, if you come into the bedroom or bathroom before it's time to leave and start asking me to hurry up, I'm just going to remind you of the time, ask you to go to another room, and close the door until I'm ready. I know this is going to seem weird at first, but I bet we'll enjoy our outings a lot more over the long run."

\section{There are three parts to assertive intervention:}

1. Empathy/validation: Try to say something that shows your understanding of the other person's feelings. This shows them that you're not trying to pick a fight, and it takes the wind out of their sails. From the above example, "I know that you get anxious when you're all ready to go and I'm not...."

2. Statement of problem: This piece describes your difficulty/dissatisfaction, tells why you need something to change. For example, “...but when you do that, I get all flustered and take even more time. By the time we get in the car, we're mad at each other and not much in the mood to have a good time."

3. Statement of what you want: This is a specific request for a specific change in the other person's behaviour. For example, "From now on, let's be sure we know what time we want to leave, and if you're ready before I am, will you please just go to another room and read the paper or watch TV?"

\section{How to be effectively assertive:}

- Use assertive body language: Face the other person, stand or sit straight, don't use dismissive gestures, be sure you have a pleasant, but serious facial expression, keep your voice calm and soft, not whiney or abrasive.

- Use "I" statements: Keep the focus on the problem you're having, not on accusing or blaming the other person. Example: "I'd like to be able to tell my stories without interruption." instead of "You're always interrupting my stories!"

- Use facts, not judgments: Example: "Your punctuation needs work and your formatting is inconsistent" instead of "This is sloppy work." or "Did you know that shirt has some spots?" instead of "You're not going out looking like THAT, are you?"

- Express ownership of your thoughts, feeling, and opinions: Example: "I get angry when he breaks his promises." instead of "He makes me angry." or "I believe the best policy is to..." instead of "The only sensible thing is to..."

- Make clear, direct, requests: Don't invite the person to say no. Example: "Will you please ...?" instead of "Would you mind...?" or "Why don't you...?" 


\section{Special techniques for difficult situations:}

- Broken record: Keep repeating your point, using a low level, pleasant voice. Don't get pulled into arguing or trying to explain yourself. This lets you ignore manipulation, baiting, and irrelevant logic. Example: You are taking something back to a store that you know gives refunds, but the clerk first questions your decision, tries to imply that there's something wrong with you because you changed your mind, tells you that she can only give a store credit, etc. Using the broken record, you walk into the store and say "I decided I don't need this and I'd like my money back." Then no matter what the clerk says, you keep repeating "I decided I don't need this and I'd like my money back." If she doesn't get it, simply ask to speak to a manager and say the same thing. Trust me, it works!

- Fogging: This is a way to deflect negative, manipulative criticism. You agree with some of the fact, but retain the right to choose your behaviour. Example: Mom: "Your skirt is awfully short; don't you think you should wear longer skirts? They're the style now." You: "You're right, skirts are longer now." Agree with as much of the facts as you want to, but don't agree to change your skirt length. Fogging is great for avoiding fights and making people stop criticising. With significant others, when you need to keep living together, it's best to quietly hear them out, then assertively give your response.

- Content to process shift: This means that you stop talking about the problem and bring up, instead, how the other person is behaving RIGHT NOW. Use it when someone's not listening or trying to use humour or a distraction to avoid the issue. Example: "You're getting off the point. I'm starting to feel frustrated because I feel like you're not listening."

- Defusing: Letting someone cool down before discussing an issue. Example: "I can see that you're upset, and I can even understand part of your reaction. Let's talk about this later." Also, if they try to stay with it, you always have the right to walk away.

- Assertive inquiry/stop action: This is similar to the content to process shift. "Let's hold it for a minute; something isn't working, what just happened? How did we get into this argument?" This helps to identify the real issue when the argument is actually about something bigger than the immediate topic.

Example "Can you help me with this statistics problem?

A-Man, will you just get off my back? You know how much I have to do today!

B-Why is it such a problem to take 15 minutes to help me with this? You told me last night that you would!

A - I get so tired of you always asking me to do these things right when I'm in the middle of something!

B-Whoa, let's take a break here. How did we get from my statistics problem to you being tired of my interruptions?"

The real problem is not the statistics problem, but its timing. Now that the problem is open for discussion, they become aware of how their arguments escalate.

- Summarisation: This helps to make sure you understand the other person. Example: "So what you're trying to tell me is...."

- Specificity: It's really important to be very clear about what you want done. This helps prevent distractions. Example: "The thing I really wish is that you'd pick your clothes up off the floor."

One of the most common problems in communications is caused by trying to read people's minds or expecting them to read yours. If you want people to respond to your ideas and needs, you have to be able to say what they are, and say it in a way that will make others want to respond nicely. If it's really scary to think about being assertive, try it first with people you don't know. Think of someone you know who is assertive and pretend you are that person. Once you become comfortable with assertive behaviours in less threatening situations, you can use it all the time. When assertiveness becomes a habit, you will wonder how you ever got along before you started using it. As people practise assertive communication, you can almost see that little spark of self-respect glimmer, flicker, take hold, and burst into flame. People can sense it when you respect yourself, and they will treat you with respect. And that is the ultimate goal of assertive communication. 
How can you be assertive?

- Know your values

- Be clear about your goals

- Be consistent in what you say

- Do not be frightened to

o say 'no' when in your mind you feel something is wrong

Show that you do not appreciate some behaviour

Being not so popular

Managing peer pressure

Know there are 3 ways that you could respond to a situation

- Aggressive response

- Submissive response

- $\quad$ Assertive response

Worksheets and Handouts have been adapted from the following sources:

- Alphonse, X. 2004. We Shall Overcome-Textbook on Life Coping Skills. Bangalore: SKIP Publication.

- Bauknecht, B. and T. Schmitz. 2001. "Education Version-Empathy". The Anger Management Program. CA: Oakland Solutions LLC.

- Beck, D. L. and R. Srivastava. 1991. "Perceived level and source of stress in baccalaureate nursing students". Journal of Nursing Education 30 (3):127-133.

- Brodie, D. 2007. Effective Time Management: 10 Tips. www.allindians.com $<$ http://www.allindians.com/articles/ business-finance/management/18/effective-time-management-10-tips>

- Bruyn, M and N. France. 2001. Gender Or Sex: Who Cares-Skill Building Pack On Gender And Reproductive Health For Adolescents And Youth Workers. Chapel Hill: IPAS.

- Demerouti, A., A. B. Bakker, F. Nachreiner et al. 2000. "A model of burnout and life satisfaction amongst nurses". Journal of Advanced Education 32 (2): 454-464.

- Engender Health. 2006. Sexual and Reproductive Health for HIV-positive Women and Adolescent Girls. New York: Engender Health.

- Hopkins, L. 2005. Assertive Communication - 6 Tips for Effective Communication <http://ezinearticles.com/? Assertive-Communication-6-Tips-For-Effective-Use\&id=10259>

- Indian Nursing Council. 2006. Code of Ethics and Professional Conduct. New Delhi: INC.

- $\quad$ INSA India. 2003. Experiencing Options. Bangalore: Books for Change.

- $\quad$ Luthans, F. 1998. Organisational Behaviour. (8 ${ }^{\text {th }}$ Edition). Boston: Irwin McGraw-Hill.

- $\quad$ NACO and UNICEF. 2006. Facilitators' Handbook for Training of Trainers. Adolescents Education Programme. New Delhi: NACO.

- $\quad$ NACO and UNICEF. 2006. Facilitators'Handbook for Training Peer Educators. Adolescents Education Programme. New Delhi: NACO.

- $\quad$ NACO and UNICEF. 2006. Growing up in a World with HIV/AIDS-FAQ Booklet for Students. Adolescents Education Programme. New Delhi: NACO.

- University of Iowa. Assertive Counselling. University Counseling Services http://www.uiowa.edu/ ucs/ asertcom.html

- USAID 2002. Tips for Developing Life Skills Curricula for HIV Prevention among African Youth: A Synthesis of Emerging Lessons. Office of Sustainable Development, Bureau for Africa: SD Publications.

- World Health Organization. 2000. Information Series on School Health Doc 9. Skills For Health- Skills Based Health Education Including Life Skills: An Important Component of a Child Friendly Health Promoting School. Geneva: WHO. 


\section{Slides}

\author{
Module 4 \\ I am Able! \\ Life Skills-My Armour
}

\section{\#4.3}

Need for Life Skills

To effectively address and meet the various challenges and demands of the profession

- Challenges of nursing students

- Theory and practical demands of the curricula

- More than 20 subjects

- University or Board exam to clear

- Long working hours during training period

- Theory and practical assignments to be done simultaneously

- Practice on human beings during their training period

- Staying away from home

- Multiple roles: student, spouse, parent, caring for the family etc

_ $\quad$ Risk of sexual harassment
\#4.2

Objectives

- Explain the need to develop life skills in the context of personal and professional demands

- List the various life skills that could be used to address sexual and reproductive health and rights

- Assess their own life skills

- Participate in activities in the class room to know how they could develop their life skills

\section{\#4.4}

Life Skills that will be Addressed

\section{- S: Stress management}

- T: Time management

- E: Emotions management

- A: Awareness of self, value clarification

- D: Decision making

- Y: Your motivation

- E: Empathy

- P: Problem solving

- I: Interpersonal relationships

- C: Communicating assertively

\section{\#4.5 \\ Stress Management}

- Several factors could cause stress

- Factors that cause stress are not the same for every one

- The same factor may cause different levels of stress in the same person

- Stress could build up in a person if the factors are not dealt with

- Too much of stress could lead to 'burnout'

- Burnout could present as physical, behavioural and emotional signs

Activity 4.2 Worksheet 4.2

\section{\#4.6}

Stress Management: Recognize 'Burnout'

- Physical signs: Headache, easily tired, abdominal pain, vomiting, diarrhea, lack of sleep

- Behavioral signs: Easily irritable, easily angered, withdraw from everyone, could be very demonstrative (act out), make mistakes on the job, lower grades, poor concentration

- Emotional signs: Over identification of others, feelings of hopelessness, depression, sarcasm/ suspicion, unable to make decision, extreme grief and sadness, lack of sensitivity to others needs, inability to invest in others emotionally 


\section{\#4.7}

\section{Stress: Managing it}

- Acknowledge it and assess presence of stress

- Examine the factors that cause it

- Address the factors. Do not avoid or run from it

- Work on those factors that you can control

- Check out if the factor is something that is within you or within the environment?

- What are specific things you can do within yourself to address the factor

- What are the specific things you can do within the environment to reduce stress?

- Will you do this alone or with the help of others?
\#4.8

Stress: Managing it (cont.)

- Find someone whom you can trust and talk to them about it

- Use different approaches to reduce stress

- Yoga, jogging, other exercises

- Listen to music, read, do something spiritual

- Do anything that you know to calm yourself

- Remember that you cannot sometimes control all factors that cause stress. ACCEPT it and move on

Handout 4.1 Worksheet 4.2

\section{\#4.9}

Stress: Managing it (cont.)

- Become aware of your self-what causes stress in you and how you would usually react

- Use steps as given before: is it something within you or outside of you?' can you control it or not?

- If stress exists then check 'Are things out of balance?'

- Network with other nurses to create a supportive environment

- Engage in something out side of work that you enjoy

- If your are a spiritual person, seek spiritual guidance

- Take time to reflect on a difficult situation \& acknowledge the difficulty

Reference-Worksheet 2.4 Module 2 Worksheet 4.3
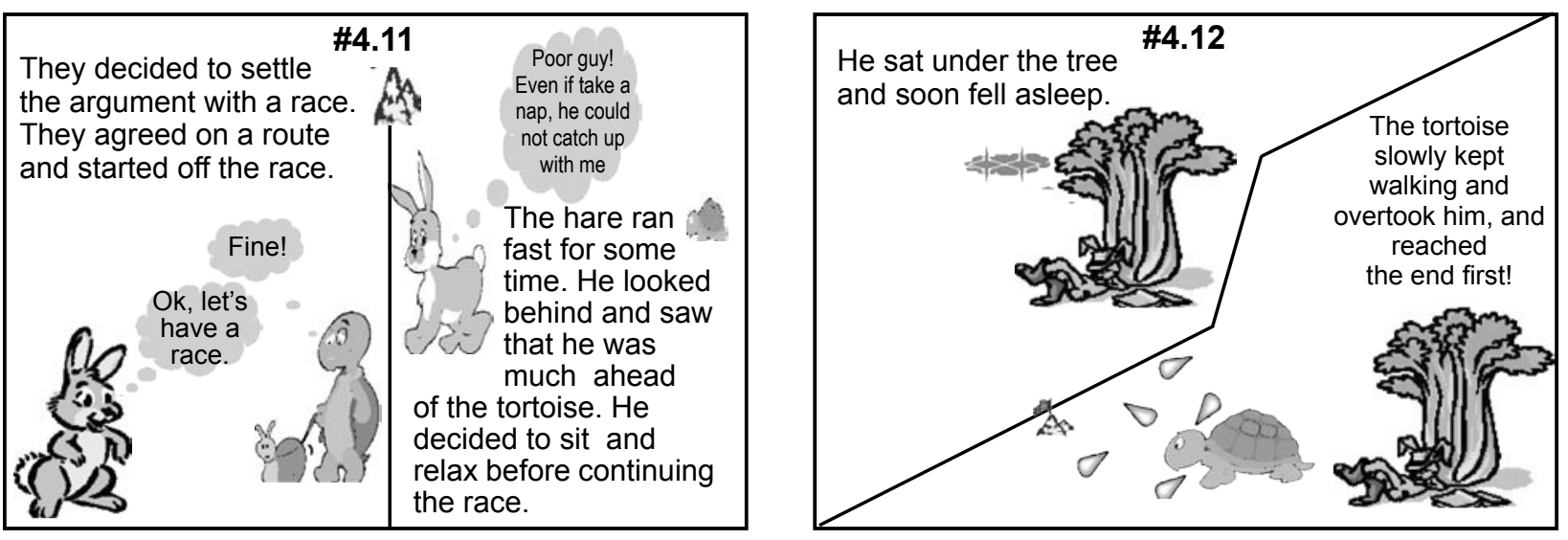


\section{\# 4.13}

- How did the Tortoise win? The hare woke up Why did the hare lose?

Who and realized that he'd lost the race.<smiles>C1[SiH2]C[AsH]1</smiles>

- What could the hare have done to win?

- What are the lessons learnt

\section{\#4.14}

\section{Time: Managing it}

- Know your goals

- What do you have to finish?

- When do you have to finish it?

- How well do you want to do?

- Maintain a log of activities - know where $u$ are now

- Categorize activities: A, B, C, D

- Complete $D$ first and then $C$, then $B$ and finally $A$

- Depends on your energy levels

- Depends on you goals

\section{\#4.15}

Time : Managing it

- Do not put off things that you have to do (do not procrastinate)

- Review: goals with others/someone you know you could trust

- Get feed back about your performance from a person you trust
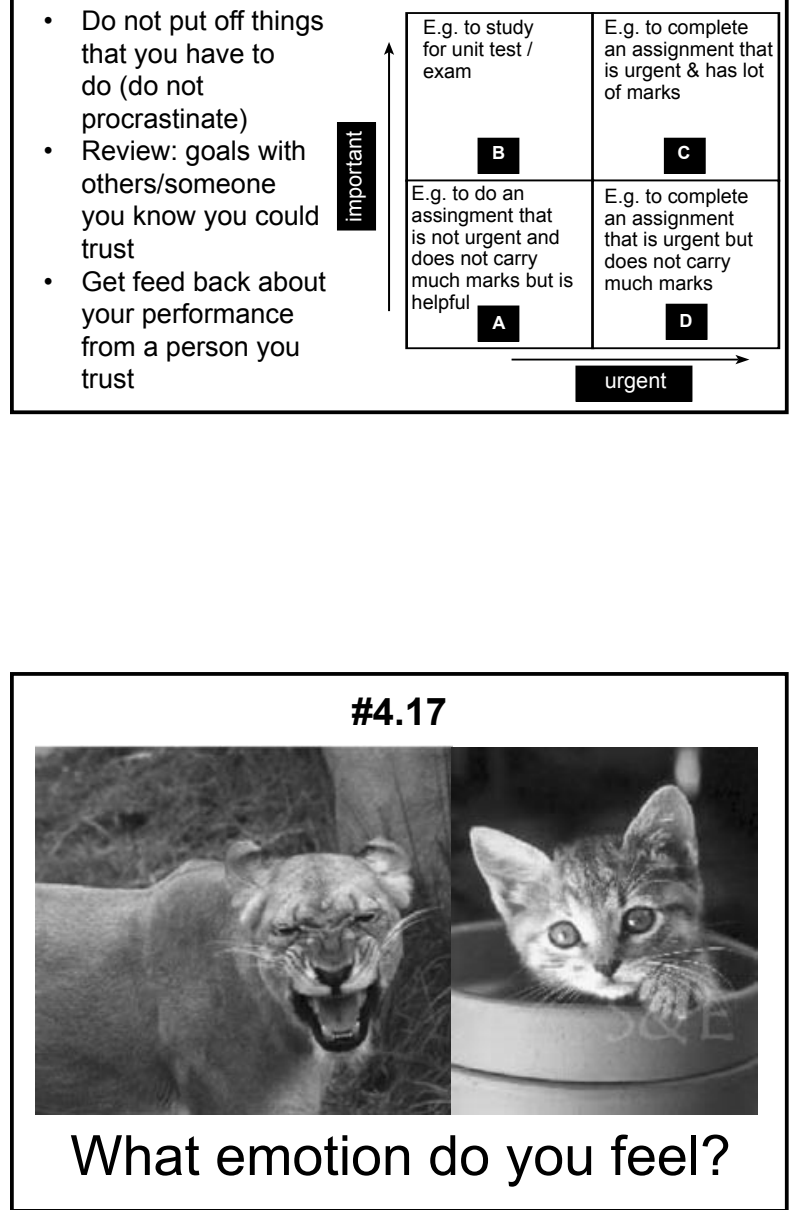

\section{\#4.16 \\ Managing Your Emotions}

- What is an emotion?

- Emotions cause physical changes (physiological processes) due to images in the imagination or memory.

- These physical changes affect our energy

- The words "emotion, motivation, motion" come from the Latin root word "emotere" which means "to move".

- Emotions move us unless the emotional energy is inhibited

Activity 4.4
\#4.18

\section{Emotions: Managing them}

- Recognize your sources of strength

- Every one has three sources of strength

- I have

- I am

- I can

- Find ways to improve these resources 


\section{\#4.19}

\section{Emotions: managing them}

- Become aware of your strengths and weaknesses

- Recognize the emotion that you experience

- Wait for a while till you can control the emotion

- Breathe in and out

- Count from 1 to 10

- Any other method

- Separate emotion from logic

- look at the situation, what caused the emotion?

- Follow the same steps given for stress if it is a negative emotion
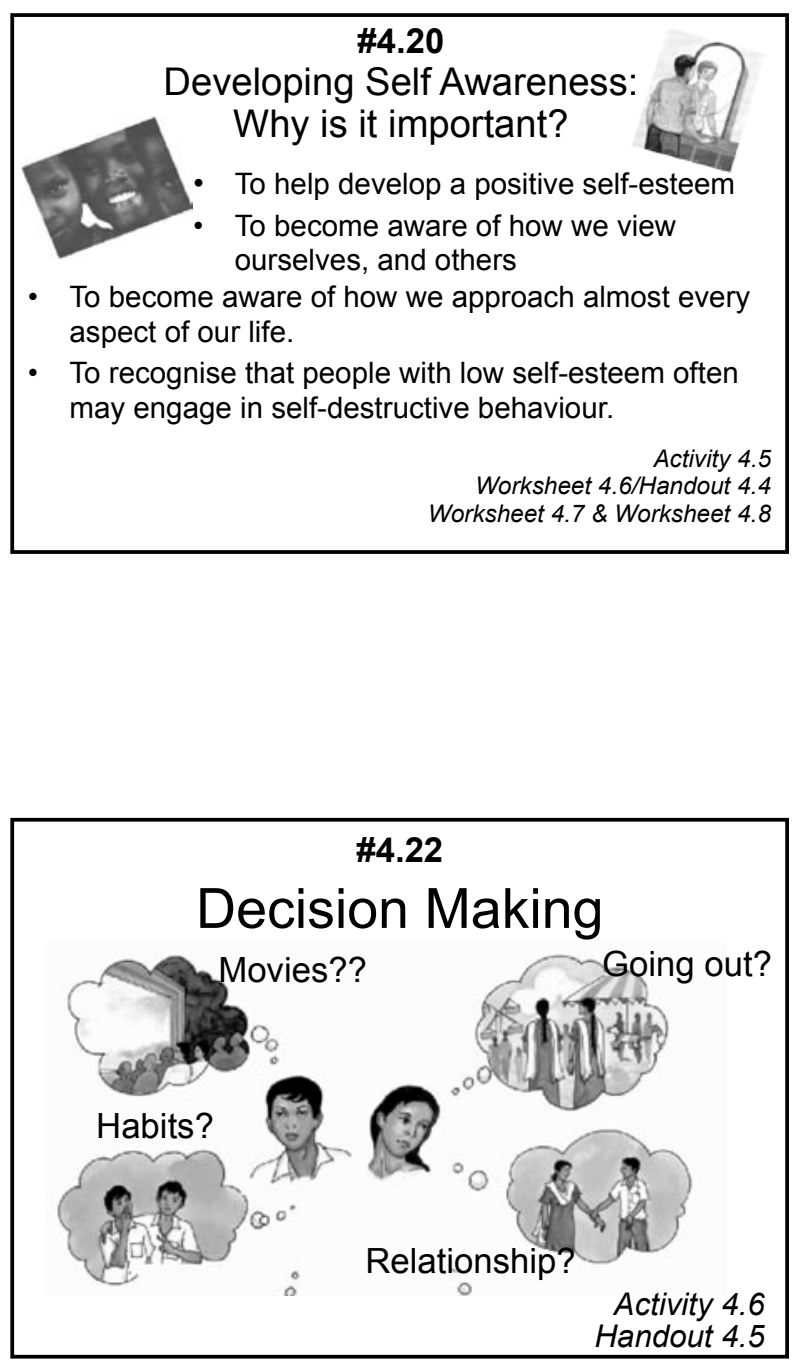

\section{\#4.23}

\section{Decision Making: POWER Model}

\footnotetext{
- $\mathrm{P}=\mathrm{PROBLEM}$ - Stop and state (or identify) the problem/ situation that requires a decision to be made.

$\mathrm{O}=$ OPTIONS - Think of different things you can do.

- $\mathrm{W}=\mathrm{WEIGH}$ - Think of each option as a 'Yes' or 'no', weigh good versus bad for all options.

The things you value should guide you in your decision making.

- $\mathrm{E}=\mathrm{ELECT} \quad$ - Choose the best option, talk to a person you respect, then take the best action. Elect the option which obtains what is important to you (values)

- $\mathrm{R}=\mathrm{REFLECT}$ - Think or reflect about what happened because of your decision.
}

\section{\#4.24}

Decision Making - In Relationships

- $\quad$ Get to know the person you are interested in or intend forming a relationship with

- $\quad$ Anticipate situations where you may have to make a sexual decision.

- Be aware of what times and places could place a need to make a sexual decision.

- Do not wait until that time to decide!

- Go into potentially sexual situation with your thoughts and values in mind.

- Talk to someone you trust 


\section{\#4.25}

\section{Decision Making—In Relationships}

- Be assertive and speak your mind to those who try to change your mind about your sexual decisions.

- Talk to your friends and peers about what you feel.

- Do not push you values on others but be proud of your own.

- You may be a positive influence on your friends by getting them to question their own values and sexual decisions

\section{\#4.26}

\section{Decision Making-Peer Pressure}

- Know what is important for you and know your values

- Be aware of yourself and your goals in life

- Talk to someone you respect and trust

- Think ahead and do not put yourself in the wrong situation or place.

- Be assertive and stand-up for your decision

- Avoid potentially threatening situations

- Get out of the situation

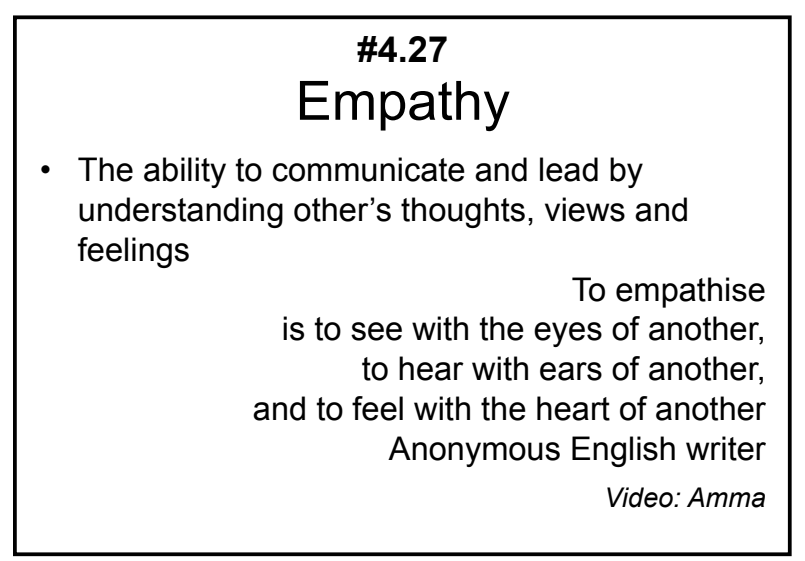

\section{\#4.29}

\section{Developing Empathy}

- Recognise the difference between empathy and sympathy.

- Look at a situation from the clients view point not yours

- Remember that a way to encourage a client to talk is to empathise with him/her.

- To empathise with the client means showing that you understand his/her feelings from his/her point of view.

- Accept what he/she thinks and feels.

- Recognize and praise what he/she is doing right.

- Teach based on the needs as perceived by him/her.

\section{\#4.28}

\section{Developing Empathy}

- Self-awareness - Know how would you feel in a

- Accepting person situation

- Develop it - Acknowledge differences and respect

Respect - Focus on improving this skill

- Respect - Show respect for others view points

- Understand others - Watch and listen to both words,

- Listen actively expressions and feelings

- Expressions - Pay attention to the words, make eye contact, observe the body language etc

- Be aware of non verbal expressions

Video : ITECH Mentoring tool kit: Post test Counseling

\section{\#4.30}

Problem Solving-What are Problems?

- P: Predictors - Help us shape our future

- R: Reminders - Remind that we need others' help

- O: Opportunity - Help us to wake up and think

B: Blessings creatively

L: Lessons - Open doors we prefer not to go

- E: Everywhere - New challenges which teach us

- M: Messages - Everyone and every place has them

- S: Solvable - They warn us about potential disaster

- S: Solvable - Every problem has a solution 


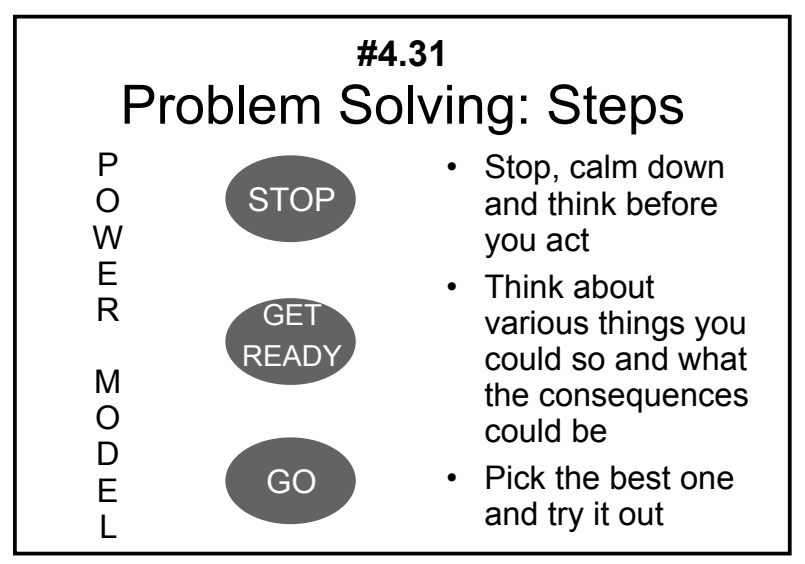

\section{\#4.33}

The hare was disappointed he had lost the race. $\mathrm{He}$ stopped and started examining the situation. $\mathrm{He}$ realized that he'd lost the race only because he had not considered his strengths and weaknesses, not managed his time well, and had lost focus of the goal. If he had not taken things for granted, there's no way the tortoise could have beaten him. So he challenged the tortoise to another race. The tortoise agreed.

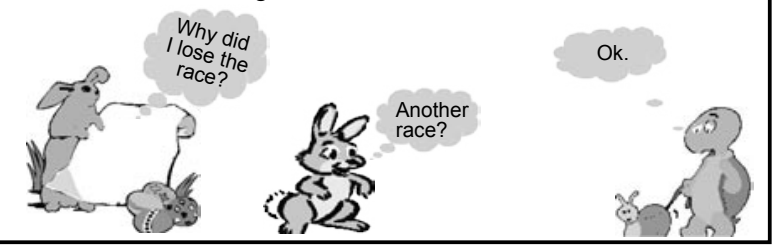

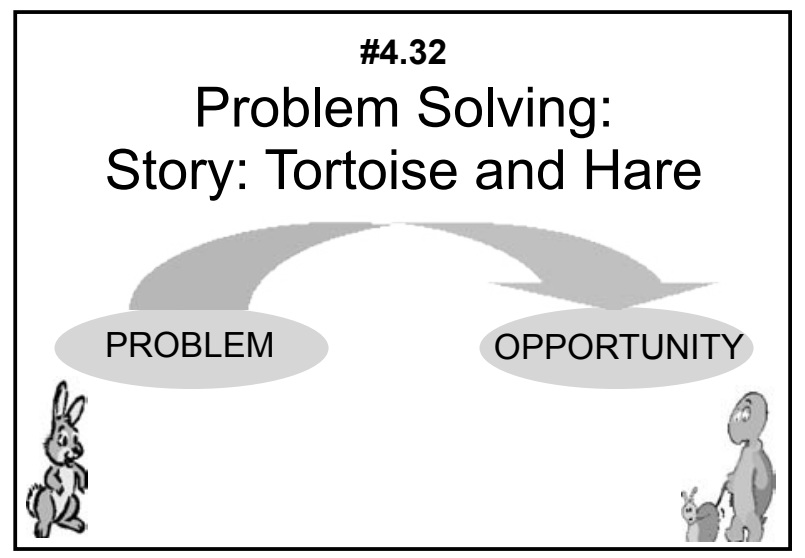
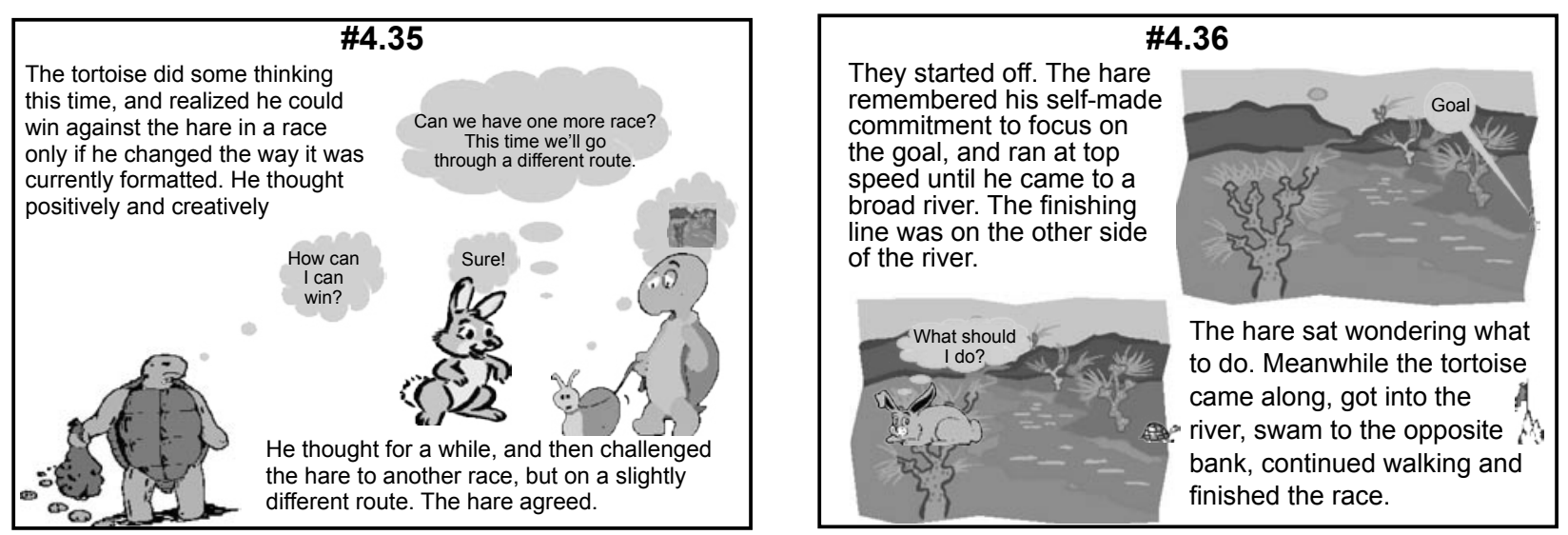

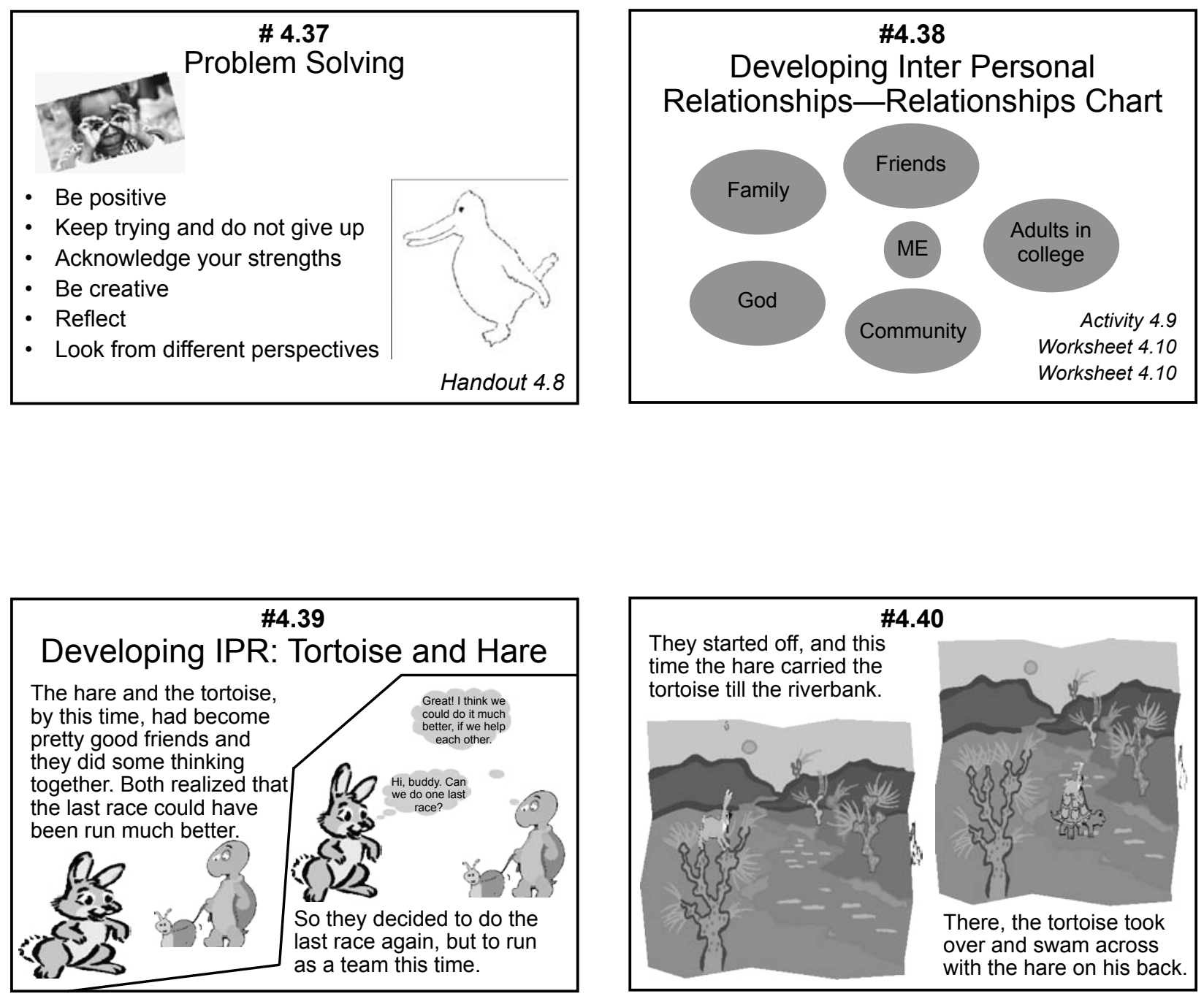

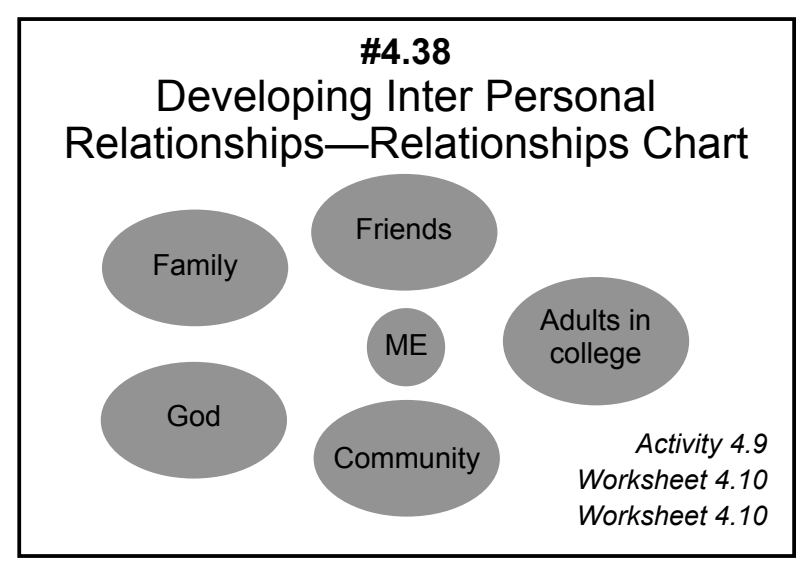

They started off, and this time the hare carried the tortoise till the riverbank. with the hare on his back.
On the opposite bank, th again carried the tortoise and they reached the finishing line

together. They both felt a greater - Be able to see the good in sense of satisfaction than they'd every problem and person felt earlier.

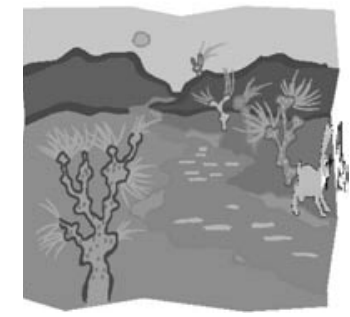

Tork as a team-better

Aim for a win-win situation

- Do not give up in a difficulty

- Work harder

- Change ways of working

Do not compete with the rival but with the situation

Worksheet 4.11

\section{\#4.42}

Communicating Assertively

- Know your values

- Form your own circle of friends who share your values and attitudes.

- Be clear about your goals and share these with your close social network

- Be consistent in what you say

- Do not be frightened to

- Say 'no' when in your mind you feel something is wrong

- Show that you do not appreciate some behaviour

Activity 4.10 Worksheet 4.12 


\section{References}

Amaro, H., A. M. Navarro, K. J. Conron et al. 2002. Cultural Influences on Women's Sexual Health. In G. Wingood \& R. DiClemente (Eds.), Handbook of Women's Sexual and Reproductive Health (pp. 43-70). New York: Kluwer Academic/Plenum Publishers.

Africa Region Gender Team. 2001. The gender discriminations of HIV/AIDS: Putting gender on the MAP. (Working draft). Washington DC: World Bank.

Ahmed, A. and S. Menon. 2006. Rights and Desire-A Facilitator's Manual to Healthy Sexuality. New Delhi: Breakthrough.

Alphonse, X. 2004. We Shall Overcome-Textbook on Life Coping Skills. Bangalore: SKIP Publication.

American Centre for International Labour Solidarity. 2007. "Module 2: HIV / AIDS, Gender and Sexuality-Trade Union Capacity Building”. HIV / AIDS Prevention and Care Project. USA: Solidarity Centre.

Anderson, P. 1997. "Perceived levels and sources of stress in beginning bachelor of nursing students". Nursing And Midwifery-Victoria University, New Zealand, 15: 101-108.

B. C. Epilepsy Society. 2008. Stress Management. West Broadway, Vancouver. <http://www.cmha.ca/BINS/content_ page.asp?cid $=4-42-216>$.

Bauknecht, B. and T. Schmitz. 2001. "Education Version-Empathy”. The Anger Management Program. CA: Oakland Solutions LLC.

Beck, D. L. and R. Srivastava. 1991. "Perceived level and source of stress in baccalaureate nursing students". Journal of Nursing Education 30 (3):127-133.

Brodie, D. 2007. Effective Time Management: 10 Tips. www.allindians.com < http://www.allindians.com/articles/businessfinance/management/18/effective-time-management-10-tips $>$.

Bruyn, M and N. France. 2001. Gender Or Sex: Who Cares-Skill Building Pack On Gender And Reproductive Health For Adolescents And Youth Workers. Chapel Hill: IPAS.

CEDPA. 2000. Gender, Reproductive Health and Advocacy Training Manual. Washington DC: CEDPA.

Crosby, R. A, R. J. Di Clemente, G. M. Wingwood et al. 2002. "Adolescents ambivalence about becoming pregnant predicts infrequent contraceptive use: A Prospective Analysis of Non pregnant African American females". American Journal of Obstetrics and Gynaecology 186 (2): 251-252.

Demerouti, A., A. B. Bakker, F. Nachreiner et al. 2000. "A model of burnout and life satisfaction amongst nurses". Journal of Advanced Education 32 (2): 454-464.

Eliot, M. 1996. "The clinical environment: A source of stress for undergraduate nurses". Australian Journal of Advanced Nursing 20(1): 34-38.

Engender Health. 2006. Sexual and Reproductive Health for HIV-positive Women and Adolescent Girls. New York: Engender Health. 
Germain, A. 2005. Making Progress: An International Agenda to Secure and Advance Sexual and Reproductive Rights and Health New York: IWHC.

Guttmacher Institute \& World Health Organisation. 2007. In Brief-Facts on Induced Abortion Worldwide. Geneva: WHO.

Hopkins, L. 2005. Assertive Communication — 6 Tips for Effective Communication $<$ http://ezinearticles.com/?AssertiveCommunication-6-Tips-For-Effective-Use\&id=10259>.

International Center for Alcohol Policies (ICAP). 2005. Module 2- Life Skills. ICAP Blue Book: Washington DC.

Indian Nursing Council. 2006. Code of Ethics and Professional Conduct. New Delhi: INC.

INSA India. 1998. Divine Sexuality. Bangalore: Ash Design and Print Unit.

INSA India. 2003. Experiencing Options. Bangalore: Books for Change.

International Women's Health Coalition. 2001. Sexual Health-Fact Sheet. New York: IWHC.

Irvin, A. 2004. Positively Informed-Lesson Plans and Guidance for Sexuality Educators and Advocates. New York: International Women's Health Coalition (IWHC).

ITECH. 2008. Empowering Nurses to Deliver HIV Nursing Care and Education (ENHANCE) Training Curriculum. Tambaram Sanatorium, Government Hospital of Thoracic Medicine, Chennai: International Training and Education Center on HIV (ITECH).

International Women's Health Coalition. 2008. Women and risk of HIV /AIDS Fact sheet. New York: IWHC.

HERA. 1998. Health Empowerment Rights and Accountability, Women's Sexual and Reproductive Rights and Health Action Sheets. New York: IWHC.

Jone's M.C and D. W. Johnston. 1997. "Distress, stress and coping in first year student nurses". Journal of Advanced Nursing. 26 (3): 475-482.

Kim, J and M. Mosei. 2007. Sisters for Life-Gender and HIV Training Manual. Intervention with Micro enterprise or AIDS and Gender Equity (IMAGE) Study; Rural AIDS and Development Action; Research (RADAR) Program School of Public Health, University of the Witwatersrand. South Africa: Small Enterprise Foundation.

Luthans, F. 1998. Organisational Behaviour. (8 ${ }^{\text {th }}$ Edition). Boston: Irwin McGraw-Hill.

McGrath H, 2007. Behaviour Management (1). Australia: Blake Education.

NACO and UNICEF. 2006. Facilitators' Handbook for Training of Trainers. Adolescents Education Programme. New Delhi: NACO.

NACO and UNICEF. 2006. Facilitators' Handbook for Training Peer Educators. Adolescents Education Programme. New Delhi: NACO.

NACO and UNICEF. 2006. Growing up in a World with HIV/AIDS-FAQ Booklet for Students. Adolescents Education Programme. New Delhi: NACO.

NACO. 2008. Policy guidelines for mainstreaming gender in HIV programmes. (Draft copy). New Delhi: NACO.

Population Council \& Parivar Seva Sanstha. 2004. Understanding Induced Abortions: Findings from a programme of research in Rajasthan, India. New Delhi: Population Council. 
Shiela, S., Huey-Shyan, Lina and Shiow-Li Hwangb. 2002. "Perceived stress and physio-psycho-social status of nursing students during their initial period of clinical practice and the effect of coping behaviours". International Journal of Nursing Studies. 39: 165-175.

Simons, G. F and G. D. Weissman. 1990. Men and Women: Partners at Work. CA, USA: Crisp Publications.

South East Asian Consortium on Gender, Sexuality and Health. 2005. Glossary of Terms on Gender and Sexuality. Thailand. <www.seaconsortium.org>

SPC/UNFPA. 1998. "Population Advocacy and Reproductive Health". IEC Projects. Reproductive Health Fact Sheets. 1-12. Noumea: Secretariat of Pacific Community.

St. John's College of Nursing. 2005. Facilitators Manual-STI and HIV /AIDS; Prevention, Care and Support. Bangalore: KSAPS and ICHAP.

TARSHI. 2006. Basics and Beyond. New Delhi: TARSHI.

UNDP/UNFPA/WHO/World Bank Special Programme of Research Development and Research Training in Human Reproduction-HRP 2004. "Sexual health-a new focus for WHO". Progress in Reproductive Health Research, No 64.

University of Iowa. Assertive Counselling. University Counseling Services <http://www.uiowa.edu/ ucs/ asertcom.html>.

USAID 2002. Tips for Developing Life Skills Curricula for HIV Prevention among African Youth: A Synthesis of Emerging Lessons. Office of Sustainable Development, Bureau for Africa: SD Publications.

Women's Coalition for the ICPD. 2001. Reproductive Health and Rights are Human Rights, New York: IWHC.

Women's Coalition for the International Conference on Population and Development (ICPD) 2001. Health, Empowerment, Rights and Accountability Action Sheets. New York: International Women's Health Coalition.

Women's Coalition for the ICPD. 1998. Emergency Contraception Is Just That-Emergency Contraception, Not Abortion. Health, Empowerment, Rights and Accountability (HERA) New York: IWHC.

World Health Organization. 1995. Teaching Modules for Basic Education in Human Sexuality. Manila: WHO Regional Office of the Western Pacific.

World Health Organization. 1995. Teaching Modules for Continuing Education in Human Sexuality. Manila: WHO Regional Office of the Western Pacific.

World Health Organization. 2000. Information Series on School Health Doc 9. Skills For Health- Skills Based Health Education Including Life Skills: An Important Component of a Child Friendly Health Promoting School. Geneva: WHO.

\section{Further readings}

Art and Soul, CREA and TARSHI, 2005. A Record of Women. New Delhi: CREA and TARSHI.

Asian-Pacific Resource and Research Centre for Women. 2006 "Monitoring Ten Years of ICPD Implementation-The Way Forward to 2015”. Asian Country Reports. Malaysia: ARROW.

Baxi, U. 2005. "Human Rights Against the Transgender Community-A Study of kothi and hijra Sex Workers in Bangalore, India". Report by People's Union for Civil Liberties, Karnataka: PUCL. 
BIPAI. 2007. HIV Curriculum for the Health Professional, Baylor International Paediatric Aids Initiative (BIPAI). Texas: Baylor College of Medicine.

CARE and ICRW. 2007. Inner Spaces Outer Faces Initiative. Washington DC: ICRW.

CEDPA. 1996. Choose a Future! Training Manual_Facilitators Handbook Washington DC: CEDPA.

Chandiramani, R., S. Kapadia., R. Khanna and G. Misra. 2002. "Sexuality and Sexual Health Behavior: A critical review of studies (1990-2000)". The Gender and Reproductive Health Research Initiative New Delhi: CREA.

Chauduri, P. 2006. "Sexual Harassment in the Workplace-Experiences of Women in the Health Sector". Health and Population Innovation Fellowship Programme Working Paper. No 1. New Delhi: Population Council.

Commission for Healthcare, Catholic Bishops Conference of India, 2007. Commitment to Compassion and Care-HIVI AIDS Policy of the Catholic Church in India New Delhi: CBCI Centre.

Congo, J. 2005. The Self Confident Woman-Building a Strong Foundation for Healthy Relationships. USA: Life Journey.

Cranny-Francis, A., W. Waring, P. Stavropoulos and J. Kirkby. 2003. Gender Studies-Terms and Debates. New York: Palmgrave MacMillan.

CREA. 2005. Adolescent Sexual and Reproductive Health and Rights in India-Working paper. New Delhi: CREA.

CREA. 2006. Sexual Rights and Social Movements in India-Working Paper. New Delhi : CREA.

CREA, SANGRAMA and TARSHI. 2004. A Conversation on Sexual Rights in India. A Report. Manesar 7-9 January 2004. New Delhi: CREA.

Crosby, R. and K. Miller. 2002. "Family Influences on Adolescent Females' Sexual Health”. Handbook of Women's Sexual and Reproductive Health. New York: Kluwer Academic/Plenum Publishers.

Crouch, S. 1999. "Sexuality and Nurses Role in Sexual Health”. British Journal of Nursing 8(9):601-6.

Crouch, S. 1999. "Sexual Health: An Overt Approach to Sexual Health”. British Journal of Nursing 8(10):669-75.

Decker, M., R. J. G. Silverman, A. Raj. 2005. "Dating Violence and Sexually Transmitted Disease/HIV Testing and Diagnosis among Adolescent Females”. Paediatrics. Vol 116 (2): 272-276.

DFID. 2006. HAAP. PLAN India, New Delhi: DFID.

Dixon, P. 2002. AIDS and YOU. UK: Operation Mobilization and ACET International Alliance.

Engender Health. 2004. Trainers Manual-Reducing Stigma and Discrimination Related to HIV and AIDS: Training for Health Care Workers. New York: Engender Health.

Esplen, E. 2007. “Gender and Sexuality—Supporting Resources Collection”. Cutting Edge Pack. UK: BRIDGE Publications.

Family Health International. 2007. Life Skills Education Toolkit for Orphans and Vulnerable Children in India. New Delhi: FHI. 
Family Health International. 2004. "Counselling, Testing and Psycho Social Support". HIV Prevention and Care in Resource Constrained Settings. USA: FHI.

Global AIDS Alliance. 2006. Zero Tolerance-Stop the Violence against Women and Children Stop HIV/AIDS. Washington DC: Global AIDS Alliance.

Germain A., J. Kidwell. 2005. "The Unfinished Agenda for Reproductive Health: Priorities for the Next 10 Years". Questia: Journal article: Vol 31 (Excerpt).

Haffner D. W, W. L. Yarber, 1997. The Guidelines for Comprehensive Sexuality Education Kindergarten to 12TH Grade. USA: SEICUS.

Handa, A. 1995. "Sex Education for Adolescents.” Nursing Journal of India LXXXVI (8): 173-177.

Ilkkaracan, P. and S. Jolly. 2007. "Gender and Sexuality-Overview Report". Cutting Edge Pack. UK: BRIDGE Publications.

Indian Nursing Council. 2001. Syllabus and Regulations-Diploma in General Nursing and Midwifery. New Delhi: INC.

Indian Nursing Council. 2004. Syllabus_Basic B.Sc. New Delhi: INC.

IPPF and WHR. 2002. Trainers Guide on Sexual Health. New York: International Planned Parenthood Federation and Western Hemisphere Region.

IWHC. 2002. "The Reality of Adolescent Girls Lives". Fact Sheet. New York: IWHC. <http://www.iwhc.org/resources/ adogirlsfactsheet.cfm>.

Iyer, S. 1999. The Struggle to be Human-Womens Rights. Bangalore : Books for Change.

Jessop, C. 2007. Escape. USA: Broadway.

Kelton, S. 1999. "Sexuality Education for Youth with Chronic Conditions”. Paediatric Nursing. 25(5):491-5.

Khanna R, S. Gurbaxani, K.Sengupta, 2002. Sexuality and Sexual Behavior: An Annotated Bibliography of Selected Studies (1990-2000). The Gender and Reproductive Health Research Initiative. New Delhi: WOHTRAC and CREA.

Kidd, R and S. Clay, 2003. Understanding and Challenging HIV Stigma Toolkit for Action-Trainers Manual USA: CHANGE and ICRW.

Kim, J., L, Ndhlovu and M, Motsei. 2007. Natural Leaders Training-Gender, HIV and Community Mobilization Training Manual IMAGE, RADAR, South Africa: School of Public Health, University of the Witswatersrand and SEF.

Krishnaswamy L. 2001. "Psycho Social Problems of Adolescents-An Exploratory Study". Indian Journal of Continuing Nursing Education. Vol 1 (1): 34-38.

Magnan, M.A, K. E. Reynolds and E.A Galvin. 2005. "Barriers to Addressing Patient Sexuality in Nursing Practice", Clinical Nurse Specialist. 14 (5): 282-289.

Magnan M.A, K.E. Reynolds. 2006. "Barriers to Addressing Patient Sexuality Across Five Areas of Specialization". Clinical Nurse Specialist.20(6):285-292. 
Maliro D., S. Muntemba. 2004. Basic Manual for Training Field Workers: Integrating Gender into HIV/AIDS Programs. Govt. of Malawi \& The World Bank.

Marlow Dr. and B. A. Redding. 1988. Textbook of Paediatric Nursing. 6th ed. Philadelphia, USA: Saunders.

McKeon, B. 2006. Effective Sex Education-The Facts. Washington DC: Advocates for Youth.

Misra, G and R. Chandiramani (Eds). 2006. Sexuality, Gender and Rights-Exploring Theory and Practice in South and South East Asia. New Delhi: Sage Publications.

Morbidity and Mortality Weekly Reports (MMWR). 2005. Recommendations and Reports. "Antiretroviral Post exposure Prophylaxis after Sexual Intercourse, Injection Drug Use, or Other Non Occupational Exposure to HIV in the United States." Recommendations from the U.S. Department of Health and Human Services, 2005/54(02); 1-20. Centres for Disease Control and Prevention.

Palmer H. 1998. "Exploring Sexuality and Sexual Health in Nursing”. Professional Nurse. 14(1):15-17.

Population Council. 2004. Sexual Coercion-Young Men's Experiences as Victim and Perpetrators. New York: Youth Net.

Population Council. 2004. Forced Sexual Relations Among Married Young Women in Developing Countries. New York :Youth Net.

Prasad K. 2007. "Sexual Harassment in the Workplace.” The Nursing Journal of India. Vol XCVVIII (1): 9-10.

Robin L, P. Dittus , R. Whitaker et al. January 2004. "Behavioural Interventions to Reduce Incidence of HIV, STD and Pregnancy among Adolescents: A Decade in Review." Journal of Adolescent Health. Vol 34 (1): 3-26.

Sangrama-VAMP. 2006. The Struggle to be Human. Sangli, Maharasthra: Arohan.

Scotti L and J. M. Leslie. 2004. Nursing Training Curriculum: HIV Practice And Reducing Stigma-Facilitator Version. New York: Population Council.

Social Aspects of HIV/AIDS Research Alliance (SAHARA) January 2008. <http://www.sahara.org.za/index.php/ View-document-details/66-It-s-raining-stones-stigma-violence-and-HIV-vulnerability-among-men-who-have-sex-withmen-in-Dakar.html>.

Swayam. 2007. Status of Women: A Reality Check-Facts on Inequality and Crimes against Women. Kolkata: Swayam.

TARSHI. 2004. Sexuality Matters. New Delhi: TARSHI.

TARSHI. 2005. The Blue Book—What you want to know about yourself, 15+ years. New Delhi: TARSHI.

TARSHI. 2005. The Red Book-What you want to know about yourself, 10-14years. New Delhi: TARSHI.

The Global Dialogue Series. 2004. Building Alliances Globally To End Violence Against Women. Working Paper 1, The Bellagio Study and Conference Center: Italy.

Turner, C., C. Wegs, B. Randall-David, J. Molloy (Eds). 2003. Effective Training in Reproductive Health: Course Designs and Delivery. Trainers Manual. Chapel Hill, NC: IPAS.

UNDP. 2000. Human Development Report. New York: UNDP. 
UNDP. 2002. Gender Approaches in Conflict and Post Conflict Situations. New York: UNDP.

UNFPA and WHO. 2006. Sexual And Reproductive Health of Women Living With HIV/AIDS-Guidelines On Care, Treatment And Support For Women Living With HIV/AIDS And Their Children In Resource Constrained Settings. WHO: Geneva.

UNFPA. 1999. Violence against Women and Girls: A Public Health Priority. New York: UNFPA.

UNFPA. 2000. State Of The World Population 2000: Lives Together, Worlds Apart. New York: UNFPA.

UNICEF. 2001. Child Protection: Trafficking Of Children. New York: UNICEF.

United Nations. 2000. The World's Women 2000: Trends and Statistics. New York: UN

United Nations. 1994. Program of Action of The International Conference On Population and Development. Cairo: UN.

United Nations. 1999. Key Actions For The Further Implementation of The Program of Action of The International Conference On Population And Development. New York: UN.

United Nations. 2000. The World's Women 2000: Trends and Statistics. New York: UN.

Women's Health Victoria. 2004. "Body Image” Women's Health Information Package' < http://www.whv.org.au>.

Women's Coalition for the ICPD. 1998. "Ensuring the Sexual and Reproductive Health of Adolescents". Health, Empowerment, Rights and Accountability (HERA) New York: IWHC.

World Health Organization. 1975. "Education and Training in Human Sexuality. The Training of Health Professionals" Technical Report Series. No 572 100. Geneva: WHO.- 


\section{Annexures}

\section{Annexure A: Energisers and icebreakers}

Remember - these are more fun when the trainers join in!

1. ANTAKSHARI: Break participants up into two teams and ask one of them to sing 2 lines of a song. The other team then has to sing a song starting with the last syllable of the song their opponents ended with. Continue for 2-5 minutes. Alternatively you could ask them to sing some small rhyme in a cyclical manner by breaking them up in to 3-4 groups. An example is 'row row your boat'

2. BODY WRITIING: Ask participants to write their name in the air with a part of their body. They may choose to use an elbow, for example, or a leg. Continue in this way, until everyone has written his or her name with several body parts.

3. COME WITHIN THE CIRCLE: Get participants to take off their footwear and make a circle with them. They have to walk around the circle formed by the footwear. When you clap hands, all must try and get within the circle. Those who are not able to fit in are out. With each turn, reduce the size of the circle by removing some of the footwear. Continue this process till you get a circle with diameter of a foot in size. Check out how many participants ultimately fit into the circle. Ideally if each one tries to help the other to get within the circle, at least eight participants should be able to fit into the last circle.

4. FORMING GROUPS: Participants are given chits of paper on which the name of an animal or bird is written. When the facilitator claps hands, the participants must make the sound of the animal/bird and thus find the other members of their group. This game will cause a lot of noise. Therefore, it is essential that you check the permissible levels of noise allowed within the premises of the institution. It is an excellent icebreaker.

5. GUESS WHO: Give each person a 3"x5"card and ask the them to write down something true about themselves that nobody else in the room knows e.g., know how to dance the salsa; have been to Nepal;have two dogs, etc. Mix up the cards and put them in a container. Have each person pick a card and read it out loud. Ask the group to try and guess who wrote the card.

6. IN THE POND - OUT OF THE POND: Draw a circle with a chalk on the floor, large enough so that all participants can form a circle around it. Tell participants that this is a pond. One of the group coordinators then takes turns to call out 'in the pond'/'out of the pond'. In response to this participants must jump into the circle or stand out of the circle. The order of calling out the two commands must be random so that participants cannot guess what action they will have to take. Continue the process till you feel an increase in the energy levels of the participants.

7. MY SLOGAN: Explain that many organizations have slogans or sayings that reflect their values and are easy for customers to remember. For example, the Coca-Cola Company uses the slogan, "Have a Coke and a Smile." Ask each person to write (or borrow) a slogan to describe him or herself and share it with the class.

8. OPPOSITES OR PAIRS: Prepare chits of paper, enough for everybody in the group. This activity can focus on either matching opposites or matching pairs. Each paper includes one word from an opposite (black/white, up/down, left/right, hot/cold) or pair (mango/sticky rice, pencil/paper, HIV test/counselling). Use concepts that relate to the topic area of the training to reinforce knowledge learned, or to introduce knowledge that will be covered later during the training. Each person picks one piece of paper and then begins to look for the person who has the matching word. The objective is for the participant to find her/his match. If this is used at the beginning of the training, use it as a way of doing introductions. When participants find their match, they should get to know one another so that can introduce the other person to the rest of the group. 
9. SHAKE ALL HANDS: Everyone in the room shakes everyone else's hand within a strict time limit of one minute. This gets energy up, and obliges each participant to acknowledge everyone else.

10. SOMETHING NEW: Ask each person to share one thing they learned about another participant on the previous day. Have the rest of the group try to guess who is being described.

11. SOMETHING FUNNY/GOOD/NEW": Have participants introduce themselves, sharing their name and something funny they did or learned on their first clinical posting or to share something good or new they have experienced in the last 24 hours.

12. STAND UP AND SIT DOWN: Tell participants that they will have to follow your instructions. Ask them to 'stand up' or 'sit down' alternatively. Continue this till you know the energy levels of the participants have increased.

13. THE SUN SHINES ON: Participants sit or stand in a tight circle with one person in the middle. The person in the middle shouts out "the sun shines on..." and names a colour or articles of clothing that some in the group possess. For example, "the sun shines on all those wearing blue" or "the sun shines on all those wearing socks" or "the sun shines on all those with brown hair". All the participants who have that attribute must change places with one another. The person in the middle tries to take one of their places as they move, so that there is another person left in the middle without a place. The new person in the middle shouts out "the sun shines on..." and names a different colour or type of clothing.

14. THREE TRUTHS AND A LIE: Give each individual a 3"x5" card and instruct them to write four statements about themselves: one of the statements should be false while three should be true. Explain that the goal is to fool people about which one is the lie. Allow five minutes to write statements; then have each person read the four statements and have the group guess the lie. Award a prize to the individual who makes the most correct guesses

15. WHAT WE HAVE IN COMMON: The facilitator calls out a characteristic of people in the group, such as 'having long hair'. All those who have long hair should move to one corner of the room. As the facilitator calls out more characteristics, such as 'likes to dance', people with the characteristic move to the indicated space. (Could also do as a stand up sit down)

16. WHERE WERE YOU? Ask each participant to pull a coin out of their purse and look at the year on the coin. Give them one minute to think about where they were and what significant event took place during that year. Ask few or all participants (depending on time) to share their memories in one or two sentences.

\section{Adapted from source:}

- $\quad$ INSA India. 2003. Experiencing Options. Bangalore: Books for Change. 


\section{Annexure B: Baseline information}

1. Institution :

2. Course : $\mathrm{GNM} / \mathrm{BSc}$

3. Age (years) :

4. Sex : Male/Female

5. Have heard the words
a. Sexuality : Yes/No
b. Sex : Yes/No
c. Gender : Yes/No

6. Have you had any training or classes on sexuality and gender in the past? (either prior to entry to the nursing profession or after joining the nursing course).
a. Yes/No
b. If yes: when
c. If yes: by whom
d. If yes, what was the duration:
e. If yes, did you find it useful? Please explain how you think it was useful?

7. Have you discussed/read about sexuality and gender in the past
a. Yes/no
b. If yes, who/what was your source?
c. If yes, with whom were you most comfortable to discuss these issues? (e.g. mother, father, sibling, friend, teacher, aunt....etc)

In the table given below, please mark against each item, the level of you agreement or disagreement. The numbers are represented in the scale. You could mark your level of agreement anywhere along the scale but it must be represented by a number (1-6). Thank you for your cooperation.

\begin{tabular}{|c|c|c|c|c|c|c|c|}
\hline & & \multicolumn{2}{|c|}{$\begin{array}{l}\text { Strongly } \\
\text { agree }\end{array}$} & \multicolumn{2}{|c|}{ Unsure } & \multicolumn{2}{|c|}{$\begin{array}{l}\text { Strongly } \\
\text { disagree }\end{array}$} \\
\hline & & 1 & 2 & 3 & 4 & 5 & 6 \\
\hline 1. & Patients expect nurses to ask about their sexual concerns. & & & & & & \\
\hline 2. & I make time to discuss sexual concerns with my patients. & & & & & & \\
\hline 3. & $\begin{array}{l}\text { I am more comfortable talking about sexual issues with my patients } \\
\text { than are most of the nurses I work with. }\end{array}$ & & & & & & \\
\hline 4. & I feel confident in my ability to address patients' sexual concerns. & & & & & & \\
\hline 5. & I am uncomfortable talking about sexual issues. & & & & & & \\
\hline 6. & Sexuality should be discussed only if initiated by the patient. & & & & & & \\
\hline 7. & Discussing sexuality is essential to patients' health outcomes. & & & & & & \\
\hline 8. & $\begin{array}{l}\text { If a patient asks me a sexually related question, I would advise to discuss } \\
\text { the matter with their physician as I feel this is their responsibility }\end{array}$ & & & & & & \\
\hline 9. & $\begin{array}{l}\text { Giving a patient permission to talk about sexual concerns is a nursing } \\
\text { responsibility. }\end{array}$ & & & & & & \\
\hline 10. & Hospitalized patients are too sick to be interested in sexuality. & & & & & & \\
\hline 11. & Sexuality is too private an issue to discuss with patients. & & & & & & \\
\hline 12. & $\begin{array}{l}\text { I understand how my patients' diseases and treatments might affect } \\
\text { their sexuality. }\end{array}$ & & & & & & \\
\hline
\end{tabular}




\section{Annexure C: How to answer questions that participants may ask}

There is no fixed formula on HOW to answer young people on 'sexuality'. Here are some hints that could help.

- Listen first: Get to know the context by asking questions in a normal calm tone. The story given in the box shows how important it is to listen first.

Sitting in the crowded waiting room one day, I heard a child ask her mother, "What is sex, Mama?" I immediately turned towards them. I mean this was real life! What was mama going to say? How do you answer a child, what is sex? Will Mama going to dodge the question? Will she talk of ways to have sex? Will she speak of safe sex? I wondered. Kids are exposed to so much these days. So, will she go into biology of penis and vagina? What about heterosexual and homosexual behaviour? Questions kept fleeting quickly through my mind. I noticed that all the people in the waiting room are looking at Mama.

But Mama surprises me. She doesn't think the way I do. First, she pauses for brief moment. She then thoughtfully asks her daughter in a calm voice, "What do you mean, dear?" The child answers, "Well Mama, I was looking at this paper and it says 'SEX: M/F. Am I M or an F?'

And I am relieved! If I was asked, I would have given the wrong answer. I had heard the question, but I had NOT LISTENED to what the child was saying.

Clarify with the person what is on his or her mind in a talk-talk manner, encouraging further talk. When adolescents ask questions, try to find out what they already know so that you can determine what they already understand (if anything) and any misconceptions they have.

- Be sensitive: Respect the age and stage that the person is in. It is not necessary to give more information than they need. Relate it to a life event. For e.g., if a participants asks you,

- Have a positive attitude: Take every question as an opportunity that the person has asked you about something, instead of going to an unreliable source. Do not ridicule, shout or embarrass them by asking them, 'why are you asking me such silly questions?' Remember it may be silly for you but it may be important for the person who asked the question. Do not ignore 'difficult' questions, they will find someone else to ask.

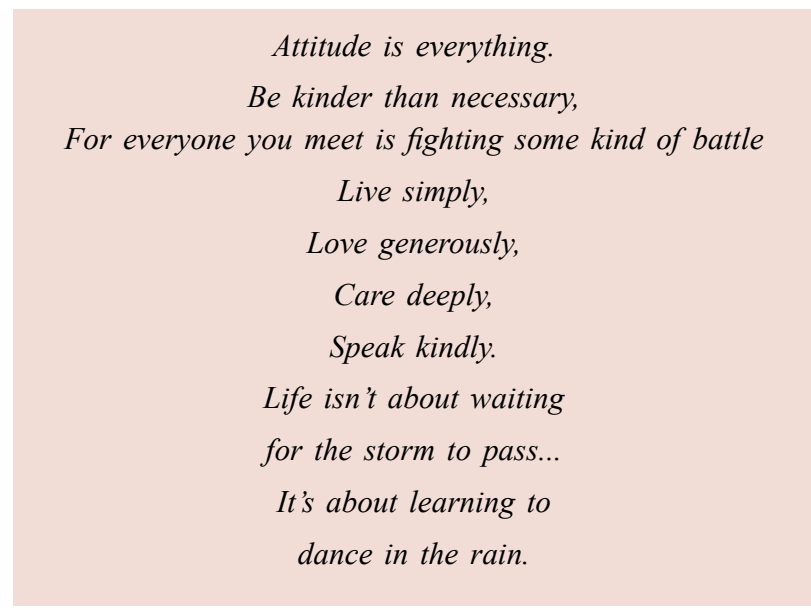

- Don't panic when you hear a question: Sometimes you may get a question that can cause you to be anxious. For example you may hear a question, 'How do I know I am pregnant?' Try not to panic. Remember that young people will probably do things that you may not want them to do. Your panic will not stop them. Good information will help them to either correct themselves or make alternate wise decisions.

- Encourage talking: Be open about talking of all kinds of things. For example a participant one day asked me 'Can the sperm swim in the water?' I asked her 'What is in your mind, would you want to tell me why you 
are asking the question?' Create an environment of trust and communication. A person should be able to say, "I can tell (you) anything". Remember a single session on sexuality will not give the person all the information he/she needs. You will have to reinforce information in different ways such as by using different examples or stories.

- Be honest: Young people like it when you share with them that you don't know all the answers. If you don't feel good talking about some questions, say so. But do so in a caring voice/tone so that it doesn't stop communication. "I feel uncomfortable answering you now. Can we speak later?" Or "May be I will ask.... to answer your questions. Is that OK?" Feel free not to answer personal questions. Remember that you can learn as much when you talk and interact with the students, acknowledge this to them.

- Know them well: Become familiar with the students environment-their language, jokes, music, films, television programs they see without judging. This will enable you better to interact with adolescents regarding sexuality.

- $\quad$ Respect differences: Beware of value-laden questions. For example you may get a question, 'What do you think about abortion?' Answer them by discussing the range of values that are held in our society, you could reinforce universal and family values. Emphasize that it is important that they form their own opinions and that others may have different viewpoints. What is important for them as nurses is to be able to respect the others point of view and to give the facts. When you need to be stern let them know that you are stern. They respect you more even if you say, "I cannot permit you to... I am your friend, but I am also you're..... (Guide/parent/teacher).

- Set limits: Mutual setting of limits for your relationship with the person helps. Limits allow the young people to feel secure, for e.g. "I can do...but these are some things that I cannot do for you..." or "You can do...but over and above that you cannot do without us". Reinforce this, even with regards to the type of questions and if you suspect that a participant is trying to corner you with personal questions.

- Develop trust in the relationship: None of the above would be possible if you don't trust the person and the person does not trust you. Remember, if the person is asking YOU a question about sex, they do trust you to give them an honest satisfying answer. Reinforce the "I trust you" belief to enable the person to make wise decisions when you are not around.

The nurse trainer is one of the most important persons in a nurse's life. The respect gained by trainers by communicating you care for them is something that will build a lifelong rich relationship and an empowered nurse. ...much beyond the nursing curriculum.

True respect is earned; it cannot be demanded.

What you give them are lessons in life.

\section{Adapted from source:}

- $\quad$ INSA India. 2003. Experiencing Options. Bangalore: Books for Change. 


\section{Annexure D : Facilitator's assessment tool}

Please fill this form in. You will not need to hand it in, it is to help you assess your skills as a trainer and identify your areas of strength and weakness. Rate yourself on a scale of 1-5 where
5: is excellent
4: is very good
3: is good
2: is average
1: is poor

1. You know your subject matter. You have studied your topic about which you are to facilitate. You are perceived as credible by learners.

2. You know your audience. You respect and listen to learners. You call them by name, if possible.

3. You are neutral and nonjudgmental. You validate everyone's experience and their right to their own perspective. You respect differences of opinion and life choices.

4. You are culturally sensitive. You are aware that your own views and beliefs are shaped by your cultural background just as your learners' culture shapes their perspectives.

5. You are self-aware. You recognize your own biases and "hot-buttons" (topics that arouse strong reactions in you) and act in a professional manner when your "hot-buttons" are pushed.

6. You are inclusive. You encourage all learners to share their experiences and contribute to the group learning process in their unique ways.

7. You are lively, enthusiastic and original. You use humour, contrasts, metaphors and suspense.

8. You keep your listeners interested and challenge their thinking.

9. You use a variety of vocal qualities. You vary your pitch, speaking rate and volume. You avoid monotones.

10. You use "body language" effectively. Your body posture, gestures and facial expressions are natural and meaningful, reinforcing your subject matter.

11. You make your remarks clear and easy to remember. You present one idea at a time and show relationships between ideas. You summarize when necessary.

12. You enhance with illustrations. You use examples, charts, and visual and audio aids to illustrate your subject matter.

13. You understand group dynamics and the stages all groups go through. You are comfortable with conflict resolution.

14. You are flexible. You read and interpret your learners' responses - verbal and nonverbal — and adapt your plans to meet their needs. You are in charge without being overly controlling.

15. You are open to new ideas and perspectives. You are aware that you don't know all the answers. 
16. You recognize that you can learn from learners as well as offer them new knowledge or perspectives.

17. You are compassionate. You understand that much of the material may have an emotional impact on learners. You are empathetic and understanding about learners' emotional reactions.

18. You are interested in evaluating your work. You encourage co-trainers and learners to give feedback.

19. When you receive negative feedback, you critically analyze it instead of becoming defensive.

20. You continuously work to improve your performance. You seek out opportunities to learn new skills and use negative feedback as an opportunity to improve.

My three biggest strengths from the list above are:

1.

2.

3.

Three areas from the list above in which I would like to improve are:

1.

2.

3. 


\section{Annexure E: The Blind Men and the Elephant}

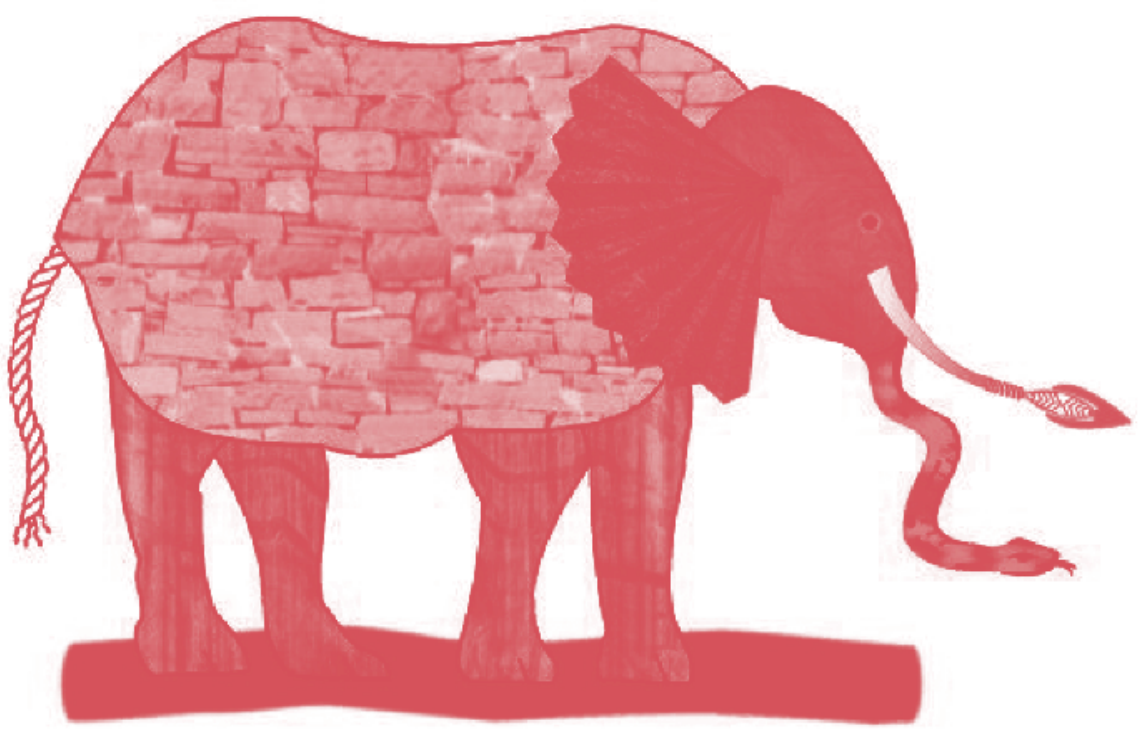

John Godfrey Saxe's (1816-1887) version of the famous Indian legend

It was six men of Indostan

To learning much inclined,

Who went to see the Elephant

(Though all of them were blind),

That each by observation

Might satisfy his mind.

The First approach'd the Elephant, And happening to fall

Against his broad and sturdy side, At once began to bawl:

"God bless me! but the Elephant

Is very like a wall!"

The Second, feeling of the tusk,

Cried,-_"Ho! what have we here

So very round and smooth and sharp?

To me 'tis mighty clear

This wonder of an Elephant

Is very like a spear!"

The Third approached the animal,

And happening to take

The squirming trunk within his hands,

Thus boldly up and spake:

"I see," quoth he, "the Elephant

Is very like a snake!"

The Fourth reached out his eager hand, And felt about the knee. 
"What most this wondrous beast is like Is mighty plain," quoth he,

"Tis clear enough the Elephant

Is very like a tree!"

The Fifth, who chanced to touch the ear, Said: "E'en the blindest man

Can tell what this resembles most;

Deny the fact who can,

This marvel of an Elephant

Is very like a fan!"

The Sixth no sooner had begun

About the beast to grope,

Then, seizing on the swinging tail

That fell within his scope,

"I see," quoth he, "the Elephant

Is very like a rope!"

And so these men of Indostan

Disputed loud and long,

Each in his own opinion

Exceeding stiff and strong,

Though each was partly in the right, And all were in the wrong!

\section{MORAL}

So oft in theologic wars,

The disputants, I ween,

Rail on in utter ignorance

Of what each other mean,

And prate about an Elephant

Not one of them has seen! 
